\title{
THE ROLE OF SOCIAL INFLUENCE IN NEW ZEALAND RURAL LANDOWNERS' LAND USE DECISIONS
}

\author{
BY
}

\section{SAMUEL NEIL HOLMES}

\begin{abstract}
A thesis
submitted to the Victoria University of Wellington in fulfilment of the requirements for the degree of Master of Environmental Studies
\end{abstract}

Victoria University of Wellington 



\section{Acknowledgments}

I would like to thank my supervisor Cath Wallace for her wise advice and

encouragement while writing this thesis. Attending Cath's authoritative lectures and tutorials on environmental theory and practice in New Zealand inspired me to carry out this research.

I would like to thank the Farm Forestry Association for allowing me to survey their members and for supporting my attendance at their annual conference. The research benefitted considerably from the survey responses provided by Farm Forestry Association members. I hope that my research findings are of interest to the group. I would like to thank Dorothée Durpoix and Ed Hearnshaw for providing advice and feedback on my research approach and text.

I would like to thank the Ministry for the Environment for supporting me to complete this research alongside my 'day job'.

Finally, I would like to thank Melody, without whose love, support and patience, this thesis would not have been possible.

I dedicate this thesis to my son, Oliver. 



\section{Abstract}

New Zealand's native bush has been substantially reduced in extent by human actions. Valuable native bush fragments remain on private land. Protection of these fragments is required on multi-generational timescales appropriate to their succession periods.

Social influence has been shown to predict human behaviour in a variety of behavioural domains and research settings. Social norms possess a self-reinforcing characteristic that may lead to the diffusion and embedding of behaviour and attitude change in society also on a multi-generational time-scale.

The role of social influence in New Zealand landowners' decisions with respect to native trees on their land is examined for two populations. One population is a shared interest group (the 'Farm Forestry Association'); the other is the general population of rural landowners. Data is gathered using questionnaires based on the Theory of Planned Behaviour.

Weak social influence is shown to be present for participants' intentions to increase or decrease native tree cover on their land. The strength of social influence is moderated by the frequency of social interaction. Contrary to the research hypothesis, the two groups do not differ in the norms they perceive nor the strength of social influence experienced. Suggestions are made for developing and applying the research methods in a small group setting. 



\section{Contents}

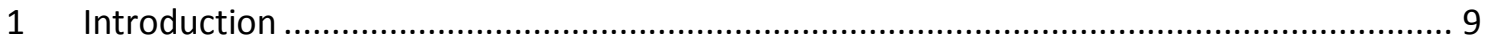

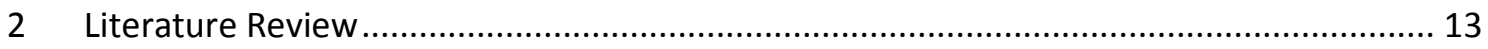

2.1 Models of individual and collective human behaviour ............................................ 13

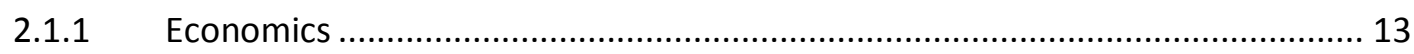

2.1.2 Challenging rationality, self-interest and individuality.................................... 14

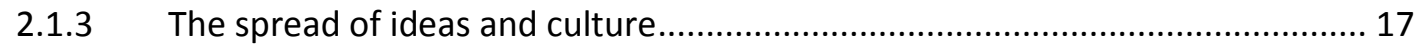

2.1.4 Predicting behaviour from social norms ....................................................... 20

2.2 Social influence on rural landowners in the environmental domain........................... 23

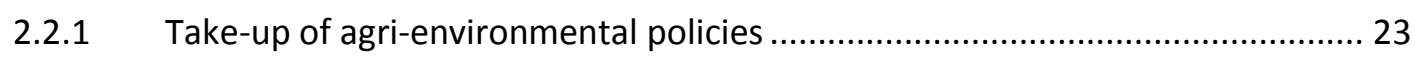

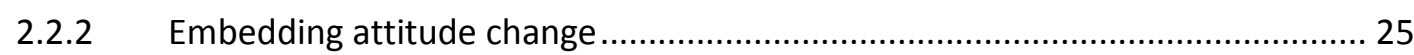

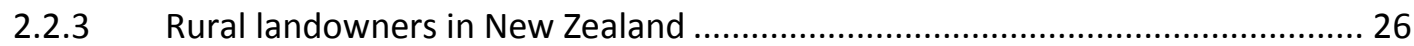

2.3 Studies of social influence on landowners using the Theory of Planned Behaviour .. 28

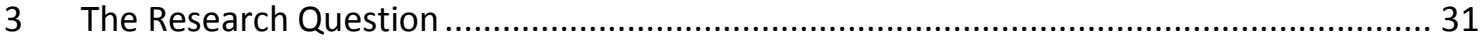

3.1 Why is this research question worth studying? ....................................................... 31

3.1.1 New Zealand native bush is important .......................................................... 31

3.1.2 Long time-horizon policies are required ......................................................... 36

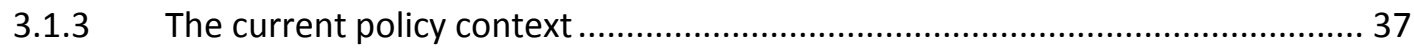

3.1.4 Current policies don't provide long-term certainty of protection....................... 43

3.1.5 Policies based on social influence have potential to be effective ...................... 46

3.1.6 Who influences New Zealand rural landowners? ............................................. 49

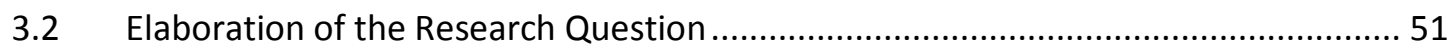

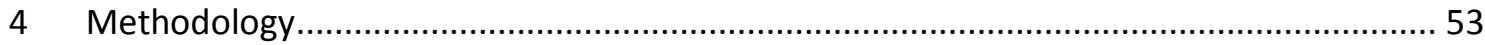

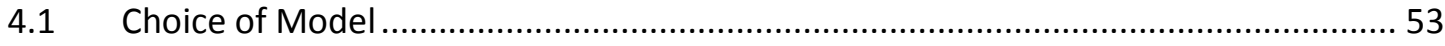

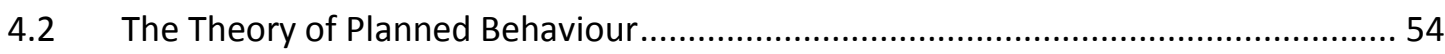

4.2.1 Behaviour versus behavioural intention ......................................................... 55

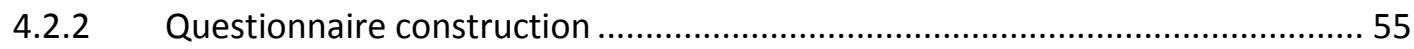

4.2.3 Measurement issues within the Theory of Planned Behaviour (TPB) ................ 57

4.2.4 Conclusions for measurement within this study ............................................... 58

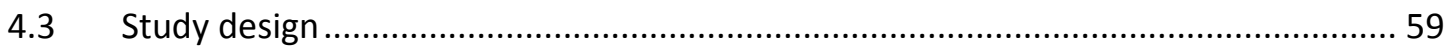

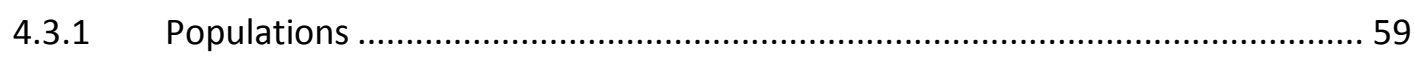

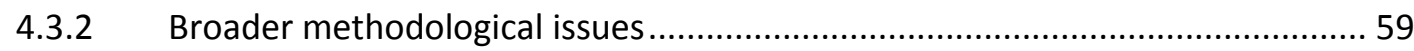

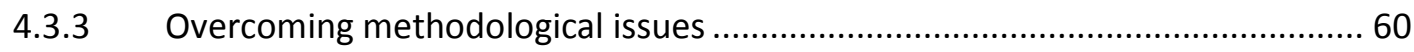

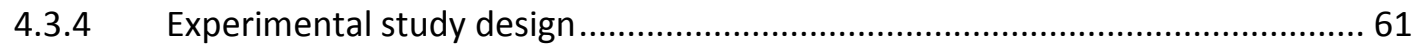

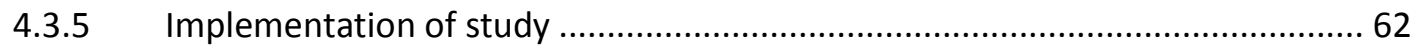

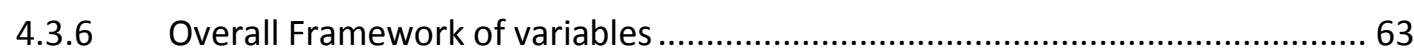

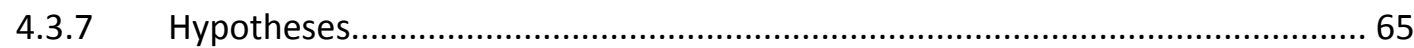

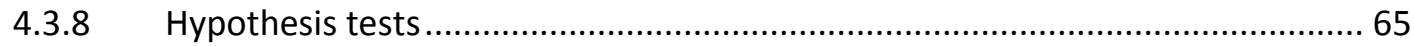




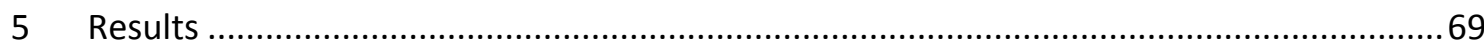

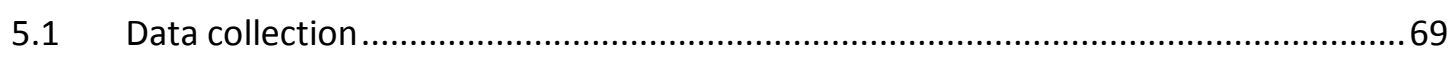

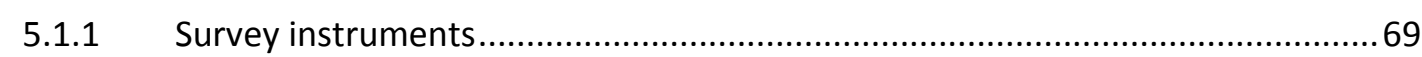

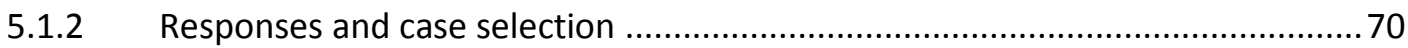

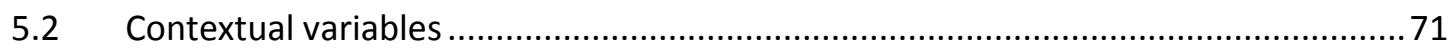

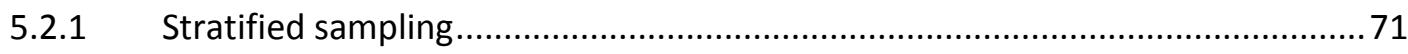

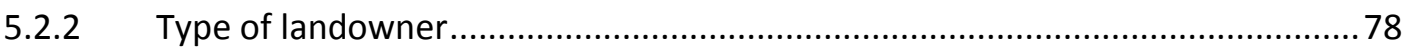

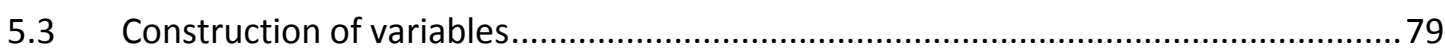

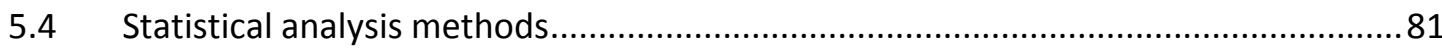

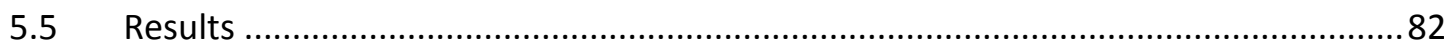

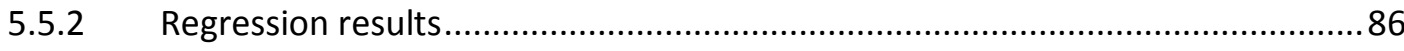

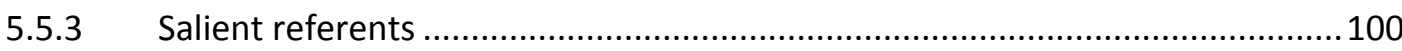

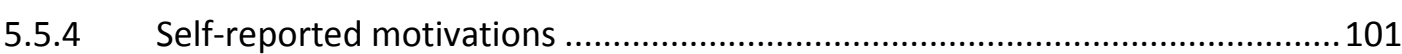

Free-text responses ........................................................................ 103

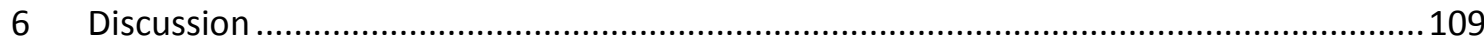

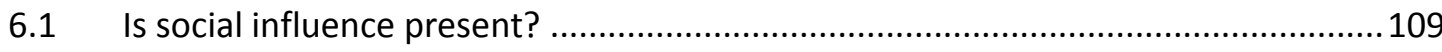

6.2 Differences between the behaviours studied ................................................... 109

6.3 Differences between the groups studied ............................................................ 110

6.3.1 Main Theory of Planned Behaviour variables............................................... 110

6.3.2 The rationale for using groups................................................................. 111

6.3.3 Why did the groups not differ? .......................................................... 111

6.4 Effect of self-monitoring ........................................................................ 113

6.5 Why is such a small social influence effect found by the Theory of Planned

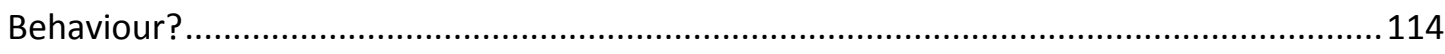

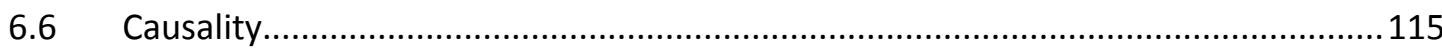

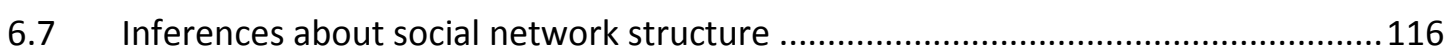

6.8 Insights from participants' stated motivations and free-text responses ................. 118

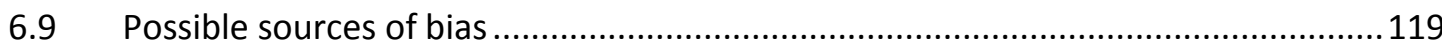

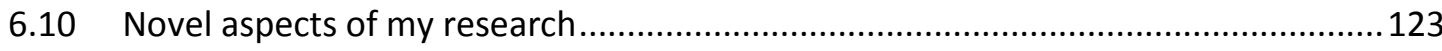

6.10.1 Unconventional treatment of Perceived Behavioural Control........................ 123

6.10.2 Measurement of Social Interaction and Confidence as moderating variables .124

6.10.3 A trans-disciplinary approach to investigating social influence ......................125

6.11 Limits to my research ........................................................................ 125

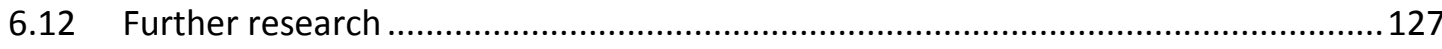

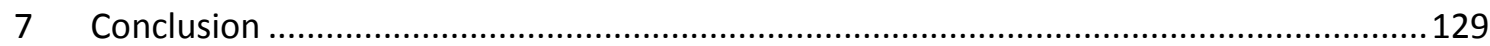

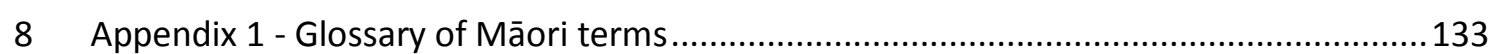

9 Appendix 2 - Theory of Planned Behaviour variable derivation...................................134

10 Appendix 3 - Postal address list methodology ................................................. 137

11 Appendix 4 - Excel macro code .............................................................. 142 


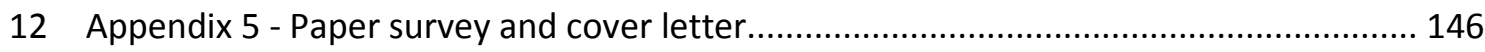

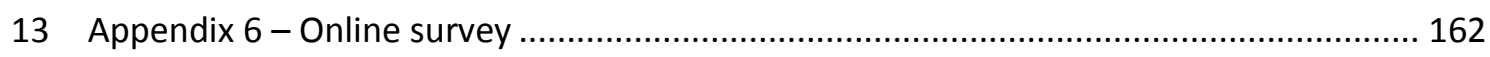

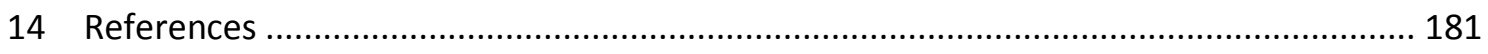





\section{Introduction}

My research seeks to understand the importance of social influence and group membership for long-term behaviour change among rural landowners with respect to native trees on their land.

Native bush fragments on private land in New Zealand represent a range of scarce ecosystems. These fragments are subject to threats including pests, subdivision for development, and surrounding agricultural activity. Social influence has been shown to predict human behaviour in a variety of behavioural domains and research settings but is a relatively unexplored approach to behavioural change in this area. Social influence may lead to particular norms of behaviour spreading or becoming embedded in society. It is therefore a potentially important consideration in the design of public policy aimed at protecting native trees on private land in the long-term.

Chapter 2 explores the literature evidence and theory on social influence as a determinant of human behaviour alongside other variables. This covers the 'microlevel' of interpersonal relations and small-group behaviour, as well as the 'macro-level' of cultural change and the diffusion of technology, ideas and norms of behaviour through society. Previous overseas and New Zealand research on how social processes may change environmental attitudes and behaviours among rural landowners is also presented here. Finally Chapter 2 surveys the methodologies employed by researchers working in the field of social influence.

Chapter 3 explains the importance of this research area for New Zealand. Native forests are part of New Zealand's unique and valuable biodiversity endowment. They include and provide habitat for endemic indigenous plant and animal species, and provide a range of values to New Zealanders. Historic human actions have drastically reduced the extent of New Zealand native forest cover, but significant native forest fragments remain on private land. These are often scarce examples of lowland ecosystems reflecting the historic tendency to convert the most productive lowlands to agriculture.

Chapter 3 also presents the relevant New Zealand context for this research. It argues that existing policies largely derive from a rational-economic view of human nature, which ignores the possibility of social influence. The chapter presents the case that 
current policies are unlikely to offer long-term stability of incentives, nor a shift in attitudes towards protection of native forests on private land. The length of native ecosystem succession periods means that consistent protection of native forests over multiple human generations is required.

Chapter 3 demonstrates the relative paucity of existing research in this specific area, in spite of recent renewed interest in collaborative and community approaches to natural resource management among other New Zealand researchers and policy makers. It proposes that cultural practices and norms of behaviour can endure on the multigenerational timescales required for the protection of native forest. Social influence offers a 'self-reinforcing' mechanism by which existing or new attitudes and behaviours towards native trees among rural landowners may become 'embedded' in culture.

Chapter 3 also discusses which people and groups might influence New Zealand landowners, in order to inform the choice of populations for study. This includes acknowledging how relationships between people and with the natural world are conceptualised within Māoritanga (Māori culture). This research does not examine the relationship of Māori people, hapu or iwi with their rohe ${ }^{1}$. That relationship is more appropriately explored using Māori concepts and epistemology than the western scientific approach employed by this research. Finally the chapter elaborates on the specific research questions to be addressed by my research.

Chapter 4 presents the primary theoretical framework and methodology used in my research: Ajzen's Theory of Planned Behaviour (1985). This choice of model versus others is justified based on its well-established status, suitability to the subject of study and time and resource constraints. Shortcomings in the framework and lessons from previous research are canvassed and addressed in my study design. My research takes a trans-disciplinary approach by drawing on theory and methodologies from a range of disciplines beyond the Theory of Planned Behaviour. Elements of Cialdini's experimental approach to detecting social influence are incorporated within my Theory of Planned Behaviour study. Social Network Analysis informs the primary study

\footnotetext{
${ }^{1}$ Please see 'Appendix 1 - Glossary of Māori terms' for definitions of these and other terms
} 
design and is used in a supplementary analysis of social network connectivity for the populations studied.

Chapter 4 also describes the choice of populations for my study. I surveyed members of the New Zealand Farm Forestry Association and a group of randomly selected rural landowners with an online and a paper survey. Questionnaires included questions designed to measure the primary Theory of Planned Behaviour variables as well as a number of other variables relevant to the research question. The behaviours studied were participants' actions to increase or decrease native tree cover on their land. I anticipated that the members of the two populations would differ in the homogeneity of their attitudes, their frequency of social interaction and the strength of social influence they experience. Comparison between the populations allowed me to study how different factors moderate the strength of social influence. The precise relationships proposed between these variables are specified in the hypotheses laid out at the end of Chapter 4.

Chapter 5 describes the process of implementing the surveys, the responses received, the data preparation and analysis, hypothesis testing and other results. 'Stratified sampling' was used to ensure the two samples were closely matched on a number of contextual variables (land title area, type of trees on land and location of land). This meant that differences between the samples on these variables were less likely to confound measurement of the key social influence variables of interest.

The relationships between Theory of Planned Behaviour variables were analysed using multiple regression analysis which allowed various hypotheses to be tested. For example, a correlation between 'intentions' and 'perceived norms' was found, which is consistent with social influence being present. A summary of participants' text comment responses is also provided, which allows a richer qualitative insight into their reasoning, constraints and motivations.

Chapter 6 discusses my findings in detail. I found social influence predicts peoples' intentions to increase or decrease native tree cover. The effect is weak compared with the predictive power of attitude. The frequency with which people talk to their peers about these issues has a substantial moderating effect on the strength of social 
influence - those with more frequent interactions with different people experience stronger social influence.

Chapter 6 also synthesises across my quantitative and qualitative research findings and draws on literature canvassed in Chapter 2 to suggest why particular hypotheses were supported whilst others were not. This chapter critically assesses the contribution of my research to the literature, considering its limitations, possible sources of bias and whether the novel aspects of my methodology have merit. Suggestions for further research are made.

Chapter 7 concludes the thesis by summarising the motivation for my research questions and how my methodology addressed these questions. I also reiterate my key findings and their implications the protection of native trees in New Zealand.

The numbered appendices provide respectively: a glossary of Māori terms used in this thesis (1), details of construction of variable measures used in my data analysis (2), details of survey postal address list preparation ( 3 and 4), a copy of the paper survey and cover letter (5) and a copy of the online survey (6). 


\section{Literature Review}

My research seeks to understand the importance of social influence and group membership for long-term behaviour change among rural landowners with respect to native trees on their land. This chapter provides the research context from the literature. This includes the evidence and theory on social influence as a determinant of human behaviour, as well as research on how social processes may change environmental attitudes and behaviours among rural landowners. The methodologies employed by researchers working in the field of social influence are also surveyed.

\subsection{Models of individual and collective human behaviour}

The most relevant approaches to studying human behaviour for my research come from Economics, Social Psychology and Anthropology. The theories of human behaviour and empirical methods of these disciplines have informed my choice of research question and the methodology. In this section I survey various disciplinary approaches and how they have explored and provided evidence for social influence.

\subsubsection{Economics}

The theoretical models of 'neo-classical economics' assume that individuals maximise their own 'utility', while acting rationally and on the basis of full information about their possible courses of action. The concept of 'utility' stems from the works of Jeremy Bentham and John Stuart Mill, who proposed maximising the aggregate utility of society as a normative goal. Utility was conceptualised by Bentham as approximating to happiness and the avoidance of pain or suffering (Bentham, 1789).

In neo-classical economics, utility gain is commonly equated to the value which an individual expects to receive from the consumption of a good or service. A consumer is assumed to be 'rational' if they can rank their preferences during a decision and only proceed where the utility gain equals or exceeds the price. The amount of utility gain associated with consumption of a good or service depends on an individual's preferences.

The assumptions made by neo-classical economics about behaviour allow practitioners to create mathematically tractable models of individual and firm decision-making in the market. The broad applicability and computational power of such models means 
they are widely used in public policy work in an attempt to predict the impacts of different 'economic incentives' on consumer and producer behaviour.

As described in the next section, different theorists have challenged three underlying assumptions of the models of human behaviour described above: rationality, selfinterest and the focus on individuals rather than on relationships and groups.

\subsubsection{Challenging rationality, self-interest and individuality}

\subsubsection{Rationality}

The possibility of rational choice given limited time, information and cognitive capacity was challenged by Herbert Simon's (1957) notion of 'bounded rationality'. Daniel Kahneman and Amos Tversky (1982) observed various biases in human decisions, which appeared to violate the rationality assumption. They found that the 'framing' of a choice can influence peoples' decisions. People also make systematic errors in judgements involving uncertainty and probabilities. The authors propose that humans have two cognitive systems - one intuitive and one deliberate (Kahneman, 2006). The intuitive system operates rapidly on those aspects of a situation which are most 'accessible' and on the basis of heuristics (or 'rules-of-thumb') to provide rapid, automatic judgements. The deliberative system is a more methodical, controlled and 'effortful' process which may (or may not) intervene to correct 'errors' made by the intuitive system.

\subsubsection{Self-interest and altruism}

Altruistic or 'pro-social' human behaviour, which appears to contradict the assumption of sole self-interest, is widely observed anecdotally such as through charity. Altruistic behaviour was documented in a large cross-cultural study of 15 diverse societies by Henrich et al. (2001). Meanwhile experimental 'public goods' experiments show that people will 'altruistically punish' defectors, which is costly for themselves but benefits the wider group by incentivising cooperation (Fehr \& Gächter, 2000).

Piliavin and Charng (1990) argue that there has been a 'paradigm shift' across multiple disciplines towards the position that "true altruism [...] does exist and is a part of human nature", rather than always having underlying egoistic motives. They find evidence that altruistic behaviour may be predicted by both personality and 
'situational' influences. Schwartz (1977) explored personality influences with his 'personal norm' concept, which embodies the feeling of 'moral obligation' that compels an individual to perform pro-social actions. Meanwhile Piliavin and Chang present studies showing "personal request and social pressure" are 'situational' influences which encourage people to donate time, charity or blood (p. 35).

\subsubsection{Social influence and group behaviour}

Utility and rational choice concepts were extended beyond economic interactions to social interactions by Homans' Exchange Theory (Homans, 1974). Homans' used evidence from observation and experimental manipulation of social interactions. He theorised that interactions involve exchange of rewards and punishments between humans in the form of activities and sentiments. Individuals are supposed to act rationally so as to maximise their expected utility gains from these interactions. Homans found that 'social approval' was a particularly important type of reward and 'generalized reinforcer' (ibid. p. 34) of behaviour used between individuals and within groups.

Early, direct, empirical demonstration of social influence was provided by Sherif (1935) and Asch (1955). They demonstrated that group members tend to 'conform' to the majority group opinion on simple judgement tasks, even when the 'group opinion' is clearly in error. Asch found that although individuals naturally make errors of judgement on these tasks less than one percent of the time, they conform to the erroneous judgement of the group 37\% of the time. This figure is an average across subjects, with some individuals consistently sticking to their own judgement and others willingly conforming. The size of this effect depends on the size and unanimity of the majority opinion. When in a group of two or three, individuals are much less likely to conform to the dissenting opinion of the other one or two in the group. As group size increases above three, $30-35 \%$ conformance is reached and remains fairly constant with larger groups. Where the subject had at least one 'partner' who agreed with him $^{2}$ rather than the majority, this depleted the size of the conformance effect, with individuals conforming to the erroneous majority judgement of the group only around ten percent of the time.

\footnotetext{
${ }^{2}$ Only male subjects were studied
} 
Deutsch and Gerard (1955) conducted further experiments to elucidate that two distinct components of social influence were at work: Normative and Informational. The former refers to conformance motivated by a desire to gain the approval of others. The latter refers to recognising that someone else's opinion may be a correct version of reality.

More recently, proponents of Self-categorization Theory have argued that group behaviour shows humans are capable of perceiving their self both as an 'individual' and as a 'depersonalised' member of a social group (Turner, Oakes, Haslam, \& McGarty, 1994). In their view, phenomena such as social norms 'emerge' and are defined at the level of the group rather than the individual, representing whatever characteristic best distinguishes the group from other groups.

Researchers studying the incentives and decisions of people facing social dilemmas have re-considered whether individuals or groups are the appropriate unit for analysis. Elinor Ostrom (1990), Arild Vatn (2005)and Daniel Bromley (1991) have used institutions (the rules adopted by people and groups to coordinate their behaviour) as a framework for the study of the interaction between people and with the environment.

Mancur Olson (1971)argued that the larger a group, the smaller the chance of its members contributing to a collective good, due to three factors: individuals receive a smaller share of the total benefit when shared among more people; larger groups face higher 'organisational costs' (p. 48); and social pressure may fail when individuals cannot all know each other personally (p. 62).

In the case of a group which faces a social dilemma, social pressure is a potential mechanism to achieve cooperation within the group. Ostrom studied the behaviour of groups who face collective action problems in the management of common pool resources (Ostrom, 1990). She defined 'institutions' as the formal and informal rules and norms of behaviour which define acceptable use of a natural resource by members of the group (p. 51). She found numerous examples from around the world of cooperatives of appropriators who had organised themselves to overcome collective action problems to sustainably manage common pool resources. She derived 
a number of characteristics of the resource, the people using it and their interactions which were generally associated with successful collective action in such cases. Ostrom demonstrated how social interaction processes are fundamental to these successes, in that they enable the development of credible commitment (to punish free-riders) and mutual monitoring of rule compliance.

\subsubsection{The spread of ideas and culture}

Other research has linked social interaction with the diffusion of innovations within society. Rogers (1962) analysed a large body rural sociology research to develop his theory of how new ideas and technology spread. He characterised adoption of an innovation over time as gradual at first, by 'innovators' and 'early adopters, then more rapid for the majority of the relevant population and slower again as the 'laggards' finally adopted. This leads to a classic 'sigmoid' curve for the cumulative adoption level of an innovation over time. Rogers noted that the components of the social system influence the rate and success of technology adoption: the social structure, the existing social norms and the presence of opinion leaders.

In his book 'The Tipping Point' Gladwell (2000) argues that the spread of ideas, behaviours and innovations in society resembles the spread of a viral epidemic. He argues that ideas and behaviours spread in a non-linear way through society - so that initial changes in behaviour or which are not widespread can abruptly become 'selfreinforcing' and proliferate to produce large-scale societal change. Gladwell's examples include the dramatic decrease in the New York crime rate in the early 1990s, linking this to interventions which such as the 'zero-tolerance' policy on vandalism, graffiti and fare-dodging. It is argued policies targeting highly visible crimes can reduce all types of crime because they send visual cues about 'socially-acceptable' behaviour. In other words a vandalised environment and fare dodgers who 'get away with it' are highly visible cues about the acceptability of criminal and anti-social behaviour more broadly.

Gladwell argues that the 'success' of an idea as an 'epidemic' depends on both the intrinsic attractiveness of the idea, as well as the idea coming into contact with specific types of people, whom he calls: Innovators, Mavens, Salesmen (sic) and Connectors. Innovators develop new ideas but may struggle on their own to convince others of 
their benefits. Mavens collect and then disseminate information about products, prices and innovations. Salesmen (sic) possess persuasive 'sales' skills which they use to convince others of the benefits of a new idea. Connectors are highly sociable people who share ideas with many others in their large social network.

Axelrod and Epstein have used agent-based computer models of social systems to simulate self-reinforcing norms based on simple rules of interaction. Epstein's model (Epstein, 2001) assumes that agents (representing people) choose between two states (representing opinions or behaviours) based on the consensus view of their neighbours. In other words, this represents a case of very strong, 'unthinking' submission to the group norm. Agents in the model rapidly organise themselves into static blocs of unified opinion, illustrating (in principle) the self-reinforcing power of norms.

A closer approximation to reality may be found in a version of Epstein's model in which the strength of adherence to the group consensus is reduced by introducing some random noise into agent decisions. This still results in blocs of consensus within the model, but neighbouring blocs grow and shrink in size, as well as new norm blocs spontaneously emerging. This could be interpreted as the shifting patterns of accepted behaviours and ideas within society.

Axelrod's 'Dissemination of Culture' (Axelrod, 1997) model features a grid of agents, each representing a group of people with a particular common 'culture'. Each culture is represented as different values (represented as numbers) for each of a number of cultural features. If neighbouring cultures share at least one cultural feature in common then it means they are capable of interacting. An interaction has results in a given probability that their other cultural features may become more closely aligned (i.e. take on a common value). When the model is run, then it is seen that from a set of random starting cultural values, a number of homogenous cultural regions tend to emerge.

The field of Social Network Analysis attempts to understand the spread of information and behaviours based on the structure of the social network itself. Society is described in terms of a network in which the people (vertices) are linked together by social 
relationships or 'ties'. In his seminal article 'The strength of weak ties', Granovetter (1973) connected existing understandings of 'micro' level (small group and clique) with 'macro' level (societal and cultural) group behaviour. He proposed that weaker ties, representing less strong or frequent relationships, are actually more important than strong ties for carrying information between groups and 'bridging social distance' ( $p$. 1369). This is because weak ties connect people who are less likely to already share common knowledge and opinions.

Milgram (1967) first began to probe the structure of social networks and the 'smallworld' phenomenon. The 'small-world' phenomenon refers to the anecdotally 'surprisingly' high rate at which strangers find they have a mutual acquaintance. His experiments with chain letters demonstrated that United States residents were only separated by 'six degrees' of intermediate acquaintances.

Strogatz and Watts (1998) found so-called 'small-world' networks present in a variety of naturally-occurring systems (neural networks of worms, a power grid and the collaborations between film actors). Other researchers found this 'small-world' structure in the reported sexual contacts of Swedish people (Liljeros, Edling, Amaral, Stanley, \& Aberg, 2001).

Albert and Barabási (2002) have presented evidence that another model - the 'scalefree network', also describes a large number naturally occurring networks, including the internet, the world-wide web, academic co-authors and patterns of sexual contacts. Scale-free networks are characterised by the fact that the frequency of nodes with a given number of connections follows a power law (Frequency $=$ Connections ${ }^{-\gamma}$ ). Pastor-Satorras \& Vespignani (2001) found that modelling of (computer virus) diffusion within scale-free networks produced markedly different results to those normally seen in epidemic modelling. Such studies normally find that viruses quickly die out if the ratio of virus infectiousness to the rate of 'curing' is below a 'critical threshold'. By contrast, the authors found that in scale-free networks there was no critical infectiousness threshold. Viruses were predicted to always spread and reach a steady state of infection rather than die out in such networks, regardless of their level of infectiousness. 
Empirical confirmation of the role of interpersonal influence in the spread of smoking cessation comes from a study by Christakis and Fowler (2008). These authors used data from a 30 year longitudinal health study. They found robust evidence that groups of smokers quit simultaneously and that the influence of smoking cessation spread across both local and long-distance social ties to three degrees of separation.

\subsubsection{Predicting behaviour from social norms}

Various theoretical models which include a social norm predictor variable (or 'normative influence') have been proposed to explain human behaviour. Those applied in the environmental domain include the Attitude-Behaviour-Context $(A B C)$ models described by Guagnano, Stern, \& Dietz (1995), Triandis' (1977) Theory of Interpersonal Behaviour and Ajzen's (1985) Theory of Planned Behaviour (TPB) .

Guagnano et al. (1995) emphasised the importance of the interaction of external contextual factors with internal attitudinal factors. The correlation between attitude and behaviour may be strong where the context facilitates it, but weak or non-existent where the context effectively compels or prohibits the behaviour. Triandis' Theory of Interpersonal Behaviour (1977) added 'habit and routine' as a predictor variable, reflecting the observed importance of people's past and habitual behaviour in determining their future behaviour.

Ajzen's (1985) Theory of Planned Behaviour (TPB) proposes that intention may be predicted from three independent variables (Attitude, Subjective Norm, and Perceived Behavioural Control). 'Attitude' results from the aggregation of beliefs about the likely outcome of a behaviour weighted by the value attached to each outcome; 'Subjective Norm' results from the aggregation of beliefs about the expectations of others weighted by motivation to comply; and 'Perceived Behavioural Control' results from belief about factors which may facilitate or prevent volitional control of the behaviour.

Figure 1 illustrates the relationship of the three predictor variables with Behavioural Intention and Behaviour. Behavioural Intention is proposed to be the immediate antecedent of actual behaviour and thus a substantive predictor of it. However, in line with Guaganano et al.'s findings on the importance of context, a lack of actual behavioural control may intervene to prevent intentions from being expressed as 
behaviour. Therefore Perceived Behavioural Control (used as a proxy for actual control) is hypothesised to moderate the relation of intention to behaviour.

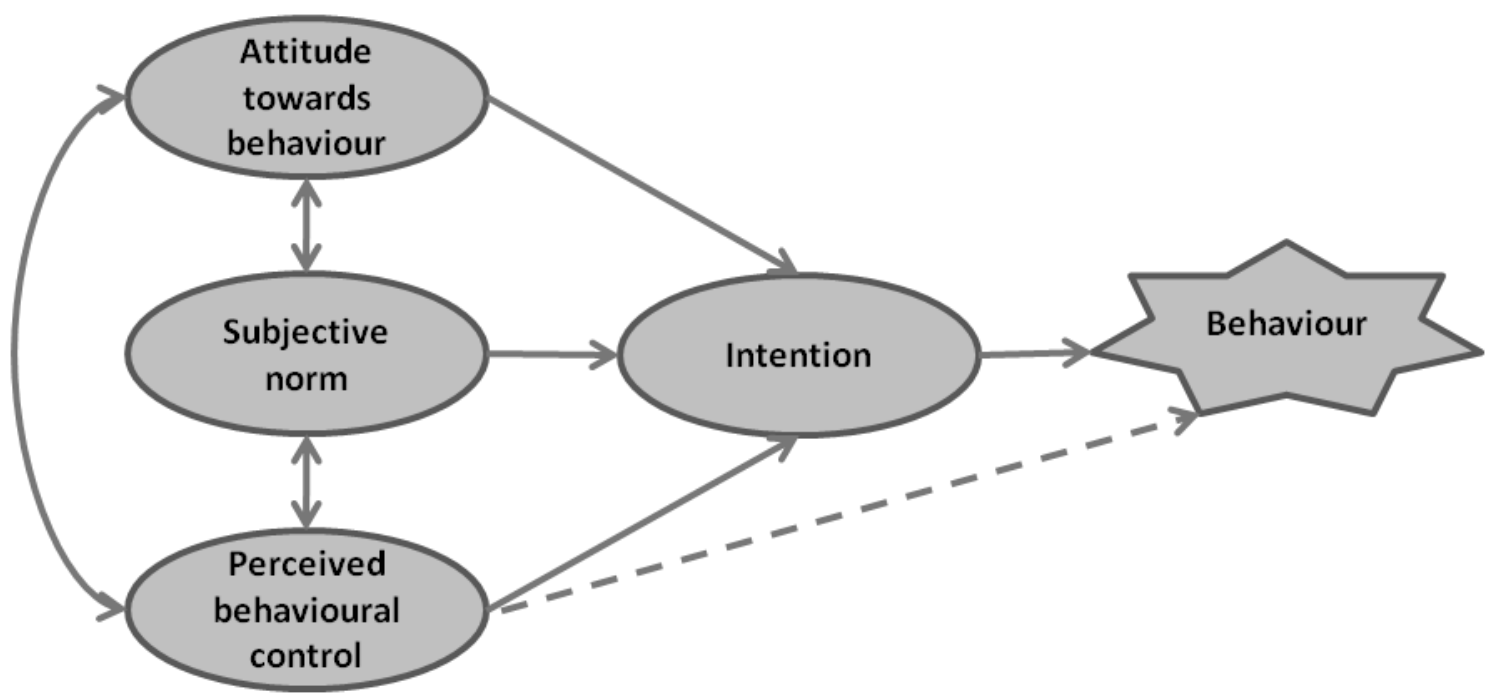

Figure 1 Variables in The Theory of Planned Behaviour. Adapted from (Ajzen, 2002)

A meta-analysis by Armitage and Conner (2001) of TPB studies found that the Ajzen's model accounted for $27 \%$ of variance in behaviour and for $39 \%$ of variance in intention. The authors also found that subjective norm was generally the weakest of the three predictors of intention. They suggest that variance and weakness in the effect of Subjective Norm between studies may stem in part from the fact that questions don't probe the 'full scope' of social influence.

Cialdini et al's (1990) field experiments on littering behaviour found relatively strong normative influence effects. They found a decrease of $61 \%$ in littering behaviour immediately after participants' attention had been surreptitiously 'focussed' on an anti-littering norm (p. 1024). They clarified the scope of the 'social norm' concept by distinguishing 'descriptive' from 'injunctive' norms. The former describes an individual's belief about the prevalence of a given behaviour (i.e. 'other people litter frequently') while the latter describes their perception of its social acceptability (i.e. 'other people would disapprove of me littering'). The Cialdini et al. study also provided strong evidence for the hypothesis that actual behavioural outcomes depend strongly on the 'salience' of a descriptive or injunctive norm in a given situation. 'Salience' refers to the prominence and relevance which the norm has in the subject's mind at the moment they make the decision of interest. 
Research of social influence on pro-environmental behaviour includes studies of toweluse in hotels (P. W. Schultz, Khazian, \& Zaleski, 2008) and domestic electricity use (Nolan, Schultz, Cialdini, Goldstein, \& Griskevicius, 2008). These studies used an experimental methodology, whereby the researchers exposed their subjects to stimuli which would influence norm perception. They provided feedback on how participants' energy (or water) conservation efforts compared with those of their neighbours (or fellow hotel guests). This research demonstrated social influence has a significant effect on behaviour and that participants substantially underestimate its importance (i.e. people are in general more heavily-influenced by others than they think they are). Nolan et al. (2008) found that simply receiving written information about neighbours' energy conservation efforts resulted in an average ten percent reduction in energy use by the recipient in the short-term.

In other fields and settings, where manipulation by researchers of norm perception has not been possible, many researchers have used the Theory of Planned Behaviour. For example, Terry, Hogg, \& White (1999) studied household recycling behaviour, Fekadu and Kraft (2002) examined the intention of Ethiopian adolescents to use contraception while Norman et al.(2005) examined the violent or otherwise intent of UK football fans and field-hockey players. These studies have attempted to improve subjective norm measurement by including measures of descriptive norms and the extent of group-identification by individuals. Researchers hypothesized that the extent of self-identification with the group by an individual would mediate the strength of social influence they experienced, so that the behaviour and attitudes of other group members would be more important than that of other acquaintances. This idea is based on identity theory, social identity theory and (the already mentioned) selfcategorization theory, whereby an individual's self-concept, perceptions and behaviour may derive partly from a mental 'self-labelling' as a member of a particular social group with particular prototypical behaviours (Stryker \& Serpe, 1982; Tajfel \& Turner, 1979). Some researchers found this to significantly increase the measured strength of social influence (Terry et al., 1999), although others tested for but found no such effect (Fekadu \& Kraft, 2002; Norman et al., 2005) 
It has also been suggested that variable individual susceptibility to social influence may confound measurement of its effect on behaviour. DeBono and Omoto (1993) used Snyder's (1986) psychometric survey instrument to measure the 'self-monitoring' personality trait alongside Theory of Planned Behaviour variables in their sample of participants. They found that high 'self-monitors' were subject to a large social influence on intention, whereas the intentions of low 'self-monitors' were more influenced by attitude. Ajzen et al. (1982) found a similar interaction but at the behaviour rather than intention level.

\subsection{Social influence on rural landowners in the environmental domain}

\subsubsection{Take-up of agri-environmental policies}

There is an extensive literature on the factors influencing farmers' participation in conservation and other 'pro-environmental' activities. A significant portion of these studies examine the impact and take-up of 'agri-environmental policies' in Europe (Burton, Kuczera, \& Schwarz, 2008; Morris \& Potter, 1995; Siebert, Toogood, \& Knierim, 2006).

Beedell and Rehman (2000) note a shift over time from quantitative studies which simply correlate policies with environmental behaviour, to more in-depth analyses of motivations to join voluntary agri-environmental schemes in order to inform improved scheme design.

Siebert et al. (2006) reviewed 160 studies on the factors affecting farmers' participation in European 'agri-environmental' schemes ${ }^{3}$. They present a range of theoretical approaches that have been applied to this question, drawn from economics, sociology, psychology and anthropology. The authors conclude that:

"decisions made by farmers are the result of complex interactions of social and cultural as well as economic and policy influences." (p 328)

\footnotetext{
${ }^{3}$ These 'agri-environmental' schemes arose from the European Economic Community Regulation 2078/92 passed in 1992. This required member states to introduce schemes offering payments to farmers for a commitment to reduce farming intensity on their land by a decrease in livestock numbers or set-aside of land for example.
} 
Siebert et al. found many studies which assume, and provide evidence for, the primacy of rational economic interest in farmers' decisions to participate in European agri-environmental schemes (Drake et al., 1999; Schramek et al., 1999). A number of studies of these European schemes also demonstrated the importance of stewardship values and of long-term family security through farm-continuity in farmers' decisionmaking (Schramek et al., 1999; Nieminen, 1999, 2000; Saaristo, 2000; Oksanen, 2003).

Siebert et al. found studies showing social influence on farmers from their neighbours (Vehkala and Vainio, 2000), the broader farming community (Oksanen, 2003) and local public figures (Luz, 1994). Officials such as 'local agents' for a scheme are identified as performing an important extension role in policy implementation through social interaction with farmers (Drake et al., 1999; Schramek et al., 1999).

The interplay of financial incentives with social influence in a Chinese government scheme of payments for keeping marginally-productive steep land under forest cover was studied directly by Chen, Lupi, He, \& Liu (2009). They found that farmers were significantly more willing to re-enrol in the scheme with a larger payment size or with higher participation by their neighbours. They concluded that social pressure could enhance the impact of financial incentives, thereby increasing their cost-effectiveness. Gass et al.(2009) and Schulte et al. (2008) point out that social processes may help when managing ecosystems which span property boundaries. Neighbouring landowners may be able to cooperate to protect and manage larger patches of forest. This is likely to reduce pressures on the ecosystem due to a smaller edge-to-area ratio and coordination may allow landowners to share some costs. This approach has been taken to protect a large indigenous forest fragment in the Waikato region (Maungatautari Ecological Island) where the pest-proof fence surrounding the reserve runs across multiple private land holdings (T. Roxburgh, Waipa District Council, personal communication, March 8, 2012). The reserve and the property titles which adjoin and overlap it can be seen in Figure 2 . 


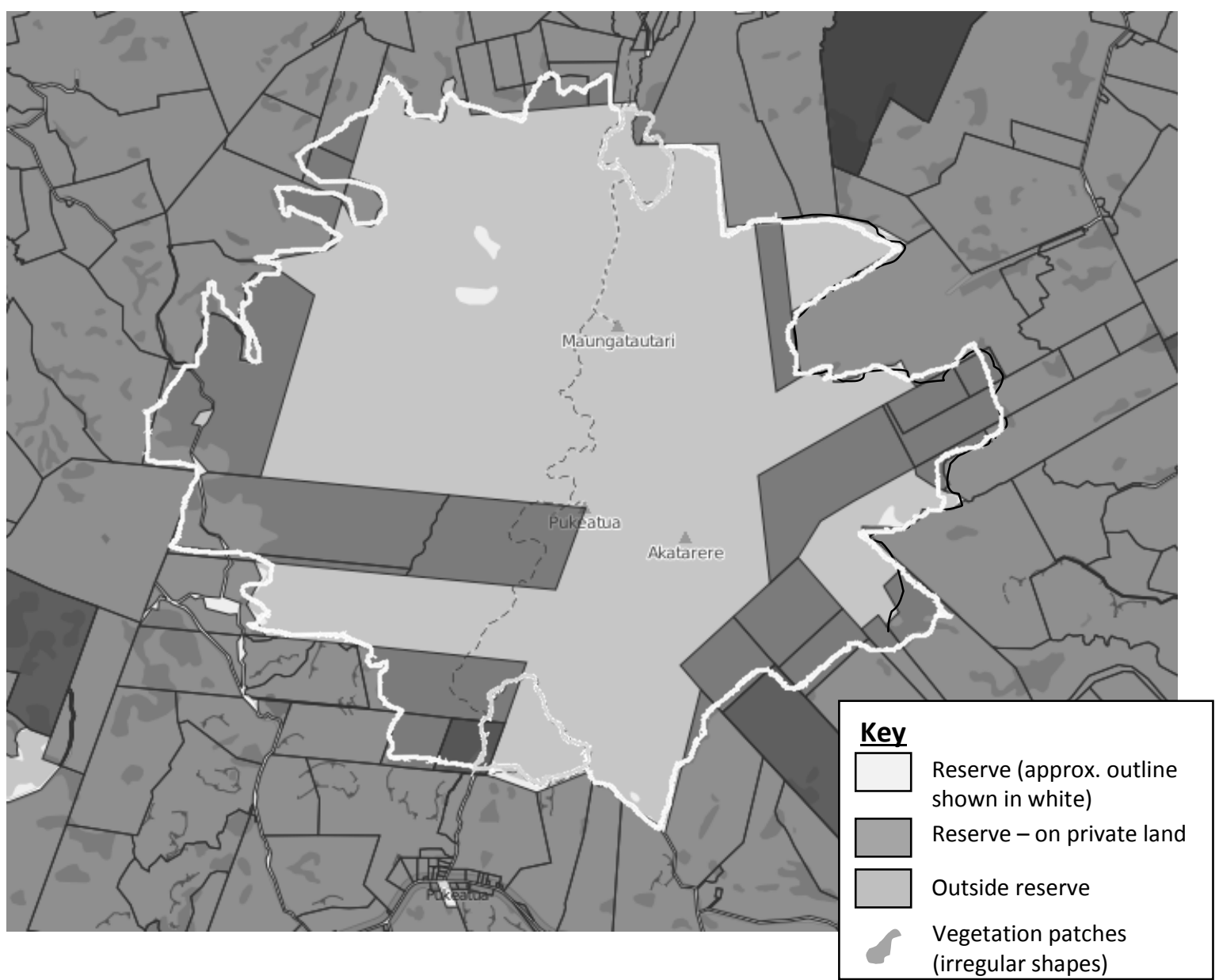

Figure $\mathbf{2}$ The Maungatautari Ecological Island reserve in Waikato. A pest-proof fence follows the reserve boundary. The polygons indicate different property titles. Image downloaded from data.linz.govt.nz $7^{\text {th }}$ October 2013.

\subsubsection{Embedding attitude change}

Morris and Potter (1995) describe how 'attitude change' has evolved as a research and (British) policy priority. They posit the development of a 'stewardship mentality' and 'attitudinal shifts' as ways to secure long term land use change. Lowe et al. (1999) argue that conventional regulatory or financial incentive policies might achieve this by gradual cognitive and normative changes in farmers and their community. However, Burton et al. (2008) found only sparse evidence of attitude change as a result of European agri-environmental schemes over the last decade and certainly no discernable, large scale shift in farming culture.

Burton et al. draw on Bourdieu's (1986) definitions of non-economic forms of capital to explain European agri-environmental schemes' ineffectiveness at changing attitudes. Bourdieu (ibid.) argues that there is inertia in the distribution of educational achievement and social status in society because knowledge and skills are types of 
'cultural capital' ${ }^{4}$. This capital allows the holder to obtain greater 'profits' in a given economic environment by performing skilled work. In addition, Bourdieu proposes that skills function as 'symbolic cultural capital' which secures 'symbolic profits' from peers in the form of distinction or prestige.

Burton et al. find evidence that cultural capital is important among German and Scottish farmers. The authors discuss the significance of 'roadside farming' in these communities, as a way for farmers to assess each other's performance. Farmers admit to placing their 'best' livestock next to the road, where their condition would be apparent to all. Cultural capital may also be demonstrated by ploughing perfectly straight and parallel lines in fields.

Burton et al. suggest that opportunities for cultural capital development and transmission are lacking from agri-environmental schemes which involve the set-aside of land and prescription of certain management practices. They suggest that farmers may resist the agricultural extensification ${ }^{5}$ required for such schemes as it runs counter to the 'good productivist farmer' stereotype with which they identify (Burton et al., 2008; Burton, 2004).

\subsubsection{Rural landowners in New Zealand}

In New Zealand, Wilson (1992) studied the attitudes of land owners in the Catlins District of the South Island within a framework of utilitarian versus naturalistic ${ }^{6}$ views of native forests on their land. Conservation behaviour was present, with around onethird of landowners having set aside native forest as some sort of official reserve or protected area. Around $80 \%$ had planted exotic forests as plantation forestry or shelterbelts. A much smaller proportion had planted native species and this activity was linked with the landowner having "botanic interest".

In terms of attitudes, some appreciation of values beyond the purely utilitarian was present, with $69 \%$ of landholders surveyed regarding forest remnants on their land as

\footnotetext{
${ }^{4}$ Note other authors have referred to learned skills and knowledge as human capital (T. W. Schultz, 1961)

${ }^{5}$ The reduction in production per unit of land area

${ }^{6}$ Wilson defines "naturalistic" as "primary interest and affection for wildlife and the outdoors".
} 
'important' or 'very important' and 73\% endorsing the importance of "keeping some forest for future generations". In general younger, more highly-educated farmers whose families had been on the land for longer were more likely to have a naturalistic rather than utilitarian attitude towards native forests.

Durpoix (2010) carried out the research probably most closely related to my own. She surveyed New Zealand owners of farms with and without native forest fragments on their environmental attitudes and behaviour and other situational variables. She found farmers with native forest fragments on their land by choice (as opposed to by chance) had stronger pro-environmental attitudes towards native forests and those attitudes had a more important 'affective' ('feelings-based') component. For farmers without native fragments, the components of attitudes towards native forests differed depending on whether the fragments were located on or off the farm. Attitudes to offfarm fragments included an affective component, whilst attitudes to on-farm fragments were more restricted to utilitarian considerations.

Durpoix found that talking and reporting being influenced by their families did influence farmers' environmental attitudes and that these attitudes translated into their behaviour towards the environment (p.199). Interactions with both family and other farmers explained a small amount ( $2.5 \%$ and $0.5 \%$ respectively) of the variance in participants' choice between planting exotic or native trees if they were to do so for farming purposes (p.403).

Durpoix measured social influence with self-reports of how participants' attitudes were influenced by others. Although suited to her methodology, this approach is not ideal for measuring social influence as participants tend to underestimate its importance (Cialdini, 2005; Nolan et al., 2008).

From a broader 'farming culture' perspective, Jay (2007) argues New Zealand farmers are embedded in an industrial-commercial complex which promotes a 'productivist' attitude and a narrow framing of environmental issues in terms of their link to productivity. Jay identifies the components of the 'industrial-commercial' complex which are claimed to shape farmer's knowledge, attitudes and objectives as: dairy technology companies, fertiliser and feed suppliers, dairy advisory services, farm discussion groups and family or peer networks. Measures such as taxes on externalities 
(such as greenhouse gas emissions) and farm-management regulations or environmental standards may be unpopular with producers whose farms' productivity they affect (Kallbekken, Kroll, \& Cherry, 2011). Professional farming groups and cooperatives may have the capacity to coordinate their members to lobby against such policies. This has happened in New Zealand in reaction to the carbon tax proposed by the Government in 2002 (Jiang, Sharp, \& Sheng, 2009, p. 8). Jay (2007) argues that such collective lobbying activities could lead to a coalescence of the individual attitudes of group members, towards the 'official' or normal group standpoint and discourage willingness to participate in environmentally-beneficial schemes more generally.

Further insight into influences on farmers' attitudes can be gained from the stakeholder-dynamics related to issues of water quality and use in Canterbury. Memon and Weber (2010) describe a lack of trust between key stakeholder groups as: oldmoney rural landed elites versus urban commercial elites and regional government versus citizens.

Rosin (2008) investigated the attitudes of New Zealand farmers to retail-driven audit schemes such as organic milk certification. The findings endorse Jay's view that milk cooperative production targets have resulted in a 'Spirit of farming' whereby farmers judge their capability as farmers on the basis of productivity. The authors claim low take-up of organic certification and resistance to the Clean Streams Accord ${ }^{7}$ can be explained by the perceived conflict of these strategies with production values.

\subsection{Studies of social influence on landowners using the Theory of Planned Behaviour}

Several researchers have applied Ajzen's Theory of Planned Behaviour (TPB) (or the related Theory of Reasoned Action, TRA) to investigate the influence of social norms on rural landowners' behaviour with respect to environment-relevant behaviours.

In the Theories of Planned Behaviour and of Reasoned Action social influence is measured by the correlation between people's intention to perform a behaviour

\footnotetext{
${ }^{7}$ A voluntary agreement on sustainable dairying between regional and central government and the dairy industry
} 
('Behavioural Intention') and the norms of behaviour they perceive among others, as measured by a 'Subjective Norm' variable. The relationship between the variables is normally investigated by regression analysis of Subjective Norm and other predictor variables on Behavioural Intention. If Subjective Norm is a statistically significant positive predictor of Behavioural Intention in the regression equation, then this indicates social influence is operating.

Relevant findings from eight studies identified in a literature search are summarised in Table 1.

Table 1 A summary of eight studies of rural landowners' behaviour which used Ajzen's methodology.

\begin{tabular}{|l|l|l|l|}
\hline Study reference & Population studied & Behaviour(s) studied & $\begin{array}{l}\text { Subjective Norm } \\
\text { statistically significant } \\
\text { positive predictor of } \\
\text { Behavioural Intention? }\end{array}$ \\
\hline $\begin{array}{l}\text { Young \& } \\
\text { Reichenbach (1987) }\end{array}$ & $\begin{array}{l}\text { Illinois non-industrial } \\
\text { private forest owners }\end{array}$ & Harvesting for timber or not & Yes \\
\hline $\begin{array}{l}\text { Luzar \& Diagne } \\
\text { (1999) }\end{array}$ & $\begin{array}{l}\text { Louisiana's wetland } \\
\text { owners. }\end{array}$ & $\begin{array}{l}\text { Voluntary participation in } \\
\text { Wetland Reserve Program (an } \\
\text { incentive based land use } \\
\text { program) }\end{array}$ & No \\
\hline $\begin{array}{l}\text { Zubair \& Garforth } \\
\text { (2006) }\end{array}$ & Pakistani farmers & Farm-level tree planting & Yes \\
\hline $\begin{array}{l}\text { Fielding, Terry, } \\
\text { Masser, Bordia, \& } \\
\text { Hogg (2005) }\end{array}$ & $\begin{array}{l}\text { Fitzroy basin farmers } \\
\text { (Australia) }\end{array}$ & $\begin{array}{l}\text { Managing riparian zones for } \\
\text { water quality impacts }\end{array}$ & No \\
\hline Hattam (2006) & $\begin{array}{l}\text { Michoacán (Mexico) } \\
\text { small-scale avocado } \\
\text { producers }\end{array}$ & $\begin{array}{l}\text { Adoption of organic } \\
\text { agriculture }\end{array}$ & Yes \\
\hline $\begin{array}{l}\text { Parminter \& Wilson } \\
\text { (2003) }\end{array}$ & $\begin{array}{l}\text { New Zealand livestock } \\
\text { farmers }\end{array}$ & $\begin{array}{l}\text { Controlling possum numbers } \\
\text { farmers }\end{array}$ & Yes \\
\hline $\begin{array}{l}\text { Carr \& Tait (1991) } \\
\text { Ean Gossum, } \\
\text { \& Mortier (2005) }\end{array}$ & $\begin{array}{l}\text { Belgian non-industrial } \\
\text { private forest owners }\end{array}$ & $\begin{array}{l}\text { Keeping or removing } \\
\text { hedgerows }\end{array}$ & Not reported \\
\hline 'Close-nature’ management & N/A \\
\hline
\end{tabular}

Four of the eight studies in the table found a statistically significant, positive effect of Subjective Norm upon Behavioural Intention, whereas two did not and two did not report on this result. It is difficult to determine or compare the size of the social influence effect operating in each case due to differences in the analyses and extent of reported results. Previous meta-analyses have pointed out specific measurement choices made by researchers for the Subjective Norm variable may moderate the measured effect (Armitage \& Conner, 2001). 
The successful use of the Theory of Planned Behaviour to detect and quantify social influence in environmentally-relevant behaviour among rural landowners makes it a candidate methodology for this research. Section 4.1 discusses the arguments for and against using the TPB and other methodologies. 


\section{The Research Question}

My research examines the effect of social influence on rural landowners' actions to voluntarily retain or increase native forest cover on their land.

\subsection{Why is this research question worth studying?}

This section presents the case for studying this research question based on the importance of the environmental issue, current policy context and existing literature research.

\subsubsection{New Zealand native bush ${ }^{8}$ is important}

\subsubsection{Historic human-made changes to forest cover}

Davis \& Cocklin (2001, p. 16) estimate that New Zealand's native forest cover fell from $80 \%(21 \mathrm{~m} \mathrm{ha})$ of the land cover to $53 \%(14 \mathrm{~m} \mathrm{ha})$ between the first arrival of Polynesian people on the islands and the arrival of Europeans. Bush was cleared by Polynesian settlers for use as gardens for growing food. A large part of lowland forests in the Eastern South Island were destroyed by fire, possibly as an unintended consequence of small-scale burning to clear land (Waitangi Tribunal, 2011, p. 238). Forest loss then accelerated dramatically for the half century following European settlement, as forest was rapidly burned or logged, converted to farmland and damaged by various introduced plant and animal species (ibid. p. 239-243). In 2002 native forest covered around 25\% (6.5m ha) of New Zealand's land area (Ministry for the Environment, 2007).

Figure 3 illustrates the extent and location of indigenous vegetation cover loss in New Zealand since the arrival of humans.

\footnotetext{
${ }^{8}$ 'Native bush' is used to refer in this thesis to refer to indigenous New Zealand forest or scrub cover.
} 


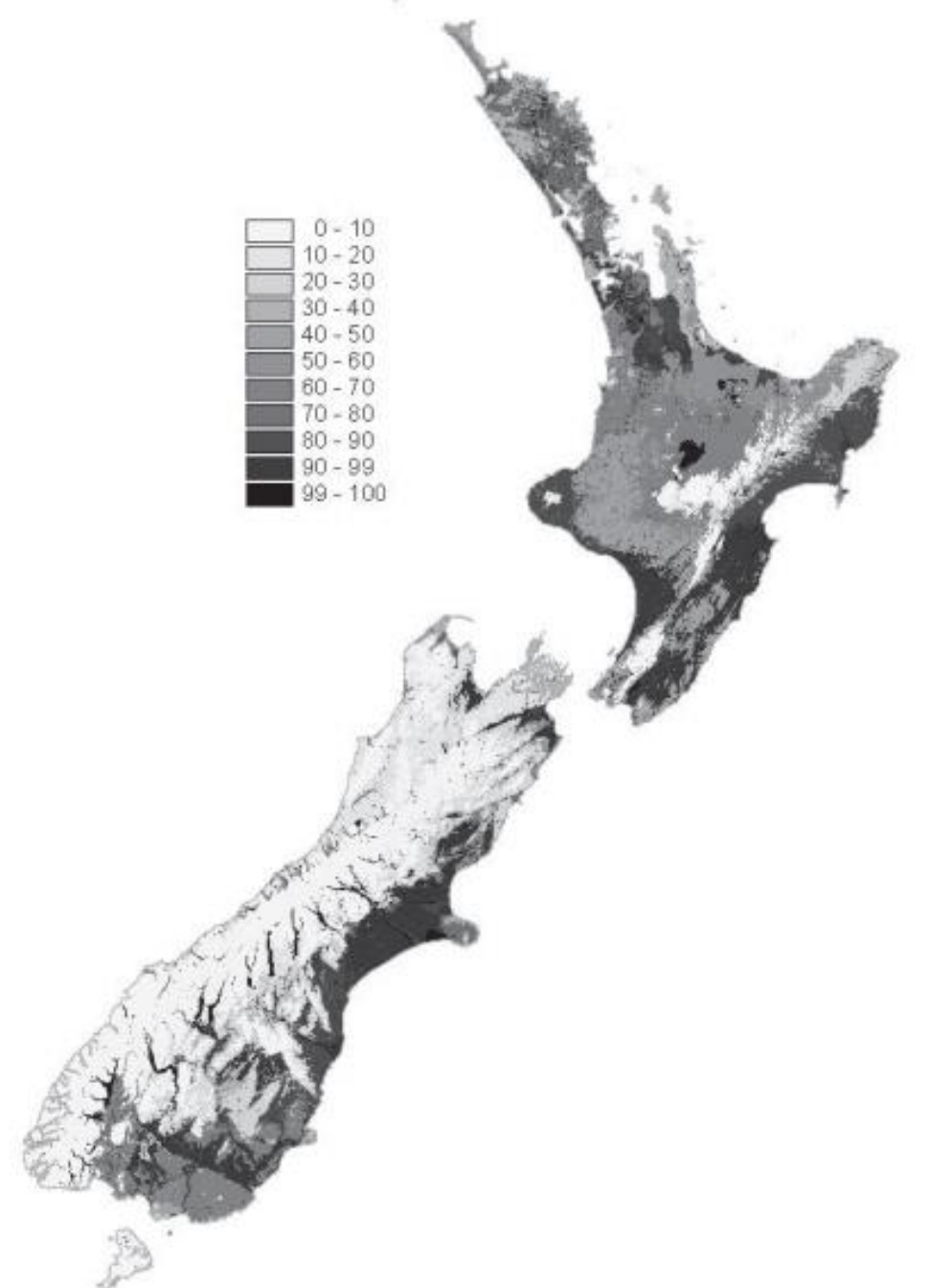

Figure 3 Map of indigenous vegetation cover loss since human settlement - shading indicates percentage lost (Ministry for the Environment, 2002, p. 218)

The Crown owned conservation estate comprises one-third of New Zealand's land (OECD, 2007) and protects around $5 \mathrm{~m}$ ha (Davis \& Cocklin, 2001 p.17) of the remaining native forest. It is unrepresentative of the full range of indigenous ecosystems such as lowland forests. Significant remnants of these native habitats are present on private land, (ibid. p. 6). such as farmland, which makes up around 55\% of New Zealand (Ministry of Agriculture and Forestry, 2010a). In 2007 there was around 1m ha of regenerating or mature native scrub and bush on New Zealand farmland (ibid.). Norton and Miller (2000) note conservation efforts must adequately address lands under productive human use due to the on-going impacts of agricultural activity on biodiversity. They point out that much of New Zealand's lowland, native habitats have been converted to agriculture due to their high intrinsic productivity. The types of 
habitat remnants in these areas are therefore scarce and subject to on-going threats from competing and surrounding agricultural activities.

Walker et al. (2006) assessed from satellite imagery the change during a five year period of remaining indigenous vegetation cover in each of 500 land environment categories. They found $46 \%$ of these environment categories had less than $20 \%$ of original indigenous vegetation cover remaining. Biodiversity loss is understood to accelerate dramatically for each increment of habitat loss beyond the $20 \%$ threshold (Department of Conservation \& Ministry for the Environment, 2007).

Walker et al. found 17,550 ha of indigenous vegetation cover was lost between 1996/97 and 2001/02. This included 3700 ha loss of indigenous cover from land environment types already at or below the $20 \%$ threshold. This represents an annual rate of loss of $0.13 \%$ of the remaining indigenous cover in these environment types. The largest share of the total indigenous cover losses were of indigenous forest (51\%) and $65 \%$ of this indigenous forest loss was replaced with exotic forest (Walker, Price, \& Rutledge, 2005, p. 55). Exotic grassland (e.g. pasture) replaced $22 \%$ of the lost indigenous cover overall. A similar analysis of 2008 satellite imagery by the Department of Conservation revealed that a further 35,000 ha of indigenous vegetation cover was lost between 2001/02 and 2008 (Department of Conservation, 2012, calculated from data in table on p. 6). The consistent loss over consecutive time periods suggests that the issue may be on-going. Although the amount of cover lost is small as a percentage, the cumulative effect over time combined with the high relative biodiversity impact in already scarce habitats makes this trend concerning.

\subsubsection{Values associated with native forests}

Forests provide multiple public goods due to their interaction with freshwater resources, soil and the atmosphere, as well as provision of habitat, cultural, aesthetic and recreational values as described in this section (J. T. Salmon, 1980, pp. 10-17).

The OECD (2007) notes New Zealand's valuable biodiversity endowment due to the high proportion of endemic indigenous plant and animal species, micro-organisms and fungi. Native forest habitat is the home to much of New Zealand's terrestrial biodiversity. 
Riparian planting with native species on farms can reduce non-point source run-off entering rivers and streams from farmland (Fielding et al., 2005), an issue which is growing in importance for New Zealand with the expansion of dairy farming.

New Zealand has a large amount of erodible land. Severe erosion problems on the East Coast on land cleared for pastoral farming and exacerbated by Cyclone Bola in 1988 led to the creation of the East Coast Forestry Project by the Government. This aimed to reduce soil losses and associated impacts on the productivity of land and siltation problems in waterways as well as providing regional employment and development (Bayfield \& Meister, 2005, p. 1). Blaschke et al. (1992) found that landslide rates in the hill country around Taranaki were two and three times higher on pasture than on scrub and indigenous forest slopes respectively, which was resulting in rapid net soil depletion.

Literature evidence of the effects of deforestation and afforestation on flood control was reviewed in a report for the Ministry for the Environment by Blaschke, Hicks, \& Meister $(2008$, p. 19,20$)$. The authors found evidence that vegetation in catchments could slow down water run-off and decrease the magnitude and duration of floods passing down rivers. Floods of greater than ten year frequency are unlikely to be mitigated, since extremely heavy rainfall overwhelms the impact of vegetation on runoff. The Ministry for Primary Industries' 'Sustainable Land Management Hill Country Erosion Programme', established in 2006, recognises the potential for this floodcontrol benefit in its funding of re-vegetation projects.

The Māori concepts of whakapapa and kaitiakitanga express some of the humanenvironment relationship within mātauranga Māori (the Māori 'worldview'). Whakapapa describes a web of genealogical relationships linking people to features of the natural world and to ancestor-gods. Within this whakapapa, people are seen as related to the plants of Aotearoa, since they are both descendants of the god Tānemahuta. The relationship is illustrated by this quote regarding the use of the harakeke/flax plant in weaving:

"[...] harakeke [...] is a descendant of the great god Tane-mahuta. The myths recorded his exploits : how he separated his father Rangi-nui (the sky) from his mother Papa- 
tuanuku (the earth), clothed his mother with trees and other plants, fought with and was defeated by his brother Tu-mata-uenga, the warlike ancestor of man. Tane proceeded to form and breathe life into the first woman and with her produced the Maori race. Thus today's Maori are related to harakeke and all the other plants: Tane is their common ancestor indeed, a Maori will refer to plant life simply as Tane, and in that respect regards the trees and other plants as ancestors, requiring respect. On the other hand, as a descendant of the victorious Tu, a Maori is able to make use of the descendants of Tane. Use is permitted, sanctioned by Tu's defeat of Tane, but it must be respectful use, for Tane too is an ancestor of the Maori people." J Patterson quoted by Waitangi Tribunal (2011, pp. 35-36)

This quote also alludes to the kaitiakitanga or guardianship aspect of the Māori relationship with the natural world which arises from their whakapapa relationship with it. Kaitiakitanga describes the obligation (and rules for customary use) which a whanau, hapu or iwi may have to preserve the physical wellbeing and mauri (spiritual wellbeing) of taonga (treasured) plant and animal species and of forests, waterways and other features and places in their rohe (ibid., p. 17). Māori customary use of plants and animals for food, medicinal, artistic and ceremonial purposes demonstrate the practical value of these natural resources. Such customary use also contributes and keeps traditional culture alive through practice and by contributing to manākitanga (hospitality) by providing kai to visitors.

The Waitangi Tribunal points out that Māori and iwi cultures have their roots in the interaction between newly arrived Polynesian people and the New Zealand environment. The alienation of land from Māori since the arrival of Europeans, combined with the damage to and destruction of natural habitats and species means Māori and iwi now struggle to fulfil the kaitiakitanga responsibilities required to express and sustain their culture (ibid, p.300)

Forests sequester $\mathrm{CO}_{2}$ from the atmosphere (act as a carbon sink) while they are growing or expanding in area. Once mature, the standing stock of forest carbon may fluctuate with the health of a forest. For example, Kurz et al. (2008) found that increased pressure from an outbreak of mountain pine beetle reduced carbon uptake by forests in Canada. The degrading effect of introduced species such as possums, pigs, 
deer and goats on native New Zealand forests may have a similar impact on carbon uptake, but this effect is currently poorly understood (Kirschbaum et al., 2009, p. 83).

The historic changes in both indigenous and exotic forests extent have contributed to New Zealand's $\mathrm{CO}_{2}$ emissions in the past. Contemporary changes due to planting and growth of exotic forests are now important for New Zealand's emissions profile, accounting for $84 \mathrm{Mt} \mathrm{CO}_{2}$ removal units reported under Commitment Period 1 of the Kyoto Protocol (ibid. p. 2).

\subsubsection{Long time-horizon policies are required}

The succession timescales for mature native bush are in the order of hundreds of years, as indicated by the $1000+$ year lifespans of kauri trees (J. T. Salmon, 1980, p. 30).

The impact of deforestation on the values and services provided by mature native forest is therefore irreversible over a few human generations. This means that attempts to preserve or increase native bush on private land need to act consistently over a similar, multigenerational timescale.

The situation for native bush fragments on private land is made more precarious by pressures from introduced animal, plant pests and micro-organisms ${ }^{9}$, the possibility of subdivision for development, and surrounding farming activity. Davis and Cocklin ( $p$. 28) claim that only formal protection (covenanting or sale to a conservation body), sustainable forest management for timber (under the Forests Amendment Act 1993) or informal protection (excluding stock, controlling pests and weeds) are likely to be to sustain the health of native bush on farmland. Excluding stock without also controlling pests and weeds is thought likely to lead to long-term decline while allowing stock access will certainly lead to long-term decline and cutting timber for firewood is likely to significantly damage habitat.

\footnotetext{
${ }^{9}$ The micro-organism Phytophthora agathis is a pathogen which infects kauri trees resulting in "kauri die back' (Ministry of Primary Industries, the Department of Conservation, Auckland Council, Northland Regional Council, Waikato Regional Council, Bay of Plenty Regional Council, Tāngata whenua, n.d.)
} 


\subsubsection{The current policy context}

\subsubsection{Protection of native forest}

Davis and Cocklin (2001) provide an overview of the policies which affect native forests in New Zealand. Around five-sixths of the remaining native forest is on the conservation estate, leaving around $1 \mathrm{~m}$ ha on private or Māori land.

Various mechanisms exist by which landowners can legally protect native habitats on their land. These include covenanting under the QEII National Trust Act 1977 and covenanting, management agreements and purchasing under the Reserves Act 1977, the Conservation Act 1987, the Historic Places Act 1993, Te Ture Whenua Māori Act 1993 and the Resource Management Act 1991 (via Heritage Protection Orders). Public funding is provided by the QEII National Trust and Nga Whenua Rahui fund to assist with fencing and other conservation expenses required by covenants. The Nature Heritage Fund and the Department of Conservation's Land Acquisition Fund provide for the purchase of private land into conservation. Where private land is formally protected, councils can grant landowners a reduction in rates to reflect this (Davis \& Cocklin, 2001, p. 20).

Walker et al. (2006) combined a database of formally protected areas ${ }^{10}$ (as at 2005) with their analysis of the extent of remaining indigenous vegetation cover in different land environments. They found $62 \%$ of remaining indigenous cover overall was under formal protection. However, those land environment types which had already lost $30 \%$ or more of their original vegetation cover nationwide were poorly protected. These types accounted for $1.2 \mathrm{~m}$ ha of vegetation cover, of which only $24 \%(298,000$ ha) was protected in 2005. Most of the unprotected cover (73\%) was indigenous forest or mānuka and/or kānuka. As pointed out by the authors, an increasing rate of biodiversity loss is expected when remaining habitat decreases beyond the $20 \%$ remaining cover threshold, making these habitats particularly important for protection. Walker et al.'s data also shows that formal protection is largely effective

\footnotetext{
${ }^{10}$ The Protected Areas of New Zealand database "includes all public conservation lands and covenants administered for the purposes of natural heritage protection by DOC, QEII Open Space and Nga Whenua Rahui covenants, and Territorial Local Authority Regional Parks." (p. 170).
} 
where it is in place, with only around one percent of the c.17,000 ha indigenous cover loss over a five year period being from formally protected areas.

The Forests Amendment Act 1993, prohibited the harvesting of original (as opposed to newly planted) native forest unless they were part of an approved 'sustainable forest management plan'. This means to harvest at a rate and manage the forest "in a way that maintains the ability of the forest growing on that land to continue to provide a full range of products and amenities in perpetuity while retaining the forest's natural values" (s.2). In other words, this means that timber yields should be non-diminishing (sustainable) and that low-impact harvesting techniques are used. Furthermore, active maintenance and protection of the forest is required: "Any necessary measures to be taken to protect the forest, and, in particular, to protect the regenerating forest from pest, stock, fire, and other threats" (s. 67J.8(a)). Approximately 50k ha of native forest is currently managed via Sustainable Management Plans according to the Ministry for Primary Industries' website (2013b).

The West Coast Forestry Accord was an agreement between Government, the forestry industry and some Environmental Non-Government Organisations (ENGOs) which allowed 'sustainable' logging and sawmilling of publicly owned native forests to continue in several areas on the West Coast of New Zealand. The Accord came to an end and the forests were transferred to the conservation estate in 2002 , amid ongoing disagreements among various stakeholders about what constituted 'sustainable' forestry (Memon \& Wilson, 2007).

The New Zealand Native Forest Accord was a non-statutory agreement signed in 1991 between a number of ENGOs, forest growers and timber processors. The New Zealand Forest Owners Association undertook that its members would protect native forests with canopy species from land clearing and disturbance when establishing plantation forests, in return for the ENGOs' support for sustainable plantation forestry with exotic species.

The fast-growing Pinus radiata is now the main tree species grown and harvested for production forestry in New Zealand. This provides timber in harvest cycles of around 25 years, compared with estimates of 80-300 years (Memon \& Wilson, 2007, p. 756) 
required for sustainable indigenous forestry. The faster returns make Pinus radiata more commercially attractive to potential growers ${ }^{11}$, although a market still exists for native hardwoods as evidenced by the $50 \mathrm{k}$ ha under sustainable management. Harvesting by clear-felling of newly planted indigenous forest is permitted under the Forest Amendment Act (Forests Act 1949, as amended, s.67D(1)(b)(i)(C)).

\subsubsection{The Resource Management Act}

Although the Forests Amendment Act 1993 precludes non-sustainable logging and sawmilling of native timber, it does not remove a private landowner's right of land clearance for conversion to other land use ${ }^{12}$. However the Resource Management Act, 1991 (RMA) may apply to this activity. Section $6(\mathrm{c})^{13}$ of the RMA defines "the protection of areas of significant indigenous vegetation and significant habitats of indigenous fauna" as a matter of national importance which those exercising functions and powers under the act should 'recognise and provide for'. The implementation of this policy depends upon it being incorporated by regional and district councils in their plan rules and policies and in consent decisions.

\subsubsection{Financial incentives}

There are various schemes of financial support or incentives for forest protection and afforestation relevant to both indigenous and exotic forests. This includes the Emissions Trading Scheme (ETS) and instruments under the Sustainable Land Management and Climate Change Plan of Action (SLMCCPA) (Ministry of Agriculture and Forestry, 2007) ${ }^{14}$.

\subsection{The Sustainable Land Management and Climate Change Plan of Action (SLMCCPA)}

Within the SLMCCPA the East Coast Forestry Project funds tree planting to reduce soil erosion.

\footnotetext{
${ }^{11}$ Other economic factors in the relative profitability of the different timbers include the additional cost of sustainable harvesting, and the higher prices fetched for hardwood than softwood timber.

12 The clearance of native forest becomes significantly less 'economic' (in monetary terms) if the timber cannot be sold to cover any of the costs.

${ }^{13}$ This section of the RMA is subject to change under amendments proposed by the Government in 2013.

${ }^{14}$ Note that the Ministry of Agriculture and Forestry became the Ministry of Primary Industries in 2012
} 
The Afforestation Grant Scheme (AGS) funds provides funds for tree planting in return for the carbon credits that would be earned by the landowner over a ten year period if they were registered in the ETS. The AGS thereby provides cash flow 'upfront' to the landowner to help fund tree establishment. The AGS favours projects which benefit soil erosion, water quality and indigenous biodiversity and prohibits deforestation within 10 years. The AGS began in 2008 but ceased offering new funds in 2013.

The Permanent Forest Sink Initiative (PSFI) attempts to create a higher level of certainty for forest protection in the long-term by entering newly (native or exotic) forested land into a 50 year PFSI covenant and providing carbon credits. 'Continuous cover' forestry is permitted for PFSI forests (Ministry for Primary Industries, 2011). ${ }^{15}$

\subsection{The New Zealand Emissions Trading Scheme}

The following information on the Emissions Trading Scheme (ETS) is taken from a publication by the Ministry of Agriculture and Forestry (2010c) unless otherwise indicated.

The treatment of forests under the ETS depends upon whether they existed on $1^{\text {st }}$ January 1990 ('pre-1990 forests') or not ('post-1989 forests'). Owners of pre-1990 exotic forests over 50 ha must pay for the carbon emitted if they deforest and change the land use (i.e. do not replant the forest). Pre-1990 indigenous forests are not covered by the ETS and therefore landowners do not face a corresponding deforestation carbon liability for clearing indigenous forest.

Owners of post-1989 exotic and native forests (established on land not forested at $1^{\text {st }}$ Jan 1990) are voluntary participants in the ETS. If they choose to register then they earn NZUs as their forests grow and are liable to pay out units when they are harvested (no matter if the forest is replanted or not).

The change in carbon content over time of a Pinus radiata and a native species forest is shown in Figure 4. Increasing carbon stocks result in a post-1989 forest owner earning

\footnotetext{
${ }^{15}$ In 2013 the Government began consulting on amendments to the Permanent Forest Sinks Initiative because the type of carbon unit (Kyoto Assigned Amount Units) will no longer be available to the New Zealand Government following its decision to not take a target under Kyoto Commitment Period 2 (Ministry for Primary Industries, 2013a)
} 
NZUs, but these must be paid back on harvesting (for a forest owner). This offers an additional cash-flow in the short-term which may be attractive for owners to invest in other opportunities with relatively short pay-back versus the 25-30 year harvesting cycle.

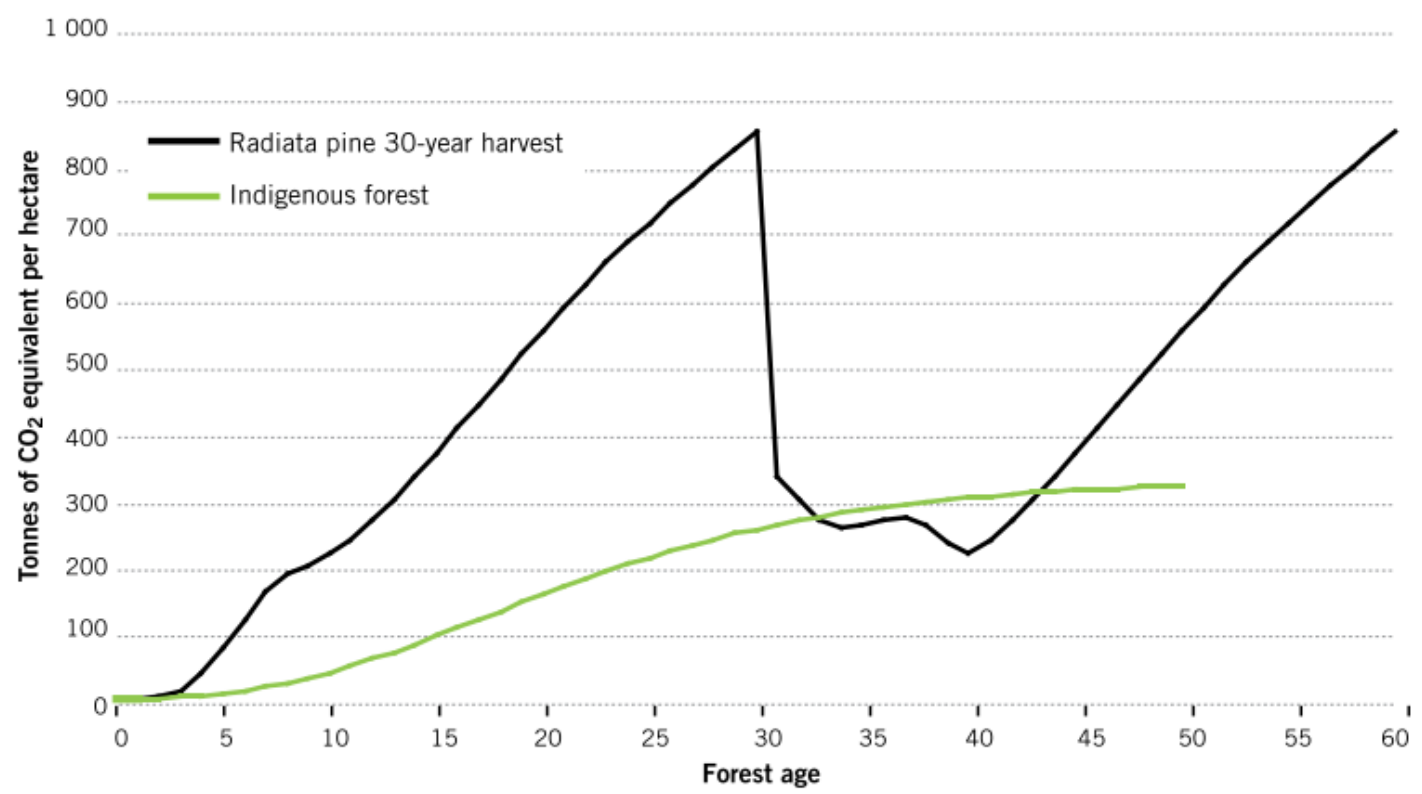

Figure 4 Typical carbon stocks in one hectare of Pinus Radiata or indigenous forest in New Zealand. Taken from Ministry for Agriculture and Forestry Introduction to Forestry in the Emissions Trading Scheme, November 2010, p.7.

The relative incentive provided by the ETS is smaller for native than exotic forests due to the slower growth rates of the former. The ETS earnings for a planted native forest are also small in absolute terms. For example, assuming one hectare of indigenous forest sequesters 300 tonnes $\mathrm{CO}_{2}$ over the 50 years following planting and an NZU price of $\$ 20$ per tonne, this implies earnings of only $\$ 120$ per hectare per year. This would provide a comparable return to sheep and beef farming in higher altitude regions of New Zealand, but not in the more productive lowlands, as can be seen from Table 2. This also ignores the additional costs of excluding stock and pest control required to maintain native forest health.

Table 2 EBITR (Earnings before interest, tax and rent) per hectare for mixed sheep and beef farms in several New Zealand regions (Beef and Lamb New Zealand Economic Service, 2013)

\begin{tabular}{|l|l|lc|}
\hline & & EBITR, \$/ha \\
\hline South Island & Class 1. S.I. High Country & $\$$ & 49 \\
\hline & Class 2. S.I. Hill Country & $\$$ & 142 \\
\hline & $\begin{array}{l}\text { Class 6. S.I. Finishing Breeding } \\
\text { (Located mainly in Canterbury } \\
\text { and Otago) }\end{array}$ & $\$ \quad 473$ \\
\hline
\end{tabular}




\begin{tabular}{|l|l|l|}
\hline & $\begin{array}{l}\text { Class 8. S.I. Mixed Finishing } \\
\text { (Mainly on the Canterbury plains) }\end{array}$ & $\$ 912$ \\
\hline
\end{tabular}

The carbon price in New Zealand decreased significantly during 2012 (Figure 5) which significantly altered the incentives and intentions of large-scale forest $(>10,000$ ha) owners, as demonstrated by the Ministry for Primary Industries' Deforestation Intentions Surveys (Manley, 2013). The surveys found that the amount of deforestation planned by owners of large-scale forests (for the period 2008-2020) had increased from 17,000 ha in 2011 to 62,000 ha in 2012 . The fact that the low carbon price was a key motivation for this change is indicated by comments made by respondents to the survey.

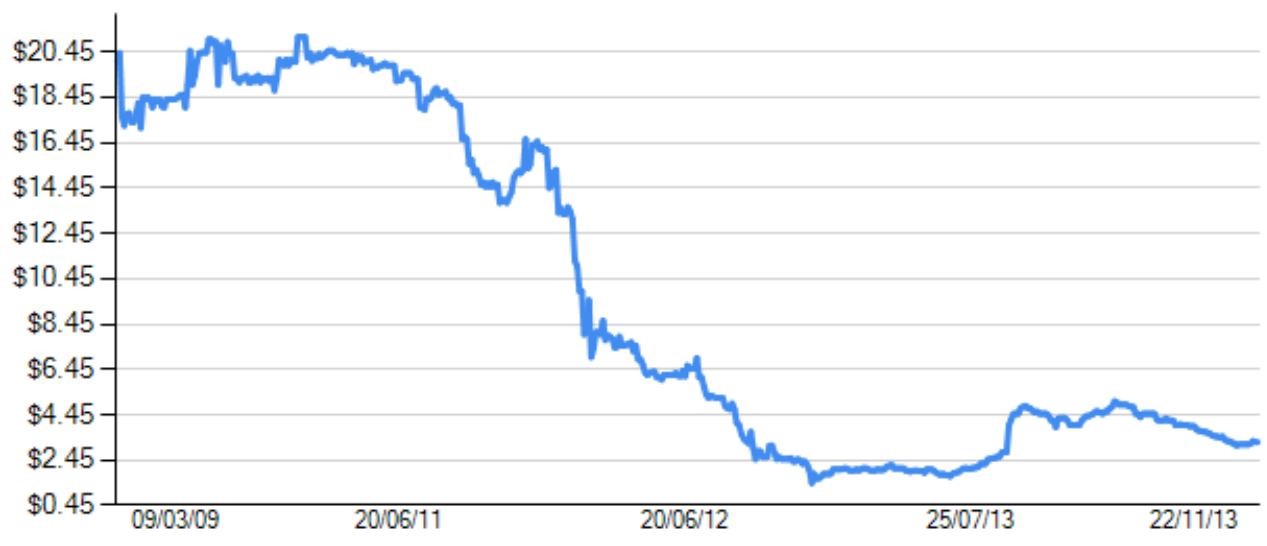

Figure 5 The NZU spot price history. Downloaded from https://www.commtrade.co.nz/ on 24/11/13

\subsubsection{Motivational and community-based approaches}

Some New Zealand policies take a more socially-sensitive approach to conservation. As well as administering covenants, the QEII Trust's statutory functions include disseminating information and encouraging preservation of valuable land environments. This function is partly achieved by field days run by covenanters. Meanwhile regional Conservation Boards established under the Conservation Act 1987 provide a forum for interaction of local community representatives with the Department of Conservation on conservation strategies for that region. Initiatives such the Ballance Farm Environment Awards and the Ministry for the Environment's Green Ribbon Awards offer public recognition of individual landowner and community action. 
There has been a move towards more 'collaborative' and community-based natural resource management in New Zealand in recent years, particular for freshwater quality. The Landcare Trust undertakes projects with rural landowner communities which result in substantial behaviour change, such as increased riparian planting ("Volcano to sea project - Landcare Trust," n.d., "Waitangi River Project - Landcare Trust," n.d., "Wetland Restoration - Landcare Trust," n.d.).

The Canterbury Water Management Strategy run by Environment Canterbury Regional Council includes direct input by local communities on formal water use and quality rules and targets (G. Salmon, 2012). Meanwhile in March 2013 the Government made water reform proposals which include "a collaborative planning process for fresh water, as an alternative to the existing RMA process" (Ministry for the Environment, 2013). This would involve local government, iwi/Māori, resource users, and community members working together from an early stage in the planning process.

These collaborative and community-based initiatives employ social interaction to resolve conflicts around common pool resources (primarily waterways). Although the development of social norms is relevant, this may not be the only motivation for such policy approaches. Ostrom's work showed that the social interaction in such situations is needed to build trust and mutual understanding, leading to enduring institutions (both rules and norms of behaviour) to manage the shared resource (Ostrom, 1990).

The need to establish rule-based institutions in order to resolve interpersonal conflict is less relevant for native bush on private land as this is not a common pool resource. The forests and trees in question for this study are grown on private land by landowners who have secure rights to the material goods they provide in terms of timber. However native forests provide multiple public goods and services for the local and wider community as described in 3.1.1.2. Therefore considering the processes by which norms of behaviour are established for this resource is nonetheless worth studying.

\subsubsection{Current policies don't provide long-term certainty of protection}

Protection of native bush on private land needs an institutional response with timehorizons of the same order of magnitude as the succession periods for that ecosystem, 
i.e. policies which maintain incentives and objectives over tens of human generations (see Section 3.1.2). As described in this section, current New Zealand policies may not provide this long-term certainty of protection.

Regulatory responses can achieve some level of stability, and have done so in the case of the land included in the Conservation Estate. However, Walker et al. found that in $2001 / 2$ around $1.7 \mathrm{~m}$ ha of indigenous forest was outside of the Conservation Estate and had no other formal legal protection (2005, p. 25). The Forests Amendment Act outlaws non-sustainable forestry of 'old-growth' indigenous forests on private land but allows clear-felling as long as the timber is not milled or sold. The Resource Management Act (RMA) in principle allows councils to prohibit such land clearance but this is at their discretion.

The proposed National Policy Statement (NPS) on biodiversity under the RMA as notified in January 2011 would require councils to more pro-actively protect native bush on private land - to achieve 'no net loss' (of biodiversity, habitat or vegetation area). The submissions received on the proposed NPS illustrate the resistance such regulatory approaches can face from private landowners (Ministry for the Environment, 2011).

The majority of rural landowners who made submissions did not support it. It was perceived by many as an infringement on property rights, for example (p.97):

"Freehold tenure of Land/Property is the cornerstone foundation of our society. To erode that right is criminal."

"To not allow a farmer to care for his farm the way he sees fit and use his judgement on protecting indigenous vegetation is not fair."

Some submitters also perceived it as unfair for government to impose obligations and opportunity costs for native bush management on private landowners without compensation. It was pointed out that those who had voluntarily invested to protect native bush on their land would be penalised by this policy relative to those who had previously cleared bush. Many favoured an approach which made use of existing voluntary landowner efforts and stewardship ethics by encouraging councils to work with landowners, rather than using regulation to effectively 'alienate' their land. 
The system of freehold private land ownership combined with the multiple public services provided by forests leads to inevitable tension between private landowners' rights and any mandated protection of native bush. Rural landowners' submissions on the proposed NPS on biodiversity illustrate the difficulty of making rules which are perceived to derogate from private property rights.

In terms of financial incentives, the Emissions Trading Scheme does not apply a deforestation penalty to 'old-growth' indigenous forest, but it, and the Permanent Forest Sinks Initiative, offer people planting native forests the chance to earn carbon credits. However, because of the relatively low-growth rates, such forests earn a poor return from carbon sequestration compared to the equivalent area of production species such as Pinus radiata (Figure 4).

Financial incentives are founded on the concept of 'rational' decision-making by landowners about tree cover on their land. Within this frame, every land use has an opportunity cost in terms of the next best alternative use (i.e. most privately beneficial). Land use decisions in New Zealand depend on the (highly volatile) carbon price as well as a number of other highly volatile variables, such as commodities (milk, meat, timber) prices. The carbon price under the ETS is potentially highly volatile since it is linked to overseas markets but also because consecutive governments are likely to have differing priorities. The range of fluctuating economic incentives puts indigenous forest on farmland at constant threat of conversion to 'productive' use depending on the farmer's beliefs about the relative benefits, and makes long-term investment decisions for native (or exotic) forestry planting very difficult.

New Zealand schemes which either purchase or subsidise the covenanting of land may achieve permanent protection for some areas of native bush. The extent of protection possible is limited by funding available and landowners' willingness to participate. Furthermore the experience with European set-aside policies suggests they are unlikely to drive significant shifts in rural landowners' attitudes if they are viewed as a removal of land from productive use ${ }^{16}$ (Section 2.2.2).

\footnotetext{
${ }^{16}$ Note that although there is a niche market for sustainably harvested native New Zealand timbers, the long-time scales involved mean native forestry is not generally considered commercially competitive with exotic forestry or livestock farming
} 


\subsubsection{Policies based on social influence have potential to be effective}

Social influence as a policy tool for private landowner decisions has not been evaluated or trialled before in New Zealand. There is substantial evidence from the literature that social influence is an important determinant of behaviour in a diverse range of domains (chapter 2).

The importance of social influence varies with the situation and the measurement technique used. Strong social influence found in laboratory (Asch, 1955; Sherif, 1935) and other experimental research (Cialdini et al., 1990) supports the view that the Theory of Planned Behaviour underestimates the predictive power of subjective norms due to measurement issues (Armitage \& Conner, 2001).

Financial incentives notably have a substantial effect on the forestry decisions as demonstrated by the negative relationship between the carbon price under the ETS and (large-scale) forest owners deforestation intentions (Manley, 2013). Some evidence of the response of small-scale foresters to price signals comes from the 1990 Pinus radiata planting boom. Peak planting of this species by small-scale foresters occurred in 1994 and 1995 (Rodenberg \& Manley, 2011), corresponding to the peak in the soft-log timber commodity price (see Figure 6). This data is not straightforward to interpret as a similar price spike in the early 2000 s did not lead to a similar planting spike. Furthermore there was a substantial transfer of forests from state to private ownership between the early and late 1990s, which may have created unusual incentives for private foresters. 


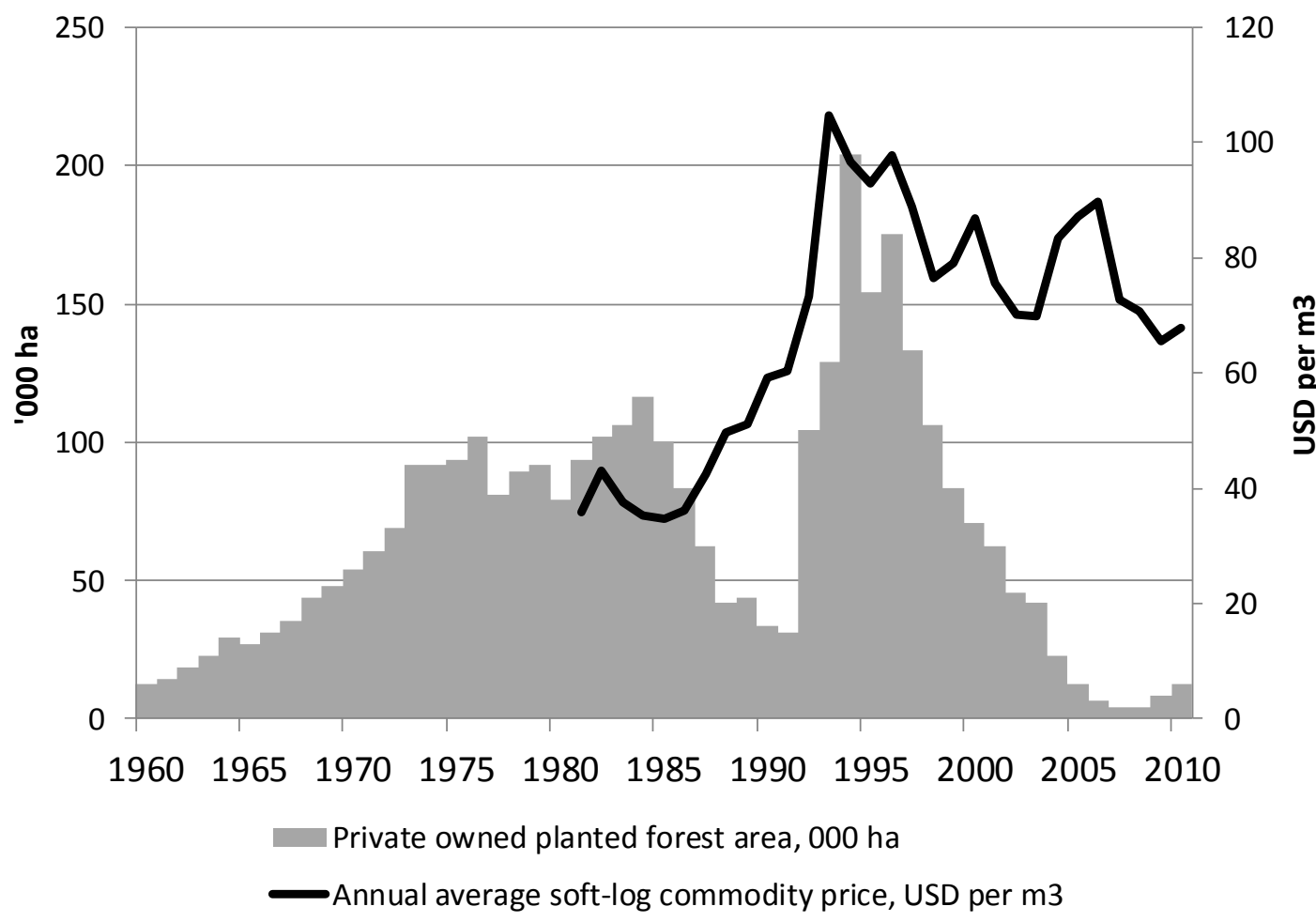

Figure 6 International soft-log prices 1982-2010 (Indexmundi, 2011) and area of planted production forest in exotic planting 1960-2010 (Ministry of Agriculture and Forestry, 2010b)

Chen et al. (2009) show that social norms can substantially reinforce or weaken the effect of financial incentives. Those researchers measured the financial incentive required to persuade Chinese landowners to re-enrol their land in a conservation scheme. When $75 \%$ of his/her neighbours were re-enrolling, the amount of money required to persuade a landowner to re-enrol was around one-third less than when only $25 \%$ of his/her neighbours were re-enrolling.

A range of social influence effect sizes have been found by Theory of Planned Behaviour studies of the environmental behaviour of rural landowners (Table 1). These range from no effect to significant (small and substantial) positive effects. A survey of New Zealand farmers with native forest fragments by Durpoix (2010) found that interactions with both family and other farmers explained a small amount of variance in participants' choice between planting exotic or native trees. In light of her findings and due to the widely recognised methodological issues with measuring social influence, Durpoix recommends that "The question of influence of peers on farmers' attitudes and behaviour towards the natural environment must be addressed further."(p.270) 
Recent New Zealand Government campaigns in other policy areas have made explicit use of social influence. The Ministry of Transport's 'DriveSocial' initiative uses advertising which 'humanises' fellow road users so that social pressure will encourage responsible driving. According to the campaign's website, “...[if] people [were] to think of the road as a social place [then] responsible road users must behave in a way that the majority of people would deem socially acceptable" (Ministry of Transport, 2013). A campaign targeting drink-driving among New Zealand youths has attempted to use social influence to achieve behaviour change in recent years. It endorses sober-driving as part of being a 'good mate' while highlighting the risks posed to young drivers and their mates by drink-driving (NZ Transport Agency, 2012).

These campaigns address behaviours which have antisocial attributes. The importance of social pressure for pro-social behaviours was noted by Piliavin and Charng (1990). Homans' (1974) Exchange Theory would interpret this as a group using approval to reward pro-social behaviour and disapproval to punish anti-social behaviour.

Pro-environmental behaviours can be seen as altruistic, in that they imply individuals are foregoing private gain for the wider public good. If landowners see active preservation of native bush as 'pro-social' or 'altruistic' behaviour it seems likely that the approval or disapproval of others will be a predictor of this behaviour.

I argued in Section 3.1.4 that there is a need for policies which achieve long-term stability for this particular environmental issue but mainstream existing New Zealand policies are not expected to achieve this for a number of reasons.

The literature on the spread of ideas through society based on self-reinforcing social norms (Section 2.1.3) suggests an alternative approach. The history of human use of New Zealand land illustrates the dynamic shift in 'normal' behaviour with respect to native bush over time. This includes the Māori burning of native bush, rapid European 'mining out' of centuries old indigenous hardwood, conversion of productive low-lands to pastoral use and the protection of mountainous regions in the Conservation Estate. The Royal Forest and Bird Society was formed in 1923, partly as a response to loss of native forests and associated native bird species (Forest \& Bird, 2013). The Department of Conservation, created in 1987, now manages crown-owned indigenous forests for 
the primary purpose of conservation. The 1990s and 2000s have seen an increasing variety of habitat protection initiatives run by various groups beyond the Department of Conservation and sometimes linked to eco-tourism (such as Zealandia in Wellington and Maungatautari Ecological Reserve in the Waikato).

My research seeks to understand if social influence could play a role in dramatic shifts in attitudes and behaviour over time such as those described in the preceding paragraph. Because of the self-reinforcing nature of social norms, policies which actively harness them offer the potential to embed lasting attitude and behaviour change, on a timescale appropriate for the ecosystem in question.

\subsubsection{Who influences New Zealand rural landowners?}

The literature on social influence emphasises that the strength of social influence may vary depending on the identity of the influencer. The Theory of Planned Behaviour (TPB) refers to those people or groups who are important sources of influence as 'salient referents'. Social identity theory and self-categorization theory (Stryker \& Serpe, 1982; Tajfel \& Turner, 1979) suggest that people are more strongly influenced by fellow group-members than by others. Some researchers have found that the extent of 'group-identification' moderates the social influence found in TPB studies.

Burton (2004) highlights two studies of farmers in the UK (Williams et al. 1994; Allison, 1996), which found their negative attitudes to forestry schemes stemmed from the poor fit with their self-identity as farmers. Burton, Kuczera and Schwarz (2008) link the failure of land set-aside and prescriptive farming conservation schemes to embed attitude change to the fact that they offer limited opportunities for farmers to demonstrate the skills and prowess of their profession to peers. Furthermore, New Zealand researchers (Jay, 2007; Memon \& Weber, 2010; Rosin, 2008) have highlighted the important influence of farming industry groups and cooperatives on farmers.

Meanwhile, groups which offer farmers a sense of belonging and social support may be important from a mental health perspective. The issue of depression and suicide among agricultural workers in New Zealand was highlighted by a 2010 publication by 
the Southern Rural Life Newspaper (O'Hara, 2010) ${ }^{17}$. A national network of Rural Support Trusts has been established in recognition of this problem. A study of depression and suicide among Australian farmers found that both social support and a 'sense of belonging' were factors which decreased suicidal thoughts (McLaren \& Challis, 2009).

With the exception of one study (Van Gossum et al., 2005) ${ }^{18}$, the previous TPB studies of rural landowners I identified did not examine the impact of group membership or identification on social influence. The preceding paragraphs suggest groups may be an important source of social influence for New Zealand farmers. Therefore I propose to study the impact of group membership on social influence within this research. This will help to confirm if some of the variance in the effect size found by previous TPB studies could be explained by diversity among study participants in terms of group membership.

There are several plausible mechanisms by which group membership could moderate social influence. Where a behaviour contributes to the group's common interest or purpose then it seems reasonable to expect the social norm among group members to differ from wider society. For example, conservation group members are likely to perceive norms more supportive of environmental behaviour among their fellow members than among society as a whole. Group members may also have more social interaction on topics relating to the group's purpose with other people in the group than with non-members. This could mean they are more confident than non-members in judging the norms of behaviour among their peer group. Group members may also feel self-identification with the group which means they give more weight to the opinions and behaviours of fellow group members than non-members. Social influence is hard to detect, so studying a group of strongly-interacting people increases the chance of detecting any effect at all.

\footnotetext{
${ }^{17}$ This newspaper issue compiled information provided by the Ministry of Health, the Ministry of Agriculture and Forestry, the Mental Health Foundation of New Zealand, Rural Support Trusts, Rural Women New Zealand, Suicide Prevention Information New Zealand and a number of mental health professionals.

${ }^{18}$ Unfortunately Van Gossum et al.'s results are difficult to interpret due to the unconventional (with respect to the Theory of Planned Behaviour) method of statistical analysis employed by the authors.
} 
The Māori concept of whanaungatanga captures the importance of the kinship provided by iwi, hapu and whanau groupings. The 'inter-connectedness' of people with each other and with aspects of the natural world are integral to Māoritanga (Māori culture). This research acknowledges, but does not specifically examine the relationship of Māori groupings with the forests in their rohe ${ }^{19}$. This is because that relationship is more appropriately explored using Māori concepts and epistemology than the western scientific approach discussed in the preceding paragraphs and employed by this research.

\subsection{Elaboration of the Research Question}

Based on discussion in this chapter, my research question is stated as follows:

"What is the influence of social norms and group membership on New Zealand rural landowners' behavioural intention with respect to native trees on their land?"

The following sub-questions will be investigated:

1. Do the social norms perceived by rural landowners influence their intentions with respect to increasing, decreasing or maintaining the native tree cover on their land?

2. Is membership of a relevant group correlated with higher social influence effects?

2a. Do these higher social influence effects result from greater social interaction, confidence and/or group-identification?

3. What is the importance of social influence relative to other known predictors of behavioural intention?

\footnotetext{
${ }^{19}$ The potential for iwi or hapu membership being a source of social influence is acknowledged by including 'my iwi or hapu' as a response option in the question: 'Which of the following people or groups did you consider when you answered questions $x-y$ ?'.
} 



\section{Methodology}

\subsection{Choice of Model}

My research seeks to understand how and why prevailing societal attitudes and behaviours towards the natural environment may become embedded over timescales of generations - and why they change. I propose that a mechanism involved in this process is social influence leading to self-reinforcing norms of behaviour.

The research question presents challenges for empirical investigation because: 1) the timescales relating to land use behaviour and decisions are on the order of years; and 2) social influence is hard to detect and to discriminate from other predictors of behaviour.

In order to study behaviour change, a longitudinal study, including recording participants' behaviour and social links over inter-generational timescales would be ideal, but would be a mammoth undertaking. Even a longitudinal study of changes in particular landowners' behaviours or attitudes on a timescale of years is impractical for my research. Studying historical changes in behaviour based on self-reports or secondary sources is feasible. This would probably require interviews resulting in qualitative data restricted to a relatively small number of participants. This might result in a richer understanding than a quantitative study of participants' beliefs about their behavioural motivations. Such a study would probably struggle to demonstrate a causal link between social influence and behavioural change because people's beliefs about how they are influenced by others are generally inaccurate (Section 2.1.4). More objective measurement could involve correlating participants' behaviour with that of other participants whom they knew, although this might require a large population $(n)$ study of densely socially-linked participants to detect the weak social influence effect.

Unfortunately the time-scale of this particular behaviour change also rules out the study designs which have demonstrated some of the strongest social influence effects. These are the experimental designs of Cialdini and others, described in Section 2.1.4, in which participants' behaviour is observed with and without the presence of a 'normative cue'. 


\subsection{The Theory of Planned Behaviour}

The theoretical framework used for quantitative measurement within this study is Ajzen's (1985) Theory of Planned Behaviour (TPB) whose variables are shown in Figure 7.

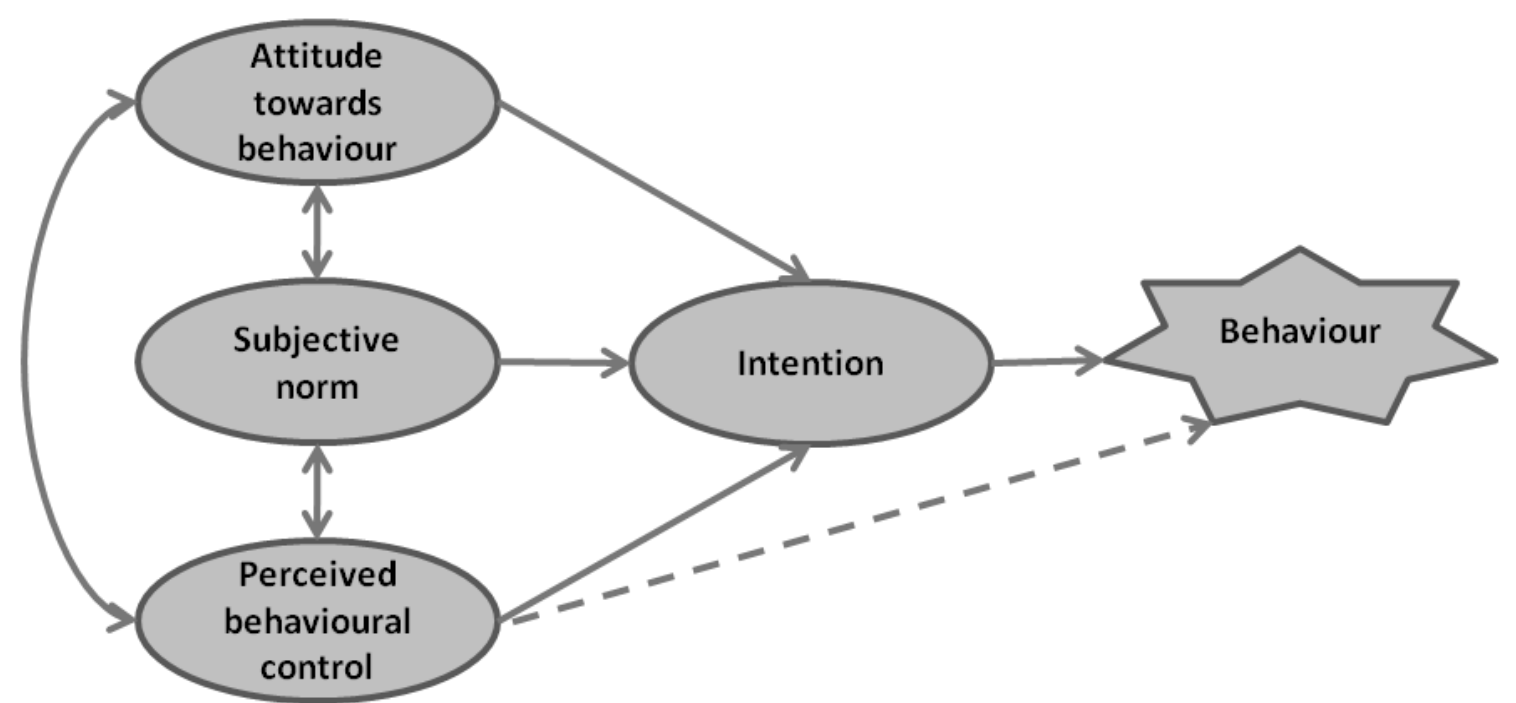

Figure 7 Variables in The Theory of Planned Behaviour. Adapted from (Ajzen, 2002)

The Theory of Planned Behaviour (TPB) offers a methodology for detecting social influence without the need for longitudinal studies of behaviour change and social links, or for experimental observations of behaviour. The TPB relies on participants' self-reports of the norms they perceive (their Subjective Norm) towards a particular behaviour as well as their intentions or actual behaviour. Intention has been found to be a fair predictor of actual behaviour, so to the extent that Subjective Norm is found to predict intention, this is claimed to demonstrate that social influence is operating. The next section elaborates on the TPB and its use in my research.

The TPB doesn't incorporate the concept of change in attitude or behaviour, but findings on the existence of social influence made using the TPB might be combined with evidence from the social network literature to make inferences about attitude and behaviour change. The social-network literature provides evidence (Section 2.1.3) that social influence may precipitate rapid, wholesale societal change when 'tipping points' are reached in the level of adoption of an idea or behaviour. My research seeks to examine if social influence is an important determinant of individual behaviour towards native trees. If it is, then together with evidence from the social-network literature, this is consistent with social influence being involved in embedding or 
changing prevailing views towards native trees on private land at a societal level. The circumstances under which a particular 'minority' set of attitudes and behaviour towards native trees might actually spread and overturn existing practices to become the new 'norm' are not the subject of this research.

The model has shown substantive predictive power of human behaviour in a variety of settings, including for private landowners decisions. A well-established methodology exists in the literature to guide study design. The most substantial predictor of intention and behaviour within the model is attitude. Subjective norm adds a small, but non-negligible measure of predictive power in most studies employing the model. The inclusion of attitude and perceived behavioural control will allow assessment of the relative importance of social influence versus these other predictors of intention and behaviour.

\subsubsection{Behaviour versus behavioural intention}

I propose to measure only intention rather than behaviour as the dependent variable. Time and resource constraints prevent the observation of actual behaviour over the timeframes relevant to land-use decisions. Using past behaviour as a proxy for future behaviour is feasible but rejected since it raises questions about the direction of causality for correlations between Subjective Norm and Attitude.

Ajzen (1985) states behaviours should be expected to correlate best with intentions when behaviour follows immediately after the statement of intent and behaviour is under volitional control. The Perceived behavioural control variable is intended to take account of the latter issue. Unfortunately the long timeframes associated with landuse decisions may weaken the link between intention and behaviour for behaviours I am studying.

\subsubsection{Questionnaire construction}

Quantitative data for TPB studies are normally gathered by questionnaire. Pre-work in the form of interviews or focus groups may be used to identify appropriate behaviour descriptions and questions which are comprehensible and relevant to participants. It is recommended to test the reliability of variable measures for both test-retest consistency and for internal consistency using Cronbach's alpha (Ajzen, 2002, p. 5). 
Within the TPB framework, either 'direct' or 'indirect' measures or both can be made of the model's three predictor variables (Attitude, Subjective Norm and Perceived Behavioural Control). The following examples (in italics) are from a TPB questionnaire guide by Icek Ajzen (2002).

A direct measure of Attitude consists of rating the behaviour along a series of semantic differential scales, for example:

"For me to walk on a treadmill for at least 30 minutes each day in the forthcoming month is: harmful/beneficial, pleasant/unpleasant, etc."

An indirect measure of Attitude requires the behavioural belief strength $(b)$ and the outcome evaluation $(e)$ attached to a given behavioural outcome to be assessed. For example for Attitudes towards lowering ones blood pressure:

Behavioural belief strength (b):

My walking on a treadmill for at least 30 minutes each day in the forthcoming month will lower my blood pressure is: extremely unlikely/extremely likely [Likert response scale]

Outcome evaluation (e):

Lowering my blood pressure is extremely bad/extremely good [Likert response scale]

The product of $b$ and $e$ would be summed across all salient behavioural outcomes to obtain an aggregate indirect measure of attitude. A similar process of applies to the other predictor variables:

Subjective Norm $=$ normative belief strength $x$ motivation to comply for each salient referent)

Perceived Behavioural Control $=$ control belief strength $x$ control belief power for each salient control factor 
Indirect measures require considerably more pre-work for the researcher but may provide additional accuracy and insight into motivations. The inclusion of indirect as well as direct measures will also at least double the number of questions in a questionnaire instrument, which is likely to reduce the response rate and therefore decrease study power.

Zubair and Garforth (2006) investigated direct versus indirect measurement in a TPB study of farm forestry intentions in Pakistan. They found comparable, substantively and statistically significant regression coefficients and regression line slopes with both types of measure. This suggests the use of direct measurement can provide acceptable results.

\subsubsection{Measurement issues within the Theory of Planned Behaviour (TPB)}

\subsubsection{Correspondence}

Ajzen and Fishbein (1977) found discrepancies in the amount of variation in behaviour and behavioural intention explained by 'attitude' between different empirical studies. They showed that the predictive power of attitudes was determined by the degree of 'correspondence' between 'target and action elements' of attitudinal and behavioural constructs used. For example, the frequency of attending ['the action'] church ['the target'] correlated with attitudes towards 'attending my church', but not with attitudes towards 'attending shared worship' or 'donating money to my church' - both of which correspond with only action or target elements of the behaviour respectively.

\subsubsection{Problems measuring norms}

Previous research has found weak and variable social influence effects with the TPB (Section 2.1.4). Armitage and Conner (2001) show the strength of social influence varies with an individual's personality type and extent of group-identification. They also argue that measures of Subjective Norm should include multiple items, including both descriptive ('what other people do') and injunctive ('what other people think I ought to do') components, in-line with Cialdini et al's (1990) findings (Section 2.1.4).

There are at least two dimensions on which the strength of an injunctive norm could be measured: the proportion of people who approve of behaviour $x$, and the strength 
with which those people hold that belief. Including questions which measure both dimensions should avoid this ambiguity for respondents and improve reliability.

A participant may judge the behaviour and opinions of his/her salient referents as encouraging, discouraging or neutral with respect to a behaviour. A fourth possibility is that the participant lacks information to make this judgement because of insufficient social interaction with salient referents or a lack of referents who are salient. Insufficient information is likely to make it difficult to answer questions about subjective norms. This could result in an excess of 'neutral' responses and/or decreased internal validity of the measure.

\subsubsection{Conclusions for measurement within this study}

Given the discussion in the preceding sections, the steps below were taken to improve subjective norm measurement accuracy and boost the study's statistical power:

1. Measurement of 'self-monitoring' personality trait alongside TPB variables was made using Snyder's 18-question instrument.

2. Multiple-item measures of Subjective Norm including descriptive and injunctive components were used.

3. Behaviours of interest were defined with high correspondence between independent and dependent variable constructs.

4. Direct measures of TPB variables were used to streamline study design and questionnaire length, improving the chance of obtaining a statistically significant result (due to more completions), while accepting reduced 'richness' of understanding about participant's motivations.

5. Including a question on 'confidence in ability to judge [subjective norm]' should detect if participants find it hard to answer questions about subjective norms because of insufficient information. This also addresses Research Question 2a. 


\subsection{Study design}

\subsubsection{Populations}

The survey was conducted on two groups: 1) members of the New Zealand Farm Forestry Association (FFA) and 2) a randomly selected group of landowners (excluding FFA members). The FFA is a national group consisting of a number of regional branches. This is not an explicitly pro-environmental or conservation group. From my discussions with various members at an FFA conference I found out that many group members practice and share an interest in forestry on their land with a variety of exotic and/or native species and appear to be motivated by a range of production, amenity and other values. The group provides a forum for discussing and sharing information on the members' interests. Opportunities for interaction include field days, an annual conference, a website and a magazine. I'm interested in the FFA group because I believe they have frequent social interaction and discussions of trees and forestry which makes social influence on land use decisions likely. Inclusion of a randomly selected group of non-FFA members allows the importance of group membership to be tested for Research Question 3.

\subsubsection{Broader methodological issues}

Three concerns arise with the design described in Section 4.2.4 and these are discussed in the following paragraphs.

\subsubsection{Power to reject the null hypothesis \\ Confounding variables}

There are probably confounding variables which strongly influence landowners' behaviour and intentions and thereby reduce the power of the study to detect a correlation between subjective norm and intention. For example, it is known from a large number of previous studies with the Theory of Planned Behaviour that Attitude and Perceived Behavioural Control are substantive predictor variables and may correlate with subjective norm.

\section{Data clustering}

The FFA members are largely farm-forestry 'enthusiasts' whom I believe to interact with each other frequently. They engage in farm-forestry behaviours regularly and are likely to perceive the same pattern of behaviour among their peers. Therefore 
measured behavioural intention and subjective norm values are likely to be clustered at the high end of both scales. This is likely to reduce the power of the study to detect a correlation.

\section{Showing causation}

Although FFA group membership is believed to make social influence more likely, there are plausible, alternative explanations for a correlation between behaviour and subjective norm.

Pre-existing and on-going farm-forestry behaviour could prompt participants to become FFA members. As members, they may subsequently develop a perception of a norm supportive of farm-forestry.

Another possibility is that FFA membership creates a perception of a norm, but influence on members' behaviour is achieved by other mechanisms, such as: sharing of information about techniques, tree species, economic opportunities and technology.

\section{Self-reporting}

All variables will be measured by self-report of 'latent mental constructs', which makes it difficult to claim to have detected an objective effect with real-world implications.

\subsubsection{Overcoming methodological issues}

The following methods were used to help address the difficulties discussed in Section

\subsubsection{1.}

\section{Confounding variables: experimental design}

Confounding variables were experimentally controlled for using within-subject comparisons in a subset of the FFA study. This used a 'test-stimulus-retest' design, i.e. measuring intention, then exposing the participants to a cue designed to 'focus' their attention on normative information immediately before measuring intention again.

\section{Data clustering: include a control group of non-FFA members}

As well as allowing the moderating effect of group membership on social influence to be tested, including the non-FFA member group was expected to help increase the range of values sampled for Behavioural Intention and Subjective Norm in the pooled population. 


\section{Showing causation}

Firstly, Attitude and Perceived Behavioural Control were measured alongside Subjective norm. Within the TPB, Attitude accounts for the benefits which a participant expects to derive from a behaviour while Perceived Behavioural Control accounts for their expectation of success if it is attempted. The alternative influence mechanisms of increased information or capacity due to FFA membership should therefore be represented within these measures. If including Subjective Norm in the regression model explains additional variance in intention, then this is evidence for it being a separate influence mechanism.

Secondly, the moderating effect of the self-monitoring personality trait on the correlation of subjective norm (SN) with intention was examined. If the correlation is stronger for higher self-monitors, this is good evidence for subjective norm and behavioural intention being related by a psychological mechanism 'within the participant's head', rather than 'externally mediated' mechanisms.

Finally, the test-stimulus-retest experimental design is intended to help demonstrate causality by manipulating the independent variable (SN) while measuring the change in the dependent variable.

\section{Self-reporting}

Measuring actual behaviour by participants after surveying their intentions would have helped to address part of the self-reporting problem. Unfortunately the work and time required for such a follow-up was beyond that achievable for a Masters thesis of this size.

\subsubsection{Experimental study design}

The experimental study required a 'cue' which increased the 'salience' of normative information for participants, immediately prior to measuring Behavioural Intention. This approach is inspired by Cialdini et al's (1990) littering studies which employed cues such as a researcher overtly littering in a litter-free environment, in order to draw attention to the 'not littering' norm.

It is challenging to devise a cue which does not make the participant suspicious about the researcher's intentions. If a participant guesses the researcher is attempting to 
influence a participant's responses this could lead to invalid data due to 'secondguessing' or resentment. This risk will decrease with a more subtle cue, but that increases the chance that the cue will not be effective in drawing attention to normative information.

A cover letter with a postal questionnaire could give a normative cue in the form of information on farm forestry activities and those carrying them out, but there would be no way of knowing if and when the participant had read it. An online questionnaire provides more control over what information is presented to a participant and in what order. Good control over cue presentation could also be obtained in a 'laboratory' setting, with the researcher controlling the environment in which questionnaires are completed (i.e. posters on walls).

The design I used for the test-stimulus-retest study was to use an online questionnaire of FFA members to administer Subjective Norm and Intention questions in a specific order:

1) Intention measurement questions

2) Subjective norm measurement questions

3) Repeat Intention questions

The subjective norm measurement questions themselves formed the 'cue' designed to make normative considerations 'salient' in the mind of the participant.

A potential issue was whether participants would attempt to be consistent during the test, rather than reporting any change in intention they might actually experience as a result of the normative cue. This issue was addressed by separating part 1 of the test from parts 2 and 3 by sufficient time (a few weeks) for the participant to forget their detailed responses to part 1.

\subsubsection{Implementation of study}

A pilot questionnaire of FFA members was used to help establish the behaviours to ask about, to test question wording and to create measures with good internal consistency for the final questionnaire. Three behaviours were included in the final survey: 
1) Increase native tree, bush or scrub cover on your land.

2) Decrease native tree, bush or scrub cover on your land.

3) Keep about the same native tree, bush or scrub cover on your land.

Other behaviours relating to conservation actions such as riparian planting and fencing to exclude livestock were considered for inclusion. The three behaviours used were chosen because any participant was likely to be able to perform at least one of these behaviours, thereby reducing the number of 'wasted' surveys.

The full survey was distributed to FFA-Members by email with a link to an online questionnaire. Then a paper version was posted to a random selection of rural landowners ('non-FFA group'). To minimise the effects of confounding variables the non-FFA group was matched with the relevant characteristics of FFA respondents by stratified sampling for land location, land area and existing land use type. The stratified sampling approach and the derivation of samples for each study are described in Chapter 5.

\subsubsection{Overall Framework of variables}

Figure 8 illustrates the proposed framework implied by the Research Questions and tested by this research. 


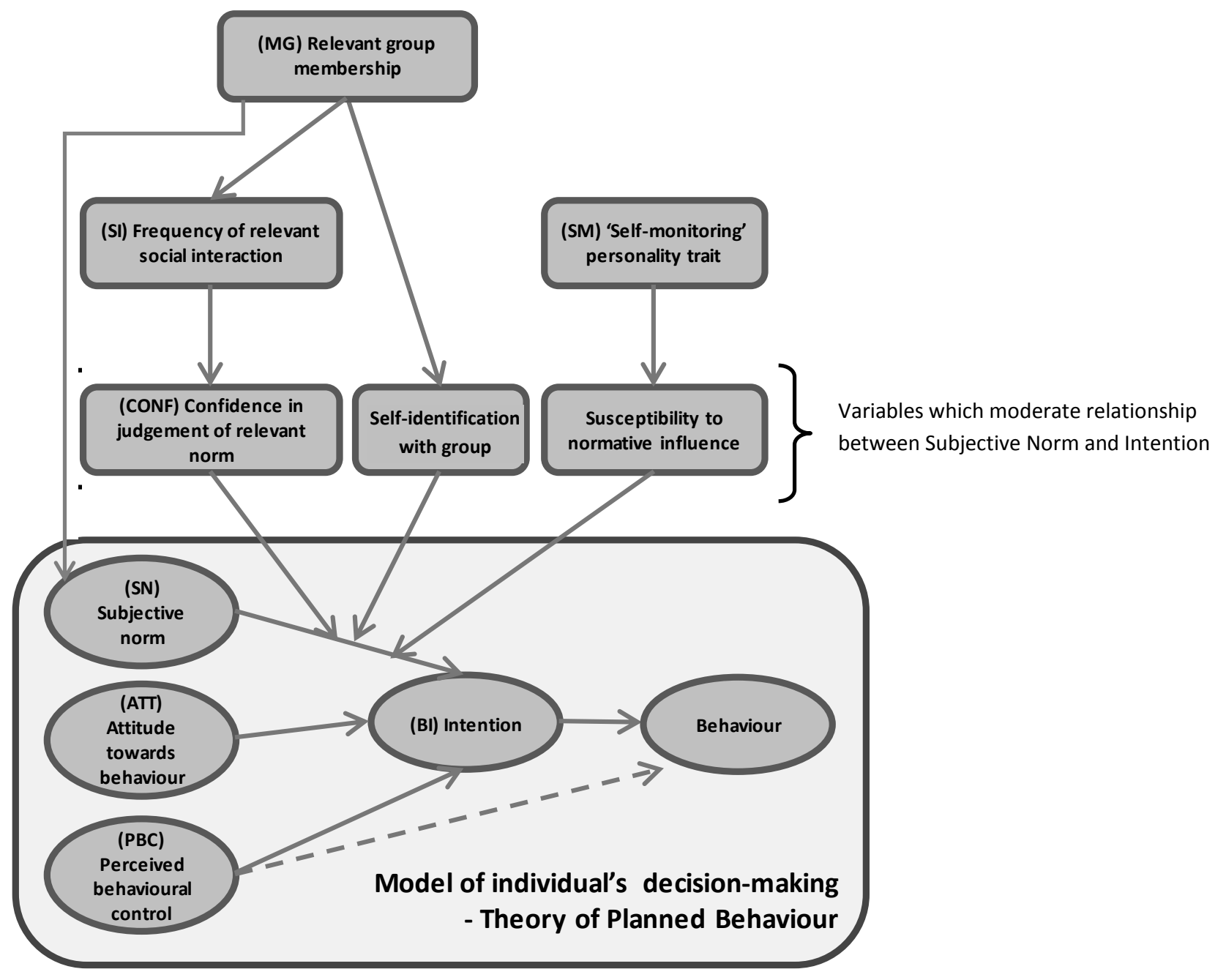

Figure 8 Overall framework of variables tested by my research 


\subsubsection{Hypotheses}

The following hypotheses are made:

H1. Landowners have a tendency to conform to the social norms they perceive among their peers in their behaviours affecting native tree cover on their land.

H2. Landowners who are more confident in their judgement of the relevant social norm are more likely to conform to that social norm.

H3. Landowners who have more, relevant social interactions ${ }^{20}$ are more confident in their judgement of the relevant social norm.

H4. Landowners who have more, relevant social interactions have a greater tendency to conform to the social norms they perceive.

H5. Landowners who are members of a social group (Group Members) whose purpose relates to land use decisions are more likely than Non-Members to conform to the social norms they perceive among their peers in their behavioural intentions for native tree cover on their land.

H6. Greater social influence between Group Members than between Non-Members is the result of 1) greater confidence about the opinions and behaviour of their peers due to more frequent, relevant social interactions; and 2) self-identification with the group.

H7. Group Members perceive different social norms for behaviours affecting native tree cover on their land to the social norms perceived by Non-Members

\subsubsection{Hypothesis tests}

The following tests will be applied to the survey data in order to test the hypotheses.

For each group (FFA-Members and Non-Members) analysed independently and as a single, pooled data set:

\footnotetext{
${ }^{20}$ Social interactions were measured in the questionnaires as conversations with others on different types of land-use for the participant's land.
} 
Test 1. Participants are expected to show a correlation between subjective norm and intention (supports H1)

Test 2. Subjective norm is expected to explain additional variance in intention beyond that explained by Attitude and Perceived Behavioural Control alone (supports $\mathrm{H} 1)$.

Test 3. People who score more highly on Snyder's self-monitoring personality trait scale are expected to show a stronger correlation between subjective norm and intention than the lower self-monitors (supports $\mathrm{H} 1$ ).

Test 4. Participants who report more frequent social interaction are expected i) to more confidently judge the relevant social norm (supports $\mathrm{H} 3$ ) and show ii) a stronger correlation and between subjective norm and intention (supports $\mathrm{H} 4$ )

Test 5. Participants who are more confident in judging the relevant norm are expected to show a stronger correlation between subjective norm and intention (supports $\mathrm{H} 2$ ).

Comparing FFA-Members with Non-Members:

Test 6. FFA-Members are expected to show a stronger correlation between subjective norm and intention than non-FFA members (supports $\mathrm{H} 5$ )

Test 7. FFA-Members are expected to report a mean subjective norm for behaviours affecting native trees on their land which is different to that reported by nonFFA members (supports H7).

Together, if the data support Hypotheses 1 to 5 (Tests 1-6 have positive results) and Tests 8-11 have positive results, then this would support H6:

Test 8. The mean fraction of relevant interactions had by FFA-Members with other FFA-Members (as opposed to with non-FFA Members) is expected to be more than 0.5 .

Test 9. The mean number of relevant social interactions had in a given time period is expected to be greater for FFA-Members than for non-FFA Members. 
Test 10. FFA-Members are expected to be more confident in their judgement of relevant social norms than non-FFA members.

Test 11. FFA-Members are expected to show a stronger correlation than non-FFA Members between intention and the interaction term of subjective norm and confidence in that norm.

NB. Test 11 is intended to demonstrate that the increased level of social influence among Group-Members versus among Non-Members is more than can be explained by increased confidence in norm judgement alone. I propose the greater salience of Group-Members' peers due to their self-identification with the group explains at least some of this additional social influence. It is not proposed to directly measure the level of group self-identification in any of the studies. There is limited space in the questionnaire to include measures of this variable and it is hoped to infer it from other data as described above.

For the experimental study, in which participants will be presented with questions in this order:

1) Behavioural Intention measurement questions $\left(\mathrm{BI}_{1}\right)$

2) Subjective norm measurement questions (SN) (doubles as 'normative cue')

3) Repeat Behavioural Intention questions $\left(\mathrm{BI}_{2}\right)$

Test 12. Participants are expected to report a behavioural intention which more closely aligns with their reported subjective norm for the behaviour immediately after they have answered questions about that subjective norm than beforehand.

Test 12 would support that any correlation found between subjective norm and behavioural intention by the other tests is in fact due to causal influence from subjective norm to behavioural intention (as opposed to causal influence in the other direction, or each being linked to a third causal variable). 



\section{Results}

\subsection{Data collection}

\subsubsection{Survey instruments}

All members of the Farm Forestry Association (FFA) with email addresses in the Association's database $(n=1213)$ were sent a link to an online questionnaire created using the Qualtrics survey system (www.qualtrics.com). Questions covered Theory of Planned Behaviour variables and the additional moderator variables discussed in Section 4.3.6. Questions were also included on contextual variables relating to participants' situations and land and their self-assessed motivations. Other questions provided information of interest to the Farm Forestry Association Board. Two followup reminder emails were sent to recipients who had not completed the survey and this appeared to boost the response rate by around 2.5 times.

Approximately one-third of FFA survey recipients were randomly assigned to the 'experimental' survey. The experimental questionnaire was identical to the full questionnaire, but omitted questions about Subjective Norms. Those participants who expressed an interest in completing a second 'experimental' questionnaire were sent one approximately seven weeks later. This second questionnaire included questions on Subjective Norms and on Intention.

The sample of non-Farm Forestry Association members was drawn from a geographic database of New Zealand land property titles including landowner names. Corresponding addresses of landowners were derived by combining this with a geographic database of the electoral roll, then converting these data into valid postal addresses using a tool on the New Zealand Post website. Appendix 3 gives full details of the procedures and software used.

A paper questionnaire was posted to 771 names and addresses, with a cover letter and postage-paid return envelope (see Appendix 5). The paper questionnaire included identical questions to the online survey on the Theory of Planned Behaviour and contextual variables. Reminder postcards were sent to recipients who had not replied within approximately one month. Fourteen of the 227 respondents to the paper survey stated they were Farm Forestry Association members. It was not possible to 
distinguish members from non-members prior to sending postal surveys. The data from the 14 Farm Forestry Association member respondents to the postal survey were removed from this completed sample and instead analysed with the responses of FFA members to the online survey.

\subsubsection{Responses and case selection}

Cases in the completed samples from the online (FFA member) and postal (non-FFA member) surveys were included in further analysis if they satisfied the following criteria:

1. Own, manage or have influence over at least one piece of land which is one hectare or more in area;

2. Have at least some influence over land use decisions for that land;

3. Have at least one of the relevant behaviours (increase or decrease native tree cover on that land) that is volitional (i.e. not obligated and not forbidden); and

4. Completed the survey without leaving substantially unfinished sections (such as all questions relevant to a particular variable with no response).

Online respondents were only included if they met the following additional criteria:

1. They stated they are a current member of the Farm Forestry Association

2. They stated they are a member as a private individual (or individuals) as opposed to a business, trust, council or other institution

The size of the survey populations, sample frames, samples and completed samples (respondents) for the online, paper and experimental surveys are shown in Table 3. 
Table 3 The derivation of samples for each study

\begin{tabular}{|c|c|c|c|c|c|c|}
\hline & $\begin{array}{l}\text { Online } \\
\text { survey } \\
\text { (FFA } \\
\text { members) }\end{array}$ & $\mathbf{N}$ & $\begin{array}{l}\text { Experimental } \\
\text { survey (FFA } \\
\text { members) }\end{array}$ & $\mathbf{N}$ & $\begin{array}{l}\text { Paper survey } \\
\text { (non FFA } \\
\text { members) }\end{array}$ & $\mathbf{N}$ \\
\hline $\begin{array}{l}\text { Survey } \\
\text { population }\end{array}$ & $\begin{array}{l}\text { FFA } \\
\text { members }\end{array}$ & c. 2000 & FFA members & c. 2000 & $\begin{array}{l}\text { NZ private } \\
\text { individual, } \\
\text { rural } \\
\text { landowners } \\
>1 \text { ha }\end{array}$ & c. $310,000^{21}$ \\
\hline $\begin{array}{l}\text { Sample } \\
\text { frame }\end{array}$ & $\begin{array}{l}\text { FFA } \\
\text { member } \\
\text { email } \\
\text { database }\end{array}$ & 1213 & $\begin{array}{l}\text { FFA member } \\
\text { email } \\
\text { database }\end{array}$ & 1213 & $\begin{array}{l}\text { Property titles } \\
\text { database }^{22}\end{array}$ & 313,805 \\
\hline Sample & $\begin{array}{l}\text { Received } \\
\text { link to main } \\
\text { survey }\end{array}$ & $860^{23}$ & $\begin{array}{l}\text { Received link } \\
\text { to } 1^{\text {st }} \\
\text { 'experimental' } \\
\text { survey }\end{array}$ & $281^{24}$ & $\begin{array}{l}\text { Paper surveys } \\
\text { sent to valid } \\
\text { addresses }\end{array}$ & $736^{25}$ \\
\hline $\begin{array}{l}\text { Completed } \\
\text { sample }\end{array}$ & & 356 & $\begin{array}{l}\text { Completed } 1^{\text {st }} \\
\text { and } 2^{\text {nd }} \\
\text { 'experimental' } \\
\text { surveys }\end{array}$ & 29 (of 38 sent) & & 227 \\
\hline $\begin{array}{l}\text { Valid } \\
\text { responses } \\
\text { (meeting } \\
\text { criteria) }\end{array}$ & & $197^{26}$ & & 29 & & 164 \\
\hline
\end{tabular}

\subsection{Contextual variables}

\subsubsection{Stratified sampling}

The sample for the survey of non-Farm Forestry Association members (non-FFA members) was deliberately matched with the Farm Forestry Association (FFA) responses on a number of contextual variables (Section 4.3.5). This was achieved by analysing the distribution of responses to the online survey by FFA members to the online survey by land cover type (native tree cover, exotic tree cover, both or neither), land location (district) and land title area. Then, the sample for the postal survey was

\footnotetext{
${ }^{21}$ Exact number depends on precision used in measuring title area and on treatment of titles with multiple records in title database.

${ }^{22}$ The property title database was processed and filtered to identify rural titles greater than 1 ha in private individual ownership. See Appendix 3 - Postal address list methodology for full details of this process and the subsequent derivation of names and addresses and stratified sampling.

${ }^{23} 913$ emails were sent but 53 were invalid email addresses so not received

${ }^{24} 300$ emails were sent but 19 were invalid email addresses so not received

${ }^{25} 771$ surveys were posted but 35 were returned to sender unopened

${ }^{26} 14$ respondents to the paper survey happened to be FFA members, and were included in that group for the analysis. Criterion six was not applied to these cases, as the information was not available.
} 
prepared by stratified random sampling from the non-FFA member sample frame. In other words, rather than randomly sampling from the non-FFA member sample frame as a whole, random samples of a given size were taken from four sub-populations who had 1) exotic tree cover, 2) native tree cover, 3) both or 4) neither on their land. The resulting sample was then re-sampled but this time from 67 sub-populations relating to council district and then finally for land title area. The information required to do this was obtained by combining geographic databases of New Zealand land property titles, District Council boundaries and land cover based on 2001/02 satellite imagery Appendix 3.

Figure 9 and Figure 10 show the distribution of land location and land title area achieved in the responses for the online survey (of FFA members) and the postal survey of (primarily ${ }^{27}$ ) non-FFA members. These graphs illustrate that a reasonably good degree of matching was achieved on these variables between the two populations in the study.

\footnotetext{
${ }^{27}$ The postal survey actually received a small number (4\%) of responses from FFA members. These responses were analysed with the rest of the FFA (online) responses. Thus the true distributions of responses from FFA members and non-members by district will differ very slightly from that in Figure 9. This does not alter the primary information conveyed by the figure that matching between the populations on district is reasonably good.
} 


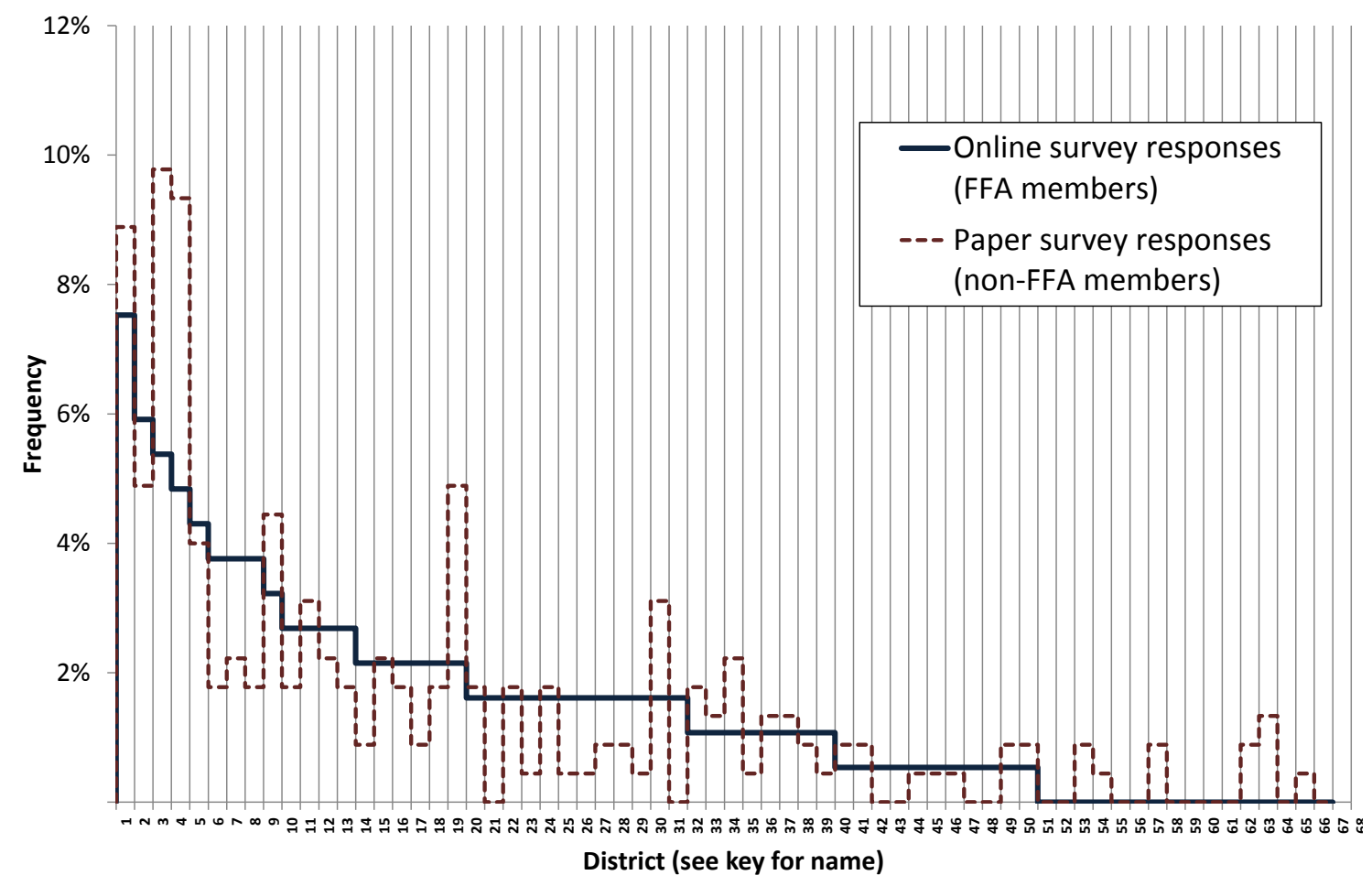

Figure 9 The distribution of responses by district for the online and paper surveys

Table 4 Key of district names

\begin{tabular}{|l|l|l|l|l|l|}
\hline 1 & Auckland Council & 23 & Horowhenua & 45 & Nelson \\
\hline 2 & Far North & 24 & Kapiti Coast & 46 & Otorohanga \\
\hline 3 & Tasman & 25 & Opotiki & 47 & South Waikato \\
\hline 4 & Hastings & 26 & Rangitikei & 48 & Tauranga City \\
\hline 5 & Whangarei & 27 & Ruapehu & 49 & Waimakariri \\
\hline 6 & Kaipara & 28 & South Taranaki & 50 & Waipa \\
\hline 7 & Marlborough & 29 & South Wairarapa & 51 & Area Outside Territorial Authority \\
\hline 8 & Masterton & 30 & Timaru & 52 & Buller \\
\hline 9 & Hurunui & 31 & Wellington City & 53 & Central Otago \\
\hline 10 & Clutha & 32 & New Plymouth & 54 & Dunedin City \\
\hline 11 & Stratford & 33 & Rotorua & 55 & Hamilton City \\
\hline 12 & Tararua & 34 & Southland & 56 & Hutt City \\
\hline 13 & Westland & 35 & Taupo & 57 & Invercargill City \\
\hline 14 & Gisborne & 36 & Thames-Coromandel & 58 & Kaikoura \\
\hline 15 & Manawatu & 37 & Waitomo & 59 & Kawerau \\
\hline 16 & Selwyn & 38 & Wanganui & 60 & Mackenzie \\
\hline 17 & Upper Hutt City & 39 & Whakatane & 61 & Napier City \\
\hline 18 & Waikato & 40 & Carterton & 62 & Palmerston North City \\
\hline 19 & Western Bay of Plenty & 41 & Central Hawke's Bay & 63 & Porirua City \\
\hline 20 & Ashburton & 42 & Christchurch City & 64 & Queenstown Lakes \\
\hline 21 & Grey & 43 & Gore & 65 & Waimate \\
\hline 22 & Hauraki & 44 & Matamata-Piako & 66 & Wairoa \\
\hline & & & & 67 & Waitaki \\
\hline
\end{tabular}




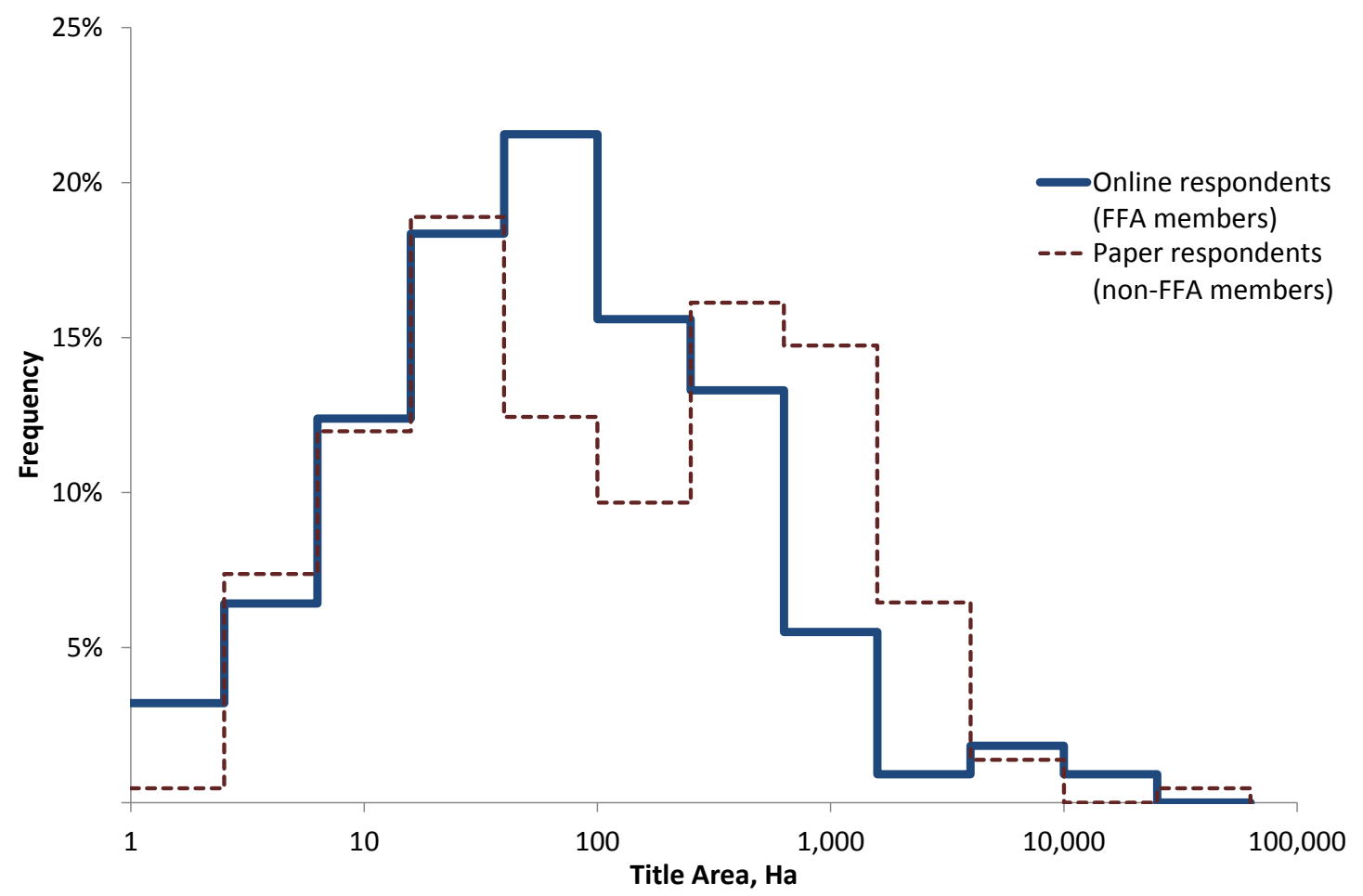

Figure 10 Distribution of responses by title area (as stated in responses) for the online and paper surveys 
Figure 11 compares the land area distribution for all New Zealand land titles greater than one hectare with that of FFA member respondents. The disparity between these distributions suggests that matching of FFA and non-FFA samples for land title area would not have been achieved with random sampling rather than stratified sampling of rural land titles.

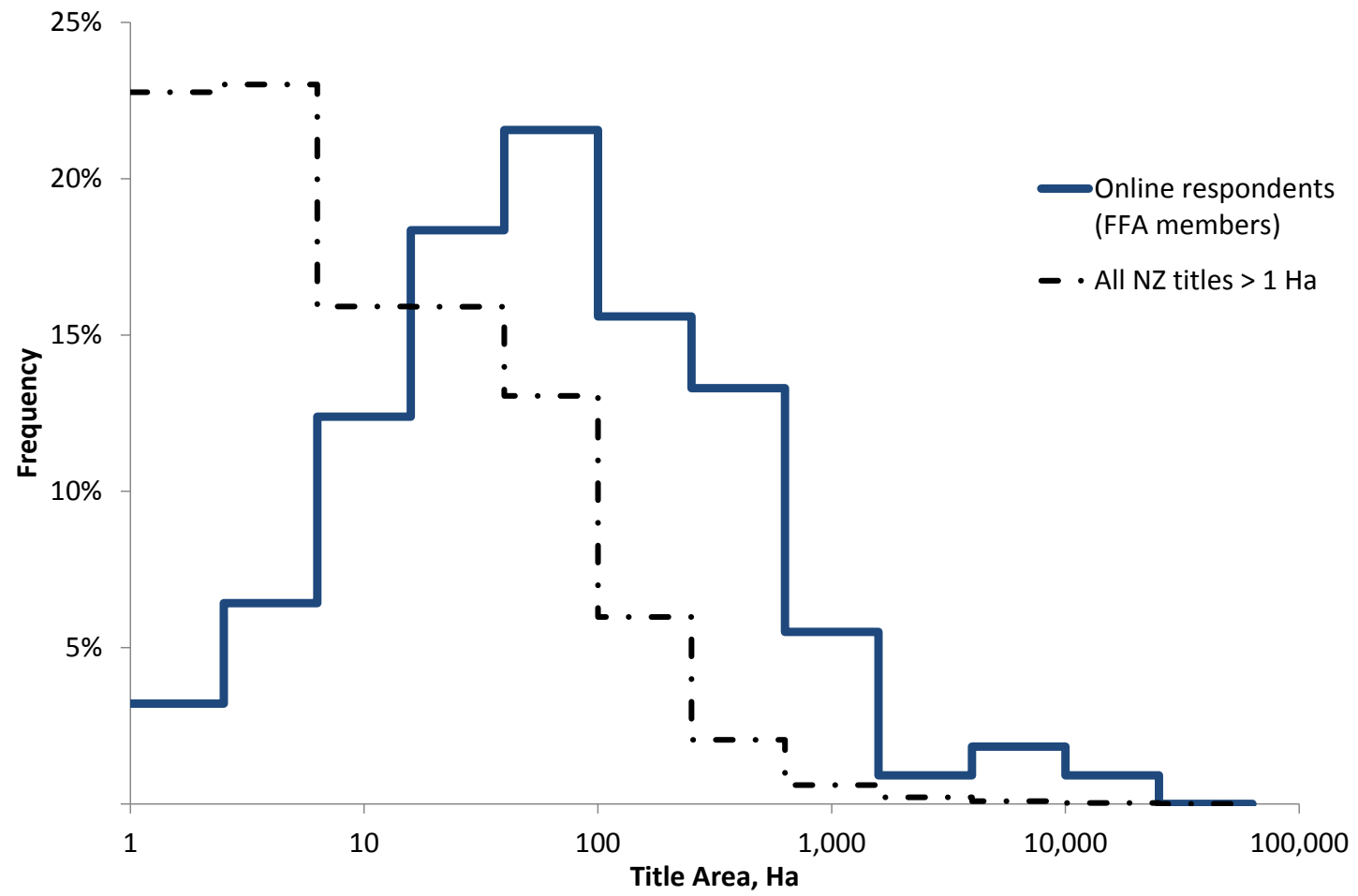

Figure 11 The distribution of land title areas for all New Zealand titles $>1$ ha (from a database of land property titles) and for online survey respondents (as stated in responses) 
The non-FFA sample was not intentionally matched for type of land cover with the FFA respondents. As shown in Figure 12, land owned by FFA respondents is significantly more likely than that of the general population (all New Zealand titles greater than one hectare) to have native or exotic tree cover. I chose a stratified sample of land titles with land cover types in the ratios shown in Table 5 for the survey of non-FFA members.

Table 5 The ratio of land cover types used in stratified sample for the paper survey address list

\begin{tabular}{|l|l|}
\hline Land cover type & Relative representation in total sample \\
\hline Both exotic and native tree cover & 6 \\
\hline Some exotic tree cover & 30 \\
\hline Some native tree cover & 30 \\
\hline No tree cover & 33 \\
\hline
\end{tabular}

I chose the proportions in Table 5 as intermediate between the ratios present in the FFA respondents and in the general population. The greater presence of tree cover on FFA-members' land than in the general population was anticipated and may be indicative of some of the difference between these populations that the research attempts to detect. However, since a large proportion of the general population has land without any native tree cover, this would have ruled them out of responding to questions about 'intention to decrease native tree cover'. Therefore I chose a stratified sampling ratio for non-FFA members which preserves some of the population differences without ruling out a substantial part of the sample from responding. 
In fact, as seen in

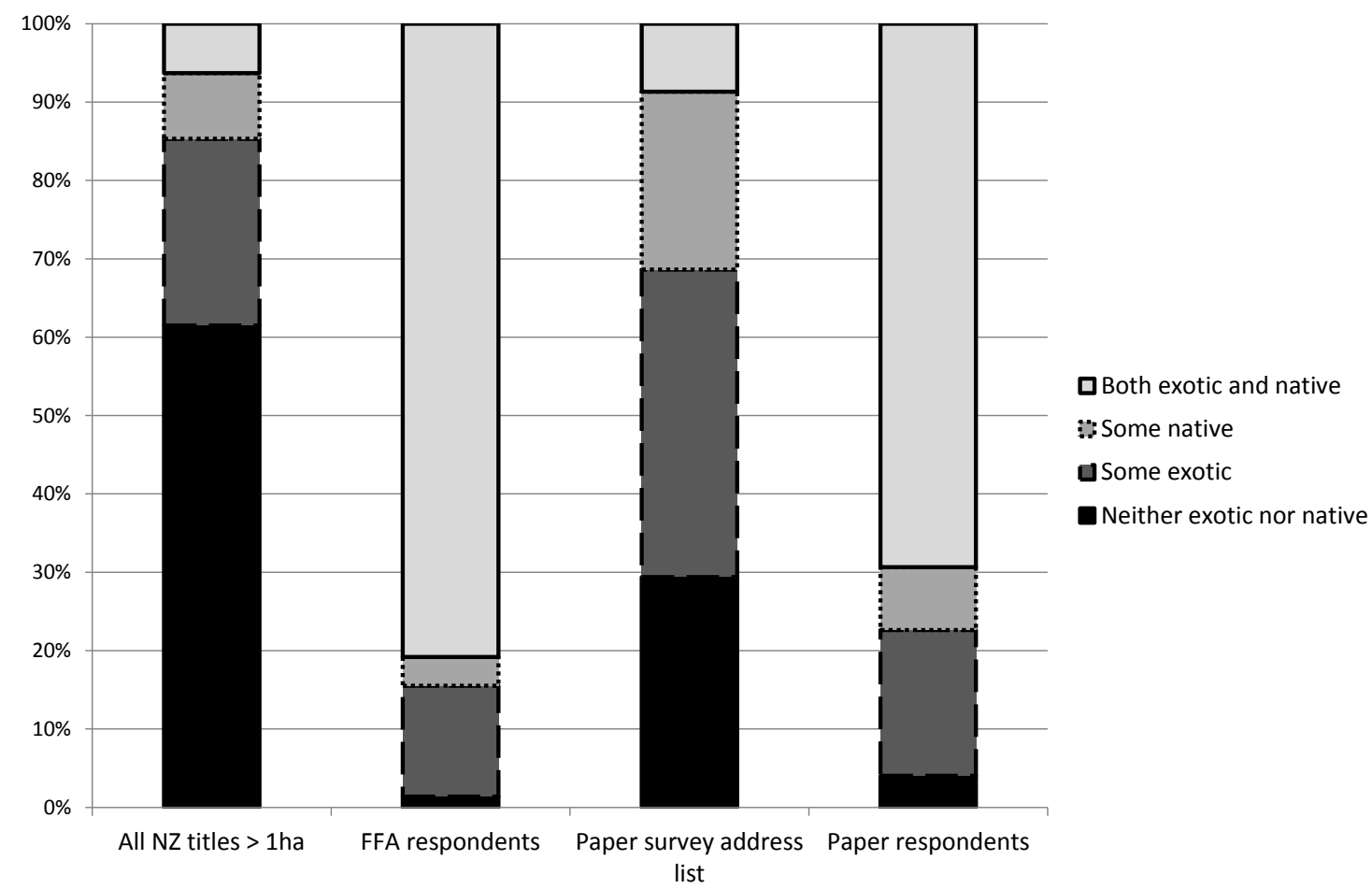

Figure 12, respondents to the paper survey showed a strong bias towards those with existing native or exotic tree cover on their land, so that the resulting sample was fairly closely matched to the FFA respondents.

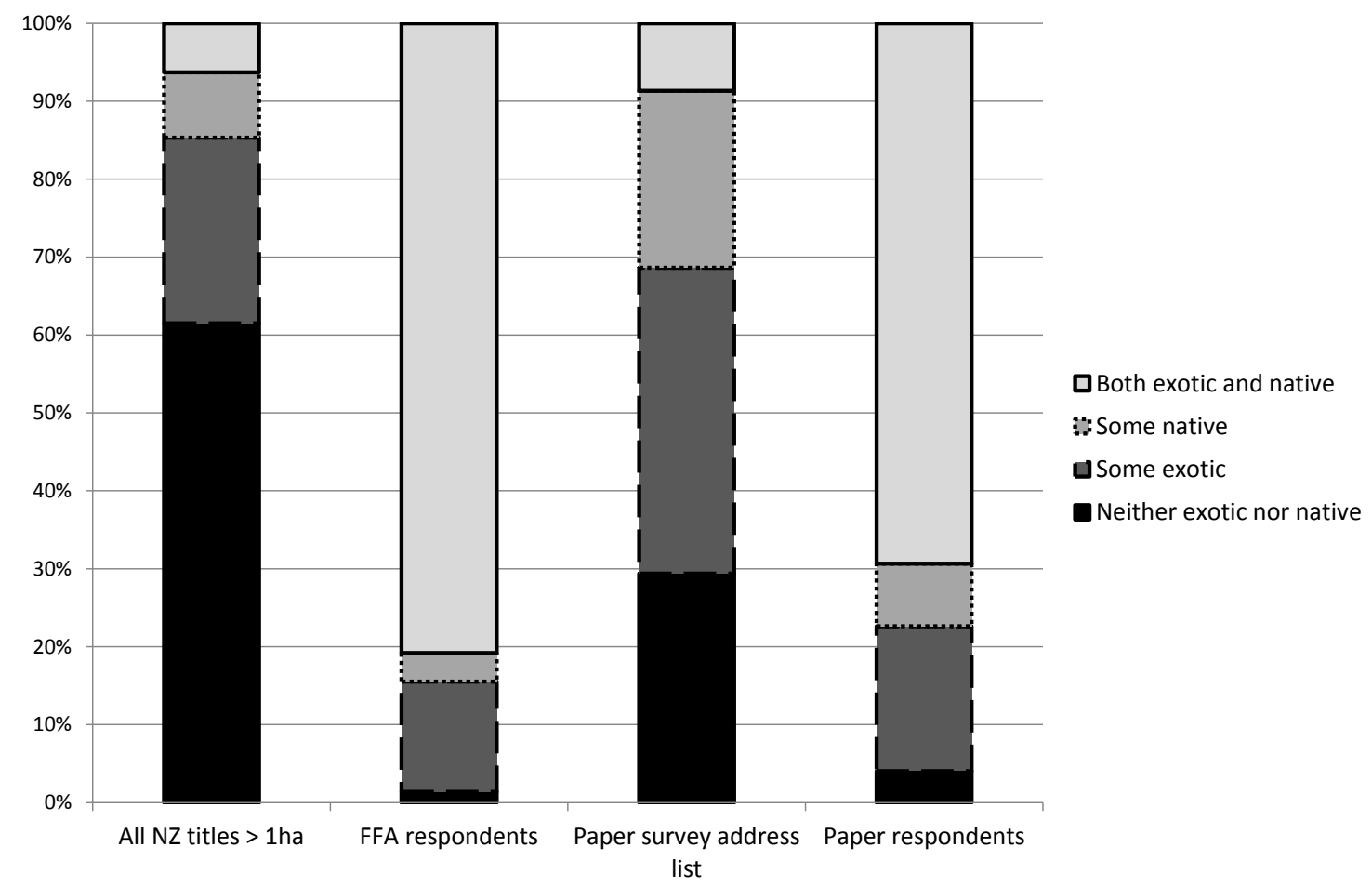

Figure 12 The proportion of exotic and native tree cover found on the land of different groups in the research. The land cover for 'All NZ titles $>1$ ha' and 'Paper survey address list' are derived from land property title and land cover databases as described in Appendix 3; the land cover for 'FFA respondents' and 'paper respondents' is as stated in their responses. 


\subsubsection{Type of landowner}

Figure 13 and Figure 14 show the types of landowners and farmers who responded in the FFA and non-FFA groups. Participants were able to tick multiple boxes in response to these questions. It is notable that FFA members in the sample are significantly more likely than the non-FFA sample to be plantation forestry owners or tree-crop farmers and less likely to be livestock farmers.

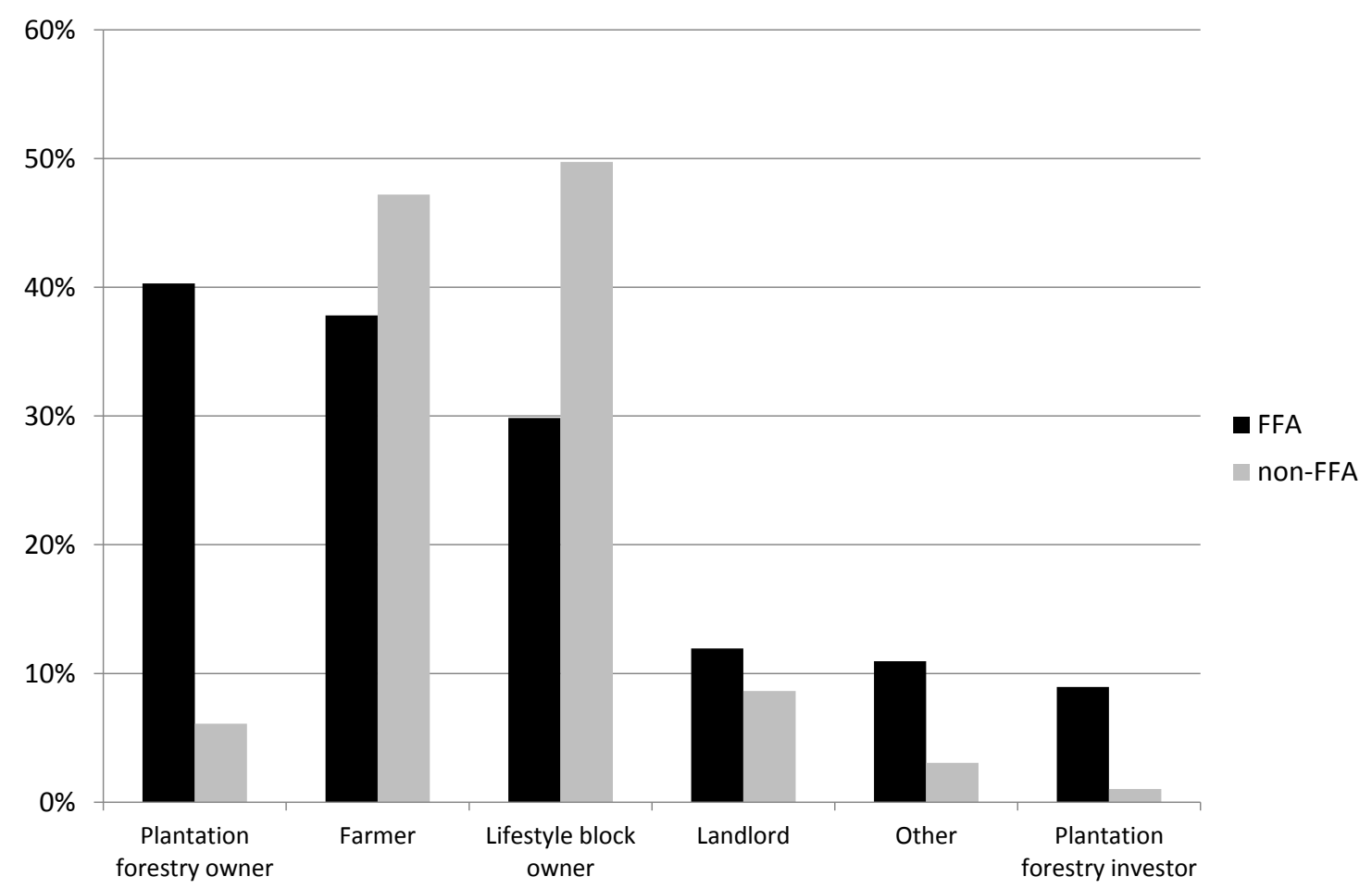

Figure 13 Proportions of participants of each landowner type for the two groups 


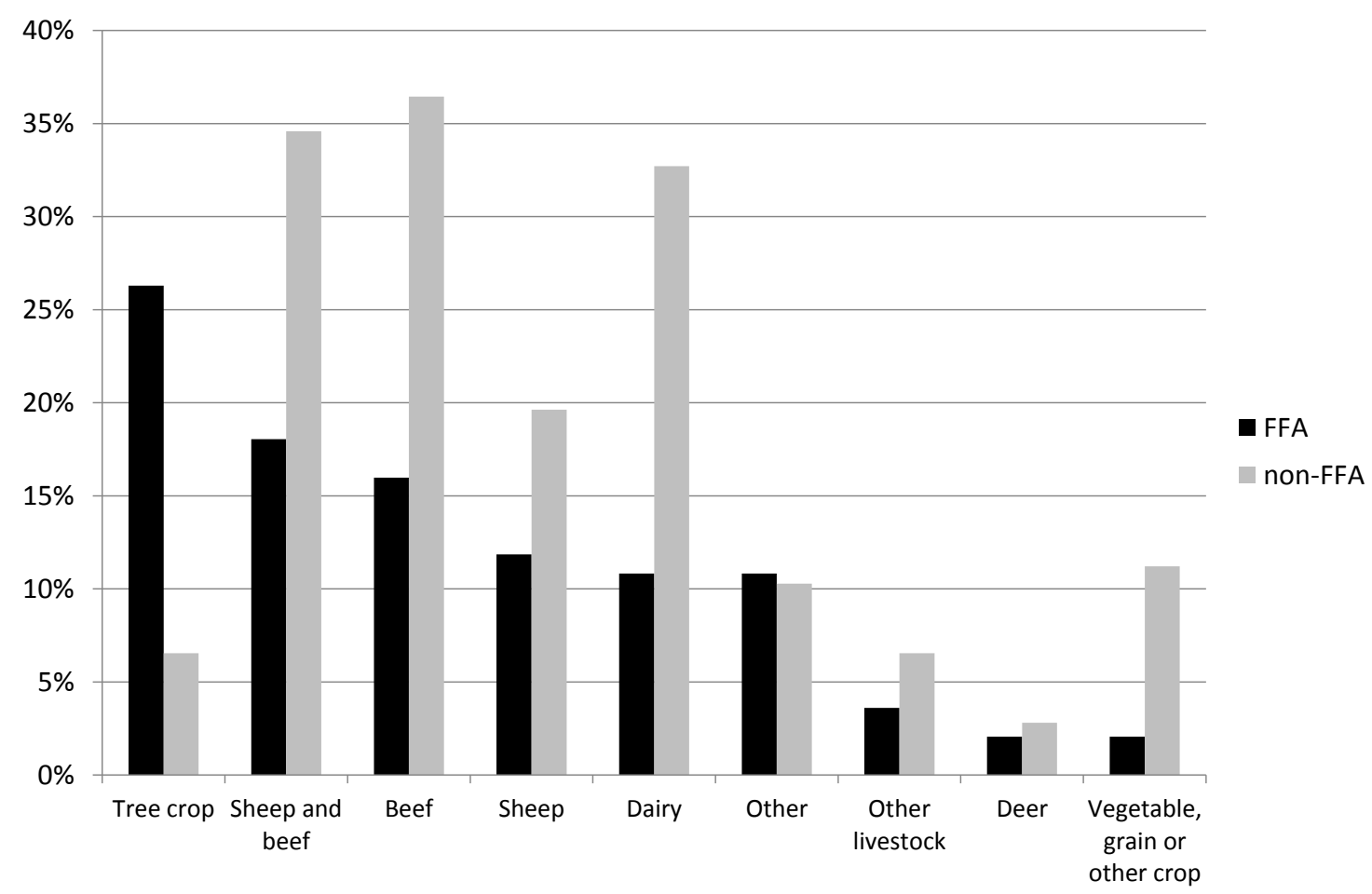

Figure 14 Proportions of each type of farmer for the two groups

\subsection{Construction of variables}

The three behaviours covered by the questionnaires were: 1) "increasing native tree, bush or scrub cover on your land", 2) "decreasing native tree, bush or scrub cover on your land" and 3) "keeping about the same native tree, bush or scrub cover on your land". Identical questions for each behaviour were included for the Theory of Planned Behaviour variables and the proposed moderating variables of Confidence and SelfMonitoring. All these questions elicited responses on seven-point scales.

I numerically coded the responses on a scale of 1 to 7 . Coding was made consistent so that high scores related to more favourable attitudes, supportive norms, intentions to perform a behaviour, higher perceived behavioural control, greater confidence in the judgement of Subjective Norm and greater Self-Monitoring traits.

Social interaction questions included some about the frequency of interaction in general, elicited on a seven-point scale, and some about the number of different people talked to in the last month and in the last year. The raw values for the latter spanned several orders of magnitude (from 0 to 5000), so the base 2 logarithm was taken to provide transformed values in the approximate range 0 to 7 (zero raw values were transformed to zero). 
I constructed variable measures by adding together numerically coded responses to appropriate questions. Appendix 2 shows the question wording for the questions included in each variable measure. Measures were tested for their reliability using Cronbach's alpha. Where reliabilities were improved by removing an item, this was done, except where doing so would have removed a distinct component of the variable that is required by theory (e.g. the Subjective Norm variable is required to include both descriptive and injunctive norm components). A single set of variable measures was used across all behaviours and both surveys.

Discussion in the literature suggests Cronbach alpha values of 0.7 or above are deemed acceptable by many researchers, although this appears to be a somewhat arbitrary choice (Lance, Butts, \& Michels, 2006). Table 6 shows reliabilities achieved by measures constructed for this research. Behavioural Intention, Attitude, Perceived Behavioural Control, Social Interaction and Self-monitoring measures were all above 0.7. Subjective Norm alpha values close to, but not above 0.7 were obtained for the online survey. Subjective Norm alpha values were particularly low for the "keep same native tree cover' behaviour so this behaviour was not used in further analysis.

Subjective Norm measures for other behaviours were deemed acceptable for use in further analysis. Acceptable levels of reliability were not achieved for the Confidence variable, so the parts of the analysis which use these measures should be treated with caution.

Table 6 The components of the variables used in the statistical analysis

\begin{tabular}{|c|c|c|c|c|}
\hline \multirow[t]{3}{*}{ Variable } & \multicolumn{4}{|l|}{ Reliability } \\
\hline & \multicolumn{2}{|l|}{ Online } & \multicolumn{2}{|l|}{ Paper } \\
\hline & $\begin{array}{l}\text { Decrease } \\
\text { trees }\end{array}$ & $\begin{array}{l}\text { Increase } \\
\text { trees }\end{array}$ & $\begin{array}{l}\text { Decrease } \\
\text { trees }\end{array}$ & $\begin{array}{l}\text { Increase } \\
\text { trees }\end{array}$ \\
\hline Attitude (ATT) & 0.95 & 0.94 & 0.96 & 0.95 \\
\hline Subjective norm (SN) & 0.68 & 0.58 & 0.78 & 0.75 \\
\hline $\begin{array}{l}\text { Perceived behavioural } \\
\text { control (PBC) }\end{array}$ & 0.82 & 0.76 & 0.81 & 0.70 \\
\hline Behavioural Intention (BI) & 0.85 & 0.83 & 0.87 & 0.89 \\
\hline Self-Monitoring (SM) & \multicolumn{2}{|l|}{0.76} & $\mathrm{~N} / \mathrm{A}$ & N/A \\
\hline Social Interaction (SI) & \multicolumn{2}{|l|}{0.74} & \multicolumn{2}{|l|}{0.81} \\
\hline Confidence (CONF) & \multicolumn{2}{|l|}{0.49} & \multicolumn{2}{|l|}{0.35} \\
\hline
\end{tabular}




\subsection{Statistical analysis methods}

Statistical analyses were carried out in SPSS. Missing data were imputed at a question level using the Expectation Maximisation technique for the main Theory of Planned Behaviour variables (Attitude, Perceived Behavioural Control, Subjective Norm, Behavioural Intention) before aggregating data into measures. Imputing at a question rather than a measure level is recommended by Gottschall, West and Enders as it produces a power advantage (2012).

The moderator variables (Self-Monitoring, Social Interaction and Confidence) were not imputed as they generally had a higher rate of missing data than the main Theory of Planned Behaviour variables (greater than ten percent) so the tendency of this method to underestimate standard errors was expected to be more significant. Missing values for these moderator variables (Self-Monitoring, Social Interaction and Confidence) were dealt with by pairwise deletion in analyses which included them.

Pooled Farm Forestry Association member (FFA) and non-member ('non-FFA') datasets were created for the 'increase native trees' and 'decrease native trees' behaviours. The binary variable 'Group' was created to distinguish FFA members (assigned a value of 1) from non-members (assigned a value of 0). Hypothesis tests were carried out by running hierarchical, multiple regression analyses of the Theory of Planned Behaviour predictor variables, and other moderator variables on the Behavioural Intention variable. Table 7, Table 9 and Table 11 show the results of three regressions, with the order of entry of independent variables, the change in $r^{2}$ value with each term entered and the significance of the $r^{2}$ change based on an F-test of change in residuals. This approach to comparing the relationships between variables within different populations follows that described in Cohen and Cohen (1975). This method is used widely for Theory of Planned Behaviour Studies in the literature.

An advantage of hierarchical regression is that it can detect the unique effect of independent variables on Behavioural Intention. This is important when the independent variables are themselves highly correlated, which is often the case for Attitude and Subjective Norm for example. Hierarchical regression allows 'statistical control' of other independent variables to detect if the independent variable of interest (i.e. Subjective Norm) has any unique effect on Behavioural Intention. 


\subsection{Results}

\subsubsection{Sample means and distributions of the main Theory of Planned Behaviour variables}

Hypothesis 7 states that:

"Group Members perceive different social norms for behaviours affecting native tree cover on their land to the social norms perceived by Non-Members"

This hypothesis can be tested by comparing the average value of Subjective Norm for FFA members with that for non-FFA members. Sample means and distributions of the Subjective Norm variable for these two groups are shown in Figure 15 and Figure 16. These illustrate fairly similar distributions for the two groups. A Z-test found there is no significant difference between the two groups in the Subjective Norm towards either behaviour. This indicates a negative result for Test 7 and means I cannot reject the null hypothesis for Hypothesis 7.

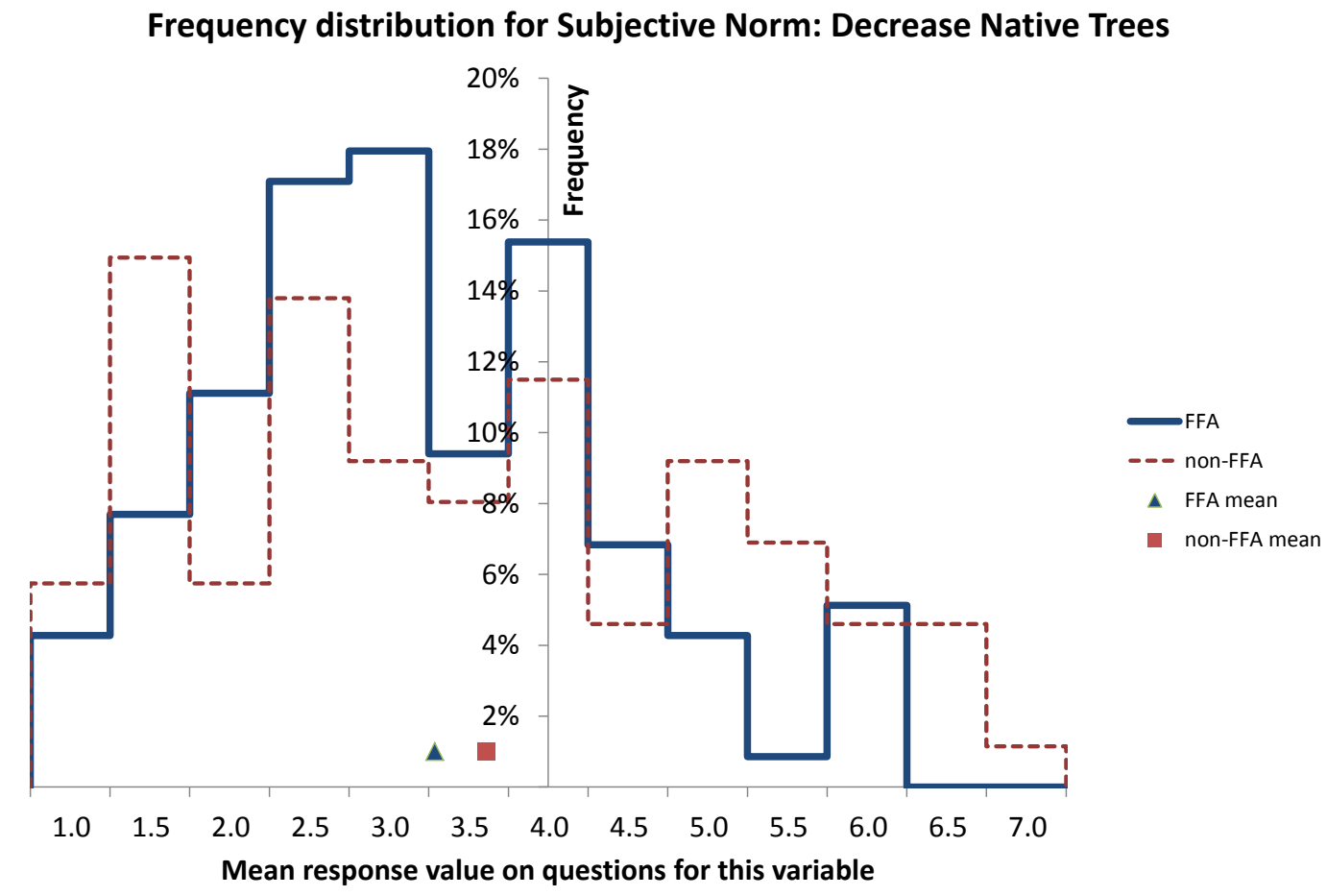

Figure 15 The distribution and sample mean of the Subjective Norm variable for the Decrease Native Trees behaviour for Farm Forestry Association members (FFA) and nonmembers (non-FFA) 
Frequency distribution for Subjective Norm: Increase Native Trees

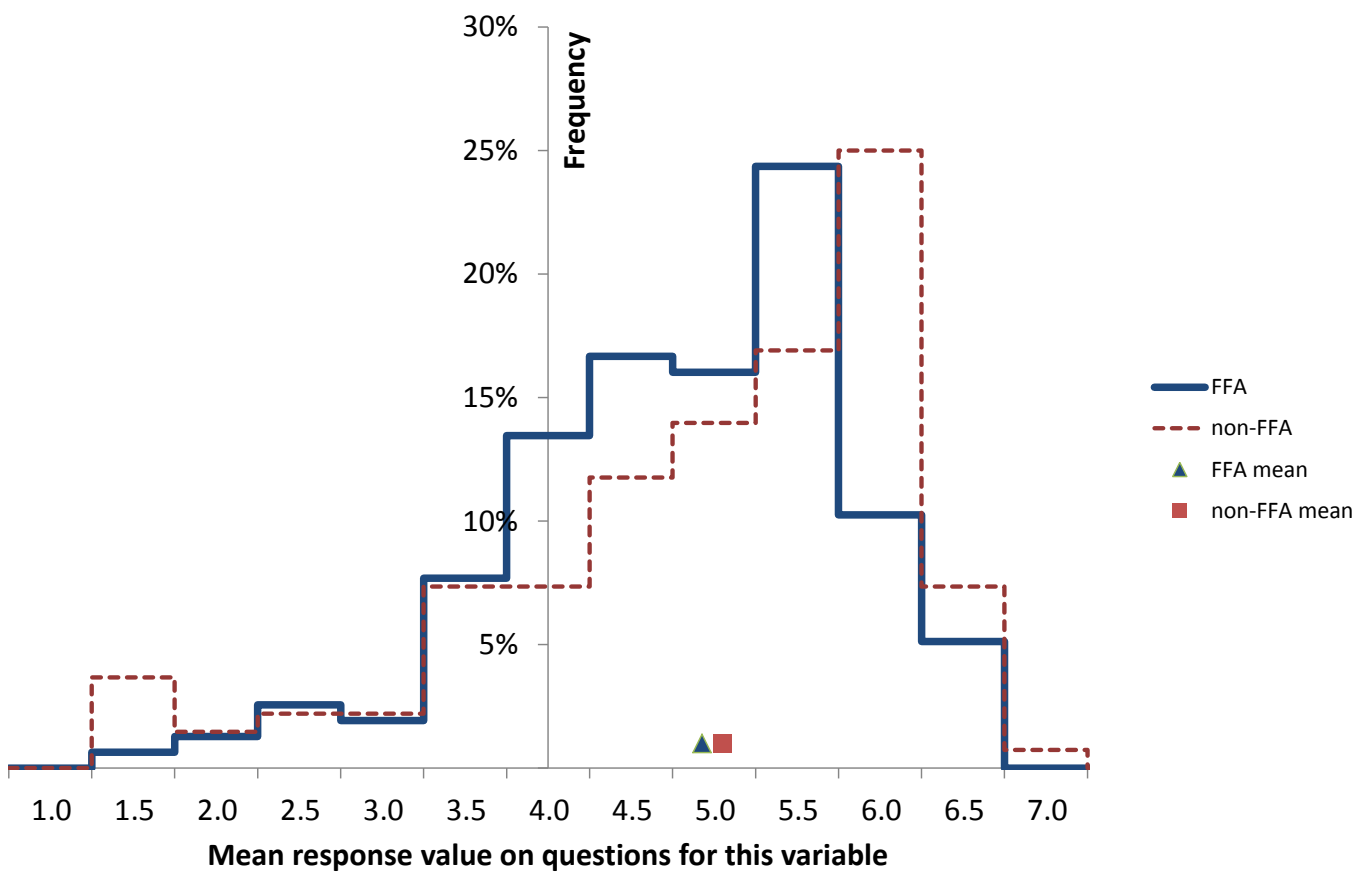

Figure 16 The distribution and sample mean of the Subjective Norm variable for the Increase Native Trees behaviour for Farm Forestry Association members (FFA) and non-members (non-FFA)

The sample means and distributions for the other Theory of Planned Behaviour variables (Attitude, Perceived Behavioural Control and Behavioural Intention) are shown in Figure 17 and Figure 18. These illustrate relatively closely-matched distributions between FFA and non-FFA groups. The differences in sample means between groups were tested with a Z-test and none are significant. In other words, FFA members and non-members do not have significantly different attitudes, intentions nor differences of perceived behavioural control towards increasing or decreasing native tree cover on their land. 
Frequency distribution for Attitude: Decrease Native Trees

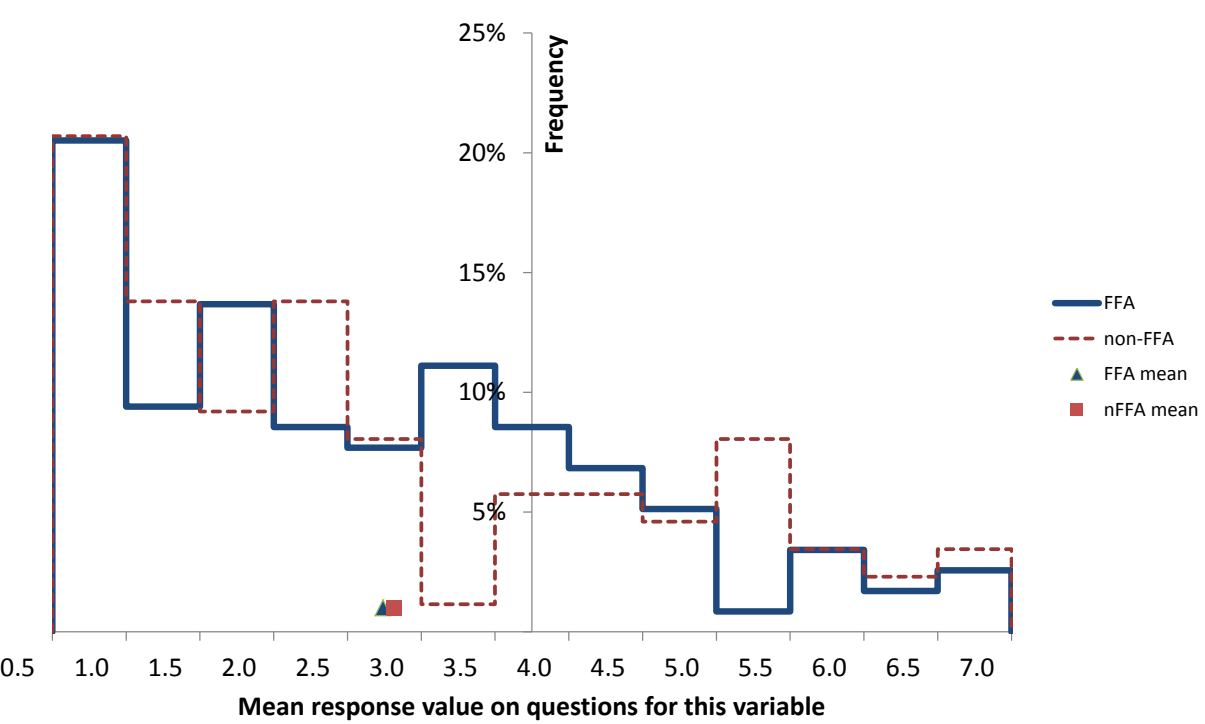

Frequency distribution for Perceived Behavioural Control: Decrease Native Trees

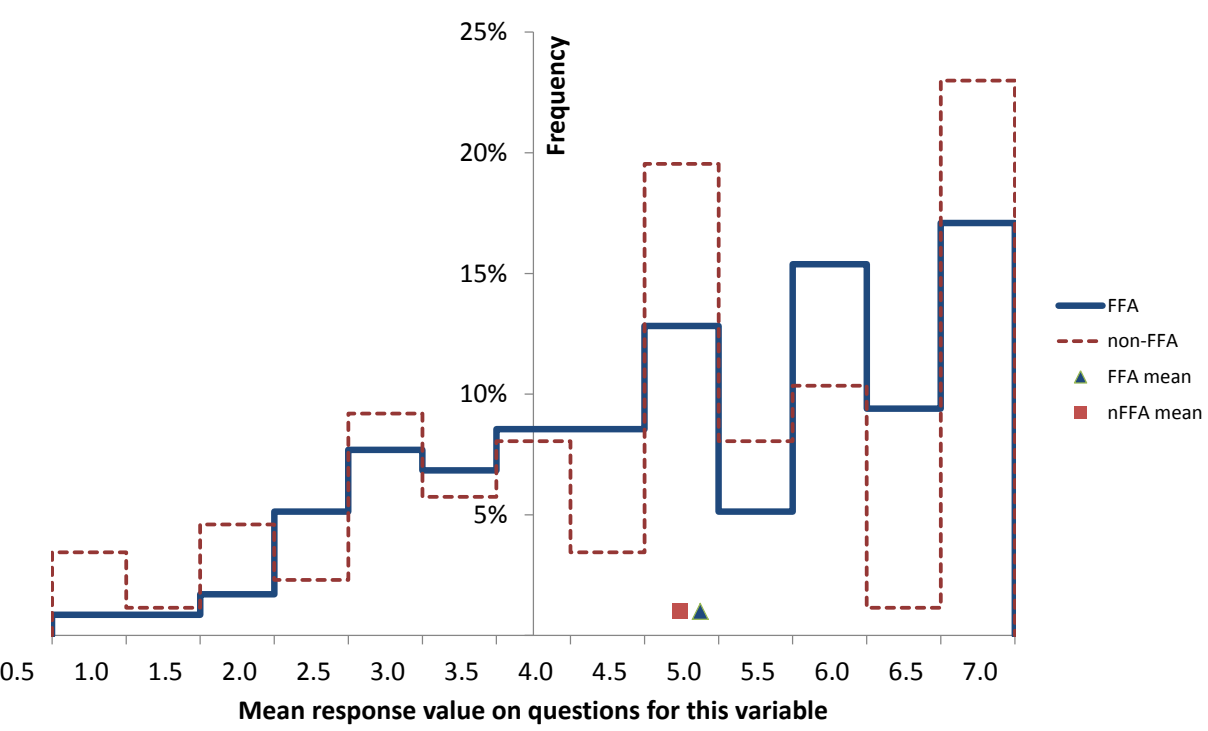

Figure 17 'Decrease native trees' behaviour - the distributions and sample means of the Theory of Planned Behaviour variables for FFA members (FFA) and non-members (nonFFA)

Frequency distribution for Behavioural Intention: Decrease Native Trees

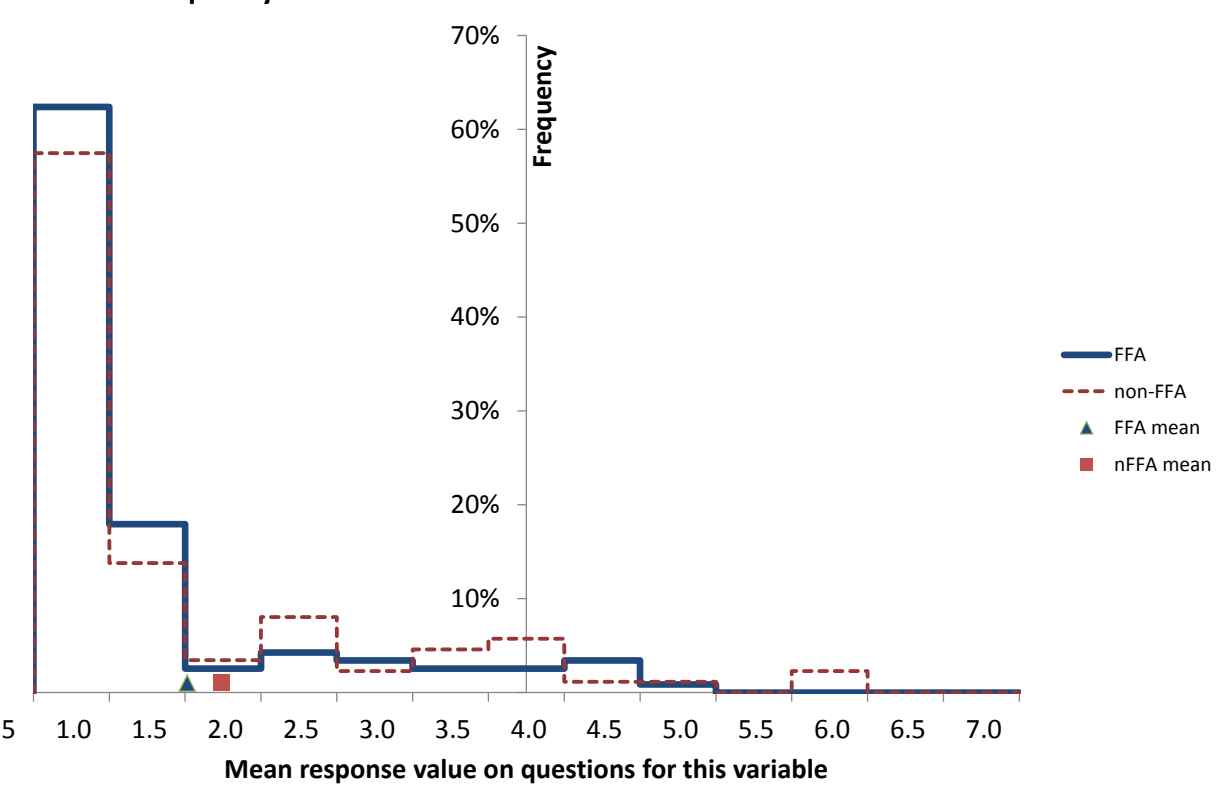




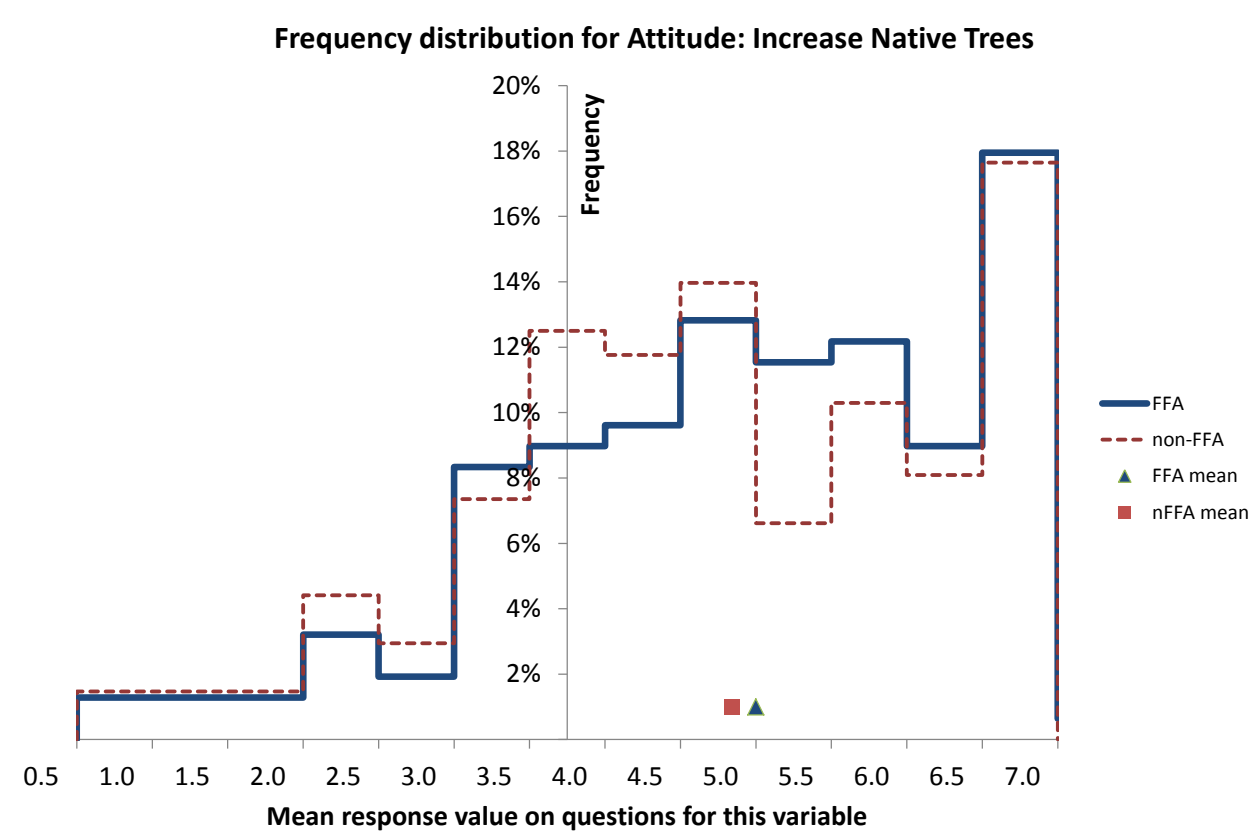

Frequency distribution for Perceived Behavioural Control Intention: Increase Native Trees

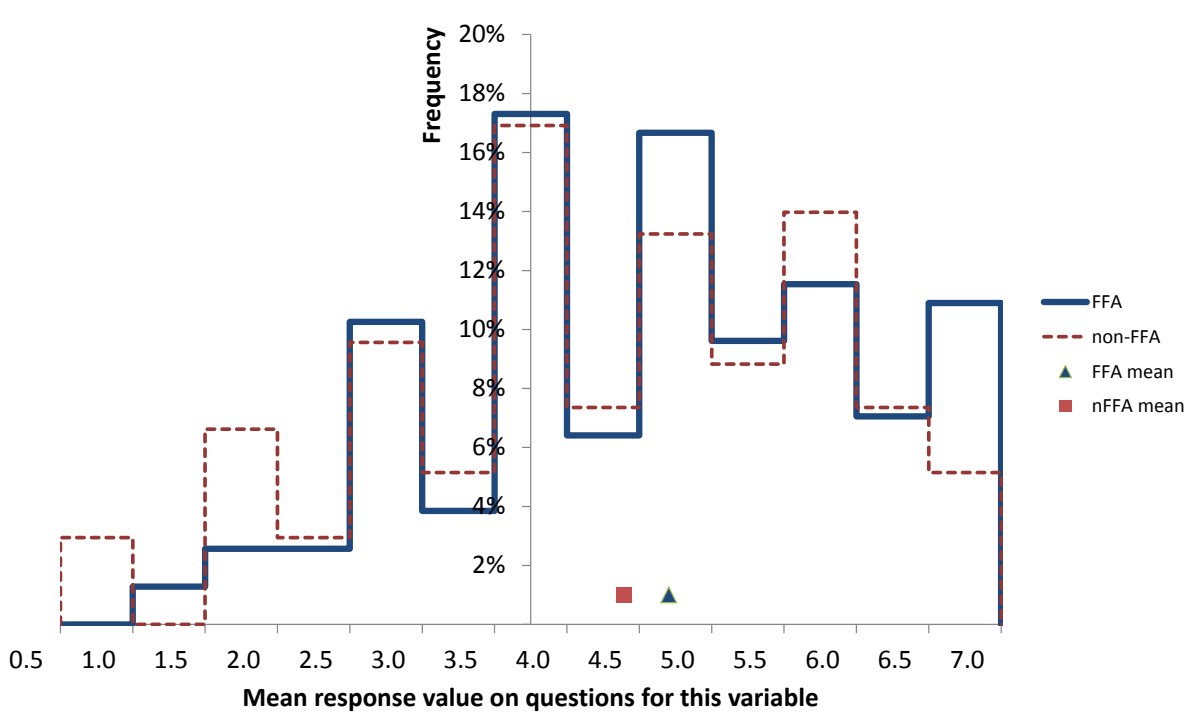

Figure 18 'Increase native trees' behaviour - the distributions and sample means of the Theory of Planned Behaviour variables for FFA members (FFA) and non-members (nFFA)

Frequency distribution for Behavioural Intention: Increase Native Trees

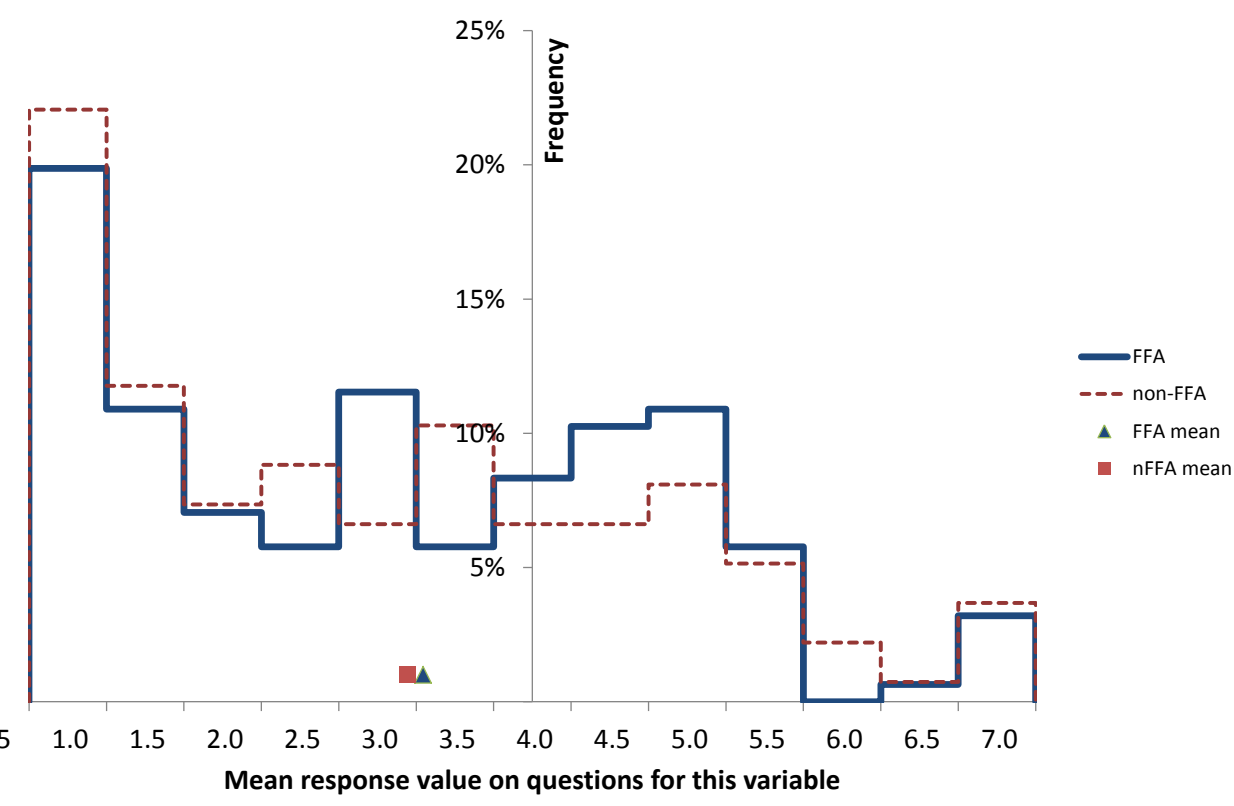




\subsubsection{Regression results}

\subsubsection{The predictive power of Subjective Norm on intention}

Hypothesis 1 states:

"Landowners have a tendency to conform to the social norms they perceive

among their peers in their behaviours affecting native tree cover on their land."

Table 7 and Table 8 show the results of regressing the main Theory of Planned

Behaviour variables on Behavioural Intention (BI) for both the increase and decrease

native trees behaviours.

Table 7 Multiple regression 1a on Behavioural Intention to decrease native trees. Independent variables are Group (representing FFA members versus non-FFA members), Attitude (ATT), Perceived Behavioural Control (PBC), Subjective Norm (SN) and the interaction term of Subjective Norm with Group

\begin{tabular}{|c|c|c|c|c|c|c|c|}
\hline Behaviour: & & & \multicolumn{5}{|c|}{ Decrease native trees, bush or scrub } \\
\hline $\mathrm{n}:$ & & & \multicolumn{5}{|l|}{204} \\
\hline $\begin{array}{l}\text { Dependent } \\
\text { variable }\end{array}$ & $\begin{array}{l}\text { Entry } \\
\text { order }\end{array}$ & $\begin{array}{l}\text { Independent } \\
\text { variable }\end{array}$ & R2 & R2 change & $\begin{array}{l}\text { Beta (at point } \\
\text { of entry to } \\
\text { model) }\end{array}$ & $\begin{array}{l}\text { Beta (in final } \\
\text { model) }\end{array}$ & Significance \\
\hline \multirow[t]{5}{*}{$\mathrm{BI}$} & 1 & Group & 0.01 & 0.01 & -0.10 & -0.04 & ns \\
\hline & 2 & ATT & 0.49 & 0.48 & 0.69 & 0.52 & $* * * *$ \\
\hline & 2 & PBC & & & -0.03 & -0.02 & ns \\
\hline & 3 & SN & 0.52 & 0.03 & 0.24 & 0.25 & $* * *$ \\
\hline & 4 & SNxGroup & 0.52 & 0.00 & -0.02 & -0.02 & ns \\
\hline
\end{tabular}

Table 8 Multiple regression $1 \mathrm{~b}$ on Behavioural Intention to increase native trees. Independent variables are Group (representing FFA members versus non-FFA members), Attitude (ATT), Perceived Behavioural Control (PBC), Subjective Norm (SN) and the interaction term of Subjective Norm with Group

\begin{tabular}{|c|c|c|c|c|c|c|c|}
\hline Behaviour: & & & \multicolumn{5}{|c|}{ Increase native trees, bush or scrub } \\
\hline $\mathrm{n}:$ & & & \multicolumn{5}{|l|}{292} \\
\hline $\begin{array}{l}\text { Dependent } \\
\text { variable }\end{array}$ & $\begin{array}{l}\text { Entry } \\
\text { order }\end{array}$ & $\begin{array}{l}\text { Independent } \\
\text { variable }\end{array}$ & $\mathrm{R} 2$ & R2 change & $\begin{array}{l}\text { Beta (at point } \\
\text { of entry to } \\
\text { model) }\end{array}$ & $\begin{array}{l}\text { Beta (in final } \\
\text { model) }\end{array}$ & Significance \\
\hline \multirow[t]{5}{*}{$\mathrm{BI}$} & 1 & Group & 0.00 & 0.00 & 0.03 & -0.03 & ns \\
\hline & 2 & ATT & 0.44 & 0.44 & 0.64 & 0.57 & $* * * *$ \\
\hline & 2 & PBC & & & 0.10 & 0.08 & * \\
\hline & 3 & SN & 0.45 & 0.01 & 0.12 & 0.11 & * \\
\hline & 4 & SNxGroup & 0.45 & 0.00 & 0.03 & 0.03 & ns \\
\hline
\end{tabular}

\begin{tabular}{|l|l|l|l|l|l|l|}
\hline Significance: & $\mathrm{p}<=$ & 0.0001 & 0.001 & 0.01 & 0.05 & 0.1 \\
\hline Symbol & & $* * * *$ & $* * *$ & $* *$ & $*$ & + \\
\hline
\end{tabular}


The $r^{2}$ value represents the proportion of the total variance in the dependent variable (Behavioural Intention) which is explained by the independent variables in the model at that point. The change in $r^{2}$ represents the increase in the proportion of variance in behavioural intention explained as each predictor variable is added. The beta values are the coefficients of each independent variable in the regression equation. The size and sign of the beta coefficients indicates the magnitude and direction of the change in Behavioural Intention as each independent variable changes in value. The significance column indicates whether the change in $r^{2}$ is statistically significant in each $\operatorname{case}^{28}$.

The first variable added is Group, representing whether participants are FFA members (coded as 1) or non-FFA members (coded as 0). My results show the Group variable is not a significant predictor of Behavioural Intention, indicating no difference in the mean intentions of the two groups for either behaviour.

The remaining rows show changes in $r^{2}$ which are statistically significant at the five percent level or better as Attitude (ATT) and Perceived Behavioural Control (PBC) and then Subjective Norm (SN) are added to the regression equation for Behavioural Intention (BI) for both behaviours. Subjective Norm is a relatively weak predictor of Behavioural Intention, explaining three percent of the variance in intention for the 'decrease native trees' behaviour and only one percent for the 'Increase native trees' behaviour. The standardized beta coefficients at the point of entry of each independent variable into the model are all positive for Attitude and Subjective Norm. This indicates an increase in these predictor variables corresponds to an increase in Behavioural Intention. These findings support Hypothesis 1.

Hypothesis 5 states:

"Landowners who are members of a social group (Group Members) whose purpose relates to land use decisions are more likely than Non-Members to

\footnotetext{
${ }^{28}$ The exception is the PBC (Perceived Behavioural Control) row: this variable was added to the regression equation at the same time as Attitude (ATT), therefore the change in $r^{2}$ and its significance has not been partitioned between the ATT and PBC variables. The significance value given for PBC relates to the significance of the beta coefficient at the point PBC enters the model.
} 
conform to the social norms they perceive among their peers in their behavioural intentions for native tree cover on their land."

The final row in Table 7 and Table 8 indicates there is no increase in $r^{2}$ on addition of the interaction term between Subjective Norm and Group, indicating no significant difference in the explanatory power of Behavioural Intention by Subjective Norm for FFA members versus non-members. This finding means I cannot reject the null hypothesis for Hypothesis 5. 


\subsubsection{The moderating effect of the Self-Monitoring personality trait}

Table 9 and Table 10 show the regression between the main Theory of Planned

Behaviour variables again, including the interaction between Subjective Norm (SN) and Self-Monitoring (SM) as the final term entered. Self-Monitoring indicates the score reported by the participant on Snyder's self-monitoring personality trait scale.

The final row in the tables shows the change in $r^{2}$ on addition of the Self-monitoring $x$ Subjective Norm interaction term (SMxSN). The effect is relatively ${ }^{29}$ substantial for the 'increase native trees' behaviour (0.04 increase in $r^{2}$ ) and significant at the one percent level. The effect is smaller for the 'decrease native trees', which shows only a 0.02 increase in $r^{2}$ and this is significant only at the ten percent level.

Table 9 Multiple regression 2a. The effect of the self-monitoring personality trait (SM) on the Subjective Norm (SN) - Behavioural Intention (BI) relationship for decreasing native tree cover (FFA population only)

\begin{tabular}{|c|c|c|c|c|c|c|c|}
\hline Behaviour: & & & \multicolumn{5}{|c|}{ Decrease native trees, bush or scrub } \\
\hline $\mathrm{n}:$ & & & \multicolumn{5}{|l|}{99} \\
\hline $\begin{array}{l}\text { Dependent } \\
\text { variable }\end{array}$ & $\begin{array}{l}\text { Entry } \\
\text { order }\end{array}$ & $\begin{array}{l}\text { Independent } \\
\text { variable }\end{array}$ & $\mathrm{R} 2$ & R2 change & $\begin{array}{l}\text { Beta (at } \\
\text { point of } \\
\text { entry to } \\
\text { model) }\end{array}$ & $\begin{array}{l}\text { Beta (in final } \\
\text { model) }\end{array}$ & Sig \\
\hline \multirow[t]{5}{*}{$\mathrm{BI}$} & 1 & ATT & \multirow[t]{2}{*}{0.41} & \multirow[t]{2}{*}{0.41} & 0.64 & 0.43 & $* * * *$ \\
\hline & 1 & PBC & & & 0.02 & 0.06 & ns \\
\hline & 2 & SN & 0.46 & 0.05 & 0.29 & -0.06 & $* *$ \\
\hline & 3 & SM & 0.46 & 0.01 & 0.08 & -0.25 & ns \\
\hline & 4 & SMxSN & 0.48 & 0.02 & 0.52 & 0.52 & + \\
\hline
\end{tabular}

Table 10 Multiple regression 2a. The effect of the self-monitoring personality trait (SM) on the Subjective Norm (SN) - Behavioural Intention (BI) relationship for increasing native tree cover (FFA population only)

\begin{tabular}{|c|c|c|c|c|c|c|c|}
\hline Behaviour: & & & \multicolumn{5}{|c|}{ Increase native trees, bush or scrub } \\
\hline $\mathrm{n}:$ & & & \multicolumn{5}{|l|}{130} \\
\hline $\begin{array}{l}\text { Dependent } \\
\text { variable }\end{array}$ & $\begin{array}{l}\text { Entry } \\
\text { order }\end{array}$ & $\begin{array}{l}\text { Independent } \\
\text { variable }\end{array}$ & $\mathrm{R} 2$ & R2 change & $\begin{array}{l}\text { Beta (at } \\
\text { point of } \\
\text { entry to } \\
\text { model) }\end{array}$ & $\begin{array}{l}\text { Beta (in final } \\
\text { model) }\end{array}$ & Sig \\
\hline \multirow[t]{5}{*}{$\mathrm{BI}$} & 1 & ATT & 0.41 & 0.41 & 0.63 & 0.59 & $* * * *$ \\
\hline & 1 & PBC & & & 0.02 & 0.02 & ns \\
\hline & 2 & SN & 0.42 & 0.01 & 0.15 & 0.58 & + \\
\hline & 3 & SM & 0.43 & 0.01 & 0.10 & 1.01 & ns \\
\hline & 4 & SMxSN & 0.47 & 0.04 & -1.08 & -1.08 & $* *$ \\
\hline
\end{tabular}

\begin{tabular}{|l|l|l|l|l|l|l|}
\hline Significance: & $\mathrm{p}<=$ & 0.0001 & 0.001 & 0.01 & 0.05 & 0.1 \\
\hline Symbol & & $* * * *$ & $* * *$ & $* *$ & $*$ & + \\
\hline
\end{tabular}

${ }^{29}$ compared with the $r^{2}$ change of 0.01 related to Subjective Norm alone 
The standardized beta coefficients for this interaction term are inconsistent between the two behaviours: positive $(+0.52)$ for the 'Decrease native trees' behaviour but strongly negative (-1.08) for the 'Increase native trees' behaviour. This indicates that for decreasing native tree cover, Subjective Norm positively predicts intention to a greater extent for higher self-monitoring participants than for lower self-monitors (although only at the ten percent significance level). Conversely, for increasing native tree cover, Subjective Norm is less positively correlated with intention for higher selfmonitors than for lower self-monitors. Although these results are not uniformly in the direction suggested by theory, there is a statistically significant moderation effect of the self-monitoring personality trait on the Subjective Norm-Intention relationship for both behaviours. This is consistent with the Subjective Norm-Intention relationship arising from an interpersonal social-influence mechanism and therefore supports Hypothesis 1. 


\subsubsection{The moderating effects of Social Interaction and Confidence in norm judgement}

Hypothesis 2 states: "Landowners who are more confident in their judgement of the relevant social norm are more likely to conform to that social norm."

Table 11 and Table 12 show the results of analyses of how the frequency of social interaction (SI) and the confidence in norm judgement (CONF) moderate the social influence experienced by participants, and if this moderation effect differs between FFA and non-FFA members.

Table 11 Multiple regression 3a.The effect of Confidence (CONF) in norm judgement and Social Interaction (SI) on the Subjective Norm - Behavioural Intention relationship for decreasing native trees.

\begin{tabular}{|c|c|c|c|c|c|c|c|}
\hline Behaviour: & & & \multicolumn{5}{|c|}{ Decrease native trees, bush or scrub } \\
\hline $\mathrm{n}:$ & & & \multicolumn{5}{|l|}{169} \\
\hline $\begin{array}{l}\text { Dependent } \\
\text { variable }\end{array}$ & $\begin{array}{l}\text { Entry } \\
\text { order }\end{array}$ & $\begin{array}{l}\text { Independent } \\
\text { variable }\end{array}$ & $\mathrm{R} 2$ & R2 change & $\begin{array}{l}\text { Beta (at } \\
\text { point of } \\
\text { entry to } \\
\text { model) }\end{array}$ & $\begin{array}{l}\text { Beta (in final } \\
\text { model) }\end{array}$ & Sig \\
\hline \multirow[t]{10}{*}{$\mathrm{BI}$} & 1 & Group & 0.01 & 0.01 & -0.10 & -0.14 & ns \\
\hline & 2 & ATT & 0.49 & 0.48 & 0.69 & 0.40 & $* * * *$ \\
\hline & 2 & PBC & & & -0.28 & -0.03 & ns \\
\hline & 3 & SN & 0.52 & 0.03 & 0.24 & -0.11 & $* *$ \\
\hline & 4 & $\mathrm{SI}$ & 0.56 & 0.04 & 0.20 & -0.32 & $* * *$ \\
\hline & 5 & CONF & 0.56 & 0.00 & 0.06 & -0.09 & ns \\
\hline & 6 & SNxSI & 0.60 & 0.04 & 0.57 & 0.53 & $* * *$ \\
\hline & 7 & SNxSIxGroup & 0.60 & 0.00 & 0.11 & 0.11 & ns \\
\hline & 8 & CONFxSN & 0.60 & 0.00 & 0.26 & 0.25 & ns \\
\hline & 9 & CONFxSNxGroup & 0.60 & 0.00 & 0.02 & 0.02 & ns \\
\hline
\end{tabular}

Table 12 Multiple regression $3 b$ - The effect of Confidence (CONF) in norm judgement and Social Interaction (SI) on the Subjective Norm - Behavioural Intention relationship for increasing native trees.

\begin{tabular}{|c|c|c|c|c|c|c|c|}
\hline Behaviour: & & & \multicolumn{5}{|c|}{ Increase native trees, bush or scrub } \\
\hline $\mathrm{n}:$ & & & \multicolumn{5}{|l|}{235} \\
\hline $\begin{array}{l}\text { Dependent } \\
\text { variable }\end{array}$ & $\begin{array}{l}\text { Entry } \\
\text { order }\end{array}$ & $\begin{array}{l}\text { Independent } \\
\text { variable }\end{array}$ & $\mathrm{R} 2$ & R2 change & $\begin{array}{l}\text { Beta (at } \\
\text { point of } \\
\text { entry ) }\end{array}$ & $\begin{array}{l}\text { Beta (in final } \\
\text { model) }\end{array}$ & Sig \\
\hline \multirow[t]{10}{*}{$\mathrm{BI}$} & 1 & Group & 0.00 & 0.00 & 0.03 & -0.15 & ns \\
\hline & 2 & ATT & 0.44 & 0.44 & 0.64 & 0.55 & $* * * *$ \\
\hline & 2 & PBC & & & 0.10 & 0.08 & + \\
\hline & 3 & SN & 0.45 & 0.01 & 0.12 & -0.07 & + \\
\hline & 4 & $\mathrm{SI}$ & 0.46 & 0.00 & 0.07 & -0.29 & ns \\
\hline & 5 & CONF & 0.46 & 0.00 & -0.02 & -0.15 & ns \\
\hline & 6 & $\mathrm{SNxSI}$ & 0.46 & 0.01 & 0.45 & 0.50 & + \\
\hline & 7 & SNxSIxGroup & 0.47 & 0.00 & -0.11 & -0.16 & ns \\
\hline & 8 & CONFXSN & 0.47 & 0.00 & 0.23 & 0.09 & ns \\
\hline & 9 & CONFxSNxGroup & 0.47 & 0.00 & 0.22 & 0.22 & ns \\
\hline
\end{tabular}

\begin{tabular}{|l|l|l|l|l|l|l|}
\hline Significance: & $\mathrm{p}<=$ & 0.0001 & 0.001 & 0.01 & 0.05 & 0.1 \\
\hline Symbol & & $* * * *$ & $* * *$ & $* *$ & $*$ & + \\
\hline
\end{tabular}


The Group Membership variable and the main Theory of Planned Behaviour (TPB) variables are added to the regression equation as in the previous analyses. This means that any increase in $r^{2}$ on addition of further terms to the equation indicates additional predictive power beyond that already achieved by the TPB variables.

Adding the interaction term between subjective norm and confidence in that norm (CONFXSN - penultimate row) does not lead to any increase in $r^{2}$ for either behaviour. This indicates that accounting for the level of confidence reported by participants in their judgement of norms does not increase the predictive power of the model for behavioural intention. Note that it was not possible to obtain acceptable reliability scores for the CONF scale, so that it is probably not valid to draw any conclusions from this null result. Therefore it is not possible to draw any inferences about Hypothesis 2.

Hypothesis 4 states:

"Landowners who have more, relevant social interactions have a greater tendency to conform to the social norms they perceive."

A relatively substantial increase in $r^{2}$ (compared to the increase for Subjective Norm alone - fourth row) is obtained when both Social Interaction ( $\mathrm{SI}-$ fifth row) $\left(0.04^{* * *}\right)$ and subsequently the product of Subjective Norm with Social Interaction (SNxSI seventh row) $(0.04 * * *)$ are added to the regression equation for the 'Decrease native trees' behaviour. By contrast, for the 'Increase native trees' behaviour, no significant increase in $\mathrm{r}^{2}$ is obtained on addition of $\mathrm{SI}$, and a very small (0.01) increase, significant only at the ten percent level, is obtained on addition of SNxSI to the regression equation. The standardized beta coefficients are all positive at the point of entry of these variables.

These results indicate that, for the 'Decrease native trees behaviour', participants with frequent social interaction have greater intentions to decrease native bush on their land, and are more likely to be influenced by their peers when formulating these intentions. For the 'Increase native trees' behaviour, the results indicate no direct influence of level of social interaction on intention, but are consistent with greater 
peer influence experienced by more highly sociable landowners when they formulate intentions. These results support Hypothesis 4.

Hypothesis 3 states:

"Landowners who have more, relevant social interactions are more confident in their judgement of the relevant social norm."

In a final regression analysis, Group Membership (Group) and Social Interaction (SI) and their interaction term (SIxGroup) were regressed on 'Confidence in norm judgement' (CONF) in that order (Table 13).

Table 13 Multiple regression 4 - The effect of Group Membership (Group) and Social Interaction (SI) on Confidence (CONF) in norm judgement

\begin{tabular}{|l|l|l|l|l|l|l|l|}
\hline Behaviour: & & \multicolumn{5}{|l|}{ All behaviours } \\
\hline $\mathrm{n}:$ & & \multicolumn{3}{|l|}{290} & \multicolumn{3}{l|}{} \\
\hline $\begin{array}{l}\text { Dependent } \\
\text { variable }\end{array}$ & $\begin{array}{l}\text { Entry } \\
\text { order }\end{array}$ & $\begin{array}{l}\text { Independent } \\
\text { variable }\end{array}$ & $\mathrm{R} 2$ & $\begin{array}{l}\mathrm{R}^{2} \\
\text { change }\end{array}$ & $\begin{array}{l}\text { Beta (at } \\
\text { point of } \\
\text { entry to } \\
\text { model) }\end{array}$ & $\begin{array}{l}\text { Beta (in } \\
\text { final } \\
\text { model) }\end{array}$ & Significance \\
\hline CONF & 1 & Group & 0.03 & 0.03 & -0.19 & -0.14 & $* *$ \\
& 2 & SI & 0.04 & 0.01 & 0.08 & 0.17 & ns \\
& 3 & SlxGroup & 0.05 & 0.00 & -0.14 & -0.14 & ns \\
\hline
\end{tabular}

The addition of Social Interaction to the regression equation does not produce a statistically significant increase in $\mathrm{r}^{2}$, indicating that Social Interaction does not predict 'Confidence in norm judgement'. As already noted, the reliability of the CONF variable is highly questionable, so valid inferences for Hypotheses 3 cannot be drawn from this result.

\subsubsection{The relationship between Social Interaction, Confidence in norm judgement and Group Membership}

Hypothesis 6 states:

"Greater social influence between Group Members than between Non-

Members is the result of 1) greater confidence about the opinions and behaviour of their peers due to more frequent, relevant social interactions; and 2) self-identification with the group."

As already established, my results indicate no significant difference between the social influence experienced by FFA members and non-FFA members. This renders 
Hypothesis 6 not strictly relevant, but it is still worth considering the results of Tests 8 -11 to help understand the reasons for this null results. The tests are shown below:

Test 8 is:

'The mean fraction of relevant interactions had by FFA-Members with other FFA-Members (as opposed to with non-FFA Members) is expected to be more than 0.5.'

Test 8 was assessed from the response of FFA members to the following two questions:

How often do you discuss different types of current or potential land-use for your land (such as pasture, production forest or native tree cover)

i) with other members of the NZ Farm Forestry Association?

ii) with non-members of the NZ Farm Forestry Association?

- Never

- Less than once a year

- Around once a year

- A few times a year

- Around once a month

- A few times a month

- More than once a week

Responses were coded from 1 ('Never') to 7 ('More than once a week'). The sample means were $\mathbf{2 . 7}$ for question ' $\mathrm{i}$ ' and 3.3 for question 'ii'. In other words, FFA members discuss land-use with other FFA members less often than they do with non-FFA members. The significance was tested using a paired difference test of the responses to these two questions. The social interaction by FFA members with non-FFA members is significantly greater $(p<0.0001)$ than with FFA-members indicating a negative result for Test 8.

Test 9 is: 
'The mean number of relevant social interactions had in a given time period is expected to be greater for FFA-Members than for non-FFA Members'

This was assessed by comparing the sample means of Monthly interaction frequency and Annual interaction frequency with unique individuals using a Z-test. The values for FFA members are significantly greater than for non-members on both items (at the five percent level for monthly and the $0.1 \%$ level for annual interaction frequency). The size of the difference corresponds to $20 \%$ more interactions with unique individuals per month and 50\% more per year for FFA members than non-members. Although these differing results for the monthly and annual comparison seem incompatible, their $95 \%$ confidence intervals overlap. The distributions and means of the combined Social Interaction variable for FFA and non-FFA members are shown in Figure 19. This is a positive result for Test 9.

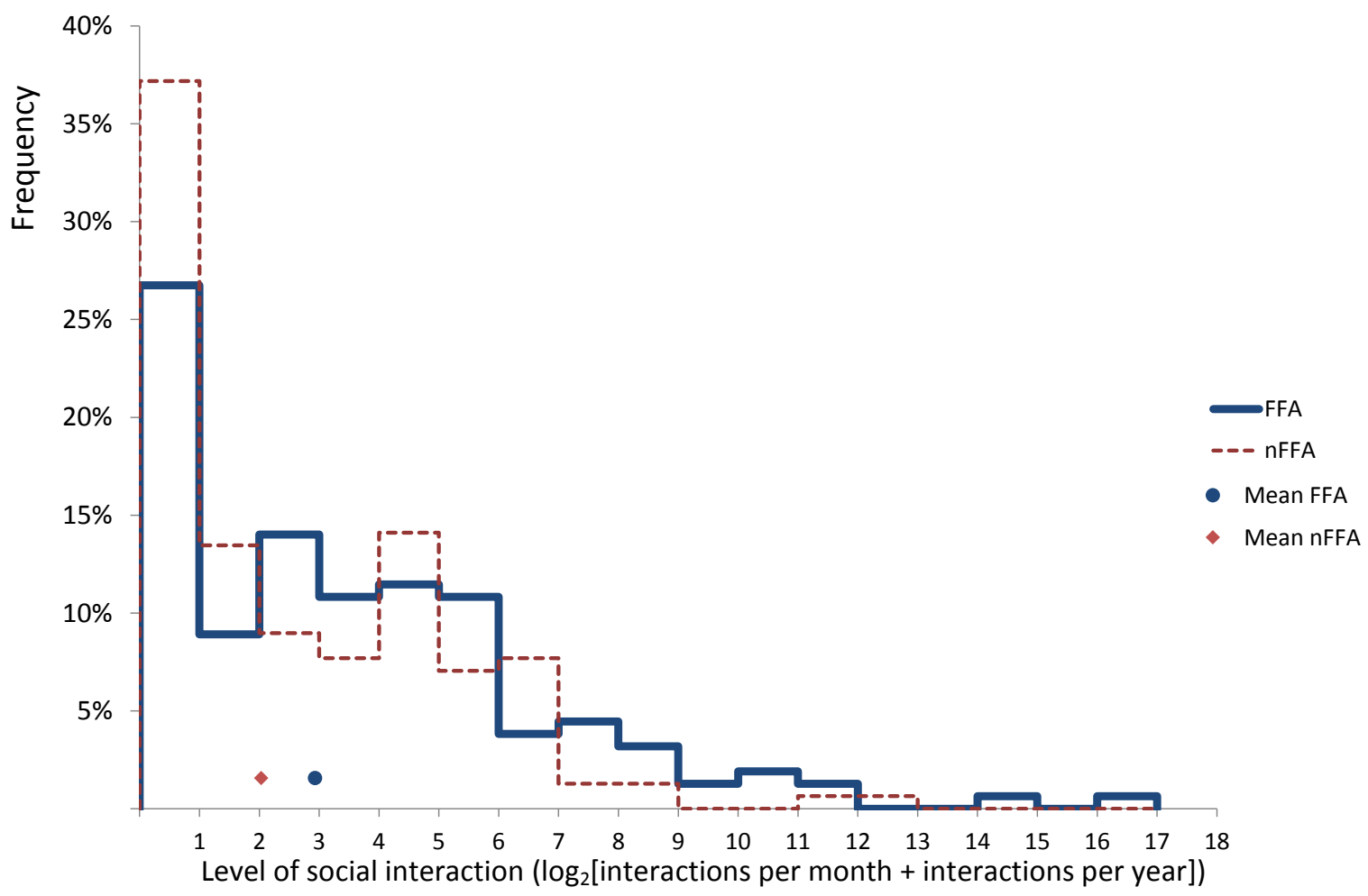

Figure 19 A histogram of values reported for social interaction frequency) by FFA and nonFFA members.

Test 10 is:

'FFA-Members are expected to be more confident in their judgement of relevant social norms than non-FFA members.' 
This was assessed by regressing Group Membership (Group) on Confidence in subjective norm (CONF). The results in Table 13 show that Group Membership produces a significant increase in $r^{2}$, although this is not substantial $\left(0.035^{* *}\right)$. The corresponding standardized beta coefficient on entry is negative which would indicate greater confidence in norm judgement by non-FFA members than by members. This is a negative result for Test 10 .

Test 11 is:

'FFA-Members are expected to show a stronger correlation than non-FFA Members between intention and the interaction term of subjective norm and confidence in that norm.'

This was assessed by regressing the interaction term CONFxSNxGroup on Behavioural Intention. The results (row 9 of Table 11 and Table 12) show that no significant change in $r^{2}$ resulted for either behaviour. This is a negative result for Test 11.

As already noted, the reliability of the CONF variable is highly questionable, so valid inferences probably cannot be drawn from these results for Tests 10 and 11 .

Since the CONF variable could not be reliably measured, I designed an additional test by including the interaction term SNXSIxGroup in the regression equation. This tests whether the moderating effect of social interaction on social influence (as described by Hypothesis 4 which my results support) differs for the FFA and non-FFA members. A positive test could imply a group 'self-identification' effect was present which increased social influence experienced by FFA-members.

This term (SNxSIxGroup) does not produce a significant change in $r^{2}$ for either behaviour (eighth row of Table 11 and Table 12). This indicates that there is no significant difference between FFA and non-FFA members in the moderating effect had by social interaction on social influence. This result therefore cannot support the existence of a group 'self-identification' effect which increases social influence among FFA-members versus non-FFA members. 


\subsubsection{Results from the experimental study}

In the experimental study, a random subset of FFA-members taking the online survey was directed to a version which omitted questions about Subjective Norms. Those completing this 'experimental survey 1 ' were then presented with a second survey ('experimental survey 2') several weeks later, this time with questions on Subjective Norm presented before repeating the questions on Behavioural Intention. The order in which questions were viewed and completed was controlled by the online survey system. Participants' Behavioural Intention responses became inaccessible before the Subjective Norm questions were presented.

The Behavioural Intention and Subjective Norm scales used the same questions and aggregate measures as in the other analyses. Change in Intention was then calculated as the difference between each participant's Behavioural Intention responses in experimental survey 1 and 2 . The Change in Intention and Subjective Norm variables were then re-coded so that the mid-point of each scale was represented as zero, with positive intentions and favourable subjective norms represented as positive numbers and with negative intentions and unfavourable norms as negative numbers. Responses from both the 'Increase native tress' and the 'Decrease native trees' behaviours were included together in the analysis, meaning that participants who responded to questions on both behaviours are included in the analysis twice. This was done in order to increase the $\mathrm{n}$ value and hence power of the analysis. Statistical inferences drawn are therefore about population-behaviour combinations rather than individuals.

Test 12 is:

'Participants are expected to report a behavioural intention which more closely aligns with their reported subjective norm for the behaviour immediately after they have answered questions about that subjective norm than beforehand'.

This was first assessed by regressing Subjective Norm on Change in Intention. The $\mathrm{r}^{2}$ value achieved is not significant at the ten percent level $(n=37)$.

In a second analysis a new variable was created:

Norm-adjusted-Intention = Change in Intention $x$ [sign of Subjective Norm] 
This variable would be expected to be more positive where a large Change in Intention is associated with a Subjective Norm in the same direction, but negative where the Change in Intention is in the opposite direction to the value of the Subjective Norm.

The sample mean of the Norm-adjusted-Intention is assessed by a Z-test to be significantly greater than zero $(n=37, p=2.9 \%)$. This result supports that participants changed their stated intentions to more closely match their subjective norm after their attention was focussed on that subjective norm.

Further separate analyses were done on the data for 'increase native trees' $(n=22)$ and 'decrease native trees' $(n=15)$ behaviours. These sample sizes are less than 30 , but exhibited outliers and skew so the normality assumption could not be made. Therefore a sign-test was carried out for the median of Norm-adjusted-Intention being significantly greater than zero. This approach further reduced the sample sizes to 14 and 7 respectively (as zero values were ignored). The medians are not significantly greater than zero at the ten percent level for either behaviour. The small sample sizes for these tests give them limited statistical power which makes their results less conclusive than the $n=37$ test with both behaviours combined.

Thus the size of the causal influence of Subjective Norm on Behavioural Intention cannot be quantified with these data.

\subsubsection{Other results}

Perceived behavioural control only achieved significance as a predictor of Behavioural Intention in the two of the six regression analyses. This was only at the five or ten percent level with a relatively small standardized beta of 0.1 and in those analyses with the greatest $\mathrm{n}$ values. The scale's component items related to 'affordability', 'ease of land use change given geography of land' and 'ease of land use change given knowledge and skills'. Acceptable reliability scores were achieved for this scale, so the low significance and effect size for this variable suggests these items are not important predictors of intention in this domain of behaviour.

Additional aspects of Perceived Behavioural Control had already been accounted for with questions to determine if behaviours were volitional (i.e. not obligated and not forbidden). Participants who reported non-volitional behaviours were not asked 
further questions about those behaviours. This approach was intended to increase the predictive power of the model but the gain in predictive power cannot be evaluated.

\subsubsection{Tests for violation of regression assumptions}

The validity of the regression analyses was checked by examining residual plots for non-normality, presence of outliers and heteroscedasticity (non-uniformly distributed standard errors). Additional checks for multicollinearity (high correlation of two or more of the independent variables) were carried out to help inform the reliability of beta coefficients.

All the regressions between the main Theory of Planned Behaviour exhibit good normality in residuals plots, except Multiple Regression 2 for the 'Decrease native trees' behaviour (regression of Attitude, Perceived Behavioural Control, Subjective Norm (SN), Self-Monitoring (SM) and SNxSM on Behavioural Intention) which has some outliers.

All the residuals plots exhibit pronounced 'boundary effects' which can be seen to result from the substantial skew in responses to the Behavioural Intention questions, with a large number of responses at the extreme negative end of the scale (see Figure 17 and Figure 18). The impact of this skewness on the residuals plots is illustrated by Figure 20.

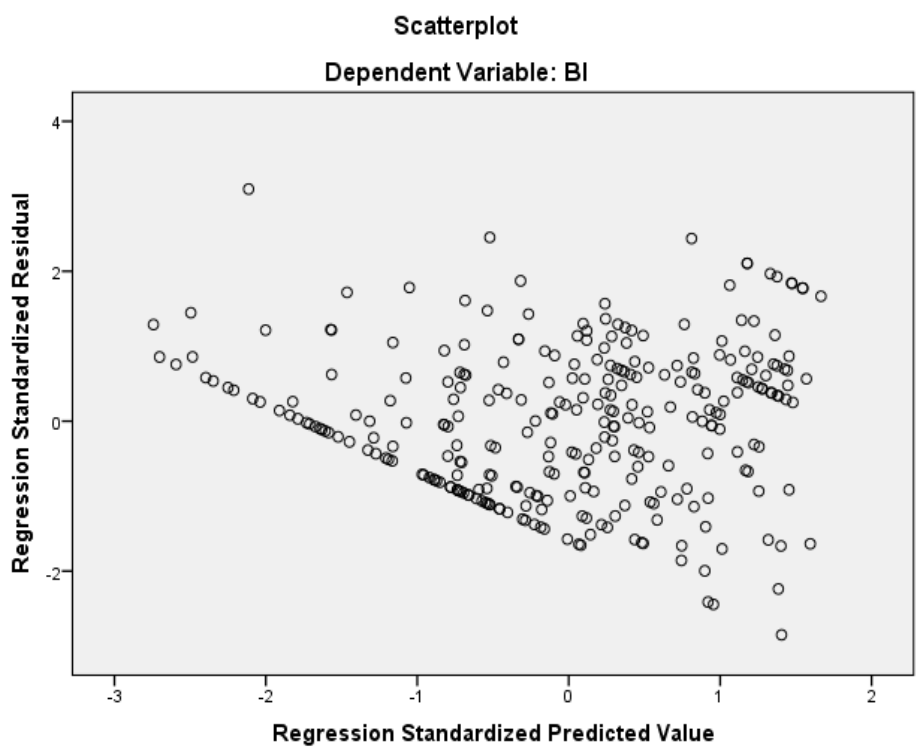

Figure 20 The residual plot from the regression of ATT, PBC, SN, Group and GroupxSN on BI. 
It appears that as a result of this effect, the errors do not have constant variance, meaning the assumption of homoscedasticity required for least squares regression may not hold. The level of heteroscedasticity appears reasonably severe, although it is not known if it is statistically significant. If significant heteroscedasticity is present then this means that statistical inferences made from the regression analysis may not be valid.

Tests revealed strong multicollinearity between Attitude and Subjective Norm, as is normally seen in studies using the Theory of Planned Behaviour (Park, 2000). This suggests that estimates of beta coefficients may not be stable. Therefore changes in $r^{2}$ were the primary indicator used of the importance of each predictor in the regression analyses. Beta coefficients were generally only used to indicate the direction of the effect, and were given at the point of each variable's entry into the regression to minimise the confounding effects of partitioning variance in the dependent variable between multiple independent variables.

\subsubsection{Salient referents}

Participants were asked which people or groups of people they considered when they answered the questions about other people's approval or disapproval (i.e. those relating to Subjective Norms). The results are shown in Figure 21.

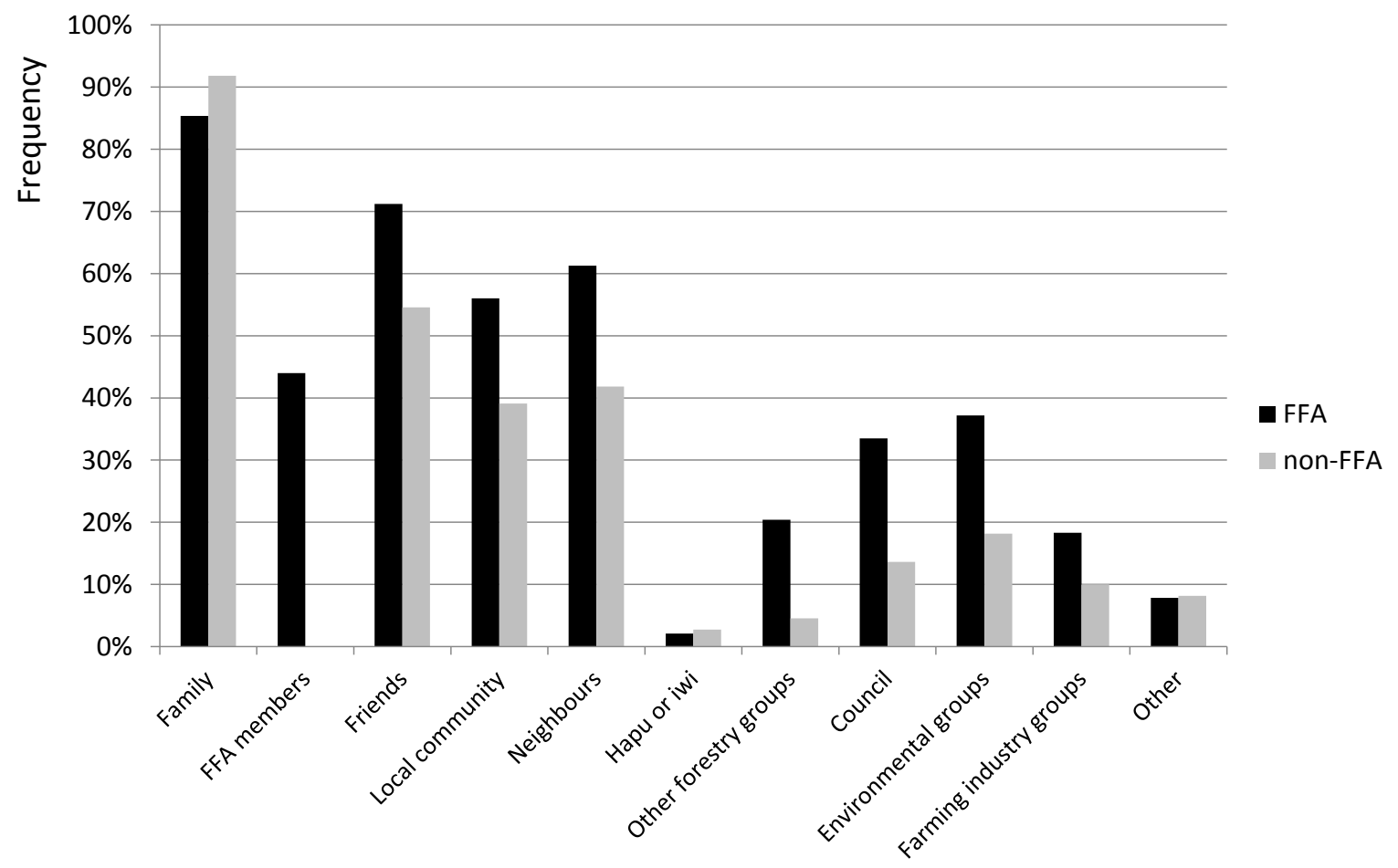




\section{Figure 21 The 'salient referents' identified by participants}

Family was the most ticked box for both FFA (85\%) and non-FFA members (92\%) and a similar proportion from each group ticked this box. This is consistent with previous research findings (see Section 2.2.3) on the importance of family influence on rural landowners. For each of the other categories of referent, the proportion of FFA members indicating these as salient was consistently higher than the proportion of non-FFA members. The exception is the 'Hapu or iwi' referent, which very few participants in either group included as salient (three for FFA and four for non-FFA).

\subsubsection{Self-reported motivations}

Participants were asked to rank by importance the factors they considered when making decisions about native tree cover on their land:

"How important are the following things when you make decisions about whether to keep, increase or decrease native tree, scrub or bush cover on your land?"

Figure 22 and Figure 23 show the results of this question for FFA members and nonFFA members respectively. The shaded bars indicate the number of participants who ranked a given factor as $1^{\text {st }}, 2^{\text {nd }}$, etc. in importance. The square plotted points indicate the 'weighted score' 30 .

\footnotetext{
${ }^{30}$ The 'weighted score' was obtained as follows for each decision factor: $\Sigma$ [number responses for each rank]x[11-rank]; Ranks over 10 were discarded.
} 


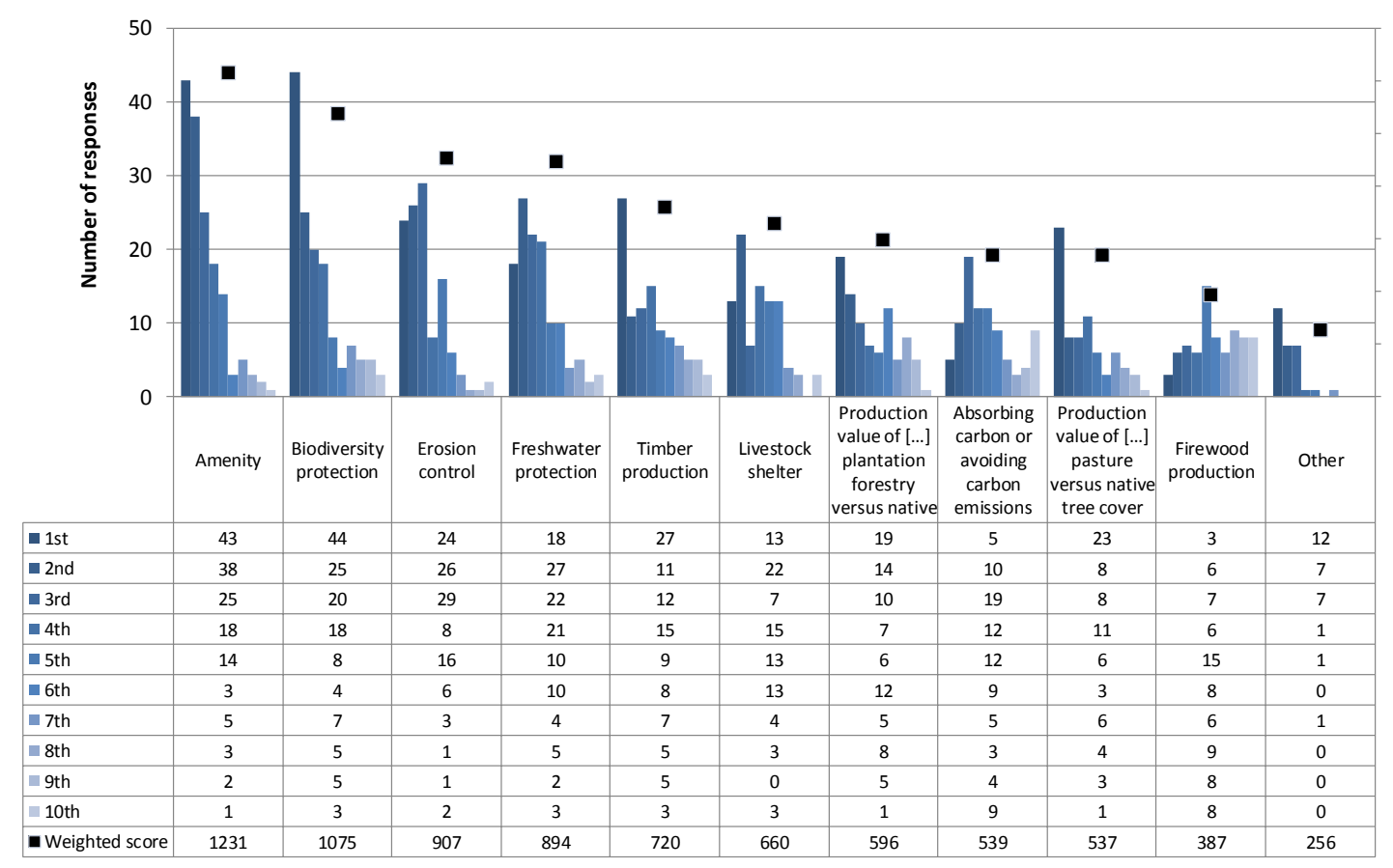

Figure 22 Farm Forestry Members' ranking by importance of factors in decisions about native trees on their land

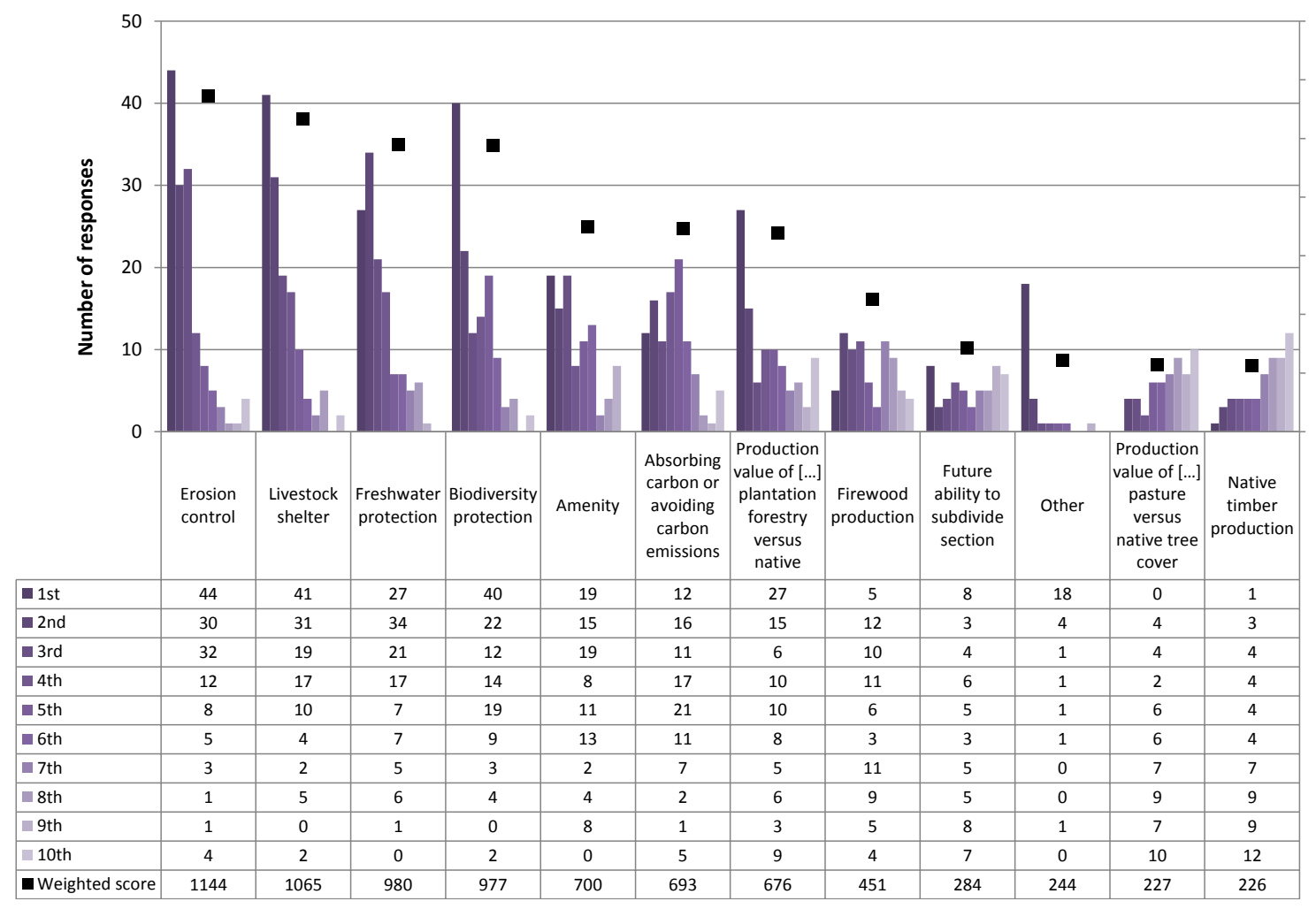

Figure 23 Non-Farm Forestry Members' ranking by importance of factors in decisions about native trees on their land 


\subsubsection{Free-text responses}

Around 600 'free-text' comments were received from participants in both the online and paper surveys in response to questions on whether participants had comments on individual sections and on the survey as a whole. These responses are a potentially rich source of additional information about the participants' motivations, particular situations and opinions. Unfortunately there was insufficient time to perform a formal qualitative analysis of these data. Therefore I read the comments and organised them into the following 'emergent' themes based on a cursory, informal analysis.

1. Motivations and contextual factors

2. Salient referents and social pressure

3. Land management and intentions

4. Government, laws and regulations

5. Comments about the survey itself

Each theme is described in more detail below.

\subsubsection{Motivations and contextual factors}

This theme includes specific benefits associated with native trees which respondents value. Native bird life, riparian protection and erosion control in particular are frequently mentioned. Some respondents note the relatively poor performance of native trees for erosion control. Other values mentioned include beautification and provision of food and fibre resources for use on the farm and for cultural uses. Many respondents comment that they value native trees without specifying particular types of value.

Many respondents mention the various constraints and issues which make increasing (or decreasing) native tree cover difficult. Commonly cited factors are financial and time considerations, the age of respondents and the land and climate characteristics. A commonly cited financial constraint is the cost of clearing, fencing and planting areas in native trees and the time associated with this. Some also comment on the cost of removing native bush, particularly mānuka from land under pasture. The likely effect on property values (either positive or negative) of native bush and the need to cover 
the cost of rates on land are also mentioned by a few respondents. On a related topic, the competition of native trees with 'productive' areas (used for exotic trees or livestock) is mentioned by a large number of respondents. The opinions expressed here mainly suggest a focus on the income available from production on the land as the primary motivation for land use decisions.

A few respondents allude to conflicting incentives more generally in terms of benefits to the environment versus recreational use by themselves (e.g. riding motorbikes). A few respondents refer to satisfaction derived from maintaining or increasing native trees, and a few mention feeling a 'responsibility' to do so.

Age is mentioned as a constraint by several FFA-members, but only one non-FFA member. Respondents point out this means difficulty with manual work, limited incomes and a smaller chance of living long enough to appreciate the fruits of their labour. Some respondents note the long time-horizons inherent in exotic and native forestry decisions, meaning that they are 'committed' to the current land-use until harvesting time. A few respondents express regret that they did not invest in native tree planting decades ago. A few respondents note that they are expecting to sell their properties shortly or don't know where they will be in a few years' time, which makes their intentions for the land use irrelevant. One respondent comments that they spent their early life 'clearing and developing' land for private landowners which had resulted in large losses of habitat, and that they would now enjoy being able to reverse some of this by planting native trees.

Comments in relation to land characteristics and climate include the problems created for establishing trees and the values provided by native bush already present in the area. Many respondents comment that they consider the native trees already present on their land to be sufficient.

A few respondents note that additional (and increasing) difficulty is posed by the need to control exotic weeds when establishing natives. One respondent notes that a large area of native bush on their land is frequently used by dope growers and this causes the landowners problems. 


\subsubsection{Salient referents and social pressure}

There are a number of comments about the frequency of social interactions relevant to discussing land-use and finding out about others' land-use behaviours. These comments indicate a wide-range of experiences and behaviours by landowners in terms of social interaction. A number of respondents comment on the large number of relevant conversations they have with other people. Some of the more social are those with related jobs (such as sawmilling or forestry consultants) and others mention interactions through the Farm Forestry Association. A large number of respondents state that they have little knowledge of other landowners' past behaviour and intentions with respect to native trees on their land. However, a similar number do describe actions taken by landowners in their area in relation to native trees. A large number feel that others wouldn't care about one's land-use and/or would not pass comment because it would be impolite.

Several respondents mention the importance of their family's or spouse's opinions and interests when they make land-use decisions.

A few respondents mention having like-minded friends or ignoring those who do not agree with them. One mentions getting information from the internet and one from reading.

Several respondents mention practical constraints on their ability to have relevant conversations about their land-use. These included being non-resident, being socially isolated due to age or simply not getting on with others.

The majority of comments on the subject of social pressure are sceptical about its importance in influencing their decisions. A few respondents note that they value advice from others who knew about trees and the importance of 'spreading the planting message'. However, in addition to the comments already mentioned about the lack of information on others' intentions and opinions, many state that they do not care and/or are not influenced by what others do or think. Some make a link between this and their exclusive right as the property holder and rate payer to make decisions about their land.

One respondent notes that a gradual increase in native area indicates a poorly-run farm. 


\subsubsection{Land management and intentions}

A very large number of respondents provide brief, to reasonably detailed, accounts covering some or all of: their land's characteristics, land-uses, current and previous management actions, their intentions for the future and ultimate desired end-state of their land. Many comments in this category give the impression that respondents are keen to explain and take pride in their choices, actions and plans for the land. These comments also frequently include various site and person-specific contextual factors, which form part of the justification for their particular course of action.

A large number of respondents mention the potential for natural regeneration of native bush in areas which are not actively cleared. Some appear to be raising this to highlight that increasing native tree area can be to some extent a 'passive' behaviour. Others mention it in the context of an on-going 'battle' on their property to clear selfsown mānuka from areas of pasture.

\subsubsection{Government, laws and regulations}

Topics under this theme include the Emissions Trading Scheme (ETS) and climate change more generally, the impact of other regulations including local and regional council planning and the risk of future regulatory change.

Several respondents note that the ETS affects the incentives they face for land-use change decisions. Some state that they are incentivised to keep land under exotic forest after harvesting rather than converting to native forest in order to avoid deforestation liabilities. Some respondents expressed frustration at not being able to earn carbon credits under the ETS to compensate them for maintaining native trees (presumably this refers to 'pre-1990' forests). Some point out that native trees grow too slowly to provide a good return from carbon credits.

Several respondents express frustration that existing legislation and/or regulations prevent them from earning an income (from timber) or clearing land of native trees. Several also express concern that changes in legislation or regulation will prevent (natural or planted) land under native trees from being harvested or cleared. For some this provides an incentive to prevent natural regeneration and to favour exotic over native forestry in case the use of the land is lost permanently to them. 
Several respondents note that they have either placed conservation covenants on their land themselves or inherited these with the title from the previous owner.

One respondent notes that their riparian planting meant they are now in compliance with regional council and Fonterra rules.

\subsubsection{Comments about the survey itself}

Comments about the survey itself highlight several issues that respondents encountered when completing it.

An important issue for the survey design was the interpretation of questions which referred to "native trees, bush and scrub". I intended this wording to refer to "native trees, native bush and native scrub", but comments made by respondents imply both ambiguity in the wording and issues with including these different types of land cover together. Some respondents state that they interpret 'scrub' as referring to exotic scrub such as gorse and broom. Others note that their attitude and intentions toward native scrub (such as mānuka) is different to that toward more mature areas of native bush.

Other comments highlight difficulties related to definitions of the behaviours covered in the survey ('increase', 'decrease', and 'keep about the same' native tree, bush or scrub cover). Some respondents comment that these actions are ambiguous if the counterfactual is not defined. Others comment that their attitudes to these behaviours would depend a great deal on their extent of that behaviour (i.e. how much increase or decrease?).

Some respondents comment that the use of double negatives in some questions as well as the presence of the same question asked in different ways, with reversed answer scales was confusing.

Some respondents found the answer scales used in the attitude questions ambiguous, because the answer may depend on the value frame used. For example: 'what I like or what makes me money' and 'economically negative value and benefit but environmentally high value and benefit'.

Several respondents comment that the survey was too long or repetitive, that it was pointless or a waste of time, or that questions were strange, obscure or had an unclear 
purpose. Two respondents comment that the questions were 'loaded' or 'biased', presumably due to the focus on native trees. Some thought the survey was irrelevant given their particular situation, although their own descriptions of their situations suggest to me that the survey was indeed relevant for them. In other words, their situations did not seem to preclude increase or decrease of natives. It is possible that they considered the survey irrelevant because it discussed behaviours they would not consider.

The questions intended to measure the self-monitoring personality trait evoke a number of responses commenting on the strangeness of the section and difficulty in answering them (see Appendix 6 - Online survey; personality questions appear at end of Part B). A few respondents make the point that their personality traits might differ according to the context and urgency of decisions and some suggest they had changed as they had got older which made it difficult to assess an 'average' state.

A small number of respondents express positive sentiments and wished me luck with the research project. 


\section{Discussion}

\subsection{Is social influence present?}

My results show that New Zealand landowners' stated intentions to decrease or increase native tree, bush or scrub cover on their land tend to conform with the behaviour and opinions they perceive among their peers. The effect is very small, with Subjective Norm accounting for three percent of variance in intention to decrease native tree cover and one percent for increasing native tree cover. I found Attitude to be a far more substantial predictor of Intention ( $48 \%$ for 'decrease native trees' and $44 \%$ for 'increase native trees'). This pattern is consistent with other studies employing the Theory of Planned Behaviour in a range of behavioural domains (Armitage \& Conner, 2001).

The overall prediction of intention achieved by the three TPB predictor variables in my research is $52 \%$ for 'decrease native trees' and $45 \%$ for the 'increase native trees' behaviour. This is substantially higher than the average of $37 \%$ found in Armitage and Connor's meta-analysis. The strong measured effect may be due to my unconventional treatment of the Perceived Behavioural Control (PBC) variable. I excluded participants from further analysis when they stated behaviours were either impossible (such as decreasing native trees when they had none on their land) or obligated (such as maintaining native trees when they were under a covenant). In the 'conventional' TPB methodology, such participants would have been included, but presumably with a very low score on the measure of PBC. The increase in predictive power with my methodology has only been achieved for a sub-set of the population and by excluding those to whom the model 'doesn't apply'. I argue this is valid where it avoids nonsensical questions (such as asking participants their intention to perform an impossible behaviour), but the motivations of excluded participants remain valid and might become important if their circumstances change.

\subsection{Differences between the behaviours studied}

Intentions to decrease native trees were highly negative for a large proportion of the population, whereas Subjective Norms for this behaviour were moderately negative, but fairly broadly distributed. For 'increasing native tree cover' there is not a particularly strong norm apparent from either intention or Subjective Norm data. 
These results indicate the 'normal' behaviour among respondents with native trees on their land is to not decrease this tree cover, but paradoxically this is not a norm they perceive strongly among their peers. It could be that people responding to these questions are unusual compared with their peers because: 1 ) only those with native trees on their land responded to these questions (others were excluded based on their answers to Perceived Behavioural Control questions); 2) only 15\% of land titles over one ha have native trees on them; and 3) by excluding people who have already cleared native trees from their land, this approach is likely to select for those with more positive intentions to preserve native trees.

My research found stronger social influence on intention and stronger prediction of intention by Attitude for the 'decrease native trees' than for the 'increase native trees' behaviour. Native tree planting is a relatively novel and unusual activity, so landowners may not generally have well-formed attitudes or intentions towards it. This could explain the decreased lower prediction of Intention by Attitude and Subjective Norm. Furthermore, where landowners consider the public goods provided by native trees on their land to be important, this could increase the importance of injunctive normative influence ('what others think of my actions'). Due to 'loss aversion' and 'status quo bias' effects (Kahneman, Knetsch, \& Thaler, 1991) injunctive normative influence might be felt more keenly for the abrupt loss of public goods from clearing native trees than for the gradual accumulation of public goods after native tree planting .

\subsection{Differences between the groups studied}

\subsubsection{Main Theory of Planned Behaviour variables}

Figure 17 and Figure 18 show distributions and mean values for the main Theory of Planned Behaviour variables. FFA members and non-members have relatively wellmatched Intentions, Attitudes, Subjective Norm and Perceived Behavioural Control values. The distributions of values are similar between the groups and there is no significant difference in any of the means between the groups.

There is no significant difference between the two groups in terms of the level of prediction of intention achieved by Subjective Norm. 
These findings are contrary to my expectation that FFA members would perceive different social norms to non-members for behaviours affecting native tree cover on their land (Hypothesis 7) and that FFA members would be more likely to conform to the social norms they perceived (Hypothesis 4).

\subsubsection{The rationale for using groups}

Here I briefly recap my rationale for including two groups in order to explore these findings further. Early experimental group conformance studies (Asch, 1955; Deutsch \& Gerard, 1955) and more recent experimental studies with manipulation of normative cues by researchers (Cialdini et al., 1990; Nolan et al., 2008; P. W. Schultz et al., 2008) have demonstrated more substantial social influence than seen by TPB studies. Variation in individual susceptibility to social influence and extent of group identification have been proposed as confounding variables which make the social influence in TPB studies weak and variable. I proposed (Section 3.1.6) that individual confidence in norm judgement may also vary. Low confidence could result when there is no well-defined 'actual norm', but rather a broad spectrum of opinions and behaviours present in a peer group. Alternatively, individuals with little social interaction may not receive information required to confidently judge the norm.

I hypothesised that FFA members would experience stronger social influence because 1) there is a better-defined 'actual norm' for behaviours relating to native trees within the group, 2) members have more relevant social interaction with each other and 3) members self-identify with the group so they are more likely to take account of each other's opinions.

\subsubsection{Why did the groups not differ?}

FFA members perceive a broad spread of Subjective Norm values and the average value is fairly neutral (i.e. the mean is close to the mid-point of the scale). The distribution is similar to, and the mean value is not significantly different from, that for non-members. This suggests I did not choose a group with a well-defined 'actual norm' nor a better-defined 'actual norm' than the general population of rural landowners.

Questions on 'confidence in norm judgement' did not yield useful results, as reliable measures of 'Confidence' could not be constructed. It is possible respondents were unaccustomed to answering questions about their own judgements ('meta-cognition'). 
The measures of social interaction did yield useful results. There is greater social influence on the intentions of participants who have more frequent, relevant social interaction. There is also a direct effect of social interaction on the 'decrease native trees' behaviour only: participants with greater levels of social interaction are more likely to intend to decrease native tree cover on their land ${ }^{31}$.

FFA members claim to have $20 \%$ more relevant social interactions per month and $50 \%$ more per year on average than non-members. Although these differing results for the monthly and annual comparison seem incompatible, their $95 \%$ confidence intervals overlap. FFA members have interactions with non-members slightly more frequently than with other members.

Since I found greater social interaction is associated with stronger social influence in general, and FFA members have greater social interaction than do non-members, the question arises why FFA members do not experience stronger social influence? This apparent paradox may be explained by the relatively small difference in social interaction levels of FFA members versus non-members. The difference is around two orders of magnitude smaller than the total spread in responses received (see Figure 24 and Figure 19). In other words, although the groups differ in their social interaction levels, they may not differ substantially enough for group differences in social influence to manifest.

I did not measure FFA members' level of self-identification with the group directly. However, responses to the following question give some indication of the 'salience' of different people and groups when participants make normative judgements:

"What people or groups of people did you consider when you answered the questions about other people's approval or disapproval?" [tick one or more boxes]

The top five most ticked answer categories by FFA members were 'Family', 'Friends', 'Neighbours', 'Local Community' and 'Other FFA members' in that order (see Figure

\footnotetext{
${ }^{31}$ The direction of the effect is difficult to establish from my analysis, as the standardized beta coefficient for $\mathrm{SI}$ on $\mathrm{BI}$ changes in sign (from positive to negative) during the course of the hierarchical regression.
} 
21). This suggests many FFA members do not consider other members to be a source of normative information.

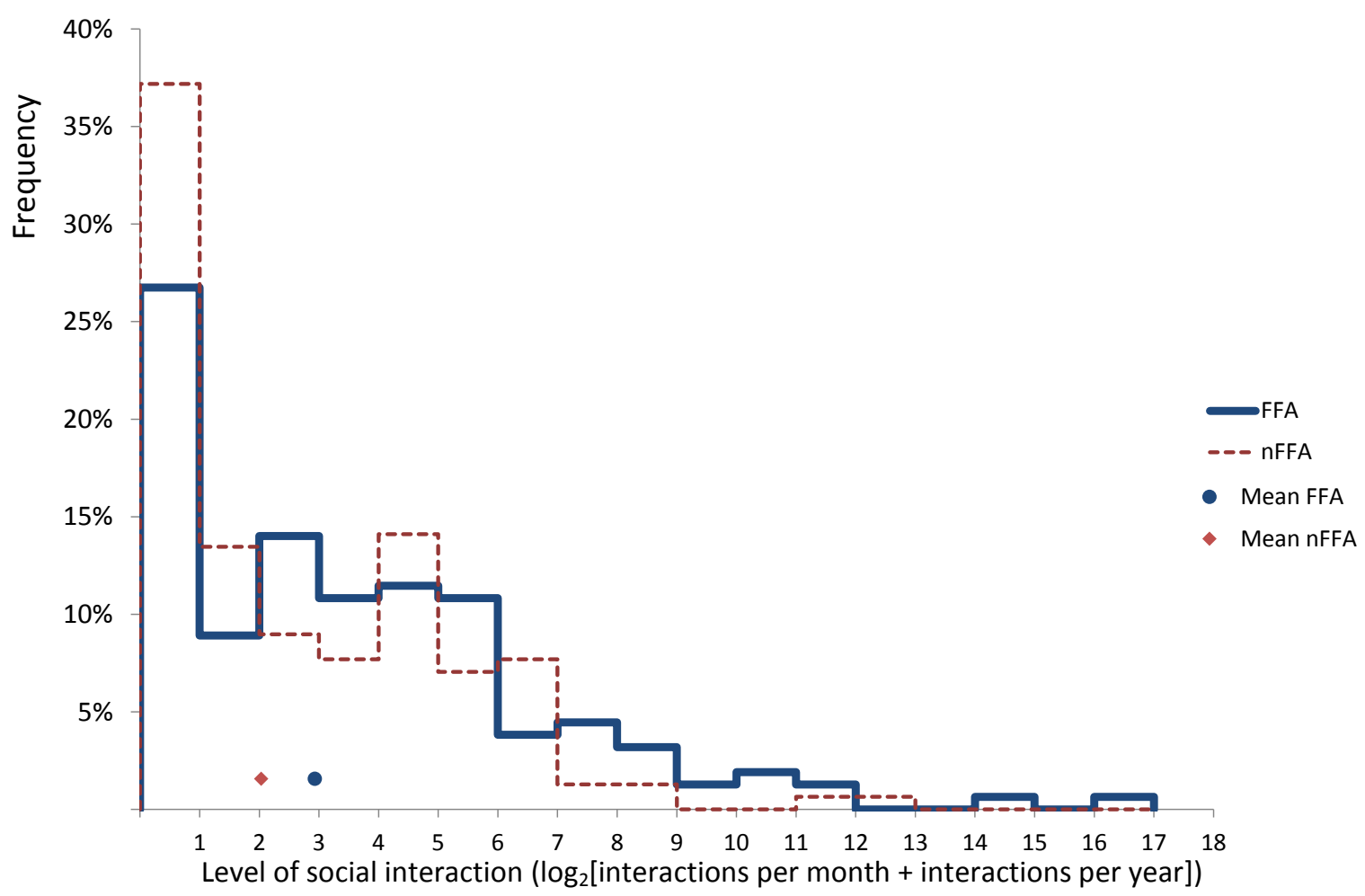

Figure $\mathbf{2 4} \mathrm{A}$ histogram of values reported for social interaction frequency by FFA and non-FFA members.

\subsection{Effect of self-monitoring}

Individual differences in the self-monitoring personality trait were expected to reflect differing susceptibility to social influence and therefore moderate the Subjective Norm-Intention relationship.

The level of self-monitoring does indeed moderate the social influence experienced by FFA members. The effect size is relatively substantial, compared with the predictive power of Subjective Norm alone. The effect differs in size and direction for the 'increase native trees' versus the 'decrease native trees' behaviour. A number of respondents commented on the strangeness and difficulty of the personality questions in their text comments (Section 5.5.5.5). Therefore the resulting measure may not be particularly reliable, which could explain its inconsistent moderating effect. 
It is difficult to assess how the Self-Monitoring variable affects the predictive power of the model as a whole. This is because the sample size was substantially reduced for this part of the analysis as only FFA members were asked these questions.

\subsection{Why is such a small social influence effect found by the Theory of Planned Behaviour?}

The strength of social influence I detected, although consistent with other Theory of Planned Behaviour studies, is far less than seen in other methodologies.

In Asch's group conformance studies, participants conformed to a clearly erroneous, unilateral group norm around 35\% of the time (Section 2.1.2.3). Cialdini found a $61 \%$ decrease in participant's chance of littering immediately after exposure to an antilittering normative cue (Section 3.1.5). By comparison, my research found that social influence, accounting for levels of social interaction, explains ten percent of the variance in landowners' intention to decrease native tree cover on their land and only $1.5 \%$ for intention to increase native tree cover. ${ }^{32}$

It seems likely this difference relates to the relative norm strength and norm salience found in these different research settings. In Asch's studies a single group member in a group of 15 faced opinions from the 14 others opposed to his ${ }^{33} \mathrm{own}^{34}$. This strong conformance created by unilateral, majority opposition was found to diminish substantially when participants faced a less than unilateral norm. The very short timeframe between norm exposure and action, combined with the physical presence of 14 other people would have made this norm highly salient for the participant.

In Cialdini's littering experiment the normative cue was deliberately designed to give the norm high salience to the participant. The researchers "exposed subjects to acute situational conditions designed to focus them on or away from particular norms" (Cialdini et al., 1990, p. 1025).

\footnotetext{
${ }^{32}$ It is difficult to directly compare the magnitude of these effects since the TPB measures intention as an ordinal variable (and analyses it as a continuous variable), whereas group conformance and normative cue studies observe behaviour as a binary variable (it is either performed or it isn't).

${ }^{33}$ Only male participants were studied.

${ }^{34}$ In fact the 14 other members were in collusion with the experimenter.
} 
The situations and behaviours I studied lack both the norm strength and the norm salience components of these group conformance and normative cue studies. The distribution of the Subjective Norm variable (Figure 17 and Figure 18) shows that few participants experienced a particularly strong norm. There was a broad spread in the Subjective Norms for both behaviours, suggesting no widely perceived 'actual' norm exists for these behaviours, in sharp contrast to the 'unilateral' norm created in conformance studies. I hoped FFA members would perceive a strong group norm, but in fact their Subjective Norms did not differ from the general population of rural landowners studied.

Land use decisions are long-term in their planning, implementation and effects and therefore likely to be made in a considered and deliberate manner. Landowners may be exposed to normative information from time-to-time in the form of others' behaviour or opinions. There is no particular reason for this to be 'salient' at the time when they make a decision.

\subsection{Causality}

The Theory of Planned Behaviour (TPB) provides a reasonable test for social influence, but a number of other plausible mechanisms could explain a correlation between Subjective Norm and Intention. For example, people may choose to associate more with others who share their attitudes and intentions. Alternatively people who associate with others with a range of views, may unconsciously select those whose opinions align with their own when answering survey questions about social influence - a form of 'confirmation bias'.

I showed the 'self-monitoring' personality trait moderates the social influence effect. This supports that the effect detected is indeed occurring 'within the participant's head', but different causal mechanisms than social influence are still conceivable. For example, high self-monitoring participants may be more likely to associate with those who share their views, or to succumb to confirmation bias when judging norms.

The results of my experimental study provide a more convincing demonstration of the direction of causality. This study raised norm salience by presenting a 'normative cue' immediately before the participant responded to questions on Intention. Participants 
reported Intentions more closely aligned with their Subjective Norms immediately after answering questions about Subjective Norms than beforehand.

This result confirms the direction of causality, and suggests norm salience moderates the strength of social influence for the behaviours I studied. The size of the moderating effect could not be quantified.

\subsection{Inferences about social network structure}

Participants show a very wide distribution in their frequency of social interactions relevant to land-use decisions (Section 5.5.2.3). This information provides insight into the structure of the social network present. Social network topology may affect diffusion of ideas and innovations (Section 2.1.3). The 'scale-free' network topology found in natural and human systems is remarkable in not exhibiting the critical infectiousness threshold for virus diffusion seen within non-scale free networks (Pastor-Satorras \& Vespignani, 2001). A common test for scale-free networks is that the number of connections to each node follows a power law of the form Frequency $=$ Connections $^{-\nu}$ (Albert \& Barabási, 2002). This is the case if a log-log plot of the data provides a straight line, with the slope being equal to a constant $(-\gamma)$. Such log-log plots are shown for the social interaction data of FFA-members in Figure 25 and non-FFA members in Figure 26.

The plots exhibit good linearity which suggests that when considering social interaction on the topic of land-use decisions, both FFA-members and non-FFA members are part of social networks with scale-free connectivity. 
FFA members

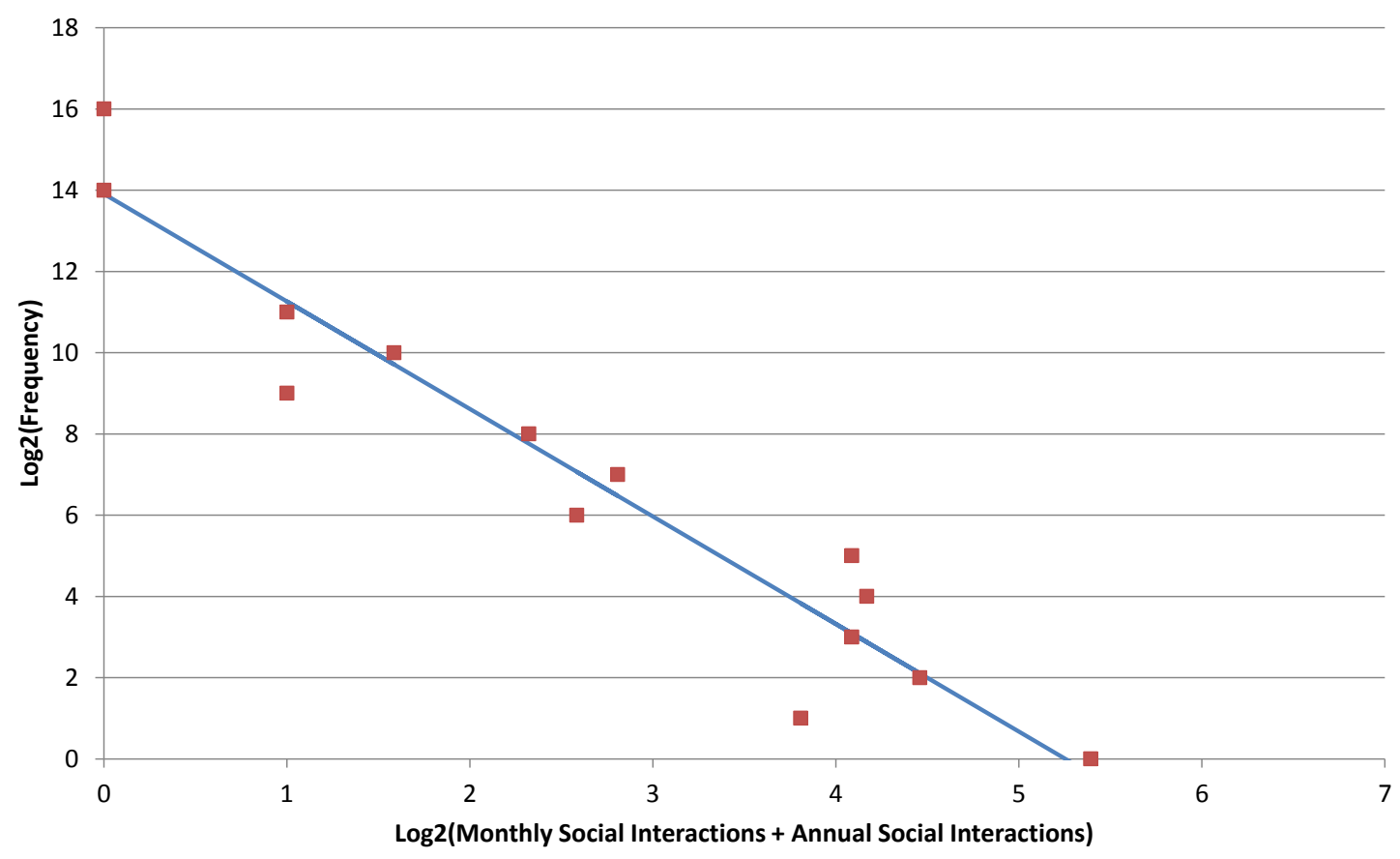

Figure 25 A Log-Log plot of the distribution of social interactions by FFA members

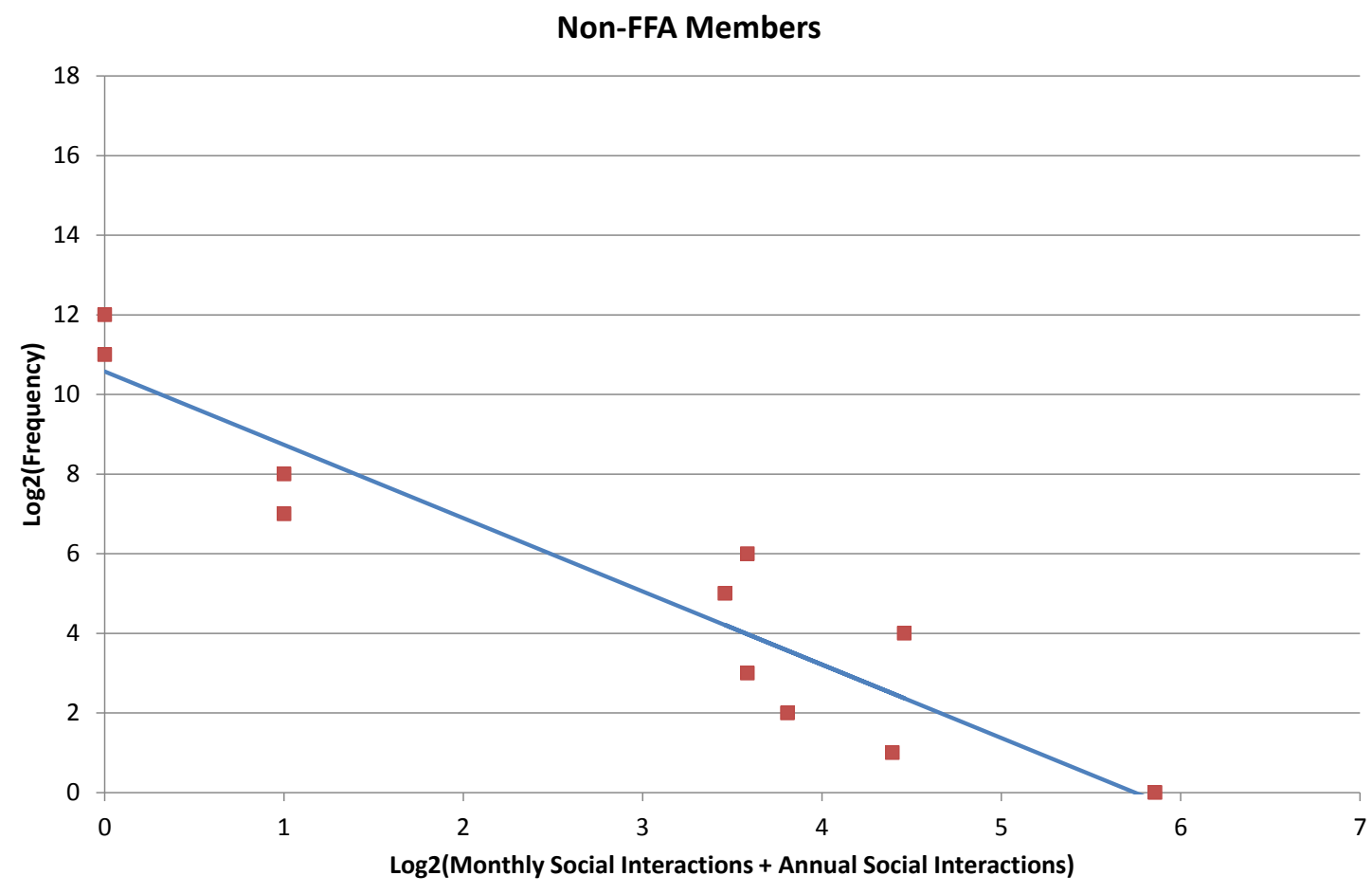

Figure 26 A Log-Log plot of the distribution of social interactions by non-FFA members

Empirical research in this relatively new area is currently limited so the exact implications of this finding are unknown. Pastor-Satorras \& Vespignani's work on critical infectiousness thresholds in scale-free networks used a simple model of computer virus diffusion. This is unlikely to properly represent the complex nature of 
human decision-making and interpersonal social influence. However, future research which combines network analysis with a model of human decision-making, such as the Theory of Planned Behaviour, could lead to a better understanding of the link between social influence and diffusion of behaviours through society.

\subsection{Insights from participants' stated motivations and free-text responses}

There was general scepticism expressed in the 'free text' responses (Section 5.5.5) towards the idea that participants' behaviour was influenced by their peers or that their own opinions would influence the decisions of others. This is at odds with my results showing that there is measureable, albeit weak, social influence operating for the populations and behaviours studied. This is consistent with Cialdini (2005) and Nolan et al.'s (2008) demonstrations that 'social influence is underestimated'.

Insight into participants' attitudes comes from answers to this question:

"How important is each of these factors do you consider when making decisions about native trees on your land?",

and from the 'free text' responses (sections 5.5.4 and 5.5.5). Environmental 'public good' factors are ranked highly by participants. 'Erosion control', 'biodiversity', 'freshwater protection' and 'amenity' ${ }^{35}$ are among the top five factors for both FFA and non-FFA members.

Competition with 'productive' land use (for pasture or exotic forestry) is ranked lower on average than the environmental 'public good' factors. This appears slightly at odds with the free-text theme that income available from production is a key motivator of land use decisions. Since free-text responses are not quantitative, it is not possible to assess the prevalence of views from these data.

Davis and Cocklin (2001) point out that without stock exclusion and active control of animal and plant pests, native bush fragments on private land are likely to suffer gradual degradation in ecosystem health. 'Biodiversity protection' was ranked highly

\footnotetext{
${ }^{35}$ The mix of public and private benefits associated with 'amenity' is likely to depend on the size and layout of a property - i.e. can people other than the landowner see and enjoy the trees?
} 
by both FFA and non-FFA groups. However, 'livestock shelter' also featured highly ranking $1^{\text {st }}, 2^{\text {nd }}$ or $3^{\text {rd }}$ for $47 \%$ of question respondents who were non-FFA members and $21 \%$ of FFA members. Unfortunately the question phrasing makes this result ambiguous. For example, participants may be using native tree cover as livestock shelter, or they may be using exotic trees which displace native tree cover. The statistical significance of this result was also not tested. Despite these caveats, this finding could indicate that around half or more of native bush fragments on private land for the general population do not have livestock excluded.

\subsection{Possible sources of bias}

Several possible sources of bias in my results are discussed below.

There is an apparent response bias towards those who already have an interest in or favourable attitude towards native trees. Figure 27 shows that owners of land with both exotic and native tree cover made up around ten percent of those sampled by the survey of non-FFA members, but $70 \%$ of responses to it. These people may have been more likely to persevere with and return the questionnaire since its subject matched their interest and circumstances. It seems likely that a similar effect will have occurred in the survey of FFA members. This may not be a major concern for the regression analysis results, since these rely on the relationships between Attitude, Subjective Norm and Behavioural Intention, rather than on their absolute values. 


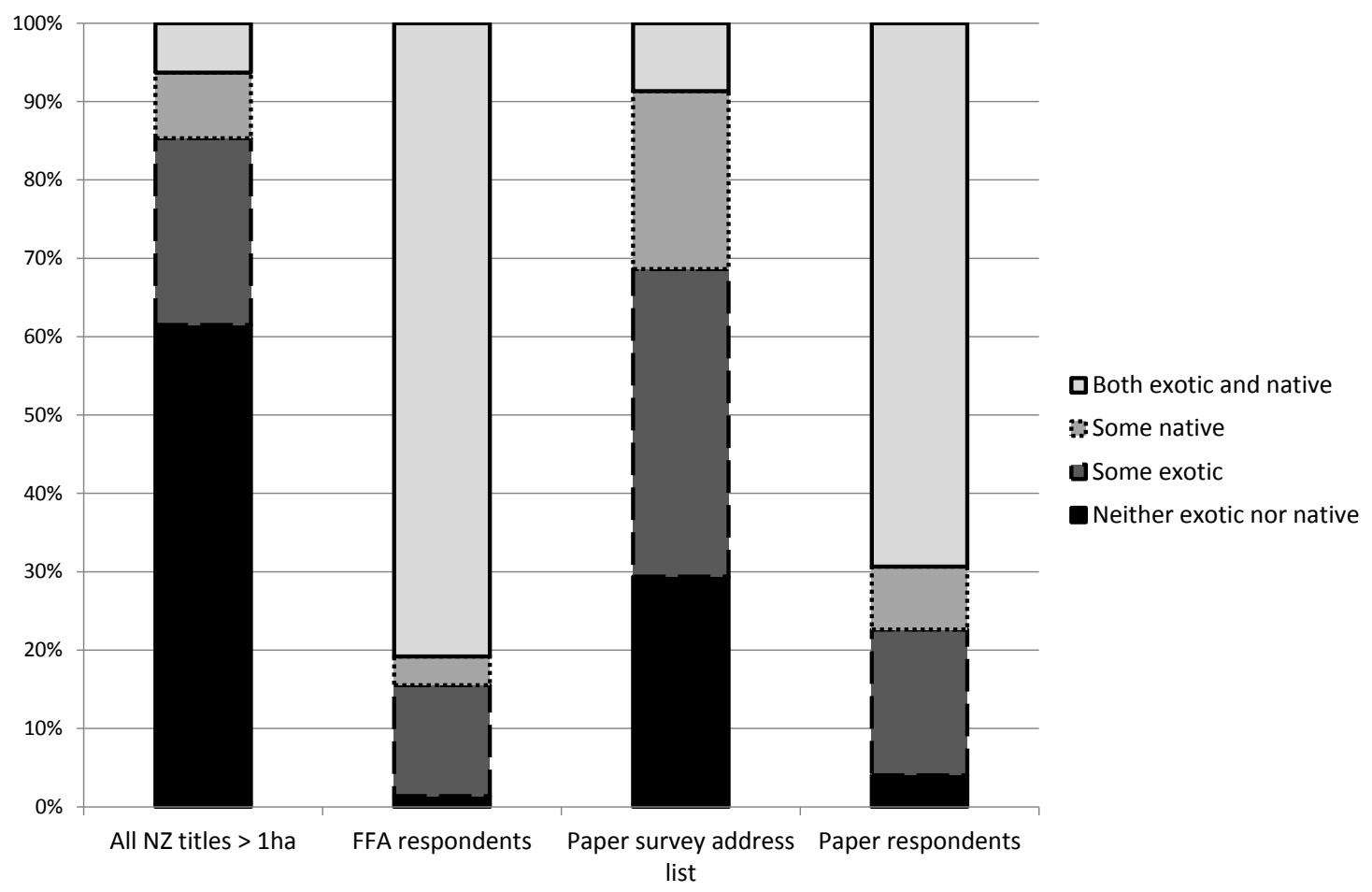

Figure 27 The proportion of exotic and native tree cover found on the land of different groups in the research. The land cover for 'All NZ titles $>1$ ha' and 'Paper survey address list' are derived from land property title and land cover databases as described in Appendix 3; the land cover for 'FFA respondents' and 'paper respondents' is as stated in their responses.

This response bias does cast doubt on the apparent norm to 'not decrease native tree cover' indicated by the intention data (Figure 28).

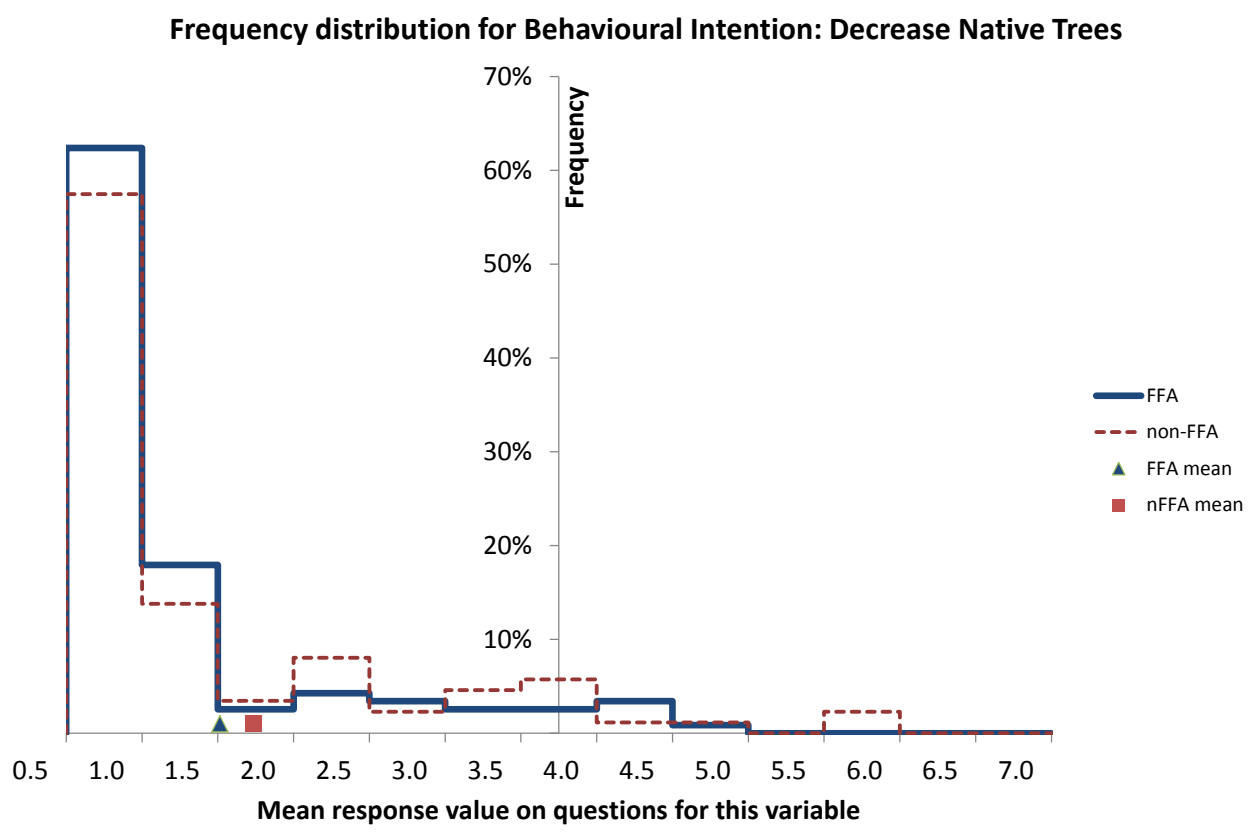


Figure 28 The distribution and mean responses of intentions to decrease native trees

If the sample is biased towards those with favourable attitudes and intentions towards existing native tree cover on their land, then this apparently strong 'intention norm' (to not decrease tree cover) may not be generalizable to the whole population of landowners with existing native tree cover.

A related effect is 'pro-social' bias of respondents - meaning those with more prosocial attitude may be more likely to persevere with and return questionnaires. This personality trait could be correlated with susceptibility to social influence or general sociability. Therefore a pro-social response bias could skew my results to show stronger social influence than is present in the population as a whole.

The sample frame for the online survey of FFA members was an email list covering $60 \%$ of FFA members. This could create an age bias, since age is likely to be negatively correlated with likelihood of having an email address

The paper survey sampled from a frame of all New Zealand property titles, which was subsequently converted to name-address combinations using the process described in Appendix 3 - Postal address list methodology. Only addresses to which NZ post delivers were used. This process was reasonably successful given that a $30 \%$ response rate was achieved and only five percent of postal surveys were returned due to unknown names or addresses. However, an unknown proportion of the outstanding $65 \%$ of unreturned postal surveys were also probably sent to invalid name-address combinations. Assuming some of these invalid name-address combinations arose from recent land ownership changes or subdivisions not recorded in databases, this could create a bias towards landowners who had been on their land for a while. Exclusion of addresses to which NZ post do not deliver (i.e. courier-only addresses) may create a bias towards properties in less isolated locations. Properties which did not have any residents (either owners or lessors) were also excluded by this sampling process.

During the postal address selection process I discarded property titles which had greater than ten owners' names listed. This was because these were considered more likely to relate to multiply-owned Māori land. I considered it was not possible to design 
a questionnaire accounting for the various types of decision-making structure likely for such land. As explained in Section 3.1.6, I also consider there are more appropriate methodologies for research on land use decisions by Māori, hapu and iwi. This almost certainly introduces a bias in my results towards non-Māori landowners.

Online surveys were distributed and completed between $29^{\text {th }}$ November 2011 and $12^{\text {th }}$ January 2012. Paper surveys were distributed in March 2012 and completed and received until June 2012. Events occurred regarding the Emissions Trading Scheme during this period which probably affected the incentives faced by survey participants. In April 2012 the Government released a consultation document (Ministry for the Environment, 2012) proposing amendments to the Scheme. These included a proposal to waive the deforestation liability on pre-1990 forest land as long as equivalent forest were planted in a different location, and to review the amount of 'free NZUs' previously offered to owners of such land as compensation. This was accompanied throughout the period of both surveys by a substantial decline in the NZU price (Figure 29).

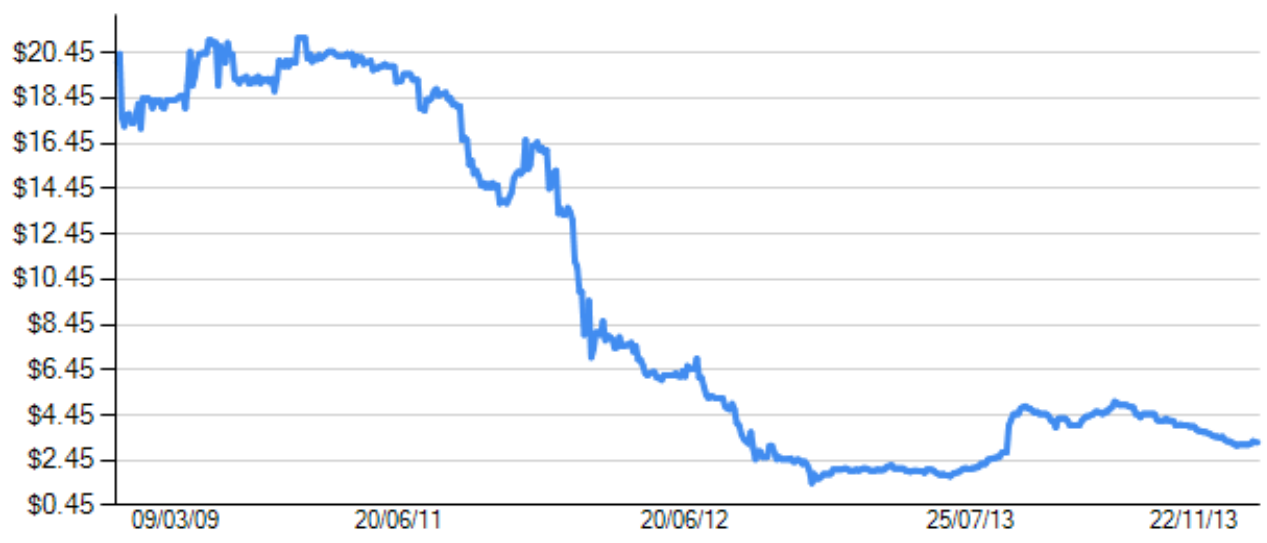

Figure 29 The NZU spot price history. Downloaded from https://www.commtrade.co.nz/ on 24/11/13

It is likely these events affected the incentives of landowners within my survey. Of particular concern is the signalling, after my survey of FFA members but during my survey of non-FFA members, of potentially reduced liabilities for deforestation. Although there is no ETS deforestation liability on indigenous forest, exotic deforestation could make way for new native tree cover or be accompanied by native deforestation if this reduced the harvesting costs for the landowner. Combined with the substantial drop in the carbon price, this would have created an uncertain and 
volatile environment for all my participants, but even more so for non-FFA members. This could reduce the certainty or consistency of the Subjective Norms they perceived among their peers, as well as producing less reliable measures of attitudes and intentions.

The FFA and non-FFA groups did not significantly differ on their average responses to any of the main Theory of Planned Behaviour (TPB) variables (Attitude, Subjective Norm, Perceived Behavioural Control and Intention). If significant differences were present then they might arguably be ascribed to the changes in external factors between surveys of the two populations. Since no significant differences were found, I have less concern that these events had a confounding impact on the between-group comparison. However, an impact which precisely 'cancelled out' a true difference between the FFA and non-FFA groups cannot be ruled out.

\subsection{Novel aspects of my research}

\subsubsection{Unconventional treatment of Perceived Behavioural Control}

I argue that the conventional treatment of Perceived Behavioural Control on an equal footing with Attitude and Subjective Norm as a predictor of Intention cannot fully capture the constraints on behaviour which people may face in the real world. In some cases regulations may make the behaviour under consideration illegal for a particular individual, such as council rules preventing clearance of bush. Although such behaviour is still in theory volitional, it is likely to be considered in a different 'decision frame' to more innocuous behaviours. In other cases, a behaviour may be literally impossible for a participant, which would render questions about his/her attitudes and intentions meaningless.

My unconventional treatment of the Perceived Behavioural Control variable appears to boost the explanatory power of the Theory of Planned Behaviour (TPB) (Section 6.1). This could have similar benefits in other behavioural domains if the same 'behavioural constraint' issues are present. Behaviours which are subject to government regulation and whose performance is highly contingent on an individual's particular circumstances are more likely to give rise to these issues within the TPB. A disadvantage of my methodology is that a substantial number of participants may be 
excluded from the study. The apparent increase in the model's predictive power is therefore only real for a sub-set of the population and there is a risk of ignoring the motivations of excluded participants. A decrease in statistical power may also occur due to reduction in sample size.

\subsubsection{Measurement of Social Interaction and Confidence as moderating variables}

Some previous Theory of Planned Behaviour (TPB) studies have included measures of sociability as a general personality trait within their predictive frameworks (Hampson, Andrews, \& Barckley, 2007; Hampson, Andrews, Barckley, \& Severson, 2006; Rhodes, Courneya, \& Jones, 2005). Surprisingly, my literature search found no previous studies that specifically measured frequency of relevant social interaction as part of a TPB methodology.

Including the Social Interaction variable in my model increased the predictive power of the model significantly and relatively ${ }^{36}$ substantially. For the 'decrease native trees' behaviour, Subjective Norm alone accounts for three percent of variance in intention, but this increases to ten percent in aggregate for Subjective Norm, Social Interaction and their interaction term. The additional predictive power is less impressive for the 'increase native trees' behaviour - from $0.8 \%$ to $1.5 \%$. This suggests Social Interaction may be a factor in explaining why social influence found by TPB research is weak and variable compared with group conformance and other experimental methodologies.

I hypothesised that the moderating effect of Social Interaction on Social Influence occurs through an intermediary variable of 'Confidence in norm judgement'. I measured Confidence with questions of the form:

"How confident are you in your answers to the questions on this page?"

I was unable to construct variable measures with acceptable reliability using these questions. Future research could attempt alternative approaches to measuring 'confidence in norm judgement'. For example, if participants give a wider range of

\footnotetext{
${ }^{36}$ Relative to the predictive power of Subjective Norm alone.
} 
answers when asked the same question multiple times, this could indicate lower confidence by them in the answer.

\subsubsection{A trans-disciplinary approach to investigating social influence}

Social influence is difficult to study for a number of reasons. Human decision-making is a complex and highly contingent process. There are multiple variables which could confound the detection of social influence relating to individual traits, experience and immediate contextual factors which may promote or hinder a particular course of action. Experimental and lab-based approaches can help control for these variables, but at the expense of real-world meaning. Social influence involves mechanisms at both the individual and group level, meaning analysis is possible at multiple scales.

I recognised these issues by using aspects from three methodologies from the literature. The Theory of Planned Behaviour is rooted in the attitudes, norms and intentions of people toward their real-world behaviours. It demonstrates correlation rather than causation however, which is why I supplemented it with a novel, experimental 'normative cue' study, following Cialdini et al. (1990). I raised the level of analysis above the individual by including two groups in my study, as well as using social interaction data to infer information about social network structure, following Albert \& Barabási (2002).

\subsection{Limits to my research}

There are a number of caveats to make around my research findings as well as fundamental limitations due to the methodology employed. As discussed in Section 6.9 , the data potentially includes biases towards those landowners who are younger and non-Māori, who have a pre-existing favourable view towards native tree cover, have a pro-social outlook, live on the property they own in non-isolated locations and/or have been on their land for a while. The research was carried out during a time when Government and carbon market incentives were uncertain and volatile.

A further limitation is introduced by my approach (for the reasons described in section 6.10.1) of excluding from further quantitative analysis those participants for whom increasing or decreasing native tree cover was impossible or obligated. This means their attitudes, subjective norms and intentions remain largely unconsidered by the 
research (except where they made free-text responses). These biases almost certainly impair the generalizability of my findings and they should be interpreted in this light.

The free-text response data revealed some ambiguities in my question wording, particularly relating to the distinction between native trees, native bush and native scrub. This issue arose in spite of the use of a pilot survey of FFA members to test question wording. It appears this ambiguity was introduced between the pilot and final survey. Ideally further pilots or expert review would have been performed but time constraints precluded the former at least. It is possible that further important ambiguities remain undetected in the questionnaire wording.

The tests of the regression assumptions presented in Section 5.5.2.7 revealed that the 'homoscedasticity assumption' appears to be violated, i.e. the standard errors are nonuniformly distributed. This means the inferences made about the statistical significance of relationships between the variables studied may not be valid. It seems plausible that this issue is present in some of the many other Theory of Planned Behaviour studies in the literature which employ this analysis technique. It appears to be a result of analysing variables derived from bounded, ordinal response scales as if they were the continuous, unbounded data type assumed by regression analysis. Unfortunately, researchers rarely publish the results of such regression assumption testing so it is not possible to verify the prevalence of this issue.

Although I took steps to improve the testing of causality by my research, the approach falls far short of a convincing demonstration of cause and effect for social influence. More compelling evidence could be provided by objectively measuring participants' actual behaviour at several points in time.

My chosen methodology provided quantitative measurement of the social influence effect with a reasonable level of generalizability. These insights were traded-off against the richer understanding of motivations, reasoning and immediate contextual factors which might have been gained through alternative, qualitative methodologies. The social influence I detected is relatively weak compared with that observed in smallgroup situations. I suggest (Section 6.5) this is because the 'situations' I studied do not feature the 'salient' and 'unanimous' norms that are found in small-group situations. 
This implies that in fact small-groups, such as landcare groups, are appropriate units of study if the full breadth and potential impact of social influence on land-use decisions is to be explored. Such studies could include both qualitative and quantitative elements, as discussed in the next section on further research.

\subsection{Further research}

It is possible that the social influence I detected extends to other landowner decisions, such as excluding livestock and controlling pests within areas of native bush. The importance of social influence is already recognised by the use of 'landcare groups' for water quality and biodiversity protection in New Zealand. My findings and methodology could help quantify social influence effects in this area.

Large-scale, longitudinal studies which track the changing social interactions between identified participants overcome some of the difficulties of studying social influence described in the preceding section (Christakis \& Fowler, 2007, 2008). Such studies are resource intensive and have therefore been restricted to the relatively well-funded field of public health. Creative combinations of the Theory of Planned Behaviour methodology with social network analysis could offer cheaper alternatives. These could build on my inclusion of the social interaction frequency variable to identify who is interacting with whom. Comparing individuals' attitude, intention and perceived norm data with that of their identified social contacts could enable identification of influential individuals and groups within the social network. Such studies could be performed on the scale of closely-interacting small groups or on a large scale where the use of social media provides large social interaction data sets.

My findings and those in the literature suggest the strength of social influence in landcare groups will depend on how unilateral and salient norms are perceived to be and on the level of social interaction. This suggests a coordinated approach could be used to harness social influence by maximising the chance of a unilateral and salient norm being reinforced through frequent social interaction. For example, this could mean encouraging a group of neighbouring landowners to simultaneously take action while frequently meeting to see and discuss each other's actions. In the longer-term, conservation behaviour may become embedded through self-reinforcing norms without further intervention by group organizers. In fact this closely describes the 
intervention model used by the Landcare Trust in the groups they facilitate. Including neighbouring landowners with native forest fragments which span shared property boundaries could increase the cost-effectiveness of conservation actions through coordinated action and reduced 'edge effects' (Gass et al., 2009; Schulte et al., 2008).

An extension of my methodology to include tracking of social interactions, network structures, attitudes, intentions, behaviours and norms over time, would be feasible in a landcare group situation where a researcher has easy, regular access to all members of a group. Such research could combine quantitative and qualitative components. The former could comprise data gathered through Theory of Planned Behaviour questionnaires and meeting attendance records. Analysis techniques could include regression analysis, comparison of intentions and actual behaviour before and after meetings and social network analysis. Qualitative components could include discourse analysis of interview and meeting records to give a more nuanced appreciation of how and why participants' attitudes, intentions and perceptions of each other shift over time. Research of this sort could improve understanding of factors enhancing social influence, including frequency and type of social interactions, social network structure, the characteristics and social behaviour of key 'opinion leaders' within the group, as well as revealing other as yet unknown factors.

More generally it is suggested that the successful and less successful, novel aspects of my research should be verified by further Theory of Planned Behaviour studies in other behavioural domains. This includes confirming the relatively substantial gain in predictive power of the Theory of Planned Behaviour model achieved by including the social interaction frequency variable and by my unconventional treatment of Perceived Behavioural Control as a 'binary filter' rather than a continuous variable. Other approaches to measuring the 'confidence in subjective norm' variable could also be trialled. Comparing the confidence among those facing a salient, unanimous actual norm versus an indistinct norm would help to further elucidate the psychological mechanism underlying social influence. 


\section{Conclusion}

This study set out to establish the importance of social influence in determining New Zealand landowners' behaviour towards native trees on their land.

Native bush fragments on private land represent a range of scarce ecosystems subject to threats including pests, subdivision for development, and surrounding agricultural activity (Section 3.1.1). Current policies do not guarantee their protection in law and do not present landowners with stable incentives (Section 3.1.4).

Social influence has been well studied with a range of questionnaire, real-world experimental and laboratory methodologies (Section 2.1.4) but is an unexplored approach to behavioural change in this area. It offers a 'self-reinforcing' mechanism by which attitudes and behaviours may become 'embedded' in culture. Social network theory uses this concept to explain why ideas may suddenly proliferate once a critical level of adoption is reached (Section 2.1.3).

The social influence literature suggests that self-identification with a peer group may increase the strength of social influence (see Section 2.1.4). Groups of different kinds may provide rural New Zealand landowners with 'normative' information about their peers' behaviour and attitudes towards native trees on their land. Examples include Fonterra and other cooperatives, Federated Farmers, Landcare groups and the catchment-level groups under the Canterbury Water Management Strategy. This research context informed my choice of research question and methodology.

My primary research question was:

"What is the influence of social norms and group membership on New Zealand rural landowners' behavioural intention with respect to native trees on their land?"

My sub-questions were:

1. Do the social norms perceived by rural landowners influence their intentions with respect to increasing, decreasing or maintaining the native tree cover on their land? 
2. Is membership of a relevant group correlated with higher social influence effects?

2a. Do these higher social influence effects result from greater social interaction, confidence and/or group-identification?

3. What is the importance of social influence relative to other known predictors of behavioural intention?

I used a questionnaire based on Ajzen's Theory of Planned Behaviour to survey two populations of rural landowners: members of the New Zealand Farm Forestry Association (FFA) and a randomly selected sample of rural landowners from the general population, matched to the FFA sample by random stratified sampling. The questionnaire included questions on landowners' intentions, attitudes and perceived norms towards increasing or decreasing tree cover on their land. Regression analysis of these data allowed me to make inferences about whether there was social influence to increase or decrease native tree cover in these populations.

I expected the two groups to differ in the norms they perceived and the strength of social influence present because of different levels of social interaction, norm strength and self-identification with the group.

My results show there is a fairly strong 'actual' norm (based on their intentions) among people with native trees already on their land to not decrease this tree cover ${ }^{37}$. However, they only perceive a relatively weak norm in this regard among their peers. There is less of a norm apparent towards increasing native tree cover (among landowners who have this as an option). The norms perceived by Farm Forestry Association members do not differ from non-members.

I found social influence predicts peoples' intentions to increase or decrease native tree cover. The effect is weak compared with the predictive power of attitude for decreasing native tree cover, and very weak for increasing native tree cover. The frequency with which people talk to their peers about these issues has a substantial

\footnotetext{
${ }^{37}$ It cannot be ruled out that the strength of this norm is overstated due to a response bias towards landowners with more favourable attitudes and intentions towards native trees already on their land.
} 
moderating effect on the strength of social influence - those with more frequent interactions with different people experience stronger social influence. It is believed to be the first time that the moderating effect of social interaction frequency on social influence has been tested for and demonstrated within a Theory of Planned Behaviour study. This finding could form an important contribution to further development of the Theory of Planned Behaviour methodology.

Farm Forestry Association (FFA) members have more relevant social interactions than non-members, but they do not experience stronger social influence as a result. This apparent paradox may be explained by the relatively small difference in social interaction levels of FFA members versus non-members. In other words, although the groups differ in their social interaction levels, they may not differ substantially enough for group differences in social influence to manifest.

FFA members have about half their relevant interactions with other members. Self-identification with their peer group was not directly measured. The lack of any difference in strength of social influence for FFA members versus the general population suggests that self-identification is either not present or not substantial enough to increase the influence of FFA members on each other.

Together these results suggest that although social influence may have a small effect, the principle reason landowners retain native tree cover on their land is their attitudes. These attitudes may be somewhat determined by a 'self-selecting' phenomenon - i.e. those who have unfavourable attitudes towards native trees have already removed them from their land. This would appear to create a strong 'actual' intention norm among landowners with native tree cover to retain it. However this 'actual' norm does not translate into the 'Subjective norm' perceived by these landowners. Rather, it appears those with native tree cover correctly perceive that the norm among the general population is not to have native tree cover.

There are overwhelmingly positive intentions to retain native tree cover among landowners who have it. Satellite data indicate relatively small rates of native tree cover loss (a fraction of a percent per year; Section 3.1.1.1). My research hints that around half of landowners with native trees on their land may use them for livestock 
shelter. This suggests livestock damage may be a more important threat to the value of native tree cover on private land than clearance and change in land use.

Although social influence was demonstrated by my research, the weak effect found suggests this would not be an effective policy tool for discouraging native bush clearance or encouraging increase in native bush area. It is plausible that the social influence I detected extends to other landowner decisions, such as excluding livestock and controlling pests within areas of native bush. Other researchers have found stronger social influence in small groups for a range of behaviours. This suggests that studying social influence on livestock exclusion and pest control behaviours in settings such as Landcare groups is a promising area for future research.

My findings and methodology could be elaborated and extended to study social influence effects in small groups. As well as providing potentially stronger social influence, small groups are conducive to more powerful research methodologies. These could combine quantitative studies which track individual perceptions and social network variables over time, with qualitative studies which provide a more nuanced understanding of how individuals' attitudes and behaviour interact with that of their peers and the group. Such research could lead to a detailed understanding of how social influence operates in such groups and could inform policy design which harnesses this effect to maintain and protect native bush on private land. 


\section{Appendix 1 - Glossary of Māori terms}

Translations taken from Waitangi Tribunal (2011), Te Papa Tongarewa website (2013) and 'Te Aka Māori-English, English-Māori Dictionary and Index', Auckland University of Technology, http ://www.maoridictionary.co.nz.

\begin{tabular}{|l|l|}
\hline Māori & English \\
\hline Whanaungatanga & $\begin{array}{l}\text { Ethic of connectedness by blood ; relationships, kinship ; the web of relationships that embraces living and dead, present and } \\
\text { past, human beings and the natural environment }\end{array}$ \\
\hline Iwi & Tribe, people \\
\hline Hapu & Clan, section of a tribe \\
\hline Whānau & Family, extended family \\
\hline Māoritanga & Māori culture, practices, and beliefs \\
\hline Rohe & Traditional tribal area, territory \\
\hline \multirow{\omega}{\omega}{} & The obligation to nurture and care for the mauri of a taonga ; ethic of guardianship, protection \\
\hline Mātiakitanga & Māori knowledge \\
\hline Aotearoa & New Zealand \\
\hline Harakeke & Phormium tenax and P cookianum - New Zealand flax \\
\hline Mauri & The life principle or living essence contained in all things, animate and inanimate \\
\hline Taonga & $\begin{array}{l}\text { A treasured possession, including property, resources, and abstract concepts such as language, cultural knowledge, and } \\
\text { relationships }\end{array}$ \\
\hline Manākitanga & A chief's and a tribe's ability to provide care and hospitality to others \\
\hline Kai & Food \\
\hline
\end{tabular}




\section{Appendix 2 - Theory of Planned Behaviour variable derivation}

\begin{tabular}{|c|c|c|}
\hline Variable & Items & Question wording $^{38}$ \\
\hline Attitude (ATT) & $\begin{array}{l}\text { ATT_VAL, } \\
\text { ATT_BEN, } \\
\text { ATT_ENJ, } \\
\text { ATT_USE, } \\
\text { ATT_PLE, } \\
\text { ATT_GOOD, } \\
\text { ATT_SENS, } \\
\text { ATT_WORTH }\end{array}$ & $\begin{array}{l}\text { 'For me to increase native tree, bush or scrub cover on my land in the next year would be...' } \\
\text { Worthless:Valuable } \\
\text { Harmful:Beneficial } \\
\text { Enjoyable:Unenjoyable } \\
\text { Useful:Useless } \\
\text { Unpleasant:Pleasant } \\
\text { Bad:Good } \\
\text { Sensible:Foolish } \\
\text { Worthwhile:Pointless }\end{array}$ \\
\hline Subjective norm (SN) & $\begin{array}{l}\text { DN_H, } \\
\text { IN_APP } \\
\text { IN_DISAP } \\
\text { IN_DISC }\end{array}$ & $\begin{array}{l}\text { I have increased native tree, bush or scrub cover on my land since I have owned or managed it: [By a very large amount: } \\
\text { Not at all] } \\
\text { If you increased native tree, bush or scrub cover on your land then how many of the people whose opinions you value } \\
\text { would approve? [None:All] } \\
\text { If you increased native tree, bush or scrub cover on your land then how many of the people whose opinions you value } \\
\text { would disapprove? [None:All] } \\
\text { Of the people whose opinions you value, what proportion would discourage you from increasing native tree, bush or } \\
\text { scrub cover on your land? [None:All] }\end{array}$ \\
\hline $\begin{array}{l}\text { Perceived } \\
\text { behavioural control } \\
\text { (PBC) }\end{array}$ & PBC_GEOG, & $\begin{array}{l}\text { Given the physical geography and condition of your land, how easy would it be to increase native tree, bush or scrub } \\
\text { cover on your land in the next year? [Extremely easy: Extremely difficult] }\end{array}$ \\
\hline
\end{tabular}

\footnotetext{
${ }^{38}$ Question wording is shown for 'increase native bush' behaviour. Equivalent wording was used for 'decrease native bush' behaviour.
} 


\begin{tabular}{|c|c|c|}
\hline Variable & Items & Question wording $^{38}$ \\
\hline & $\begin{array}{l}\text { PBC_KNOW, } \\
\text { PBC_AFFORD }\end{array}$ & $\begin{array}{l}\text { Given your knowledge, skills and time how easily could you increase native tree, bush or scrub cover on your land in the } \\
\text { next year? [Extremely easily: Only with great difficulty] } \\
\text { Given your financial resources, could you afford to increase native tree, bush or scrub cover on your land in the next } \\
\text { year? [Easily affordable: Completely unaffordable] }\end{array}$ \\
\hline $\begin{array}{l}\text { Behavioural } \\
\text { Intention (BI) }\end{array}$ & INT_1YR, & $\begin{array}{l}\text { I intend to do the following with native tree, bush or scrub cover on my land in the next year: [Significantly } \\
\text { decrease it: Keep it the same: Significantly increase it] }\end{array}$ \\
\hline & INT_PROB_1YR, & $\begin{array}{l}\text { What are the chances of you doing this increasing native tree, bush or scrub cover on your land in the next } \\
\text { year? [Virtually certain: Extremely unlikely] }\end{array}$ \\
\hline & INT_PROB_5YR & $\begin{array}{l}\text { What are the chances of you doing this increasing native tree, bush or scrub cover on your land in the next } \\
\text { five years? [Virtually certain: Extremely unlikely] }\end{array}$ \\
\hline
\end{tabular}




\begin{tabular}{|l|l|l|}
\hline Variable & Items & Question wording $^{38}$ \\
\hline Social Interaction (SI) & SI_MONTH, & $\begin{array}{l}\text { Approximately how many different people have you talked to about different types of land-use for your land } \\
\text { (such as pasture, production forest or native tree cover in the last month? }\end{array}$ \\
\hline SI_YEAR & $\begin{array}{l}\text { Approximately how many different people have you talked to about different types of land-use for your land } \\
\text { (such as pasture, production forest or native tree cover in the last year? }\end{array}$ \\
\hline Confidence (CONF) & $\begin{array}{l}\text { CONF_INJ, } \\
\text { CONF_DN }\end{array}$ & $\begin{array}{l}\text { [After questions on injunctive norms] How confident are you in your answers to these questions? } \\
\text { [After questions on descriptive norms] How confident are you in your answers to these questions? }\end{array}$ \\
\hline
\end{tabular}




\section{Appendix 3 - Postal address list methodology}

Detailed postal address list preparation procedure

\begin{tabular}{|c|c|c|c|}
\hline Step & $\begin{array}{l}\text { Number } \\
\text { of records }\end{array}$ & GIS details & Comments, URLs etc. \\
\hline LINZ GIS NZ Titles data (public domain) & & & http://data.linz.govt.nz \\
\hline Download layer & & $\begin{array}{l}\text { NZ Property Titles; Layer ID } \\
804\end{array}$ & \\
\hline $\begin{array}{l}\text { With Property titles layer loaded in ESRI ArcMap } \\
10.0\end{array}$ & & & Available from VUW \\
\hline $\begin{array}{l}\text { Remove intersects with residential areas (Clip } \\
\text { command) }\end{array}$ & & $\begin{array}{l}\text { NZ Residential Area Polygons } \\
\text { (Topo 1:50k); Layer ID } 325\end{array}$ & $\begin{array}{l}\text { http://data.linz.govt.nz } \\
\text { NB. This step removes a very large number of titles } \\
\text { within towns/cities which aren't of interest for this } \\
\text { research }\end{array}$ \\
\hline \multicolumn{4}{|l|}{ Remove titles $<1$ ha } \\
\hline \multicolumn{4}{|l|}{ Intersect with: } \\
\hline Territorial Authority boundaries & & $\begin{array}{l}\text { NB this layer has a bug in it; } \\
\text { 'Far North District is listed } \\
\text { twice }\end{array}$ & $\begin{array}{l}\text { http://koordinates.com/layer/198-nz-territorial- } \\
\text { authorities-2008-yearly-pattern/ }\end{array}$ \\
\hline \multirow[t]{4}{*}{ Native areas derived from LCDB2 dataset } & & $\begin{array}{l}\text { Union of the following } \\
\text { LCDB2 classes: }\end{array}$ & $\begin{array}{l}\text { http://www.mfe.govt.nz/issues/land/land-cover- } \\
\text { dbase/classes.html }\end{array}$ \\
\hline & & 69: Indigenous forest & LCDB2 data available from VUW SGEES GIS team \\
\hline & & 52: Manuka and or kanuka & \\
\hline & & 54: Broadleaved indigenous & \\
\hline
\end{tabular}




\begin{tabular}{|c|c|c|c|}
\hline & & hardwoods & \\
\hline & & 55: Sub alpine shrubland & \\
\hline \multirow{8}{*}{ Exotic areas derived from LCDB2 dataset } & & Union of LCDB2 classes: & LCDB2 data available from VUW SGEES GIS team \\
\hline & & $\begin{array}{l}\text { 62: Afforestation (not } \\
\text { imaged) }\end{array}$ & \\
\hline & & $\begin{array}{l}\text { 63: Afforestation (imaged, } \\
\text { post LCDB 1) }\end{array}$ & \\
\hline & & 64: Forest - Harvested & \\
\hline & & $\begin{array}{l}\text { 65: Pine Forest - open } \\
\text { canopy }\end{array}$ & \\
\hline & & $\begin{array}{l}\text { 66: Pine forest - closed } \\
\text { canopy }\end{array}$ & \\
\hline & & 67: Other exotic forest & \\
\hline & & 68: Indigenous forest & \\
\hline Export resulting layer to Excel as DBF file & & & $\begin{array}{l}\text { This is now a list of all property title over } 1 \text { ha, outside } \\
\text { residential areas, with the territorial authority and } \\
\text { whether exotic or native land cover is present on each. }\end{array}$ \\
\hline \multicolumn{4}{|l|}{ In Excel: } \\
\hline Consolidate records by Title & 313,000 & & $\begin{array}{l}\text { Some titles have separate entries in the property titles } \\
\text { layer, corresponding to components such as } \\
\text { easements etc. }\end{array}$ \\
\hline \multicolumn{4}{|c|}{ Calculate $\%$ exotic and \% native tree cover by title } \\
\hline Random stratified sampling & & & $\begin{array}{l}\text { Categorise records into appropriate 'buckets' then } \\
\text { take a random sample from each bucket of the size } \\
\text { required to give the desired ratio of each type of } \\
\text { record in the sample. }\end{array}$ \\
\hline By tree category & 87,000 & & (No trees:Only Exotics:Only Natives:Both $=33: 30: 30: 6$ ) \\
\hline By title area & 17,000 & & (To match FFA response title area distribution) \\
\hline
\end{tabular}




\begin{tabular}{|c|c|c|c|}
\hline By Territorial authority & 5,053 & & $\begin{array}{l}\text { (To match FFA response Territorial authority } \\
\text { distribution) }\end{array}$ \\
\hline Exclude titles with $>9$ owners & 4,976 & & \\
\hline \multicolumn{4}{|l|}{ Import $\mathrm{n}=4976$ titles subset back into ArcGIS } \\
\hline Intersect with NZ electoral addresses & & & $\begin{array}{l}\text { http://data.linz.govt.nz/\#/layer/779-nz-street-address- } \\
\text { electoral/webservices/ }\end{array}$ \\
\hline \multicolumn{4}{|l|}{ Export to Excel } \\
\hline $\begin{array}{l}\text { Exclude records returning }>1 \text { address match per } \\
\text { title }\end{array}$ & 1929 & & \\
\hline Lookup owner names for each title in LINZ data & & $\begin{array}{l}\text { NZ Property Titles Including } \\
\text { Owners; Layer ID = } 805\end{array}$ & \multirow{3}{*}{$\begin{array}{l}\text { Need to be a member of the 'Restricted Data Group' to } \\
\text { access this data } \\
\text { Contact LINZ via the Linz data site to request to be } \\
\text { added; } \\
\text { Before doing this you need to be registered with the } \\
\text { site, then the layer appears in the menu and the link } \\
\text { for requesting access becomes visible }\end{array}$} \\
\hline & & & \\
\hline & & & \\
\hline
\end{tabular}




\begin{tabular}{|c|c|c|}
\hline \multirow[t]{6}{*}{$\begin{array}{l}\text { Lookup owner names from excel using a 'WFS } \\
\text { query' using the two macros given in Appendix } 4 \text { - } \\
\text { Excel macro code }\end{array}$} & & $\begin{array}{l}\text { WFS access also needs to be requested from LINZ to } \\
\text { use the excel Macro method; }\end{array}$ \\
\hline & & $\begin{array}{l}\text { Details are given on the LINZ site under your } \\
\text { dashboard once registered: } \\
\text { http://data.linz.govt.nz/my/api/ }\end{array}$ \\
\hline & & $\begin{array}{l}\text { I used this WFS method because it meant I did not } \\
\text { need to download the entire NZ Property Titles } \\
\text { Including Owners layer }\end{array}$ \\
\hline & & $\begin{array}{l}\text { The requirements of the Restricted Data Group mean } \\
\text { you need to have adequate controls around the data } \\
\text { which is downloaded }\end{array}$ \\
\hline & & $\begin{array}{l}\text { Therefore only downloading the owners names that } \\
\text { you need seems to be prudent, and this is what the } \\
\text { WFS query from excel does. }\end{array}$ \\
\hline & & $\begin{array}{l}\text { Records in the NZ Property Titles Layer (ID 804) and NZ } \\
\text { Property Titles Including Owners Layer (ID = 805) share } \\
\text { the same ID number, so workings can be done in the } \\
\text { non-restricted layer ( } 804 \text { ) and the owner names added } \\
\text { as the last step by an WFS query of layer } 805 \text { as } \\
\text { described above using the excel macros provided in } \\
\text { Appendix (also available online) }\end{array}$ \\
\hline $\begin{array}{l}\text { Exclude all records with the following words in the } \\
\text { Owner field }\end{array}$ & 1269 & \\
\hline \multicolumn{3}{|l|}{ Limited } \\
\hline \multicolumn{3}{|l|}{ Her Majesty the Queen } \\
\hline Incorporated & & \\
\hline
\end{tabular}




\begin{tabular}{|c|c|c|c|}
\hline Council & & & \\
\hline Trust & & & \\
\hline Proprietors & & & \\
\hline LLC & & & \\
\hline University & & & \\
\hline $\begin{array}{l}\text { Lookup 1st line of address previously retrieved } \\
\text { from NZ Electoral addresses layer on NZ Post } \\
\text { Address Finder }\end{array}$ & & $\begin{array}{l}\text { www.nzpost.co.nz/tools/apf- } \\
\text { new }\end{array}$ & $\begin{array}{l}\text { The electoral address is a physical address which } \\
\text { usually differs from the proper postal address }\end{array}$ \\
\hline $\begin{array}{l}\text { Process may be done manually or automated } \\
\text { using 'Mozenda' web scraping software }\end{array}$ & & & http://www.mozenda.com/ \\
\hline & & & Mozenda software is very intuitive to set-up and use \\
\hline & & & $\begin{array}{l}1000 \text { free look-ups are allowed with the free-trial } \\
\text { version }\end{array}$ \\
\hline $\begin{array}{l}\text { Keep postal addresses (as opposed to physical } \\
\text { addresses) returned by NZ post address finder }\end{array}$ & & & \\
\hline $\begin{array}{l}\text { If multiple matching addresses returned by } \\
\text { address-finder, then: }\end{array}$ & 1154 & & \\
\hline $\begin{array}{l}\text { Check against Territorial Authority data already } \\
\text { linked to title }\end{array}$ & & & \\
\hline If no unambiguous match then reject record & & & \\
\hline $\begin{array}{l}\text { Exclude addresses where NZ Post address finder } \\
\text { tool states they do not deliver to that address }\end{array}$ & 771 & & \\
\hline
\end{tabular}




\section{Appendix 4 - Excel macro code}

\section{Excel macro code used to query LINZ online database}

The Excel macro code supplied here is for use with the methodology for retrieving property title owner data using WFS queries from the LINZ online database described in Appendix 3 - Postal address list methodology.

The code can also be downloaded from:

Macro 1 ('hyp') https://docs.google.com/file/d/OB1Fec8QQmiKHUG5YazRZM2RScDA/edit?usp=sharing

Macro 2 ('hyp3') https://docs.google.com/file/d/OB1Fec8QQmiKHVGxESVBOdktaR1E/edit?usp=sharing

\section{Macro 1 ('hyp')}

Dim r As Range

Dim t As Workbook

Sub hyp()

' Macro written by Sam Holmes, 2012

' This excel macro generates links to lookup title owners on the LINZ data service

' Specifically it takes one or more ID numbers, in cells which are selected, corresponding to records in the LINZ data layer: NZ Property Titles Including Owners; Layer ID = 805

' It then generates hyperlinks which are WFS queries to the LINZ data service

' These hyperlinks if followed will retrieve the owners (and title no as a check) and put them in the cells to the right of the cell with the ID in

'If you want to see what's happening while the macro is working then put a comment mark (') in front of the next line Application.ScreenUpdating = False

$y=$ ActiveWorkbook. Name

$\mathrm{n}=$ Selection. Count

$\mathrm{j}=0$

oldStatusBar = Application.DisplayStatusBar

Application.DisplayStatusBar $=$ True

For Each a In Selection

$\mathrm{i}=\mathrm{a}$.Value

Set $r=a$.Offset $(0,1)$

r. Value $=\mathrm{i}$ 
'Insert your own OGC Web Services key in the next line where shown; LINZ will issue you one of these keys on request

addr $=$

"http://wfs.data.linz.govt.nz/[INSERT_YOUR_OWN_ogc_WEB_SERVICES_KEY_HERE]/wfs?REQUEST=GetFeature\&TYPENAME=v:X805\&pr opertyName=title_no,owners\&Filter=\%3CFilter\%3E\%3CPropertylsEqualTo\%3E\%3CPropertyName\%3Eid\%3C/PropertyName\%3E\%3CLiter al\%3E" \& i \& "\%3C/Literal\%3E\%3C/PropertylsEqualTo\%3E\%3C/Filter\%3E\&outputformat=csv"

Worksheets(1).Hyperlinks.Add $r$, addr

Application.StatusBar = WorksheetFunction.Text(j / n, "0\%") \& " Complete..."

$j=j+1$

Next a

Application ScreenUpdating $=$ True

Application.StatusBar $=$ False

End Sub

Application.DisplayStatusBar = oldStatusBar

\section{Macro 2 ('hyp3')}

Dim $r$ As Range

Sub hyp3()

' Macro written by Sam Holmes, 2012

' This Excel Macro should be used after the 'hyp' macro has been used to generate hyperlinks to query the 'NZ Property Titles Including Owners; Layer ID = 805' layer on the Linz data site

'!! Each hyperlink needs to have 'TRUE' in the cell 3 cells to the right of it, else the macro ignores it !!

' This macro follows the hyperlinks in the selected cell or cells

' Each link retrieves data from the LINZ WFS server which appears in a csv file

' You might have to change your internet browser settings so that csv files are automatically opened when a csv-generating hyperlink is clicked in excel

' The macro copies the data from the csv file into the working spreadsheet, next to the cell containing the hyperlink

' The data copied is from the 'owners' and 'Title_no' fields

' Put a comment mark (') in front of the next line if you want to see what's going on while the macro runs (it will be slower though)

Application.ScreenUpdating $=$ False

$\mathrm{y}=$ ActiveWorkbook. Name

$\mathrm{n}=$ Selection.Count 
oldStatusBar = Application.DisplayStatusBar

Application.DisplayStatusBar $=$ True

'This section changes the colour of cells which have been processed to yellow

For Each $r$ In Selection

r.Interior. ThemeColor $=x \mid$ ThemeColorAccent3

' If the cell 3 to the right of the hyperlink cell does not contain 'TRUE' then the hyperlink is ignored

If . . Offset $(0,3)$.Value $=$ False Then GoTo 10

' The next line follows ('Clicks on') the hyperlink which prompts a csv file to open with the WFS retrieved data in it r.Hyperlinks(1). Follow

owners = ActiveSheet.Range("c2").Value

title no = ActiveSheet.Range("b2").Value

ActiveWorkbook.Close savechanges:=False

title_no_text $=$ "'" \& title_no

r. Offset $(0,1) \cdot$ Value $=$ owners

r.Offset $(0,2)$.Value $=$ title_no_text

' This section updates the statusbar with the progress made

Application.StatusBar = WorksheetFunction.Text(j / n, "0\%") \& " Complete..."

$10 \mathrm{j}=\mathrm{j}+1$

$\mathrm{k}=\mathrm{k}+1$

'After Every 50 hyperlinks the file is saved. This is to avoid losing data if the system crashses (which it tends to do)

If $k / 50=1$ Then

ActiveWorkbook.Save

$\mathrm{k}=0$

End If

Next $r$

Application.ScreenUpdating $=$ True

Application.StatusBar $=$ False

End Sub

Application.DisplayStatusBar = oldStatusBar 
12 Appendix 5 - Paper survey and cover letter 


\section{VICTORIA UNIVERSITY OF WELLINGTON Te Whare Wananga o te Upoko o te Ika a Maui

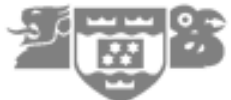

\section{Research on landowner decisions}

$23^{\text {rd }}$ March 2012

Dear Landowner,

My name is Sam Holmes. I am doing my Masters thesis in Environmental Studies at Victoria University of Wellington. I am researching how New Zealand landowners make decisions about their land.

Because you are a landowner, my project needs your opinions I would really appreciate you completing my questionnaire, which should take less than 30 minutes.

You are included in my random sample of landowners from publicly available data provided by Land Information New Zealand.

My questionnaire has two parts:

Part A: Factual information about you and your land

Part B: Your opinions and decisions about your land

I will analyze the combined responses of the many landowners who complete the questionnaire in my written thesis. All names, contact details or identifying details will be removed before analysis and publication.

My supervisor, Senior Lecturer, C. Wallace may also see the individual responses to the questionnaires to help with the analysis. Other than this, all data will be kept confidential.
Once I have written my thesis, I will:

1. Submit it to the School of Geography, Environment and Earth Sciences for marking. After marking, the thesis will be available in the University library and online.

2. Possibly write articles based on my thesis for academic journals and present my results at academic, policy and professional conferences.

Within three years of completing my research I will destroy all paper and electronic records of your questionnaire responses.

You can change your mind and withdraw from the project after completing the survey. To do so simply contact me before l begin data analysis (1st June 2012).

I will put my research findings online once finished, which is likely to be in 2013. If you are interested in seeing these please give your email address at the end of the questionnaire.

Thank you in advance for your time and contribution to my research. If you have any questions about the project, please contact me or my supervisor.

\section{Sam Holmes (Researcher)}

sam.holmes@vuw.ac.nz

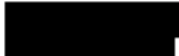

\section{Senior Lecturer C. Wallace (Supervisor)}

School of Geography, Environment and Earth Sciences Victoria University of Wellington

PO Box 600, Wellington

cath.wallace@vuw.ac.nz (subject must start with “Sam Holmes Research") 


\section{Part A - You and your land}

\section{The decisions of New Zealand Landowners}

A survey by Sam Holmes

VICTORIA UNIVERSITY OF WELLINGTON

Te Whare Wananga o te Upoko o te Ika a Maui
1 Do you own, manage or have influence over at least one piece of land which is $\mathbf{1}$ hectare or more in area?

( 1 hectare is 2.5 acres or 10,000 square metres)

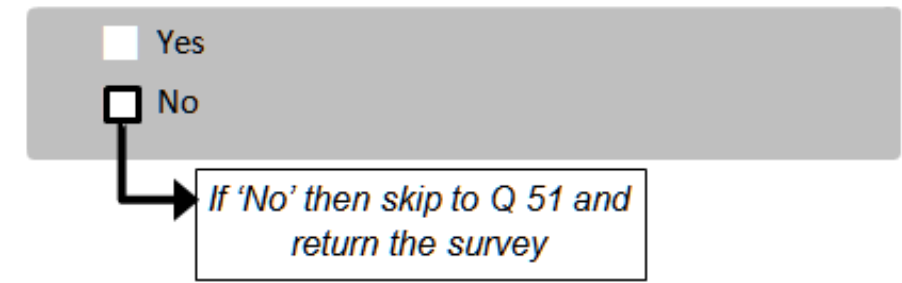

2 How much influence do you have over land-use decisions for your land?

'Your land' means the largest piece of land which you own, manage or have influence over.

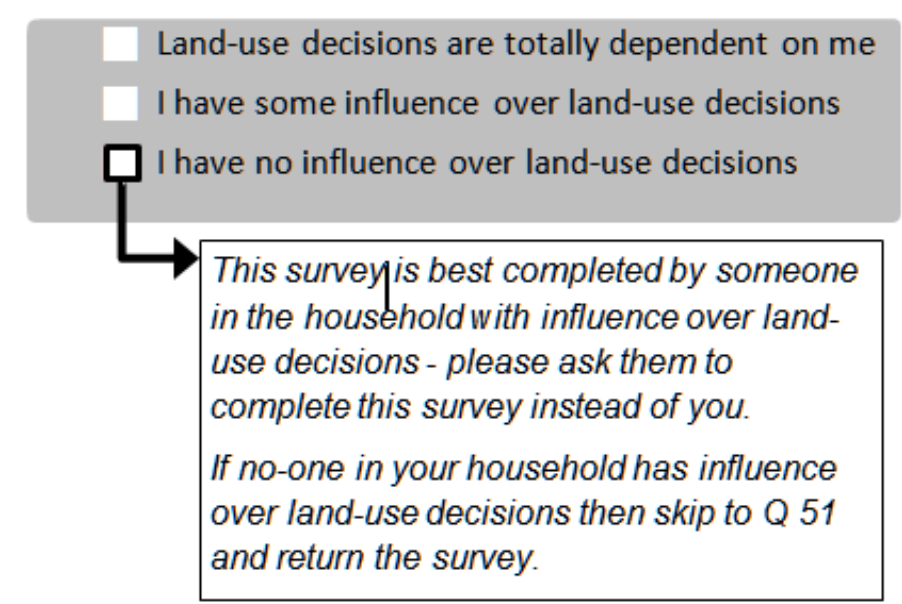


3 How would you describe yourself? (Tick all which apply)

\begin{tabular}{l} 
Lifestyle block owner \\
Plantation forestry landowner \\
Plantation forestry investor \\
Landlord \\
$\square$ Farmer (go to Q3a) \\
Other (please specify) \\
\hline
\end{tabular}

3a If you ticked 'Farmer' then what are the main activities on your farm? Please place a ' 1 ' by the most important, a ' 2 ' by the next, and so on.

Sheep farming

Sheep and beef farming Beef cattle farming Dairy cattle farming Deer farming Other livestock farming Tree crop growing (excluding timber) Vegetable/grain/other crop growing Other (please specify)
4 Are you a member of the New Zealand Farm Forestry Association?

\begin{tabular}{|l|} 
Yes \\
No \\
Lapsed member \\
\hline
\end{tabular}

5 How long have you managed your land? (The largest piece of land which you own, manage or have influence over)

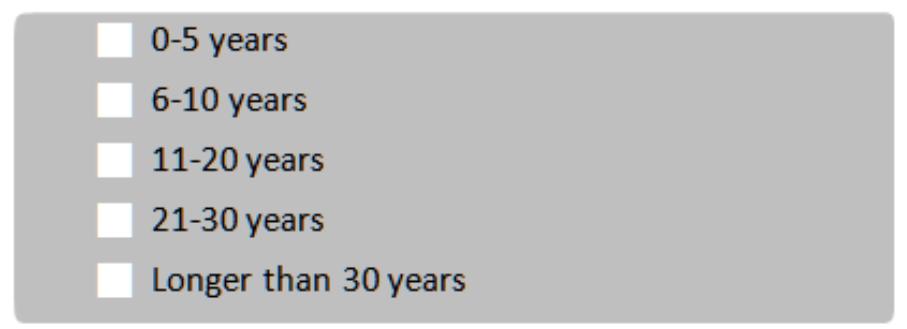

6 What is the approximate area of your land? (The largest piece of land which you own, manage or have influence over) Please give your answer in hectares, acres or square metres.

\begin{tabular}{|c|c|}
\hline & ha \\
\hline or & acres \\
\hline or & square metres \\
\hline
\end{tabular}


7 How much of your largest piece of land is under exotic tree cover (approximately)?

This means all non-New Zealand native trees of all ages, including planted areas, shelterbelts and wilding pines but not scrub such as broom or gorse.

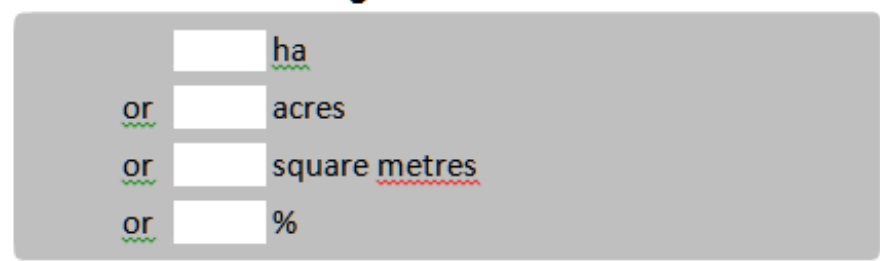

8 How much of your largest piece of land is under New Zealand native tree cover (approximately)?

This means natural and planted native tree areas of all ages, including regenerating native bush and scrub such as manuka and tree ferns.

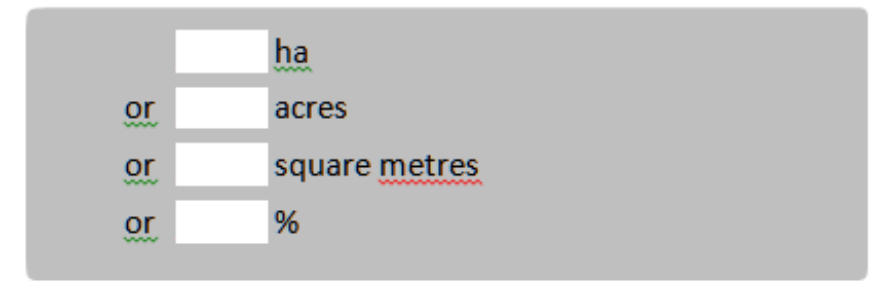

Any comments you have about the section you just completed:

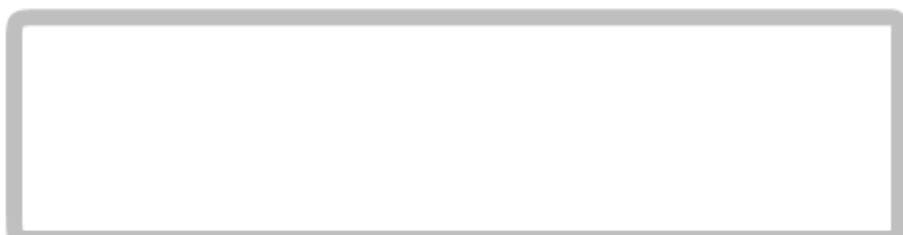

Part B - Your opinions and decisions about your land

All questions about 'Your Land'refer to the largest piece of land which you own, manage or have influence over.

9 Is it possible to increase native tree, bush or scrub cover on your land in the next year?

'Impossible or Not Applicable' means something is genuinely not possible or doesn't apply to your land, not just that it is difficult, expensive or undesirable.

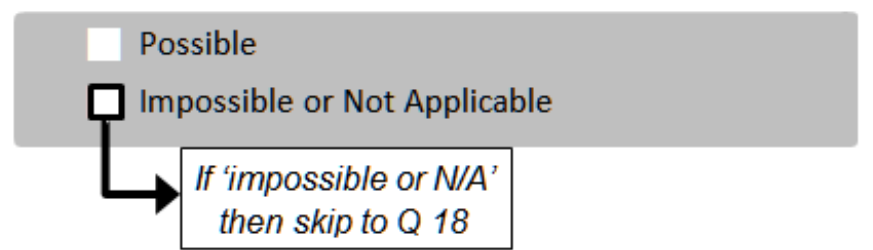

10 Do you have a choice about whether you increase native tree, bush or scrub cover on your land in the next year?

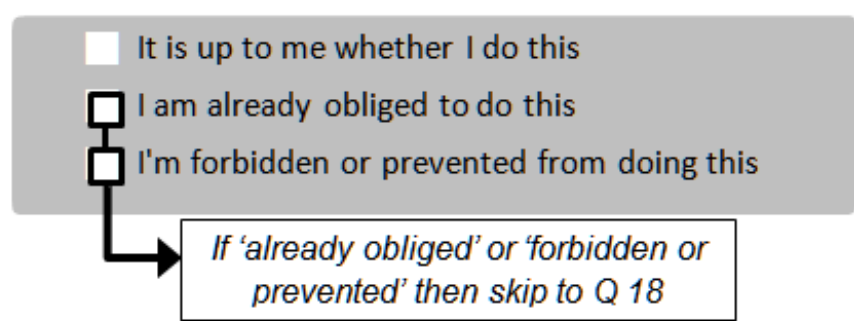


11 Given the physical geography and condition of your land, how easy would it be to increase native tree, bush or scrub cover on your land in the next year?

Tick one box on the rating scale below to show your answer.

\begin{tabular}{|r|r|r|r|r|r|r|l|l|}
\hline $\begin{array}{r}\text { Extremely } \\
\text { easy }\end{array}$ & & & & & & & & $\begin{array}{l}\text { Extremely } \\
\text { difficult }\end{array}$ \\
\hline
\end{tabular}

12 Given your knowledge, skills and time how easily could you increase native tree, bush or scrub cover on your land in the next year?

\begin{tabular}{|r|r|r|r|r|r|r|l|l|}
\hline $\begin{array}{r}\text { Extremely } \\
\text { easily }\end{array}$ & & & & & & & & $\begin{array}{l}\text { Only with } \\
\text { great difficulty }\end{array}$ \\
\hline
\end{tabular}

13 Given your financial resources, could you afford to increase native tree, bush or scrub cover on your land in the next year?

\begin{tabular}{|r|r|r|r|r|r|r|r|l|}
\hline $\begin{array}{r}\text { Easily } \\
\text { affordable }\end{array}$ & & & & & & & & $\begin{array}{l}\text { Completely } \\
\text { unaffordable }\end{array}$ \\
\hline
\end{tabular}

14 Read the statement below and carefully rate it on each scale. When answering, consider the overall effects versus other things you could do with your land. Consider this in a broad sense for yourself and for the people and things which matter to you.

Please tick one box on each row.

'For me to increase native tree, bush or scrub cover on my land in the next year would be...'

\begin{tabular}{|r|l|l|l|l|l|l|l|l|}
\hline Worthless: & & & & & & & & :Valuable \\
\hline Harmful: & & & & & & & & :Beneficial \\
\hline Enjoyable: & & & & & & & & :Unenjoyable \\
\hline Useful: & & & & & & & & :Useless \\
\hline
\end{tabular}

\begin{tabular}{|r|r|r|r|r|r|r|r|l|}
\hline Unpleasant: & & & & & & & & :Pleasant \\
\hline Bad: & & & & & & & & :Good \\
\hline Sensible: & & & & & & & & :Foolish \\
\hline Worthwhile: & & & & & & & & :Pointless \\
\hline
\end{tabular}


15 If you increased native tree, bush or scrub cover on your land then how many of the people whose opinions you value would...

...approve?

\begin{tabular}{|c|c|c|c|c|c|c|c|}
\hline None: & 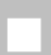 & 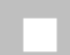 & 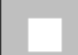 & 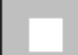 & 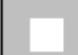 & 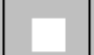 & :All \\
\hline
\end{tabular}

\section{-..disapprove?}

\begin{tabular}{|r|l|l|l|l|l|l|l|l|}
\hline None: & & & & & & & & \\
\hline
\end{tabular}

16 How confident are you in your answer to question 15?

\begin{tabular}{|r|l|l|l|l|l|l|l|l|}
\hline $\begin{array}{r}\text { Not at all } \\
\text { confident }\end{array}$ & & & & & & & & $\begin{array}{l}\text { Extremely } \\
\text { confident }\end{array}$ \\
\hline
\end{tabular}

17 Of the people whose opinions you value, what proportion would discourage you from increasing native tree, bush or scrub cover on your land?

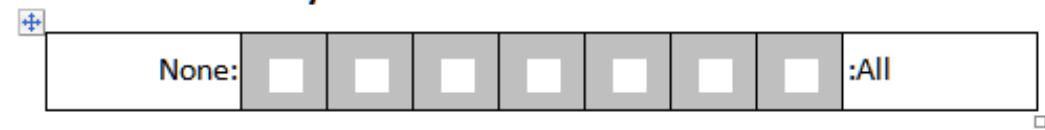

Any comments you have about the section you just completed:

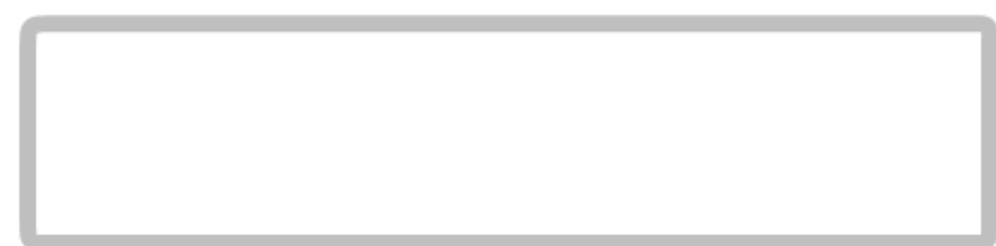

18 Is it possible to decrease native tree, bush or scrub cover on your land in the next year?

'Impossible or Not Applicable' means something is genuinely not possible or doesn't apply to your land, not just that it is difficult, expensive or undesirable.

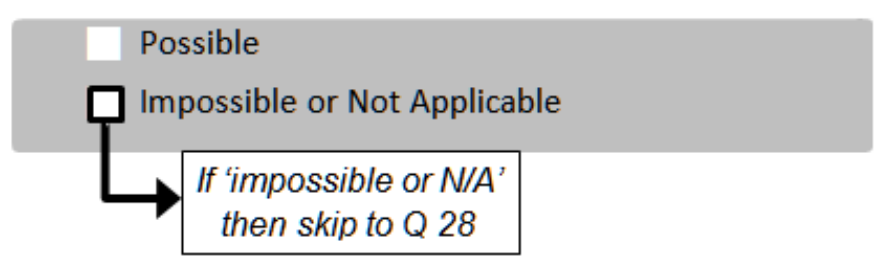

19 Do you have a choice about whether you decrease native tree, bush or scrub cover on your land in the next year?

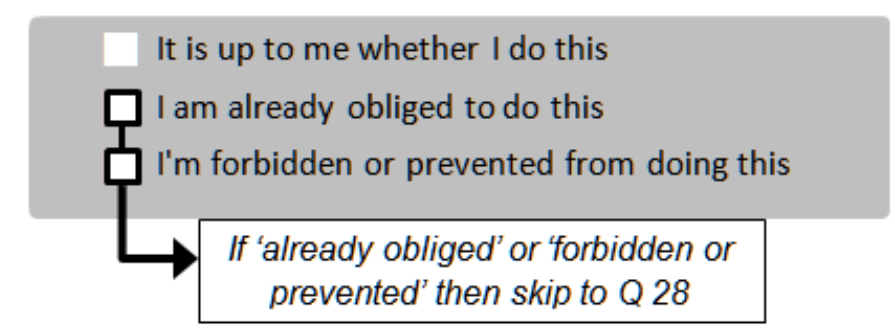


20 Given the physical geography and condition of your land, how easy would it be to decrease native tree, bush or scrub cover on your land in the next year?

\begin{tabular}{|r|l|l|l|l|l|l|l|l|}
\hline $\begin{array}{r}\text { Extremely } \\
\text { easy }\end{array}$ & & & & & & & & $\begin{array}{l}\text { Extremely } \\
\text { difficult }\end{array}$ \\
\hline
\end{tabular}

21 Given your knowledge, skills and time how easily could you decrease native tree, bush or scrub cover on your land in the next year?
22 Given your financial resources, could you afford to decrease native tree, bush or scrub cover on your land in the next year?
23 Read the statement below and carefully rate it on each scale. When answering, consider the overall effects versus other things you could do with your land. Consider this in a broad sense for yourself and for the people and things which matter to you.

\section{Please tick one box on each row.}

'For me to decrease native tree, bush or scrub cover on my land in the next year would be...'

\begin{tabular}{|r|l|l|l|l|l|l|l|l|}
\hline Worthless: & & & & & & & & :Valuable \\
\hline Harmful: & & & & & & & & :Beneficial \\
\hline Enjoyable: & & & & & & & & $:$ Unenjoyable \\
\hline Useful: & & & & & & & & :Useless \\
\hline
\end{tabular}

\begin{tabular}{|r|r|r|r|r|r|r|r|l|}
\hline Unpleasant: & & & & & & & & :Pleasant \\
\hline Bad: & & & & & & & & $:$ Good \\
\hline Sensible: & & & & & & & & :Foolish \\
\hline Worthwhile: & & & & & & & & :Pointless \\
\hline
\end{tabular}


24 If you decreased native tree, bush or scrub cover on your land then how many of the people whose opinions you value would:

...approve?

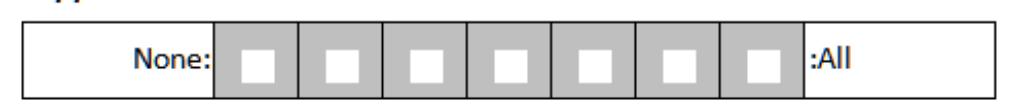

...disapprove?

\begin{tabular}{|r|l|l|l|l|l|l|l|l|}
\hline None: & & & & & & & & \\
\hline
\end{tabular}

25 How confident are you in your answer to question 24?

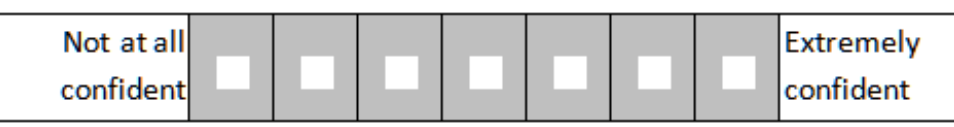

26 Who did you consider when you answered the questions about other peoples' approval or disapproval ( 24 and 15)? Tick one or more boxes.

\begin{tabular}{l} 
My Family \\
My friends \\
People in my local community \\
My immediate neighbours \\
My hapu or iwi \\
Members of forestry groups \\
People from the regional or district council \\
Environmental and conservation groups \\
Farming industry groups \\
Other people or groups of people (please list) \\
\hline
\end{tabular}

27 Of the people whose opinions you value, what proportion would discourage you from decreasing native tree, bush or scrub cover on your land?

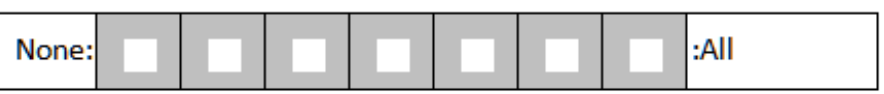

Any comments you have about the section you just completed: 
28 Is it possible to keep about the same amount of native tree, bush or scrub cover on your land in the next year (including if current cover is zero)?

'Impossible or Not Applicable' means something is genuinely not possible or doesn't apply to your land, not just that it is difficult, expensive or undesirable.

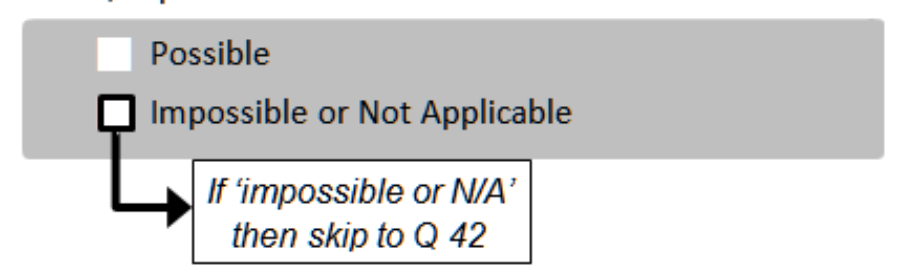

29 Do you have a choice about whether you keep about the same amount of native tree, bush or scrub cover on your land in the next year (including if current cover is zero)?

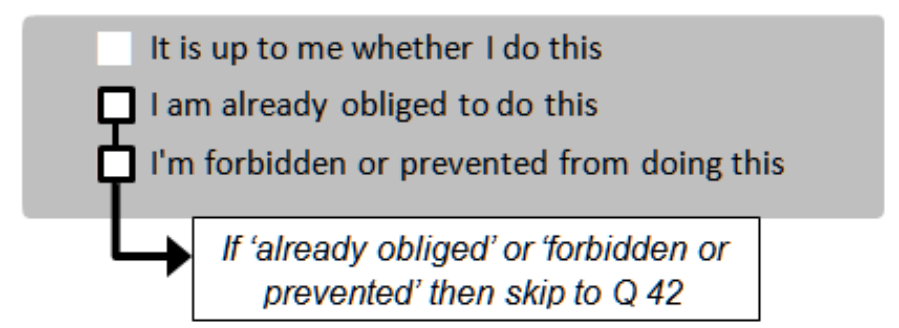

30 Given the physical geography and condition of your land, how easy would it be to keep about the same amount of native tree, bush or scrub cover on your land in the next year (including if current cover is zero)?

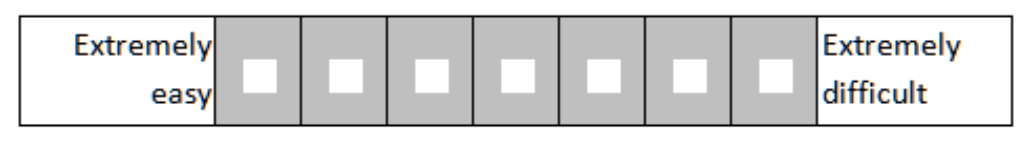

31 Given your knowledge, skills and time how easily could you keep about the same amount of native tree, bush or scrub cover on your land in the next year (including if current cover is zero)?

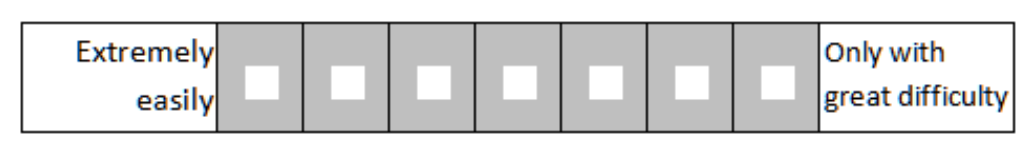

32 Given your financial resources, could you afford to keep about the same amount of native tree, bush or scrub cover on your land in the next year (including if current cover is zero)?

\begin{tabular}{|r|r|r|r|r|r|r|r|l|}
\hline $\begin{array}{r}\text { Easily } \\
\text { affordable }\end{array}$ & & & & & & & $\begin{array}{l}\text { Completely } \\
\text { unaffordable }\end{array}$ \\
\hline
\end{tabular}


33 Read the statement below and carefully rate it on each scale. When answering, consider the overall effects versus other things you could do with your land. Consider this in a broad sense for yourself and for the people and things which matter to you.

\section{Please tick one box on each row.}

'For me to keep about the same amount of native tree, bush or scrub cover on my land in the next year would be...'

\begin{tabular}{|r|l|l|l|l|l|l|l|l|}
\hline Worthless: & & & & & & & & :Valuable \\
\hline Harmful: & & & & & & & & $:$ Beneficial \\
\hline Enjoyable: & & & & & & & & :Unenjoyable \\
\hline Useful: & & & & & & & & :Useless \\
\hline Unpleasant: & & & & & & & & :Pleasant \\
\hline Bad: & & & & & & & & :Good \\
\hline Sensible: & & & & & & & & :Foolish \\
\hline Worthwhile: & & & & & & & & :Pointless \\
\hline
\end{tabular}

34 If you kept about the same amount of native tree, bush or scrub cover on your land then how many of the people whose opinions you value would:

...approve?

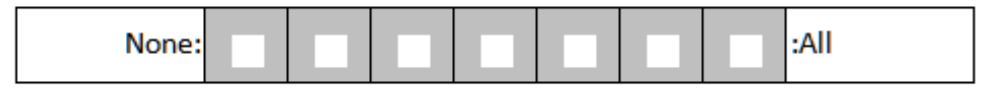

...disapprove?

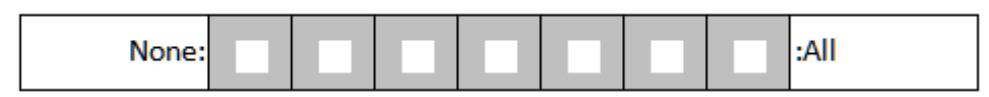

35 How confident are you in your answer to question 34?

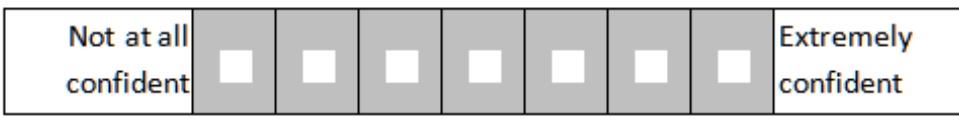

36 of the people whose opinions you value, what proportion would discourage you from keeping about the same amount of native tree, bush or scrub cover on your land?

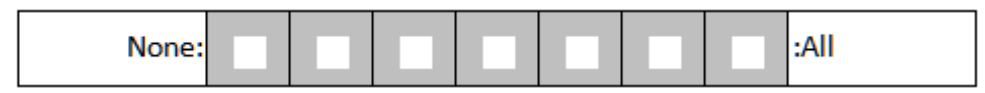

Any comments you have about the section you just completed:

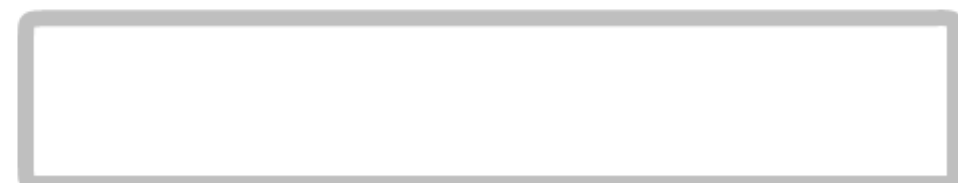


37 Of the people you know with suitable land in your local area, what proportion have

... a greater share of their land under native tree, bush or scrub cover than you?

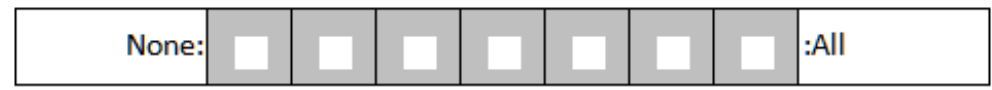

... a lesser share of their land under native tree, bush or scrub cover than you?

\begin{tabular}{|r|l|l|l|l|l|l|l|l|}
\hline None: & & & & & & & & \\
\hline
\end{tabular}

... about the same share of their land under native tree, bush and scrub cover as you?

\begin{tabular}{|r|l|l|l|l|l|l|l|l|}
\hline None: & & & & & & & & :All \\
\hline
\end{tabular}

38 How confident are you in your answers to question 37?

\begin{tabular}{c|l|l|l|l|l|l|l|l|}
$\begin{array}{c}\text { Not at all } \\
\text { confident }\end{array}$ & & & & & & & $\begin{array}{l}\text { Extremely } \\
\text { confident }\end{array}$ \\
\hline
\end{tabular}

39 Of the people you know with suitable land in your local area, what proportion have planted native trees on their land in the last few years?

\begin{tabular}{|r|l|l|l|l|l|l|l|l|}
\hline None: & & & & & & & & :All \\
\hline
\end{tabular}

40 of the people you know with suitable land in your local area, what proportion have cleared native tree, bush or scrub cover on their land in the last few years?

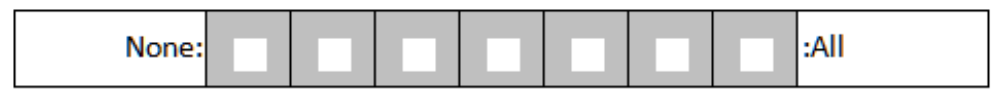

41 How confident are you in your answers to the questions on this page?

\begin{tabular}{l|l|l|l|l|l|l|l|} 
None: & & & & & & & \\
\hline
\end{tabular}

Any comments you have about the section you just completed:

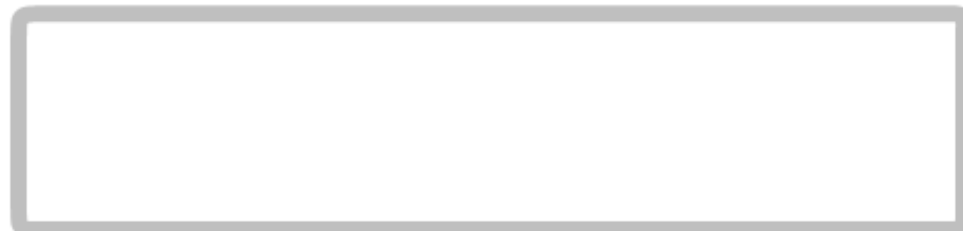


42 I have increased native tree, bush or scrub cover on my land since I have owned or managed it:

\begin{tabular}{|r|r|r|r|r|r|r|r|l|}
\hline $\begin{array}{r}\text { By a very } \\
\text { large amount }\end{array}$ & & & & & & & & Not at all \\
\hline
\end{tabular}

43 I have decreased native tree, bush or scrub cover on my land since I have owned or managed it:

\begin{tabular}{|r|r|r|r|r|r|r|l|l|}
\hline $\begin{array}{r}\text { By a very } \\
\text { large amount }\end{array}$ & & & & & & & & Not at all \\
\hline
\end{tabular}

44 I intend to do the following with native tree, bush or scrub cover on my land...
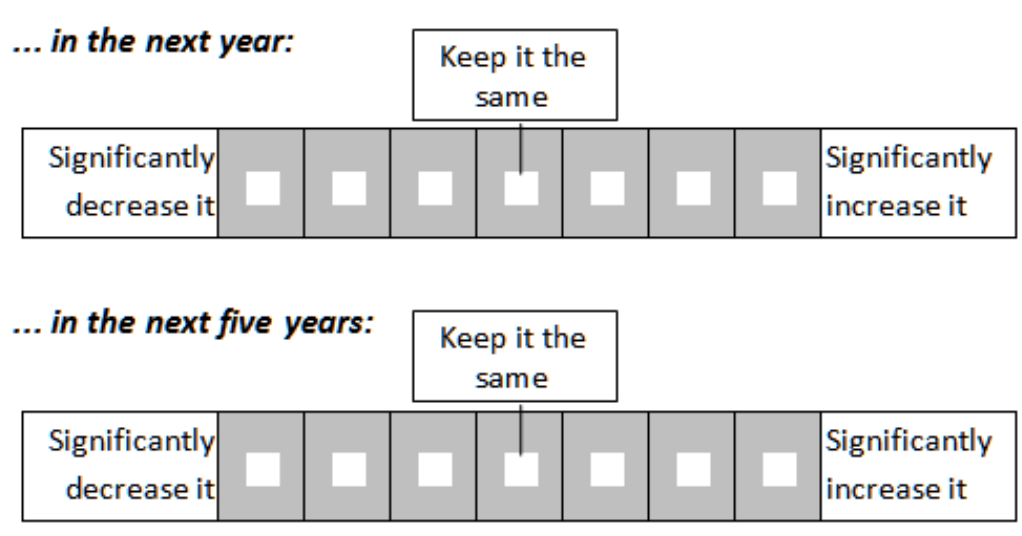

45 What are the chances of you doing this...

... increasing native tree, bush or scrub cover on your land in the next year?

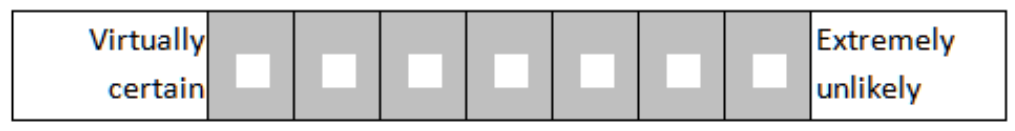

\section{... in the next five years?}

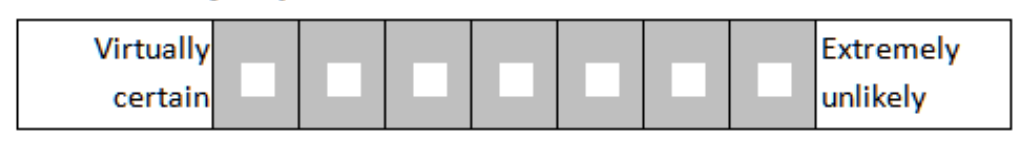

46 What are the chances of you doing this...

... decreasing native tree, bush or scrub cover on your land in the next year?

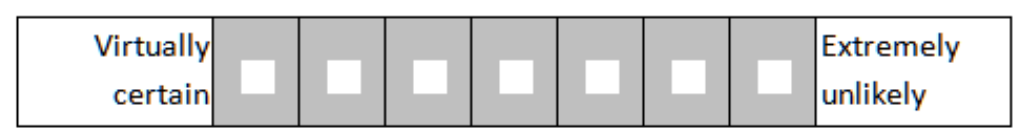

... in the next five years?

\begin{tabular}{|r|l|l|l|l|l|l|l|l|}
\hline $\begin{array}{r}\text { Virtually } \\
\text { certain }\end{array}$ & & & & & & & & $\begin{array}{l}\text { Extremely } \\
\text { unlikely }\end{array}$ \\
\hline
\end{tabular}




\section{What are the chances of you doing this...}

... keeping about the same amount of native tree, bush or scrub cover on your land for the next year (including if current cover is zero)?

\begin{tabular}{|r|r|r|r|r|r|r|l|l|}
\hline $\begin{array}{r}\text { Virtually } \\
\text { certain }\end{array}$ & & & & & & & & $\begin{array}{l}\text { Extremely } \\
\text { unlikely }\end{array}$ \\
\hline
\end{tabular}

... keeping about the same area of native tree, bush or scrub cover on your land for the next five years (including if current cover is zero)?
Any comments you have about the section you just completed:

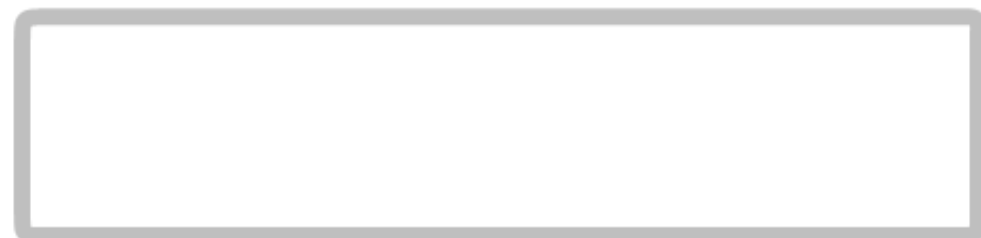

48 How important are the following things when you make decisions about whether to keep, increase or decrease native tree, scrub or bush cover on your land?

Please place a ' 1 ' by the most important, a ' 2 ' by the next, and so on until you have covered all the things which motivate you. If you can't distinguish between items then you can give two or more items the same number.

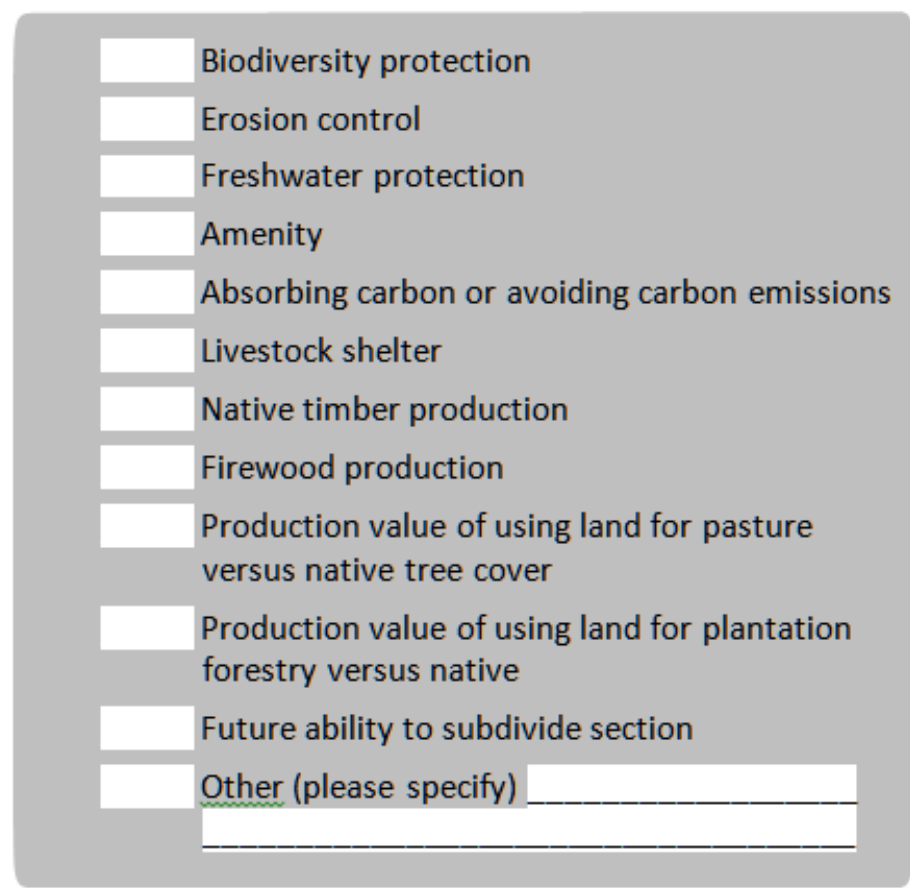


49 How often do you discuss different types of current or potential land-use for your land (such as pasture, production forest or native tree cover) with other people?

Tick one box
Never
Less than once a year
Around once a year
A few times a year
Around once a month
A few times a month
More than once a week

50 Approximately how many different people have you talked to about different types of land-use for your land (such as pasture, production forest or native tree cover)...

...in the last month

$$
\text { people }
$$

...in the last year?

people
51 --END OF QUESTIONNAIRE--

Please give any questions or comments you may have about the whole survey:

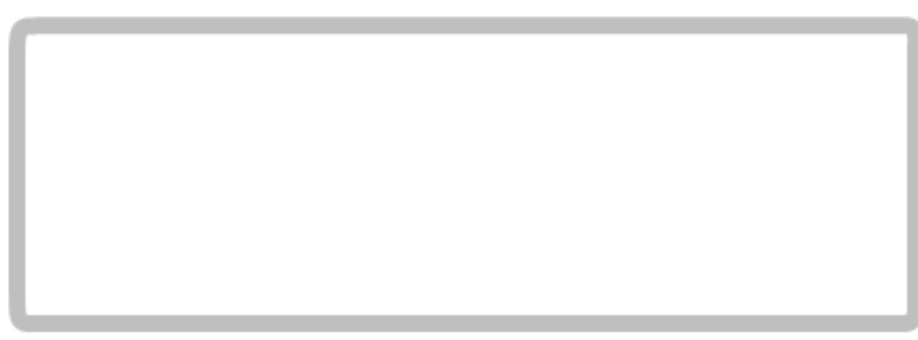

Now please read and sign the consent form opposite 


\section{Consent to take part in this research}

- I have read and understood an explanation of this research project. I have had an opportunity to contact the researcher to ask

questions and have had any questions answered to my satisfaction.

- I understand how the responses I give will be used by the researcher as described in the letter that came with this survey.

- I understand that for all uses of the data my name and contact details will be removed before analysis and that my responses will not be attributed to me in any way that will identify me.

- I understand that I may withdraw myself and my responses from this project before 1st June 2012, but after this date it will not be possible to withdraw as my response data will have been included in the analysis.

- I understand that all records of individual questionnaire responses will be destroyed within three years of completion of the project.

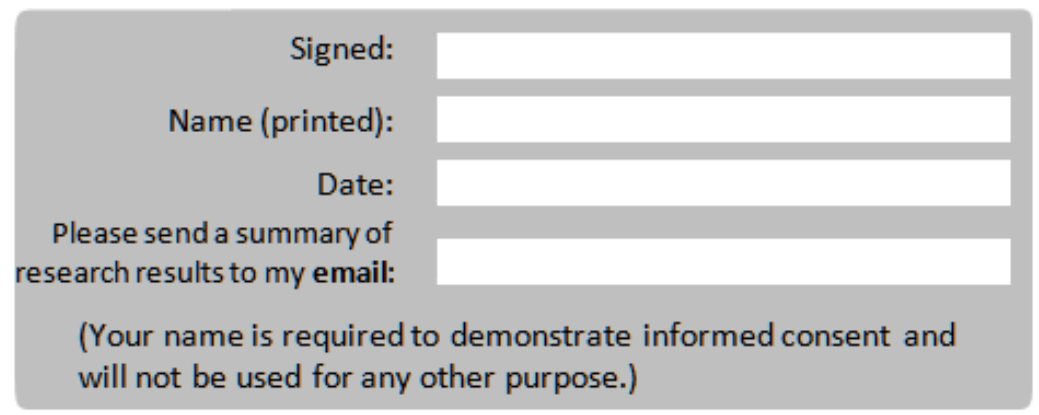

Once you've signed above please turn the page...
Please check you have signed on the previous page then return your completed questionnaire in the FREEPOST envelope provided.

Thank you so much for your time and effort taking part in my survey.

\section{Sam Holmes}

\section{Survey return address:}

Freepost Authority 240286

Landowner Survey

PO Box 15254

Miramar

Wellington 6022 


\section{Appendix 6 - Online survey}

\section{I:}

Part A - You and your land

\section{Q. Are you a member of the New Zealand Farm Forestry Association?}

No

Lapsed member

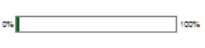

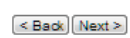

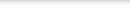

Q. Are you a member of the NZFFA as

Private individual (or individuals)

Institution (such as District or Regional Council)

Other (please specify)

Q. How long have you been a member of the New Zealand Farm Forestry Association?

$0-5$ years

(7) 6-10 years

(1) 11-20 years

21-30 years

(2) Longer than 30 years

Q. Which branch of the NZFFA are you a member of?

Please choose from the drop-down list, which is ordered from 'North' to 'South' $\rightarrow$

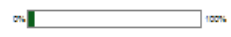

Q. Do you own, manage or have influence over at least one piece of land which is 1 hectare or more in area?

(1 hectare is 2.5 acres or 10,000 square metres)

$$
\text { Yes }
$$

No

\begin{tabular}{|c|c|}
\hline \multirow[t]{2}{*}{$\square$} & \\
\hline & $\langle B a d$ Next $>$ \\
\hline
\end{tabular}

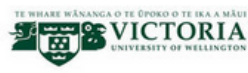

Q. How much influence do you have over land-use decisions for your
land?

'Your land' means the largest piece of land which you own, manage or have influence over.

Land-use decisions are totally dependent on $m$

I have some influence over land-use decisions

Prave no influence over land-use decisions 
These questions ask about 'your land'. This means the largest piece of land which

Q. How would you describe yourself?

Please answer this question in relation to the largest piece of land which you own, manage or have influence over.

You can tick more than one box.

$\square$ Plantation forestry landowner

- Plantation forestry investor

$\square$ Lifestyle block owner

$\square$ None of the above (please speciff)

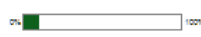

Q. How long have you managed your land?

\section{$0-5$ years}

11-20 years

21-30 years

Longer than 30 years

Q. Where is your land located?

Island
Region
District or City Council


These questions ask about 'your land'. This means the largest piece of land which

\section{Q. What is the approximate area of your land?}

Please give your answer in hectares, acres or square metres.

\begin{tabular}{ll}
\hline & hectares \\
or & acres \\
\hline or & sq metres
\end{tabular}

\section{Q. How much of your land is under exotic tree cover (approximately)?}

\section{This means all non-New Zealand native trees of all ages, including planted areas}

shelterbelts and wilding pines but not scrub such as broom or gorse.

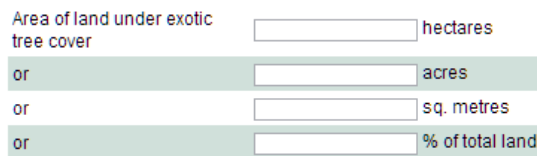

\section{Q. How much of your land is under New Zealand native tree}

\section{cover (approximately)?}

This means natural and planted native tree areas of all ages, including regenerating native bush and scrub such as manuka and tree ferns.

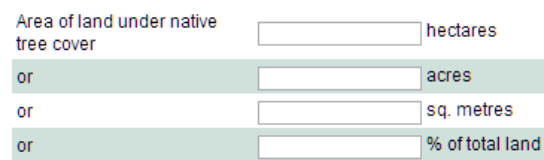

Any comments you have about the section you have just completeted
Part B - Your opinions and decisions about your land

All questions about 'Your Land' refer to the largest piece of land which you own. manage or have influence over

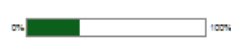

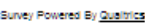

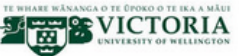

Q. Is it possible to do the following on your land (assuming you had the

'Impossible or Not Applicable' means something is absolutely, logically impossible or doesn't apply to your land, not just that it is difficult, expensive or undesirable. e.g.

\begin{tabular}{|c|c|c|}
\hline & Possible & Impossible or Not Applicable \\
\hline $\begin{array}{l}\text { Increase native tree, } \\
\text { bush or scrub cover on } \\
\text { your land in the next } \\
\text { year }\end{array}$ & 0 & 0 \\
\hline $\begin{array}{l}\text { Decrease native tree, } \\
\text { bush or scrub cover on } \\
\text { your land in the next } \\
\text { year }\end{array}$ & 0 & 0 \\
\hline $\begin{array}{l}\text { Keep about the same } \\
\text { amount of native tree, } \\
\text { bush or scrub cover on } \\
\text { your land in the next } \\
\text { year (including if } \\
\text { current cover is zero) }\end{array}$ & 0 & 0 \\
\hline & 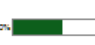 & \\
\hline
\end{tabular}


Q. Do you have a choice about whether you do this or not?

\begin{tabular}{|c|c|c|c|}
\hline & \begin{tabular}{|} 
It is up to me whether I \\
do this
\end{tabular} & $\begin{array}{c}\text { I am already obliged to } \\
\text { do this }\end{array}$ & $\begin{array}{l}\text { I'm forbidden or } \\
\text { prevented from doing } \\
\text { this }\end{array}$ \\
\hline $\begin{array}{l}\text { Increase native tree, } \\
\text { bush or scrub cover on } \\
\text { your land in the next } \\
\text { year }\end{array}$ & 0 & 0 & 0 \\
\hline $\begin{array}{l}\text { Decrease native tree, } \\
\text { bush or scrub cover on } \\
\text { your land in the next } \\
\text { year }\end{array}$ & 0 & 0 & 0 \\
\hline $\begin{array}{l}\text { Keep about the same } \\
\text { amount of native tree, } \\
\text { bush or scrub cover on } \\
\text { your land in the next } \\
\text { year (including if } \\
\text { current cover is zero) }\end{array}$ & 0 & 0 & 0 \\
\hline
\end{tabular}
Q. Given the physical geography and condition of your land, how easy
would it be to do this?

Use the rating scale below to show your answer.

\begin{tabular}{|c|c|c|c|c|c|c|c|}
\hline & $\begin{array}{c}\text { Extremely } \\
\text { easy }\end{array}$ & & & & & & $\begin{array}{c}\text { Extremely } \\
\text { difficult }\end{array}$ \\
\hline $\begin{array}{l}\text { Increase native tree, } \\
\text { bush or scrub cover on } \\
\text { your land in the next } \\
\text { year }\end{array}$ & 0 & 0 & 0 & 0 & 0 & 0 & 0 \\
\hline $\begin{array}{l}\text { Decrease native tree, } \\
\text { bush or scrub cover on } \\
\text { your land in the next } \\
\text { year }\end{array}$ & 0 & 0 & 0 & 0 & 0 & 0 & 0 \\
\hline $\begin{array}{l}\text { Keep about the same } \\
\text { amount of native tree, } \\
\text { bush or scrub cover on } \\
\text { your land in the next } \\
\text { year (including if } \\
\text { current cover is zero) }\end{array}$ & 0 & 0 & 0 & 0 & 0 & 0 & 0 \\
\hline
\end{tabular}

Q. Given your knowledge, skills and time how easily could you achieve

\begin{tabular}{l|c|c|c|}
\hline & $\begin{array}{c}\text { Extremely } \\
\text { easily }\end{array}$ & & $\begin{array}{c}\text { Only with } \\
\text { great } \\
\text { difficulty }\end{array}$ \\
\hline $\begin{array}{l}\text { Increase native tree, } \\
\text { bush or scrub cover on } \\
\text { your land in the next } \\
\text { year }\end{array}$ & & &
\end{tabular}


Q. Given your financial resources, could you afford to do this?

\begin{tabular}{|c|c|c|c|c|c|c|c|}
\hline & $\begin{array}{c}\text { Easily } \\
\text { affordable }\end{array}$ & & & & & & $\begin{array}{l}\text { Completely } \\
\text { unaffordable }\end{array}$ \\
\hline $\begin{array}{l}\text { Increase native tree, } \\
\text { bush or scrub cover on } \\
\text { your land in the next } \\
\text { year }\end{array}$ & 0 & 0 & 0 & 0 & 0 & 0 & 0 \\
\hline $\begin{array}{l}\text { Decrease native tree, } \\
\text { bush or scrub cover on } \\
\text { your land in the next } \\
\text { year }\end{array}$ & 0 & 0 & 0 & 0 & 0 & 0 & 0 \\
\hline $\begin{array}{l}\text { Keep about the same } \\
\text { amount of native tree, } \\
\text { bush or scrub cover on } \\
\text { your land in the next } \\
\text { year (including if } \\
\text { current cover is zero) }\end{array}$ & 0 & 0 & 0 & 0 & 0 & 0 & 0 \\
\hline
\end{tabular}

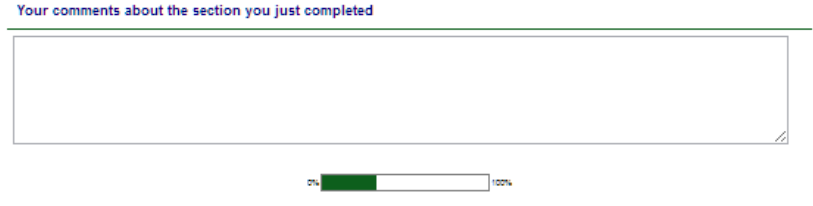

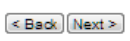

Q. Rate each statement on each scale below.

Q.nsider the overall effects versus other things you could do with your land Consider this in a broad sense for yourself and for the people and things which

Please use all four scales for each statement.

'For me to increase native tree, bush or scrub cover on my land in the next year would be...

\begin{tabular}{r|lllllll|l} 
Harmful & 0 & 0 & 0 & 0 & 0 & 0 & 0 & Beneficial \\
Enjoyable & 0 & 0 & 0 & 0 & 0 & 0 & 0 & Unenjoyable \\
Worthless & 0 & 0 & 0 & 0 & 0 & 0 & 0 & Valuable \\
Useful & 0 & 0 & 0 & 0 & 0 & 0 & 0 & Useless
\end{tabular}

'For me to decrease native tree, bush or scrub cover on my land in the next year would be.."

Harmful $\bigcirc \bigcirc \bigcirc \bigcirc \bigcirc \bigcirc \bigcirc$ Beneficia Worthless 0000000 Valuable Useful 0000000 Useles Enjoyable 100000000000

'For me to keep about the same amount of native tree, bush or scrub cover

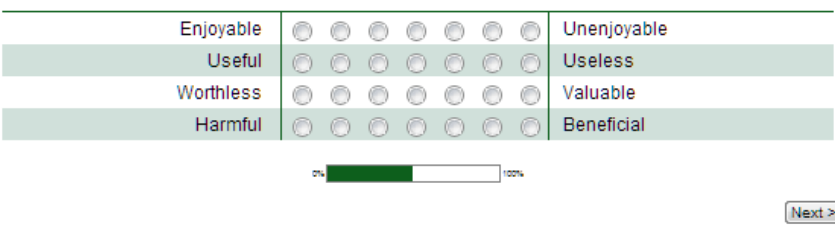




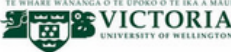

Q. Rate each statement on each scale below.

Consider the overall effects versus other things you could do with your land. things which

Please use all four scales for each statement.

'For me to increase native tree, bush or scrub cover on my land in the next year would be...

\begin{tabular}{r|lllllll|l} 
Unpleasant & 0 & 0 & 0 & 0 & 0 & 0 & 0 & Pleasant \\
Bad & 0 & 0 & 0 & 0 & 0 & 0 & 0 & Good \\
Sensible & 0 & 0 & 0 & 0 & 0 & 0 & 0 & Foolish \\
Worthwhile & 0 & 0 & 0 & 0 & 0 & 0 & 0 & Pointless \\
& & & & & & &
\end{tabular}

'For me to decrease native tree, bush or scrub cover on my land in the next Bad 0000000 Good Worthwhile 1000000 Pointless Unpleasant 1000000 Pleasant

'For me to keep about the same amount of native tree, bush or scrub cover

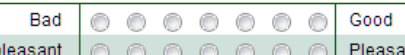

Unpleasant 10000000000 Pleasant \begin{tabular}{r|lllllll|l} 
Worthwhile & 0 & 0 & 0 & 0 & 0 & 0 & 0 & Pointles \\
Sensible & 0 & 0 & 0 & 0 & 0 & 0 & 0 & Foolish
\end{tabular}

Your comments about the section you just completed

Q. How many people, whose opinions you value, would approve if you...

...increased native tree, bush or scrub cover on your land?
None
decreased native tree, bush or scrub cover on your land?
None
kept about the same amount of native tree, bush and scrub cover on your land
(including if current cover is zero)?
None

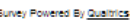


Q. How many people, whose opinions you value, would disapprove if you...

\begin{tabular}{l}
$\ldots$ increased native tree, bush or scrub cover on your land? \\
None \\
$\ldots$ decreased native tree, bush or scrub cover on your land? \\
None \\
(including if current cover is zero)? \\
\hline $\begin{array}{l}\text { None } \\
\text { native tree, bush and scrub cover on your land }\end{array}$
\end{tabular}

Q. How confident are you in your answers to these questions about other peoples' approval or disapproval?

Not at all
confident

Extremely
confident

Q. Who did you consider when you answered these questions about other Q.

Tick one or more boxes.

$\square$ Environmental and conservation groups

$\square$ People in my local community

$\square$ My family

People from the regional or district councl

$\square$ My friends

$\square$ My hapu or iw

$\square$ My immediate neighbours

$\square$ Members of forestry groups other than the NZ Farm Forestry Association

$\square$ Members of the NZ Farm Forestry Association

$\square$ Farming industry groups

$\square$ other people or groups of people (please list) 
Q. of the people you know with suitable land in your local area, what proportion have...

... a greater share of their land under native tree, bush or scrub cover than you?
None
.. a lesser share of their land under native tree, bush or scrub cover than you?
None
you?
$\begin{aligned} & \text { None } \\ & \text { abut the same share of their land under native tree, bush and scrub cover as }\end{aligned}$

Q. How confident are you in your answers to the questions on this page?

\begin{tabular}{|c|c|c|c|c|c|c|}
\hline \multirow{2}{*}{$\begin{array}{c}\text { Not at all } \\
\text { confident } \\
0\end{array}$} & \multirow[b]{2}{*}{0} & \multirow[b]{2}{*}{0} & \multirow[b]{2}{*}{0} & \multirow[b]{2}{*}{0} & \multirow[b]{2}{*}{0} & \multirow{2}{*}{$\begin{array}{c}\text { Extremely } \\
\text { confident } \\
0\end{array}$} \\
\hline & & & & & & \\
\hline & & & & & & $\langle B a d x$ Next $>$ \\
\hline
\end{tabular}

Q. Of the people you know with suitable land in your local area, what proportion have planted native trees on their land in the last few years?

None 10 All

Q. Of the people you know with suitable land in your local area, what 列 the last few years?

None

Q. How confident are you in your answers to the questions on this page?

\begin{tabular}{cccc}
\hline $\begin{array}{c}\text { Not at all } \\
\text { confident } \\
0\end{array}$ & $\begin{array}{c}\text { Extremely } \\
\text { confident } \\
0\end{array}$
\end{tabular}

$\langle\operatorname{sadx}[\operatorname{Next}>$ 


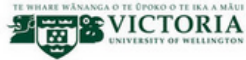

Q. What are the chances of you doing this...

... increasing native tree, bush or scrub cover on your land in the next year

\begin{tabular}{|c|c|c|c|c|c|c|}
\hline $\begin{array}{l}\text { Virtuallyy } \\
\text { certain }\end{array}$ & & & & & & $\begin{array}{c}\text { Extremely } \\
\text { unlikely }\end{array}$ \\
\hline 0 & 0 & 0 & 0 & 0 & 0 & 0 \\
\hline \multicolumn{7}{|c|}{$\ldots$ in the next five years? } \\
\hline $\begin{array}{l}\text { Virtuallyy } \\
\text { certain }\end{array}$ & & & & & & $\begin{array}{l}\text { Extremely } \\
\text { unlikely }\end{array}$ \\
\hline (c) & (D) & O & 0 & 0 & 0 & 0 \\
\hline
\end{tabular}

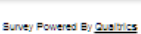

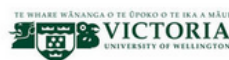

Q. What are the chances of you doing this...

列 for the next year (including if current cover is zero)?

$\begin{aligned} & \text { Virtually } \\ & \text { certain }\end{aligned}$
S

keeping about the same area of native tree, bush or scrub cover on your land for the next five years (including if current cover is zero)?

\begin{tabular}{|c|c|c|c|c|c|c|}
\hline $\begin{array}{l}\begin{array}{l}\text { Virtually } \\
\text { certain }\end{array} \\
\text { a }\end{array}$ & & & & & & $\begin{array}{c}\text { Extremely } \\
\text { unlikely }\end{array}$ \\
\hline 0 & 0 & 0 & 0 & 0 & O & 0 \\
\hline
\end{tabular}

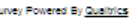

\section{Q. What are the chances of you doing this...}

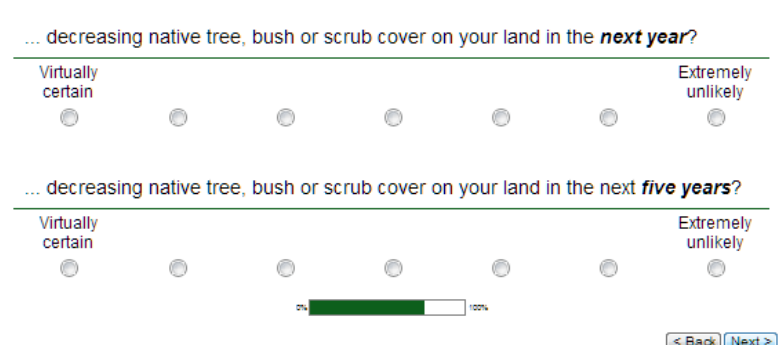

《Bad $\sqrt{\text { Next }>}$ 
Q. How important are the following things when you make decisions about whether to keep, increase or decrease native tree, scrub or bush cover on ur land?

Please place a ' 1 ' by the most important, a ' 2 ' by the next, and so on until you have If you can't distinguish between items then you can give two or more items the same number.

$$
\square \text { Erosion control }
$$

Production value of using land for plantation forestry versus native tree cover

7 Firewood production

Production value of using land for pasture versus native tree cover

Livestock shelter

Timber production

Absorbing carbon or avoiding carbon emissions

Amenity

iodiversity protection

Freshwater protection

Other (please specify)
Other (please specify)

Your comments about the section you just completed

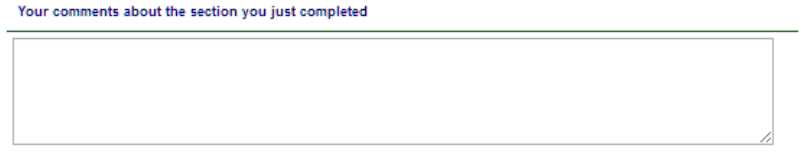

Q. How often do you discuss different types of current or potential landfour land (such as pasture, production forest or native tree cover)..

\begin{tabular}{l}
...with other members of the NZ Farm Forestry Association? \\
\hline $\begin{array}{l}\text { Never } \\
\text { onss than a year }\end{array}$ Around once Afew a year \\
a year
\end{tabular}

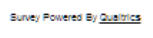


Q. Approximately how many different people have you talked to about different types of land-use for your land (such as pasture, production forest or native tree cover)...

in the last month

Dont know

Q. Approximately how many different people have you talked to about

tion forest or native tree cover)...

in the last year?

Dont know

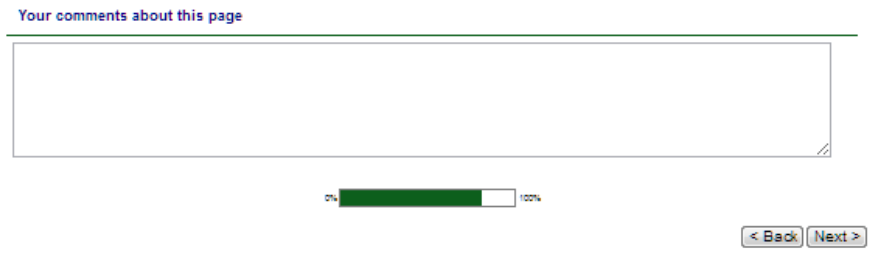

This question asks about your personality by describing how you normally behave. be very valuable for the research and no individual responses will be disclosed or individuals

Describe yourself as you behave in life generally.

\section{Q. How accurate is each word on the left to describe you?}

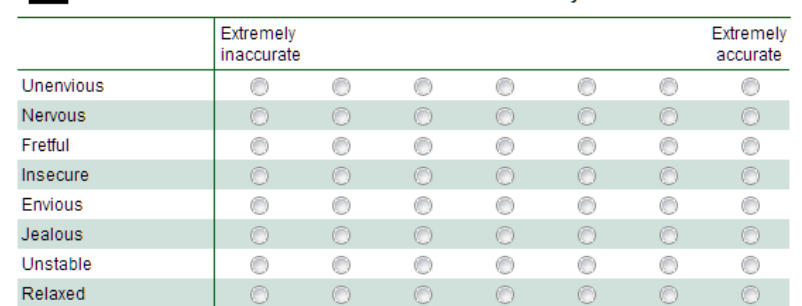

Your comments about this page

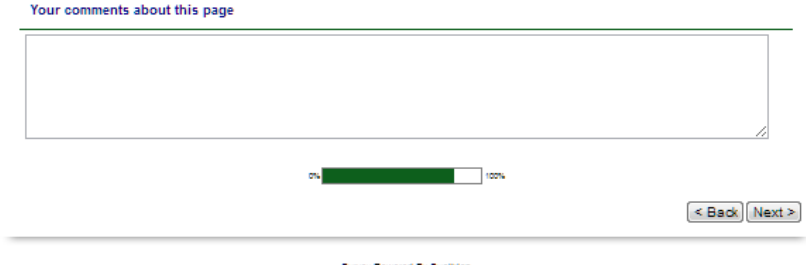

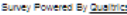


Part C - Your opinions about the services of the NZ Farm Forestry Association

Q. Below is a list of services which the NZ Farm Forestry Association currently performs.

Rate each service from 'worthless' to 'valuable' by ticking one box on each row.

\begin{tabular}{|c|c|c|c|c|c|c|}
\hline & Worthless & & & & Valuable & Don't know \\
\hline Branch newsletters & 0 & 0 & 0 & 0 & 0 & 0 \\
\hline Annual Conference & (c) & 0 & 0 & (c) & (c) & 0 \\
\hline Branch meetings & (c) & 0 & 0 & 0 & 0 & 0 \\
\hline NZFFA website & (c) & 0 & 0 & 0 & 0 & 0 \\
\hline $\begin{array}{l}\text { Getting information } \\
\text { from other members }\end{array}$ & 0 & 0 & 0 & 0 & 0 & 0 \\
\hline $\begin{array}{l}\text { Special interest } \\
\text { groups }\end{array}$ & 0 & 0 & (c) & 0 & 0 & O \\
\hline Indigena magazine & (c) & C & (c) & 0 & (c) & (c) \\
\hline $\begin{array}{l}\text { Advocating for the } \\
\text { small forest grower's } \\
\text { rights with government }\end{array}$ & (c) & 0 & 0 & 0 & 0 & O \\
\hline Field days & 0 & 0 & 0 & 0 & 0 & 0 \\
\hline Tree Grower magazine & (c) & 0 & (c) & 0 & 0 & O \\
\hline
\end{tabular}

Your comments about this page

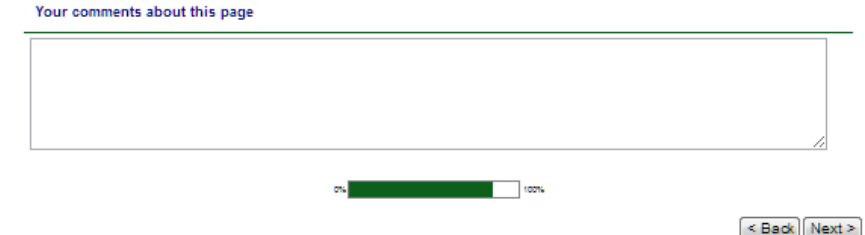

Q. Below is a list of possible services which the NZ Farm Forestry Association could carry out.
How valuable would you personally find each service?

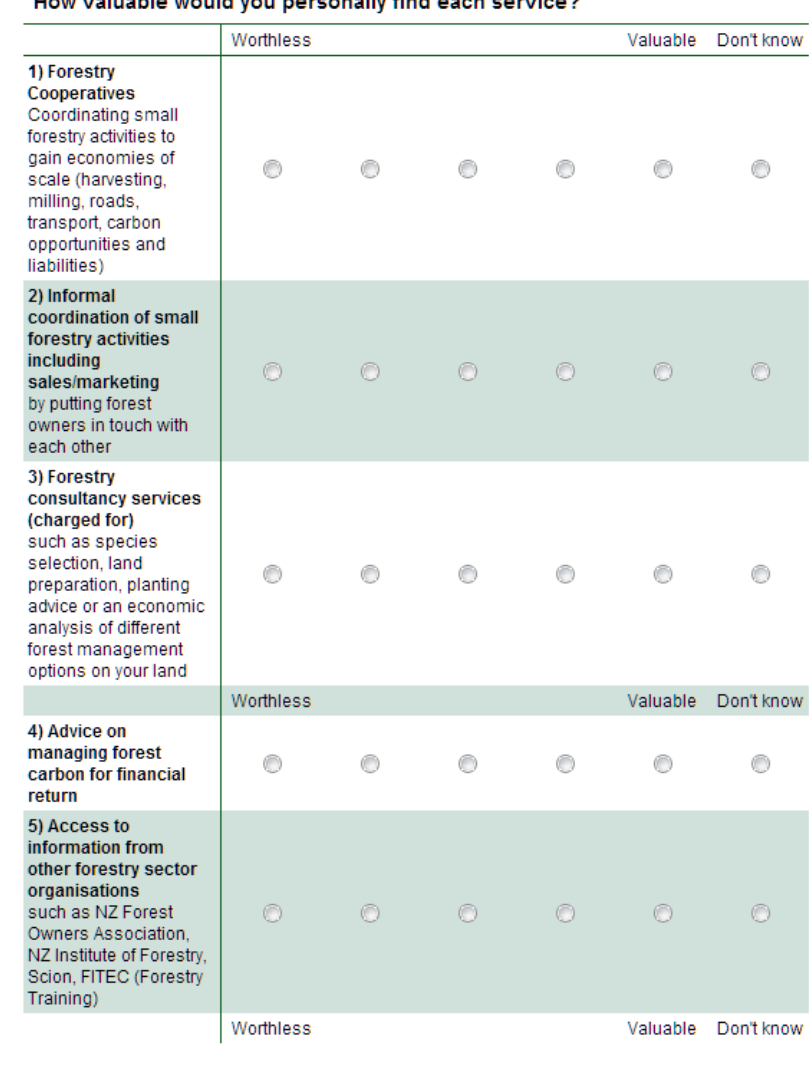

Your comments about this page 
Q. Below is another list of possible services which the NZ Farm Forestry Association could carry out.
How valuable would you personally find each service?

\begin{tabular}{|c|c|c|c|c|c|c|}
\hline & Worthless & & & & 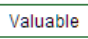 & Don't know \\
\hline $\begin{array}{l}\text { 6) Forest Stewardship } \\
\text { Council (FSC) } \\
\text { certification } \\
\text { Assistance for small } \\
\text { forest growers to } \\
\text { obtain FSC certification } \\
\text { of their forestry } \\
\text { operations. This may } \\
\text { provide benefits for } \\
\text { market access and } \\
\text { timber prices. }\end{array}$ & 0 & 0 & 0 & 0 & 0 & 0 \\
\hline $\begin{array}{l}\text { 7) Promoting the farm } \\
\text { forestry concept and } \\
\text { ethos to non-members }\end{array}$ & (c) & 0 & (1) & 0 & 0 & (c) \\
\hline \multirow{2}{*}{$\begin{array}{l}\text { 8) Online access to } \\
\text { back-issues of tree- } \\
\text { grower }\end{array}$} & 0 & 0 & 0 & 0 & 0 & 0 \\
\hline & Worthless & & & & Valuable & Don't know \\
\hline $\begin{array}{l}\text { 9) Training in practical } \\
\text { forestry activities } \\
\text { (chainsaws, planting, } \\
\text { pruning) }\end{array}$ & 0 & 0 & 0 & 0 & 0 & 0 \\
\hline \multirow[t]{2}{*}{$\begin{array}{l}\text { 10) Offering expertise } \\
\text { to groups doing native } \\
\text { planting (e.g. } \\
\text { Landcare groups, } \\
\text { schools) }\end{array}$} & (c) & 0 & 0 & 0 & 0 & 0 \\
\hline & Worthless & & & & Valuable & Don't know \\
\hline
\end{tabular}

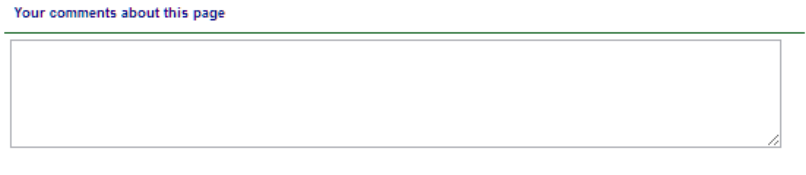

Q. Below is the same list of possible services as in the previous

questions.
Do you think the NZFFA should start offering each service?

\begin{tabular}{|c|c|c|c|}
\hline & Yes & No & Don't know \\
\hline $\begin{array}{l}\text { 1) Forestry } \\
\text { Cooperatives }\end{array}$ & 0 & 0 & O \\
\hline $\begin{array}{l}\text { 2) Informal } \\
\text { coordination of small } \\
\text { forestry activities }\end{array}$ & 0 & 0 & 0 \\
\hline $\begin{array}{l}\text { 3a) Charged-for } \\
\text { forestry consultancy } \\
\text { services } \\
\text { for NZFFA members }\end{array}$ & 0 & 0 & 0 \\
\hline \multirow{2}{*}{$\begin{array}{l}\text { 3b) Charged-for } \\
\text { forestry consultancy } \\
\text { services } \\
\text { for non-NZFFA } \\
\text { members }\end{array}$} & & & \\
\hline & Yes & No & Don't know \\
\hline $\begin{array}{l}\text { 4) Advice on managing } \\
\text { forest carbon for } \\
\text { financial return }\end{array}$ & 0 & 0 & 0 \\
\hline $\begin{array}{l}\text { 5) Access to } \\
\text { information from other } \\
\text { forestry sector } \\
\text { organisations }\end{array}$ & 0 & 0 & 0 \\
\hline $\begin{array}{l}\text { 6) Forest Stewardship } \\
\text { Council Certification } \\
\text { assistance }\end{array}$ & 0 & 0 & 0 \\
\hline \multirow[t]{2}{*}{$\begin{array}{l}\text { 7) Promoting the farm } \\
\text { forestry concept to } \\
\text { non-members }\end{array}$} & 0 & 0 & O \\
\hline & Yes & No & Dont know \\
\hline $\begin{array}{l}\text { 8) Online access to } \\
\text { back-issues of tree- } \\
\text { grower }\end{array}$ & 0 & 0 & (6) \\
\hline $\begin{array}{l}\text { 9) Training in practical } \\
\text { forestry activities }\end{array}$ & 0 & 0 & 0 \\
\hline \multirow[t]{2}{*}{$\begin{array}{l}\text { 10) Offer expertise to } \\
\text { other grouns doing } \\
\text { native planting }\end{array}$} & 0 & 0 & 0 \\
\hline & Yes & No & Don't know \\
\hline
\end{tabular}


Q. Are there any other services or activities which you think the NZFFA

should be doing but which it isn't currently?
This could include activities which are currently done very rarely or on a small scale.

Suggestion 1

Suggestion 2

Suggestion 3

Enter more suggested
services or activities her

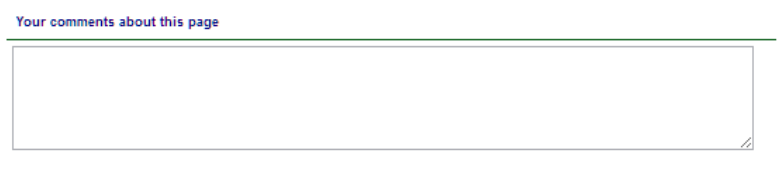

$+2$

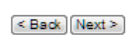

Q. How do you prefer to get information about tree planting, management, harvesting and marketing?

If you have a preferred option then write $a$ ' 1 ' by it.

If you can't distinguish between items then you can it. number.

Face to face
By looking on a website

Via an email magazine or newsletter

Via a printed magazine or newsletter

\section{Q. Are you a member of any of these forestry associations?}

\section{$\square$ NZ Institute of Forestry}

$\square$ NZ Forest Owners' Association

$\square$ Kyoto Forest Owners' Association

$\square$ New Zealand Tree Crops Association

$\square$ A managed forest partnership (please specify)

$\square$ Other (please specify)

Q. Do you get regular forestry technical notes from log brokers such as PF Olsen \& Associates, Rayonier or FOMS?

Your comments about this page

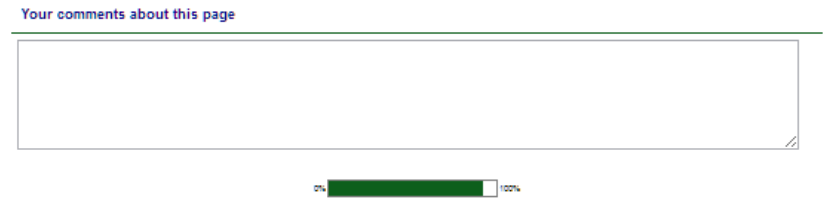

《Bad $N$ Next $>$ 


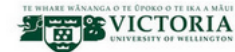

Your answers to the following questions will help the NZ Farm Forestry Association if

Q. Do you have any Pinus Radiata plantations on ANY land that you own, manage or have influence over?

No

Your comments about this page
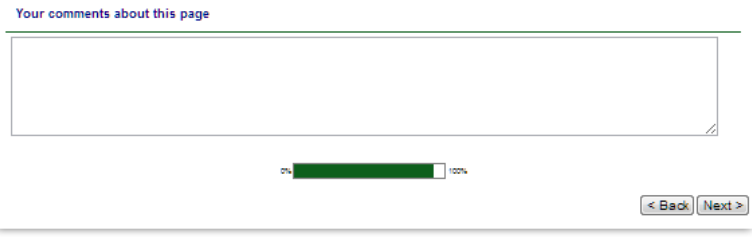

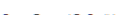

Q. What is the main tending regime used on your Pinus Radiata forests?

Pruned
Unpruned

Both pruned and unpruned

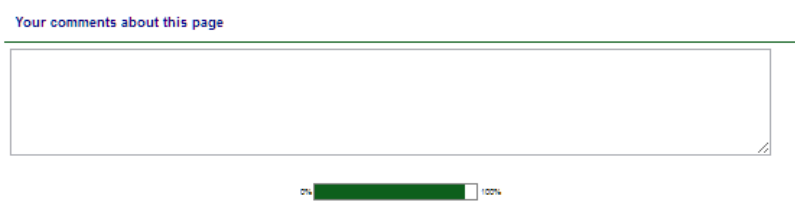

$\langle\operatorname{Bad} \propto \pi$ Next $>$

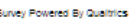


Q. What is the approximate area and age of each tree species on ALL your
land in hectares?

This refers to ALL land you own or have influence over.

\begin{tabular}{|c|c|c|c|c|c|}
\hline & Plus rabsta & $\begin{array}{l}\text { Cupresses } \\
\text { Macrocanpa }\end{array}$ & 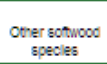 & $\begin{array}{l}\text { Eucalyt } \\
\text { specles }\end{array}$ & 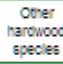 \\
\hline Total (all 8gass) & $\square^{m^{3}}$ & $\square^{\mathrm{m}}$ & $\square^{\mathrm{na}}$ & $\square^{\mathrm{m}}$ & $\square^{\text {ns }}$ \\
\hline 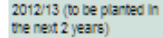 & $\square^{\mathrm{ng}}$ & $\square^{\text {na }}$ & $\square^{\mathrm{ng}}$ & $\square^{\mathrm{ma}}$ & $\square^{\mathrm{ng}}$ \\
\hline 2011 (0 years olo) & $\square^{\mathrm{la}}$ & $\square^{\text {ma }}$ & $\square^{\text {na }}$ & $\square^{\text {na }}$ & $\square^{\text {na }}$ \\
\hline 2010 ( 1 year olo) & $\square^{\mathrm{ra}}$ & $\square^{\text {13 }}$ & $\square^{\text {na }}$ & $\square^{\mathrm{na}}$ & $\square^{\mathrm{ng}}$ \\
\hline 2009 (2 years olo & $\square^{\text {ra }}$ & $\square^{\text {na }}$ & $\square^{\text {ma }}$ & $\square^{\mathrm{m}}$ & $\square^{13}$ \\
\hline 2008 (3 jears 106$)$ & $\square^{\mathrm{na}}$ & $\square^{\mathrm{na}}$ & $\square^{\mathrm{na}}$ & $\square^{\mathrm{ma}}$ & $\square^{\mathrm{ng}}$ \\
\hline 2007 (4 jears o10) & $\square^{\mathrm{ma}}$ & $\square^{\text {ma }}$ & $\square^{\text {ma }}$ & $\square^{\mathrm{B}}$ & $\square^{\text {ma }}$ \\
\hline 2006 (5) jears o6) & $\square^{\mathrm{ng}}$ & $\square^{\text {ma }}$ & $\square^{\mathrm{ra}}$ & $\square^{\mathrm{na}}$ & $\square^{\mathrm{ng}}$ \\
\hline 2005 (6) (6)ars 0106$)$ & $\square^{\mathrm{ma}}$ & $\square^{\text {ma }}$ & $\square^{\text {ma }}$ & $\square^{\mathrm{ma}}$ & $\square^{\mathrm{m}} \mathrm{s}$ \\
\hline 2004 (7 years 010) & $\square^{\mathrm{ra}}$ & $\square^{\text {la }}$ & $\square^{\text {na }}$ & $\square^{\mathrm{ng}}$ & $\square \square^{\mathrm{ng}}$ \\
\hline 2003 (8 years 010$)$ & $\square^{\mathrm{ra}}$ & $\square^{m}$ & $\square^{\text {m }}$ & $\square^{\mathrm{m}}$ & $\square^{\mathrm{na}}$ \\
\hline 2002 (9 g ears & $\square^{\mathrm{na}}$ & $\square^{\text {na }}$ & $\square^{\text {na }}$ & $\square^{\mathrm{ma}}$ & $\square^{\mathrm{ng}}$ \\
\hline 1 (1) (10 years 016) & $\square^{\mathrm{ra}}$ & $\square^{\text {13 }}$ & $\square^{\text {na }}$ & $\square^{\mathrm{n}}$ & $\square^{\mathrm{ng}}$ \\
\hline 2000 (11 years 016) & $\square^{\mathrm{ma}}$ & $\square^{13}$ & $\square^{\mathrm{ng}}$ & $\square^{\mathrm{na}}$ & $\square^{\text {ng }}$ \\
\hline 1999 (12 years ol6) & $\square^{\mathrm{ra}}$ & $\square^{\text {13 }}$ & $\square^{\text {na }}$ & $\square^{\mathrm{na}}$ & $\square^{\text {nas }}$ \\
\hline 1998 (13) (13:ara & $\square^{n}$ & $\square^{n a}$ & $\square^{n 3}$ & $\square^{\mathrm{m}}$ & $\square^{n 3}$ \\
\hline 1997 (14 fears dilo) & $\square^{\mathrm{ma}}$ & $\square^{\text {ma }}$ & $\square^{\text {ma }}$ & $\square^{\mathrm{m}}$ & $\square^{\mathrm{rg}}$ \\
\hline 1996 (15 years 010) & $\square^{\mathrm{ra}}$ & $\square^{13}$ & $\square^{\mathrm{ng}}$ & $\square^{\mathrm{na}}$ & $\square^{\mathrm{ng}}$ \\
\hline 1995 (16 years oilo) & $\square^{\mathrm{na}}$ & $\square^{\text {na }}$ & $\square^{\mathrm{na}}$ & $\square^{\mathrm{n}}$ & $\square^{\text {na }}$ \\
\hline 894 (17 years olo) & $\square^{\mathrm{na}}$ & $\square^{\text {na }}$ & $\square^{\text {na }}$ & $\square^{\mathrm{na}}$ & $\square^{\mathrm{ng}}$ \\
\hline 1993 (18 years ol6) & $\square^{\mathrm{ma}}$ & $\square^{\mathrm{ra}}$ & $\square^{\text {坣 }}$ & $\square^{\text {na }}$ & $\square^{\mathrm{na}}$ \\
\hline 1992 (19 years 010) & $\square^{\mathrm{ng}}$ & $\square^{\mathrm{na}}$ & $\square^{\mathrm{na}}$ & $\square^{\mathrm{na}}$ & $\square^{\text {ng }}$ \\
\hline 1991 (20) $\operatorname{eara}$ oilo) & $\square^{\mathrm{ra}}$ & $\square^{\text {ha }}$ & $\square^{\text {ma }}$ & $\square^{\mathrm{ma}}$ & $\square^{13}$ \\
\hline 1990 (21 years ollo) & $\square^{\mathrm{ng}}$ & $\square^{\mathrm{ra}}$ & $\square^{\text {na }}$ & $\square^{\mathrm{na}}$ & $\square^{\mathrm{na}}$ \\
\hline 1989 (22 years ol6) & $\square^{\mathrm{na}}$ & $\square^{\text {13 }}$ & $\square^{\mathrm{ma}}$ & $\square^{\mathrm{n}}$ & $\square^{\mathrm{ma}}$ \\
\hline 1968 (23) years ofor) & $\square^{\mathrm{na}}$ & $\square^{n}$ & $\square^{\text {na }}$ & $\square^{\mathrm{na}}$ & $\square^{\text {ns }}$ \\
\hline 1967 (24 years & $\square^{\mathrm{na}}$ & $\square^{\mathrm{m}}$ & $\square^{\text {na }}$ & $\square^{\mathrm{m}}$ & $\square^{\text {ra }}$ \\
\hline 1986 (25 years 010) & $\square^{\mathrm{na}}$ & $\square^{\text {13 }}$ & $\square^{\text {na }}$ & $\square^{\mathrm{na}}$ & $\square^{\text {na }}$ \\
\hline 1905 (26) years 016$)$ & $\square^{\mathrm{ra}}$ & $\square^{\text {na }}$ & $\square^{\text {na }}$ & $\square^{\text {ng }}$ & $\square^{\mathrm{pa}}$ \\
\hline 1984 (27 years 016) & $\square^{\mathrm{na}}$ & $\square^{13}$ & $\square^{\text {n }}$ & $\square^{\mathrm{n}}$ & $\square^{\mathrm{ng}}$ \\
\hline 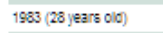 & $\square^{13}$ & $\square^{\text {ma }}$ & $\square^{\text {na }}$ & $\square^{\mathrm{ma}}$ & $\square^{\mathrm{na}}$ \\
\hline 1962 (29 jears 010) & $\square^{\mathrm{ma}}$ & $\square^{\mathrm{ma}}$ & $\square^{\text {na }}$ & $\square^{\mathrm{na}}$ & $\square^{\text {ng }}$ \\
\hline 1981 (30) years ofle) & $\square^{\mathrm{ra}}$ & $\square^{\text {13 }}$ & $\square^{\text {na }}$ & $\square^{\mathrm{ma}}$ & $\square^{\text {13 }}$ \\
\hline 1950 (31 years ollo) & $\square^{\mathrm{pa}}$ & $\square^{\text {na }}$ & $\square^{n 3}$ & $\square^{\mathrm{ma}}$ & $\square^{\mathrm{ng}}$ \\
\hline 1979 (32 years olo) & $\square^{\mathrm{la}}$ & $\square^{\text {na }}$ & $\square^{\text {na }}$ & $\square^{\mathrm{ma}}$ & $\square^{\text {ma }}$ \\
\hline 1978 (33 years o10) & $\square^{\mathrm{ng}}$ & $\square^{\mathrm{na}}$ & $\square^{\text {na }}$ & $\square^{\mathrm{m}}$ & $\square^{\text {na }}$ \\
\hline 1977 (34 years olo) & $\square^{\mathrm{ma}}$ & $\square^{\mathrm{ma}}$ & $\square^{\text {na }}$ & $\square^{\mathrm{n}}$ & $\square^{\text {ma }}$ \\
\hline 1976 (35 jears 0010) & $\square^{\text {ng }}$ & $\square^{n g}$ & $\square^{\mathrm{na}}$ & $\square^{\mathrm{ma}}$ & $\square^{\mathrm{rg}}$ \\
\hline 1975 (36 years 0100) & $\square^{\mathrm{na}}$ & $\square^{\text {ra }}$ & $\square^{\text {m }}$ & $\square^{\mathrm{ma}}$ & $\square^{\mathrm{ng}}$ \\
\hline 1974 (37 years olo) & $\square^{\mathrm{na}}$ & $\square^{\text {na }}$ & $\square^{\mathbf{n}}$ & $\square^{\mathrm{n}}$ & $\square^{\mathrm{ng}}$ \\
\hline $1973(33$ year ofor) & $\square^{\mathrm{ng}}$ & $\square^{\text {na }}$ & $\square^{\text {ra }}$ & $\square^{\mathrm{n}}$ & $\square^{\mathrm{na}}$ \\
\hline 1972 (39 years ollo) & $\square^{\mathrm{na}}$ & $\square^{\text {na }}$ & $\square^{\text {na }}$ & $\square^{\mathrm{na}}$ & $\square^{\mathrm{ng}}$ \\
\hline 1971 (40 jears 0106$)$ & $\square^{\mathrm{n}}$ & $\square^{\text {ma }}$ & $\square^{\text {na }}$ & $\square^{\mathrm{m}}$ & $\square^{13}$ \\
\hline 1970 (41 years olb) & $\square^{\text {na }}$ & $\square^{\text {na }}$ & $\square^{\text {na }}$ & $\square^{\mathrm{ma}}$ & $\square^{\text {na }}$ \\
\hline 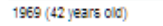 & & & & $\square^{13}$ & \\
\hline & 列 & (3) $>3$ & $p^{\mathrm{na}}$ & $\square^{\mathrm{na}}$ & 等 \\
\hline
\end{tabular}

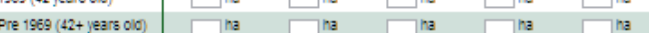

59

\section{Q. Would you like to be kept up to date about any progress the NZFFA}

If you choose to provide your name and contact details, they will only be associated with your answers to Part $A$ of the survey (the factual questions about you and you land) and Part C of the survey (questions about the value of different NZFFA

Your name and contact details will NOT be associated with your answers to Part about your land-use decisions, opinions and personality). All names, contact detals or identifying details will be removed before analysis and publication of Part $B$ for the

The NZFFA may use these details to contact you again but will not disclose them to anyone else.

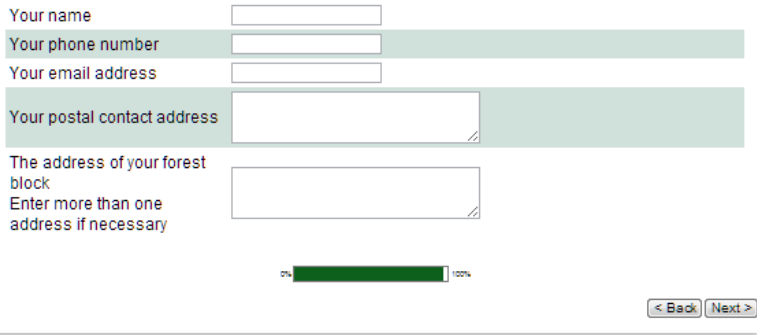

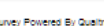




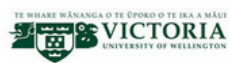

-.-END OF SURVEY..-

Q. Would you be willing to take part in a focus group to discuss topics like those in this survey further?

Yes

-.-END OF SURVEY...

Please give any questions or comments about the whole survey

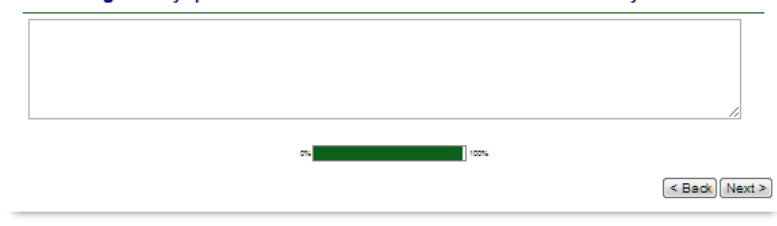

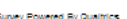

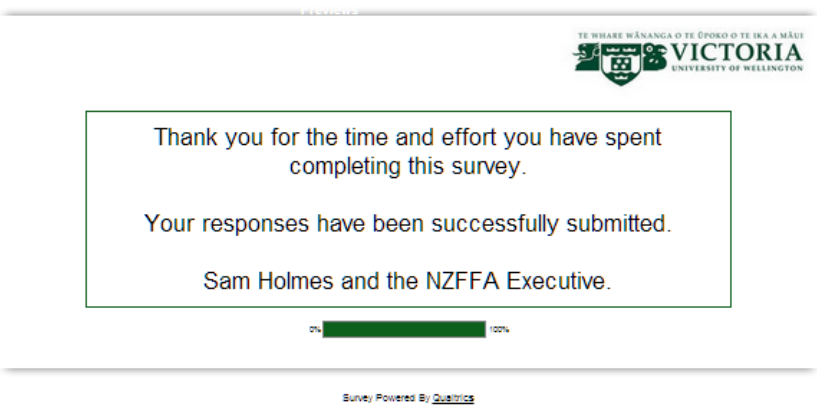





\section{References}

Ajzen, I. (1985). From intentions to actions: A theory of planned behavior. In Actioncontrol: From cognition to behavior (Vol. 11, p. 39). Springer Berlin Heidelberg. Ajzen, I. (2002). Constructing a TPB questionnaire: Conceptual and methodological considerations. Retrieved May 26, 2013, from http://chuang.epage.au.edu.tw/ezfiles/168/1168/attach/20/pta_41176_76883 52_57138.pdf

Ajzen, l., \& Fishbein, M. (1977). Attitude-behavior relations: A theoretical analysis and review of empirical research. Psychological Bulletin, 84, 888-918.

Ajzen, I., Timko, C., \& White, J. B. (1982). Self-monitoring and the attitude-behavior relation. Journal of Personality and Social Psychology, 42, 426.

Albert, R., \& Barabási, A.-L. (2002). Statistical mechanics of complex networks. Reviews of Modern Physics, 74(1), 47.

Armitage, C. J., \& Conner, M. (2001). Efficacy of the Theory of Planned Behaviour: A meta analytic review. British Journal of Social Psychology, 40, 471-499.

Asch, S. E. (1955). Opinions and social pressure. Scientific American, 193(5), 31-35. Axelrod, R. (1997). The dissemination of culture: a model with local convergence and global polarization. Journal of Conflict Resolution, 41(2), 203-226.

Bayfield, M. A., \& Meister, A. D. (2005). East Coast Forestry Project. Wellington: Ministry of Agriculture and Forestry. Retrieved from http://citeseerx.ist.psu.edu/viewdoc/download?doi=10.1.1.177.3423\&rep=rep $1 \&$ type $=p d f$

Beedell, J. D. C., \& Rehman, T. (2000). Using social-psychology models to understand farmers' conservation behaviour. Journal of Rural Studies, 16, 117-127. 
Beef and Lamb New Zealand Economic Service. (2013). ECONOMIC SERVICE SHEEP \& BEEF FARM SURVEY; MARLBOROUGH / CANTERBURY; 2013-14 FORECAST AND QUINTILE ANALYSIS OF FINAL 2011-12 SURVEY DATA (No. P13041). Beef and Lamb New Zealand.

Bentham, J. (1789). An Introduction to the Principles of Morals and Legislation.

Blaschke, P., Hicks, D., \& Meister, A. (2008). Quantification of the Flood and Erosion Reduction Benefits, and Costs, of Climate Change Mitigation Measures in New Zealand. Wellington: Ministry for the Environment. Retrieved from http://www.mfe.govt.nz/publications/climate/quantification-flood-erosionreduction-apr08/html/index.html

Blaschke, P. M., Trustrum, N. A., \& DeRose, R. C. (1992). Ecosystem processes and sustainable land use in New Zealand steeplands. Agriculture, Ecosystems \& Environment, 41, 153-178.

Bourdieu, P. (1986). The forms of capital. In J. E. Richardson (Ed.), Handbook of theory of research for the sociology of education. Greenwood, New York.

Bromley, D. W. (1991). Environment and economy: property rights and public policy. Oxford: Basil Blackwell Ltd.

Burton, R. J. (2004). Reconceptualising the "behavioural approach"in agricultural studies: a socio-psychological perspective. Journal of Rural Studies, 20(3), 359371.

Burton, R. J., Kuczera, C., \& Schwarz, G. (2008). Exploring farmers' cultural resistance to voluntary agri-environmental schemes. Sociologia Ruralis, 48, 16-37.

Carr, S., \& Tait, J. (1991). Differences in the attitudes of farmers and conservationists and their implications. Journal of Environmental Management, 32, 281-294. 
Chen, X., Lupi, F., He, G., \& Liu, J. (2009). Linking social norms to efficient conservation investment in payments for ecosystem services. Proceedings of the National Academy of Sciences, 106, 11812.

Christakis, N. A., \& Fowler, J. H. (2007). The spread of obesity in a large social network over 32 years. New England Journal of Medicine, 357(4), 370-379.

Christakis, N. A., \& Fowler, J. H. (2008). The collective dynamics of smoking in a large social network. New England Journal of Medicine, 358(21), 2249-2258.

Cialdini, R. B. (2005). Basic Social Influence Is Underestimated. Psychological Inquiry, $16,158-161$.

Cialdini, R. B., Reno, R. R., \& Kallgren, C. A. (1990). A focus theory of normative conduct: Recycling the concept of norms to reduce littering in public places. Journal of Personality and Social Psychology, 58, 1015.

Cohen, J., \& Cohen, P. (1975). Applied multiple regression/correlation analysis for the behavioral sciences. Oxford, England: Lawrence Erlbaum.

Davis, P., \& Cocklin, C. (2001). Protecting Habitats on Private Land. Perspectives from Northland, New Zealand (No. SfC181). Wellington: Department of Conservation.

DeBono, K. G., \& Omoto, A. M. (1993). Individual differences in predicting behavioral intentions from attitude and subjective norm. The Journal of Social Psychology, 133(6), 825-831.

Department of Conservation. (2012). DOC biodiversity indicators - 2012 assessment: supplementary material. Wellington: Department of Conservation.

Department of Conservation, \& Ministry for the Environment. (2007). Protecting our places. Information about the Statement of National Priorities for Protecting Rare and Threatened Biodiversity on Private Land. Wellington. 
Deutsch, M., \& Gerard, H. B. (1955). A study of normative and informational social influences upon individual judgment. Journal of Abnormal and Social Psychology, 51(3), 629-636.

Drake, L. P., Bergstrom, P., \& Svedsater, P. (1999). Farmers' attitude and uptake. In Countryside stewardship: farmers, policies and markets (pp. 89-111). Oxford: Elsevier Science.

Durpoix, D. (2010). Farmers' attitudes and behaviour towards the natural environment: a New Zealand case study (Thesis for Doctor of Philosophy in Ecology). Massey University, Palmerston North, New Zealand.

Epstein, J. M. (2001). Learning to Be Thoughtless: Social Norms and Individual Computation. Computational Economics, 18(1), 9-24. doi:10.1023/A:1013810410243

Fehr, E., \& Gächter, S. (2000). Cooperation and punishment in public goods experiments. The American Economic Review, 90(4), 980-994.

Fekadu, Z., \& Kraft, P. (2002). Expanding the theory of planned behaviour: the role of social norms and group identification. Journal of Health Psychology, 7, 33.

Fielding, K. S., Terry, D. J., Masser, B. M., Bordia, P., \& Hogg, M. A. (2005). Explaining landholders' decisions about riparian zone management: The role of behavioural, normative, and control beliefs. Journal of Environmental Management, 77, 12-21.

Forest \& Bird. (2013, July 29). About Us | Forest and Bird. Retrieved August 11, 2013, from http://www.forestandbird.org.nz/about-us 
Gass, R. J., Rickenbach, M., Schulte, L. A., \& Zeuli, K. (2009). Cross-boundary coordination on forested landscapes: investigating alternatives for implementation. Environmental Management, 43, 107-117.

Gladwell, M. (2000). The Tipping Point: How Little Things Can Make a Big Difference. New York: Little, Brown and Company.

Gottschall, A. C., West, S. G., \& Enders, C. K. (2012). A Comparison of Item-Level and Scale-Level Multiple Imputation for Questionnaire Batteries. Multivariate Behavioral Research, 47(1), 1-25. doi:10.1080/00273171.2012.640589

Granovetter, M. S. (1973). The strength of weak ties. American Journal of Sociology, $1360-1380$.

Guagnano, G. A., Stern, P. C., \& Dietz, T. (1995). Influences on attitude-behavior relationships a natural experiment with curbside recycling. Environment and Behavior, 27(5), 699-718.

Hampson, S. E., Andrews, J. A., \& Barckley, M. (2007). Predictors of the development of elementary-school children's intentions to smoke cigarettes: Hostility, prototypes, and subjective norms. Nicotine \& Tobacco Research, 9(7), 751-760.

Hampson, S. E., Andrews, J. A., Barckley, M., \& Severson, H. H. (2006). Personality predictors of the development of elementary school children's intentions to drink alcohol: the mediating effects of attitudes and subjective norms. Psychology of Addictive Behaviors, 20(3), 288.

Hattam, C. (2006). Adopting organic agriculture: An Investigation using the theory of planned behaviour. In Poster paper prepared for presentation, International Association of Agricultural Economics Conference, Gold Coast, Australia. 
Henrich, J., Boyd, R., Bowles, S., Camerer, C., Fehr, E., Gintis, H., \& McElreath, R. (2001). In search of homo economicus: behavioral experiments in 15 smallscale societies. The American Economic Review, 91(2), 73-78.

Homans, G. C. (1974). Social behavior: Its elementary forms. New York: Harcourt Brace Jovanovich.

Indexmundi. (2011). Soft logs Monthly Price US\$ per cubic metre. Retrieved from http://www.indexmundi.com/commodities/?commodity=softlogs $\&$ months $=360$

Jay, M. (2007). The political economy of a productivist agriculture: New Zealand dairy discourses. Food Policy, 32, 266-279.

Jiang, N., Sharp, B., \& Sheng, M. (2009). New Zealand's emissions trading scheme. New Zealand Economic Papers, 43(1), 69-79.

Kahneman, D. (2006). Nobel Laureate Presentation. A perspective on judgement and choice: Mapping bounded rationality. In Progress in Psychological Science Around the World. Volume 1 Neural, Cognitive and Developmental Issues.: Proceedings of the 28th International Congress of Psychology. Psychology Press. Kahneman, D., Knetsch, J. L., \& Thaler, R. H. (1991). Anomalies: The endowment effect, loss aversion, and status quo bias. The Journal of Economic Perspectives, 5(1), 193-206.

Kahneman, D., Slovic, P., \& Tversky, A. (1982). Judgment under uncertainty: Heuristics and biases. Cambridge University Press.

Kallbekken, S., Kroll, S., \& Cherry, T. L. (2011). Do you not like Pigou, or do you not understand him? Tax aversion and revenue recycling in the lab. Journal of Environmental Economics and Management, 62(1), 53-64. 
Kirschbaum, M., Trotter, C., Wakelin, S., Baisden, T., Curtin, D., Dymond, J., ... Arnold, G. (2009). Carbon stocks and changes in New Zealand's soils and forests, and implications of post-2012 accounting options for land-based emissions offsets and mitigation opportunities including appendices. Landcare Research Contract Report: LC0708/174, 1û457. Lincoln: Landcare Research New Zealand Ltd.

Retrieved from

http://www.landcareresearch.co.nz/publications/researchpubs/LULUCF_Repor t_Apr_09.pdf

Kurz, W. A., Dymond, C. C., Stinson, G., Rampley, G. J., Neilson, E. T., Carroll, A. L., ... Safranyik, L. (2008). Mountain pine beetle and forest carbon feedback to climate change. Nature, 452, 987-990.

Lance, C. E., Butts, M. M., \& Michels, L. C. (2006). The Sources of Four Commonly Reported Cutoff Criteria What Did They Really Say? Organizational Research Methods, 9(2), 202-220.

Liljeros, F., Edling, C. R., Amaral, L. A. N., Stanley, H. E., \& Aberg, Y. (2001). The web of human sexual contacts. Nature, 411(6840), 907-908.

Lowe, P., Ward, N., \& Potter, C. (1999). Attitudinal and institutional indicators for sustainable agriculture. In F. Brouwer \& B. Crabtree (Eds.), The Role of Indicators in Agricultural Policy Development (pp. 263-278). Wallingford: CAB International.

Luzar, E. J., \& Diagne, A. (1999). Participation in the next generation of agriculture conservation programs: the role of environmental attitudes. The Journal of Socio-Economics, 28(3), 335-349. doi:10.1016/S1053-5357(99)00021-9

Manley, B. (2013). Deforestation Survey 2012. MPI Technical Paper No: 2013/02. Wellington: Ministry for Primary Industries. 
McLaren, S., \& Challis, C. (2009). Resilience among men farmers: the protective roles of social support and sense of belonging in the depression-suicidal ideation relation. Death Studies, 33(3), 262-276.

Memon, P. A., \& Weber, E. P. (2010). Overcoming obstacles to collaborative water governance: Moving toward sustainability in New Zealand. Journal of Natural Resources Policy Research, 2, $103-116$.

Memon, P. A., \& Wilson, G. A. (2007). Contesting governance of indigenous forests in New Zealand: The case of the West Coast Forest Accord. Journal of Environmental Planning and Management, 50(6), 745-764.

Milgram, S. (1967). The small world problem. Psychology Today, 2(1), 60-67.

Ministry for Primary Industries. (2011). Guide to the Permanent Forest Sink Initiative. Wellington: Ministry for Primary Industries. Retrieved from http://www.mpi.govt.nz/newsresources/publications.aspx?title=Guide\%20to\%20the\%20Permanent\%20Fores t\%20Sink\%20Initiative

Ministry for Primary Industries. (2013a). Permanent Forest Sink Initiative: Proposed Changes to Unit Type and First Stage of a Review of the Operation of the Scheme (No. 2013/17). Wellington: Ministry for Primary Industries.

Ministry for Primary Industries. (2013b, May 14). Indigenous Forestry Sustainable Management of Private Indigenous Forests. Retrieved May 19, 2013, from http://www.mpi.govt.nz/forestry/forestry-in-nz/indigenous-forestry.aspx Ministry for the Environment. (2007). Environmental Reporting: Native land cover with legal protection by Land Cover Database class. Website. Retrieved from 
http://www.mfe.govt.nz/environmental-reporting/land/area-native-landcover-indicator/native-cover/lcdb/current-table.html

Ministry for the Environment. (2011). Proposed National Policy Statement on Indigenous Biodiversity Summary of Submissions. Wellington.

Ministry for the Environment. (2012). Updating the New Zealand Emissions Trading Scheme: A consultation document (No. INFO 646). Wellington: New Zealand Government.

Ministry for the Environment. (2013). Freshwater reform 2013 and beyond (No. ME 1109). Wellington: Ministry for the Environment.

Ministry of Agriculture and Forestry. (2007). Sustainable Land Management and Climate Change Plan of Action. Retrieved from http://www.maf.govt.nz/climatechange/slm/poa/page.htm Ministry of Agriculture and Forestry. (2010a). Land use statistics: Land use in New Zealand, 1972 to most recent (Vol. 2010). Wellington.

Ministry of Agriculture and Forestry. (2010b). National Exotic Forest Description.

Retrieved June 18, 2010, from

http://www.maf.govt.nz/Portals/0/Documents/forestry/statistics/nefd/nefd2010-prov-table-1.xls

Ministry of Agriculture and Forestry. (2010c, November). Forestry in the Emissions Trading Scheme. Retrieved from http://maxa.maf.govt.nz/sustainableforestry/2010-introduction-to-forestry-in-ets.pdf Ministry of Primary Industries, the Department of Conservation, Auckland Council, Northland Regional Council, Waikato Regional Council, Bay of Plenty Regional Council, Tāngata whenua. (n.d.). Keep Kauri Standing. Retrieved August 11, 2013, from http://www.kauridieback.co.nz/ 
Ministry of Transport. (2013). Drive Social. Retrieved from

http://www.nzta.govt.nz/about/advertising/drive-social

Morris, C., \& Potter, C. (1995). Recruiting the new conservationists: farmers' adoption of agri-environmental schemes in the UK. Journal of Rural Studies, 11, 51-63.

Nolan, J. M., Schultz, P. W., Cialdini, R. B., Goldstein, N. J., \& Griskevicius, V. (2008). Normative social influence is underdetected. Personality and Social Psychology Bulletin, 34, 913.

Norman, P., Clark, T., \& Walker, G. (2005). The theory of planned behavior, descriptive norms, and the moderating role of group identification. Journal of Applied Social Psychology, 35, 1008-1029.

Norton, D. A., \& Miller, C. J. (2000). Some issues and options for the conservation of native biodiversity in rural New Zealand. Ecological Management \& Restoration, 1, 26-34.

NZ Transport Agency. (2012). Drink-driving. Retrieved from http://www.nzta.govt.nz/about/advertising/drink-driving/trapped.html O'Hara, Y. (2010, October). Down on the farm: Depression and mental health in the rural South. Southern Rural Life. Dunedin. Retrieved from https://docs.google.com/viewer?url=http\%3A\%2F\%2Fwww.mentalhealth.org.n z\%2Ffile\%2FMedia-Grants\%2FPDFs\%2Fdown-on-the-farm-in-the-ruralsouth.pdf

OECD. (2007). OECD Environmental Performance Reviews: New Zealand. Paris: OECD.

Olson, M. (1971). The Logic of Collective Action. Harvard University Press.

Ostrom, E. (1990). Governing the commons: The evolution of institutions for collective action. Cambridge University Press. 
Park, H. S. (2000). Relationships among attitudes and subjective norms: Testing the theory of reasoned action across cultures. Communication Studies, 51(2), 162175. doi:10.1080/10510970009388516

Parminter, T. G., \& Wilson, J. A. (2003). Strategies to encourage the adoption of a case study of New Zealand farmers and their possum control practices. In Proceedings of the New Zealand Society of Animal Production (Vol. 63, pp. 6668).

Pastor-Satorras, R., \& Vespignani, A. (2001). Epidemic spreading in scale-free networks. Physical Review Letters, 86(14), 3200.

Pierce, J. T. (1996). The conservation challenge in sustaining rural environments. Journal of Rural Studies, 12(3), 215-229.

Piliavin, J. A., \& Charng, H.-W. (1990). Altruism: A review of recent theory and research. Annual Review of Sociology, 27-65.

Rhodes, R. E., Courneya, K. S., \& Jones, L. W. (2005). The theory of planned behavior and lower-order personality traits: Interaction effects in the exercise domain. Personality and Individual Differences, 38(2), 251-265.

Rodenberg, J., \& Manley, B. (2011). Small forests in New Zealand: a survey of landowner objectives and management. New Zealand Journal of Forestry, $56(2), 15-19$.

Rogers, E. M. (1962). The Diffusion of Innovations. The Free Press, New York.

Rosin, C. (2008). The conventions of agri-environmental practice in New Zealand: farmers, retail driven audit schemes and a new spirit of farming. GeoJournal, $73,45-54$. 
Salmon, G. (2012). Canterbury Water Management Strategy - a case study in collaborative governance (No. CR 136). Wellington: Ministry for the Environment.

Salmon, J. T. (1980). The native trees of New Zealand. Auckland: Reed.

Schramek, J., Biehl, D., Buller, H., \& Wilson, G. (1999). Implementation and effectiveness of agri-environmental schemes established under Regulation 2078/92. Frankfurt: European Commission.

Schulte, L. A., Rickenbach, M., \& Merrick, L. C. (2008). Ecological and economic benefits of cross-boundary coordination among private forest landowners. Landscape Ecology, 23(4), 481-496.

Schultz, P. W., Khazian, A. M., \& Zaleski, A. C. (2008). Using normative social influence to promote conservation among hotel guests. Social Influence, 3, 4-23.

Schultz, T. W. (1961). Investment in human capital. The American Economic Review, 51(1), 1-17.

Schwartz, S. H. (1977). Normative Influences on Altruism. Advances in Experimental Social Psychology, 10, 221-279.

Sherif, M. (1935). A study of some social factors in perception: Chapter 3. Archives of Psychology, 1935, 27, No. 187, 23- 46.

Siebert, R., Toogood, M., \& Knierim, A. (2006). Factors Affecting European Farmers' Participation in Biodiversity Policies. Sociologia Ruralis, 46, 318-340.

Simon, H. (1957). Models of Man: social and rational; mathematical essays on rational human behavior in society setting. New York: Wiley. 
Snyder, M., \& Gangestad, S. (1986). On the nature of self-monitoring: Matters of assessment, matters of validity. Journal of Personality and Social Psychology, $51,125$.

Stryker, S., \& Serpe, R. T. (1982). Commitment, identity salience and role behaviour. In Personality, Roles, and Social Behavior (pp. 199-218). New York: Springer.

Tajfel, H., \& Turner, J. C. (1979). An integrative theory of intergroup conflict. In Intergroup relations: Essential readings. Key readings in social psychology. (pp. 94-109). New York: Psychology Press.

Te Papa Tongarewa. (2013). Te kaupapa - Exhibition themes and ideas. Retrieved November 24, 2013, from http://www.tepapa.govt.nz/WhatsOn/exhibitions/ETuAke/Pages/ExhibitionThe mes.aspx

Terry, D. J., Hogg, M. A., \& White, K. M. (1999). The theory of planned behaviour: Selfidentity, social identity and group norms. British Journal of Social Psychology, $38,225-244$.

Triandis, H. (1977). Interpersonal Behaviour. Monterey, Calif: Brooks/Cole.

Turner, J. C., Oakes, P. J., Haslam, S. A., \& McGarty, C. (1994). Self and collective: Cognition and social context. Personality and Social Psychology Bulletin, 20, 454-454.

Van Gossum, P., Luyssaert, S., Serbruyns, I., \& Mortier, F. (2005). Forest groups as support to private forest owners in developing close-to-nature management. Forest Policy and Economics, 7, 589-601.

Vatn, A. (2005). Rationality, institutions and environmental policy. Ecological Economics, 55(2), 203-217. doi:10.1016/j.ecolecon.2004.12.001 
Volcano to sea project - Landcare Trust. (n.d.). Retrieved August 11, 2013, from http://www.landcare.org.nz/Regional-Focus/Auckland-Office

Waitangi River Project - Landcare Trust. (n.d.). Retrieved August 11, 2013, from http://www.landcare.org.nz/Regional-Focus/Whangarei-Office/Waitangi-RiverProject

Waitangi Tribunal. (2011). Ko Aoteatoa Tenei: A Report into Claims Concerning New Zealand Law and Policy Affecting Maori Culture and Identity. Wai 262. Wellington: Legislation Direct.

Walker, S., Price, R., \& Rutledge, D. (2005). New Zealand's remaining indigenous cover: recent changes and biodiversity protection needs. Wellington: Department of Conservation.

Walker, S., Price, R., Rutledge, D., Stephens, R. T., \& Lee, W. G. (2006). Recent loss of indigenous cover in New Zealand. New Zealand Journal of Ecology, 30(2), 169177.

Watts, D. J., \& Strogatz, S. H. (1998). Collective dynamics of "small-world"networks. Nature, 393(6684), 440-442.

Wetland Restoration - Landcare Trust. (n.d.). Retrieved August 11, 2013, from http://www.landcare.org.nz/Regional-Focus/Hamilton-TaurangaOffices/Wetland-Restoration

Wilson, G. A. (1992). A survey on attitudes of landholders to native forest on farmland. Journal of Environmental Management, 34, 117-136.

Young, R. A., \& Reichenbach, M. R. (1987). Factors influencing the timber harvest intentions of nonindustrial private forest owners. Forest Science, 33(2), 381393. 
Zubair, M., \& Garforth, C. (2006). Farm level tree planting in Pakistan: the role of farmers' perceptions and attitudes. Agroforestry Systems, 66, 217-229. 